\title{
A Comprehensive System of Energy Intensity Indicators for the U.S.: Methods, Data and Key Trends
}

DB Belzer

August 2014

\section{Pacific Northwest} NATIONAL LABORATORY 



\title{
DISCLAIMER
}

This documentation was prepared as an account of work sponsored by an agency of the United States Government. Neither the United States Government nor any agency thereof, nor Battelle Memorial Institute, nor any of their employees, makes any warranty, express or implied, or assumes any legal liability or responsibility for the accuracy, completeness, or usefulness of any information, apparatus, product, or process disclosed, or represents that its use would not infringe privately owned rights. Reference herein to any specific commercial product, process, or service by trade name, trademark, manufacturer, or otherwise does not necessarily constitute or imply its endorsement, recommendation, or favoring by the United States Government or any agency thereof, or Battelle Memorial Institute. The views and opinions of authors expressed herein do not necessarily state or reflect those of the United States Government or any agency thereof.

\author{
PACIFIC NORTHWEST NATIONAL LABORATORY \\ operated by \\ BATTELLE \\ for the \\ UNITED STATES DEPARTMENT OF ENERGY \\ under Contract DE-AC05-76RL01830 \\ Printed in the United States of America \\ Available to DOE and DOE contractors from the \\ Office of Scientific and Technical Information, \\ P.O. Box 62, Oak Ridge, TN 37831-0062; \\ ph: (865) 576-8401, fax: (865) 576-5728 \\ email: reports@adonis.osti.gov
}

\begin{abstract}
Available to the public from the National Technical Information Service, U.S. Department of Commerce, 5285 Port Royal Rd., Springfield, VA 22161 ph: (800) 553-6847, fax: (703) 605-6900

email: orders@ntis.fedworld.gov

online ordering: http://www.ntis.gov/ordering.htm
\end{abstract}



PNNL-22267

\section{A Comprehensive System of Energy Intensity Indicators for the U.S.: Methods, Data and Key Trends}

DB Belzer

August 2014

Prepared for U.S. Department of Energy under Contract DE-AC05-76RL01830

Pacific Northwest National Laboratory

Richland, Washington 99352 



\begin{abstract}
This report describes a comprehensive system of energy intensity indicators for the United States that has been developed for the Department of Energy's Office of Energy Efficiency and Renewable Energy (EERE) over the past decade. This system of indicators is hierarchical in nature, beginning with detailed indexes of energy intensity for various sectors of the economy, which are ultimately aggregated to an overall energy intensity index for the economy as a whole. The aggregation of energy intensity indexes to higher levels in the hierarchy is performed with a version of the Log Mean Divisia index (LMDI) method. Based upon the data and methods in the system of indicators, the economy-wide energy intensity index shows a decline of about $14 \%$ in 2011 relative to a 1985 base year. Discussion of energy intensity indicators for each of the broad end-use sectors of the economy - residential, commercial, industrial, and transportation - is presented in the report. An analysis of recent changes in the efficiency of electricity generation in the U.S. is also included. A detailed appendix describes the data sources and methodology behind the energy intensity indicators for each sector.
\end{abstract}




\section{Summary}

Increasing energy efficiency continues to be viewed by policymakers and the public as an important national goal. As has been recognized since the energy crises of the 1970s, energy efficiency can be viewed as an energy resource that can reduce the need for new energy supplies and infrastructure. This report examines progress toward greater energy efficiency that has taken place in the U.S. over the past four decades. The means by which this examination is conducted is through the development of a comprehensive set of energy intensity indicators for various sectors of the U.S. economy. Energy intensity, defined as annual energy use divided by a measure of annual economic activity is used to represent energy efficiency in the various sectors as well as for the U.S. economy as whole. The indicators are shown in terms of indexes, typically based to the year 1985, that can be conveniently employed to measure improvements in energy efficiency over time. In the report, the indicators have been developed for the period 1970 through 2011.

This report draws upon work undertaken to support a system of U.S. energy intensity indicators sponsored by U.S. Department of Energy's Office of Energy Efficiency and Renewable Energy (DOE/EERE). The primary purpose of this activity has been to inform policymakers and the public of ongoing progress to improve energy efficiency in the U.S. The intensity indicators were originally developed in response to the May 2001 National Energy Policy, which directed DOE to support the improvement of energy efficiency as a national priority for the U.S.

\section{S.1 General Methodology}

The EERE system of energy intensity indicators is primarily disaggregated by major energy enduse sector defined by the Department of Energy's Energy Information Administration (EIA): 1) residential, 2) commercial, 3) industrial, and 4) transportation. Depending upon data availability, these sectors are further disaggregated into subsectors (e.g, passenger transportation and freight transportation), and below that level into specific industries, transportation modes, or regions. At the top level of this hierarchical system is an intensity index for the economy as whole. The system also includes intensity indicators for electricity generation.

The system of energy intensity indicators recognizes major implications of distinguishing energy consumption by end users, either in the form of direct (fossil) fuel consumption or in the form of electricity. Energy intensity indexes are constructed separately for both forms of energy consumption. Separate estimates for fuels and electricity consumption permit more aggregate analyses to be conducted with either one of two commonly used definitions of total energy: 1) delivered, the sum of fuels and electricity use, and 2) source (or primary), where electricity losses from electricity generation and transmission are assigned to the end user and added to delivered energy. With regard to source energy intensity, the EERE system takes into account improvements in the electricity generation efficiency that have occurred over time. The source 
energy from which these improvements have been removed has been termed (for convenience) "adjusted" source energy.

The interpretation of energy intensity indexes as indicators of changes in energy efficiency in large part depend upon the choice of activity for each sector. In general, the preferred procedure is to use physical-based measures of activity, such as floor area in buildings, passenger-miles of travel, and ton-miles of freight. Table S.1 presents the primary activity measures used in the system of indicators, as well some alternative measures that are included in the detailed database underlying the system of intensity indicators.

Table S.1 Activity measures by major end-use sector

\begin{tabular}{|c|c|c|}
\hline Sector & Primary Activity Measure & Alternative Measures \\
\hline Residential & $\begin{array}{l}\text { Square feet of occupied housing } \\
\text { units }\end{array}$ & $\begin{array}{l}\text { Number of households } \\
\text { Population }\end{array}$ \\
\hline Commercial & $\begin{array}{l}\text { Square feet of commercial } \\
\text { buildings }\end{array}$ & \\
\hline Industrial & $\begin{array}{l}\text { Real measures of gross output, } \\
\text { (i.e., deflated value of shipments } \\
\text { adjusted for inventory change) }\end{array}$ & $\begin{array}{l}\text { Gross domestic product (GDP) } \\
\text { (value added) contributed from } \\
\text { sector - for higher levels of } \\
\text { aggregation, but only to measure } \\
\text { structural change }\end{array}$ \\
\hline Transportation & Passenger-miles, Ton-miles & Vehicle-miles in highway modes \\
\hline Electric Power Sector & $\mathrm{kWh}$ of electricity generation & \\
\hline
\end{tabular}

The EERE system uses a rigorous mathematical methodology to isolate changes in energy use that can be attributed to energy efficiency (or intensity) from those that can be described as structural factors. Structural factors include those changing aspects of the economy that are not (or only indirectly) related to improvements in energy efficiency. Classic among previous studies of energy use in manufacturing in the U.S. and elsewhere has been the consideration of changes in the composition of industrial output that can affect intensity measures based upon aggregate data. That is, a major structural factor behind reductions in aggregate energy intensity in manufacturing in many developed countries has been the relative decline of energy-intensive industries (e.g., primary metals, chemicals, and paper).

The EERE system uses what is termed the log mean Divisia index (LMDI) method to decompose changes in energy use (and energy intensities) for aggregate sectors into separate indexes for energy intensity and other indexes that represent various types of structural factors. This method 
was developed by B.W. Ang and K. Choi in the late 1990s and is employed by other countries and international organizations in the development of similar energy intensity indicators.

In broadest terms, the LDMI method is used to decompose energy consumption at any level of aggregation into three major components, all expressed as indexes relative to a selected base year and satisfying the following relationship:

$$
\text { Energy }(\text { index })=\text { Activity (index) } x \text { Energy Intensity (index) } x \text { Structure (index) }
$$

When combining the intensity indexes from two or more different activities, the shares of energy consumption (with slight adjustment) serve as weights in calculating a weighted average of yearto-year changes in the intensities for the various activities. The same set of weights is used to develop the index related to structure, only in this case the weights are applied to the (year-toyear changes in) shares of activity related to the different activities (e.g., the shares of ton-miles of freight carried by trucks or rail). The resulting weighted-average (aggregate) year-to-year changes (expressed as changes in the logarithms) are then cumulated over time to develop a time series index. This manner of construction of the various LDMI indexes has the desirable property that the percentage change between any two time periods is not dependent on the choice of a base period for the entire index.

Because energy consumption is used to develop the weights to combine indexes from different sectors, the measures of activity need not be common. Thus, for example, an intensity index for total transportation can be defined by weighting the separate indexes for passenger transportation (where activity is expressed as passenger-miles) and freight (where activity is expressed as tonmiles). The same method of construction holds at the economy-wide level, where the separate energy intensities from the four major end-use sectors are aggregated. In this sense, the economy-wide index of energy intensity can be viewed as analogous to the chain-weighted price index for GDP.

\section{S.2 Data}

Underlying the EERE system of energy intensity indicators is an extensive set of energy and economic data for the U.S. As described in a detailed appendix to this report, a considerable amount of data construction and estimation is required to go along with the data collection efforts. The primary examples of data construction involve the development of time series of floor space in both the residential and commercial building sectors. In neither case is a publicly available, annual source of data available.

Table S.2 provides a listing of some of the major data sources used in the development of the energy intensity indicators. (More complete references/citations for these sources are provided in Appendix A and the list of references.) 
Table S.2. Listing of major data sources

\begin{tabular}{|c|c|c|}
\hline Sector & Energy & Activity \\
\hline Residential & $\begin{array}{l}\text { Annual Energy Review } 2011 \\
\text { (EIA 2012a) } \\
\text { Monthly Energy Review July } \\
2014 \text { (EIA 2014) } \\
\text { State Energy Data System (EIA) }\end{array}$ & $\begin{array}{l}\text { Annual Housing Survey, } \\
\text { American Housing Survey (U.S. } \\
\text { Census Bureau), various years } \\
\text { Residential Energy Consumption } \\
\text { Survey (RECS), EIA, various } \\
\text { years } \\
\text { Characteristics of New Housing } \\
\text { (U.S. Census Bureau) }\end{array}$ \\
\hline Commercial & $\begin{array}{l}\text { Annual Energy Review } 2011 \\
\text { (EIA 2012a) } \\
\text { Monthly Energy Review July } \\
2014 \text { (EIA 2014) } \\
\text { State Energy Data System (EIA) }\end{array}$ & $\begin{array}{l}\text { McGraw-Hill Construction, Inc. } \\
\text { as published in the Statistical } \\
\text { Abstract of the U.S. } \\
\text { Commercial Building Energy } \\
\text { Consumption Survey (CBECS), } \\
\text { EIA, various years }\end{array}$ \\
\hline Industrial & $\begin{array}{l}\text { Manufacturing Energy } \\
\text { Consumption Survey, EIA, } \\
\text { various years } \\
\text { Annual Survey of Manufactures, } \\
\text { U.S. Census Bureau } \\
\text { National Energy Accounts (see } \\
\text { Appendix A) }\end{array}$ & $\begin{array}{l}\text { Measures of industrial gross } \\
\text { output and value added, obtained } \\
\text { from Bureau of Economic } \\
\text { Analysis website. } \\
\text { Measures of gross output for } \\
\text { input-output industries, obtained } \\
\text { from Bureau of Labor Statistics } \\
\text { website. }\end{array}$ \\
\hline Transportation & $\begin{array}{l}\text { Transportation Energy Data } \\
\text { Book, Oak Ridge National } \\
\text { Laboratory, various editions } \\
\text { Bureau of Transportation } \\
\text { Statistics, website } \\
\text { Transportation in America, } 19^{\text {th }} \\
\text { and } 20^{\text {th }} \text { editions, Eno } \\
\text { Transportation Foundation }\end{array}$ & $\begin{array}{l}\text { Transportation Energy Data } \\
\text { Book, Oak Ridge National } \\
\text { Laboratory, various editions } \\
\text { Bureau of Transportation } \\
\text { Statistics, website } \\
\text { Transportation in America, } 19^{\text {th }} \\
\text { and } 20^{\text {th }} \text { editions, Eno } \\
\text { Transportation Foundation }\end{array}$ \\
\hline Electric Utilities & $\begin{array}{l}\text { Annual Energy Review } 2011 \\
\text { (EIA 2012a), various tables in } \\
\text { chapter } 8 \text { of this document }\end{array}$ & $\begin{array}{l}\text { Annual Energy Review } 2011 \\
\text { (EIA 2012a), various tables in } \\
\text { chapter } 8 \text { of this document }\end{array}$ \\
\hline
\end{tabular}


In addition to the need to construct annual series of floor space for the buildings sectors, several other areas require specific procedures to fill in data gaps and account for series breaks in the time series data. A particularly difficult issue involves how to interpolate the quantities of fuel consumption in manufacturing between the periodic Manufacturing Energy Consumption Surveys (MECS) conducted by the Energy Information Administration. Since the 1980s, the Census Bureau's Annual Survey of Manufactures (ASM) has requested respondents provide only the cost of the fuels purchased. Thus, to develop annual energy consumption estimates, some method must be developed to appropriately weight the different prices of fuels consistent with their consumption in individual manufacturing industries and also account for statistical discrepancies between the MECS and the ASM when conducted during the same years. The lack of annual data for both electricity and fuel quantities in the mining and construction sectors also requires interpolation (and extrapolation) procedures. The basic objective in those cases where such procedures must be applied is to minimize distortion in the underlying long-run trends in energy intensity.

\section{S.3 Economy-wide Indexes of Energy Intensity}

An energy intensity index for the entire U.S. economy is constructed as a weighted average of the (adjusted) source energy indexes for the four major end-use sectors. The LDMI approach facilitates this construction. Even though the measures of activity vary by sector, an aggregate index can be developed by using the shares of energy use to weight the component indexes.

A natural comparison is suggested between the intensity index constructed in this bottom-up fashion to an index based upon the energy-GDP ratio. Figure S.1 shows this comparison, with 1985 once again selected as the base year of the index.

The economy intensity index clearly shows a smaller long-run trend reduction than the energyGDP index. In the past quarter-century (1985-2011), the economy-wide energy intensity index fell about $14 \%$, while the energy-GDP index fell by more than double that amount approximately $36 \%$.

The energy-GDP ratio suffers from number of limitations. While the amount of energy used in the numerator of this ratio is similar to that used across the intensity indicators developed here, the measure of activity is decidedly different. Moreover, GDP is influenced by a variety of structural factors that will affect energy consumption independent of underlying changes in energy efficiency. 


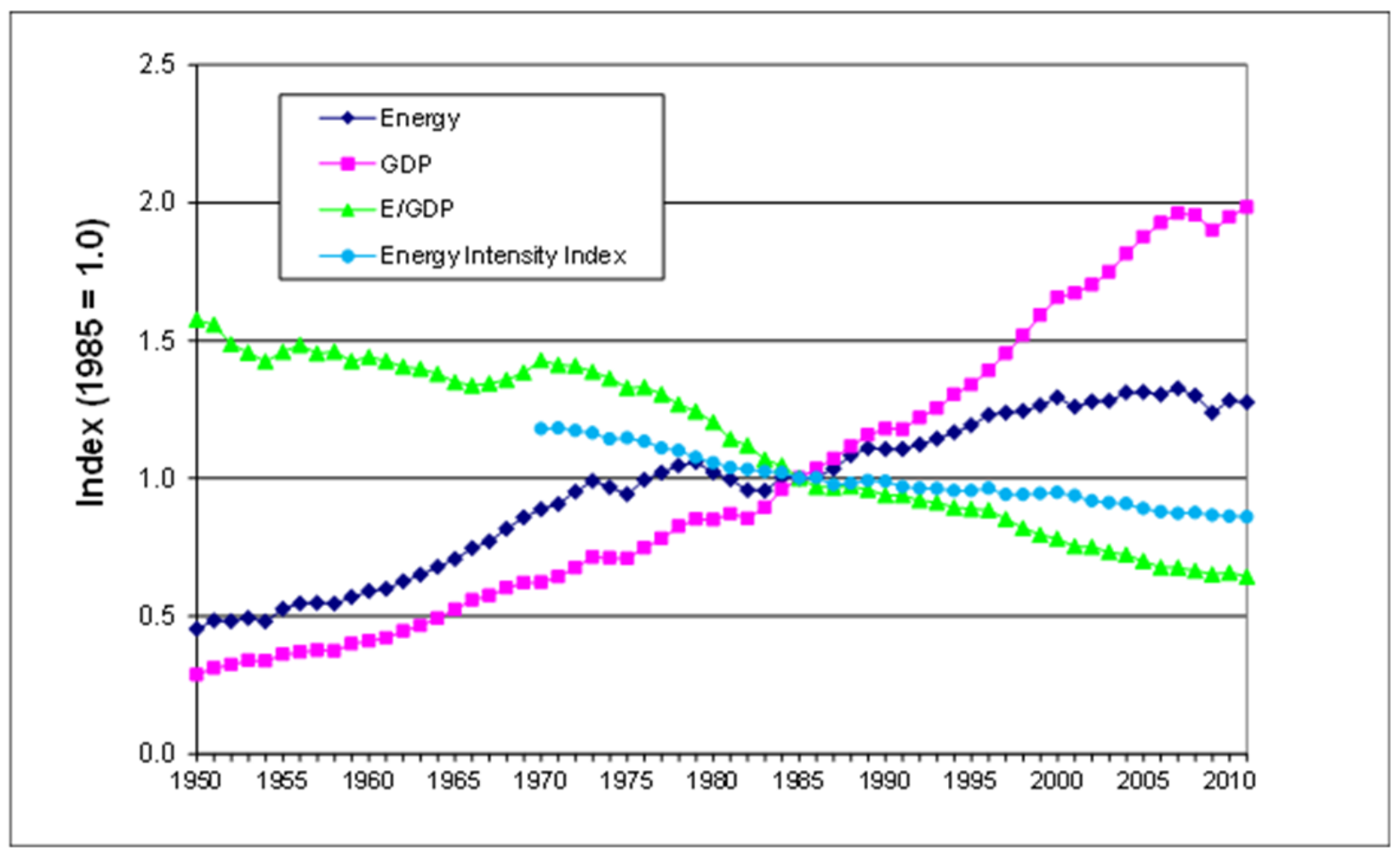

Figure S.1. Economy-wide indexes of energy intensity, economic activity, and energy use

\section{S.4 Trends Over Sub-Periods}

It is informative to explore the changes in energy intensity by sector across sub-periods. As shown in Figure S.2, the entire period has been divided in three sub-periods: 1970-1985, 19852000, and 2000-2011. Because the time periods are of unequal length, the values represented in the figure are normalized to show annual percentage changes in energy intensity (between the initial and terminal years of each sub-period). The energy intensity estimates for the end-use sectors are based upon the "adjusted" source definition of total energy.

The most notable aspect of examining the bars in the figure is that the average rates of intensity decline were dramatically smaller in the 1985-2000 period compared to 1970-1985, but then generally fell by a larger and more consistent degree over the last decade sub-period. The most significant examples of this pattern were in the industrial, commercial, and electric utility sectors.

The economy-wide intensity indexes shown in the right-most set of bars reflect the general behavior of the sector-specific results over these same sub-periods. The source intensity index is the most appropriate index from an aggregate economy point of view. From an annual rate of decline of just over $1 \%$ per year during the $1970-1985$ period, the rate slowed to just $0.2 \%$ per 
year (decline) over the next 15 years. However, over last 11 years of the data period, source energy intensity declined at nearly the same rate as in the initial period.

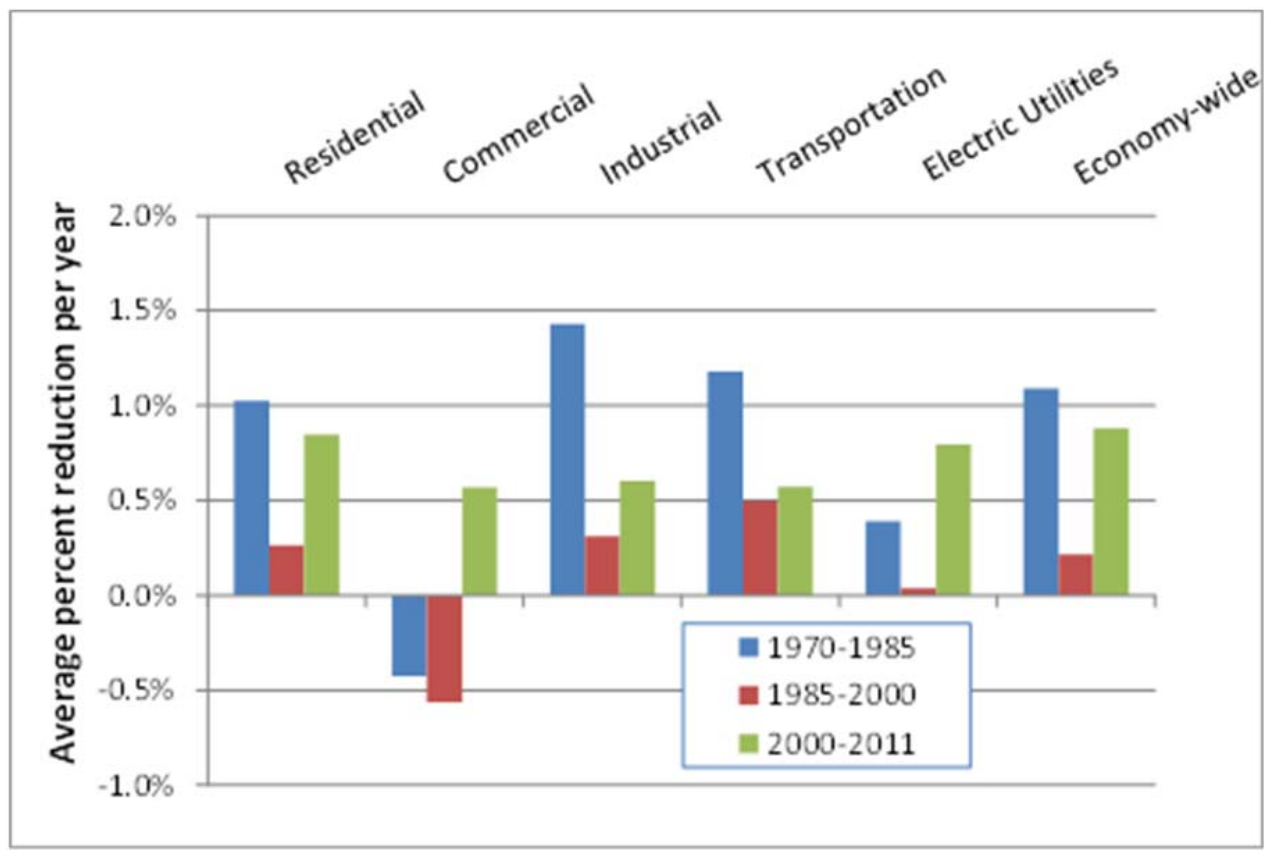

Figure S.2. Average percentage changes in source energy intensities by sub-period (adjusted source intensities for end-use sectors)

While it is beyond the scope of this report to provide an explanation of the behavior of the energy intensity indexes, several general observations can be made. The important role of energy prices in influencing behavior with regard to energy use is clearly evident in the subperiod results. The first sub-period represents one in which energy prices rose dramatically in response to the two oil-related crises of the 1970s (1973-1974, and 1979-1980). After the collapse of the petroleum market in 1986, the ensuing 15 years or so were marked by general energy price stability. Finally, the increase in energy prices that occurred over much of the previous decade, particularly for natural gas and oil, likely spurred renewed activity to achieve greater energy efficiency.

However, responses to energy prices are likely not the only factors yielding progress toward greater energy efficiency. Public policies and programs at all levels — states, utilities, and federal - contributed to lower energy consumption, particularly in the buildings and industrial sectors. At the federal level, mandatory equipment efficiency standards, promotion of more stringent building energy codes, as well as targeted research and development (R\&D) to support industrial energy efficiency have all yielded energy savings, particularly since 1995. Many electric utilities around the U.S. have aggressively promoted energy efficiency programs 
including improved lighting and space conditioning in residential and commercial buildings. These programs have taken on renewed vigor in the latter portion of the previous decade and thus may be a measureable influence on the more robust intensity reduction trends identified in this study.

\section{S.5 Key Trends by Sector}

This report presents detailed results related to energy intensity for each of the major end-use sectors as well as the electric utility sector. As mentioned above, energy intensity indexes have been developed separately for electricity, total fuels, delivered energy, and source energy. A fifth measure of energy, the "adjusted" source energy, where the effects of increases in electricity generation energy efficiency have been removed from the published source energy consumption (Tables $2.1 \mathrm{~b}$ through $2.1 \mathrm{~d}$ in the Annual Energy Review), is typically the preferred overall metric displayed in the EERE system. This measure also assigns the energy used (lost) in the generation and transmission to the end-use sector itself, but seeks to differentiate between the effects of improved electricity generation efficiency and changes in the intensity of delivered electricity (because both effects are reflected in the published source energy consumption by EIA). A straightforward method of implementing this adjustment is to hold the ratio of electricity losses to sales constant at the value for a selected year (1985 to be consistent with the index base). The actual method used in the system of intensity indicators employs the LDMI approach. In practice, the two methods yield very similar results.

Figures S.3 through S.6 all show the calculated time series energy intensities based upon this (electricity efficiency adjusted) source energy construct. The first of these four, Figure S.3, shows key indexes related to energy use, activity, and (adjusted) source energy intensity for the residential sector. Since 1985, there has been significant increase in average housing unit size, estimated to have increased by approximately $25 \%$. The number of housing units has increased by about $30 \%$. The structure index includes short-run variations in the intensity caused by weather, as well as the relatively small changes in overall intensity that relate to population shift across census regions and some greater proportion of single-family homes in the overall housing stock.

Figure S.4 presents the most aggregate indicators for the commercial sector. The top two indexes show the magnitude of commercial floor space and (adjusted source) energy use relative to 1985 . From 1985 to 2011 , commercial floor space increased about $46 \%$ and energy use about $62 \%$. The energy intensity index, relative to 1985 , was computed to be about 1.08 in 2011 . The remaining line in the figure shows the estimated weather adjustment factors, normalized to be 1.0 in 1985. In general, the weather factors show a variation about $4 \%$ over the entire time period. The weather factors for 2010 and 2011 are both over 2\% (compared to 1985), resulting from very warm summers (as measured by cooling degree-days across the U.S.). 


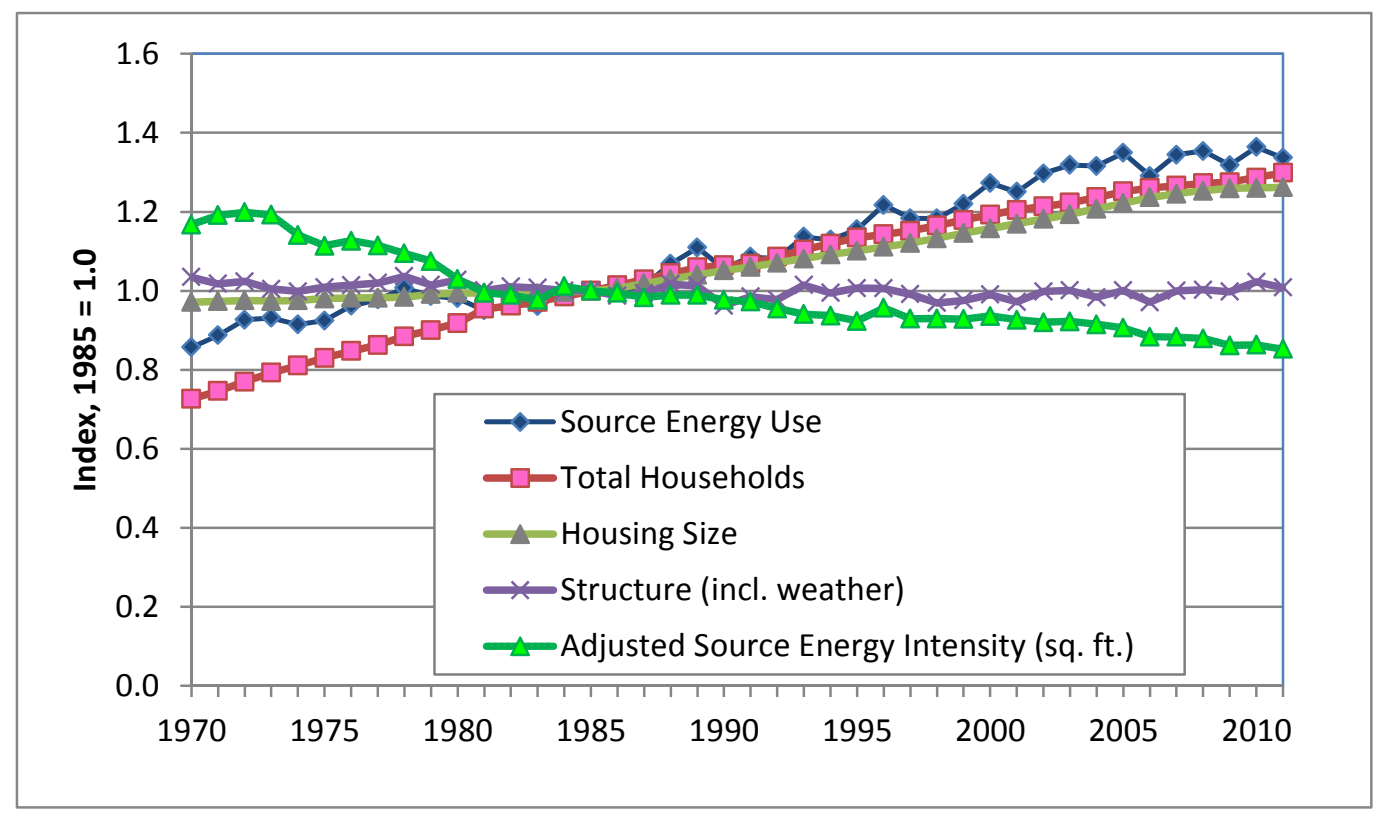

Figure S.3. Energy intensity and related indexes for the residential sector, 1970-2011

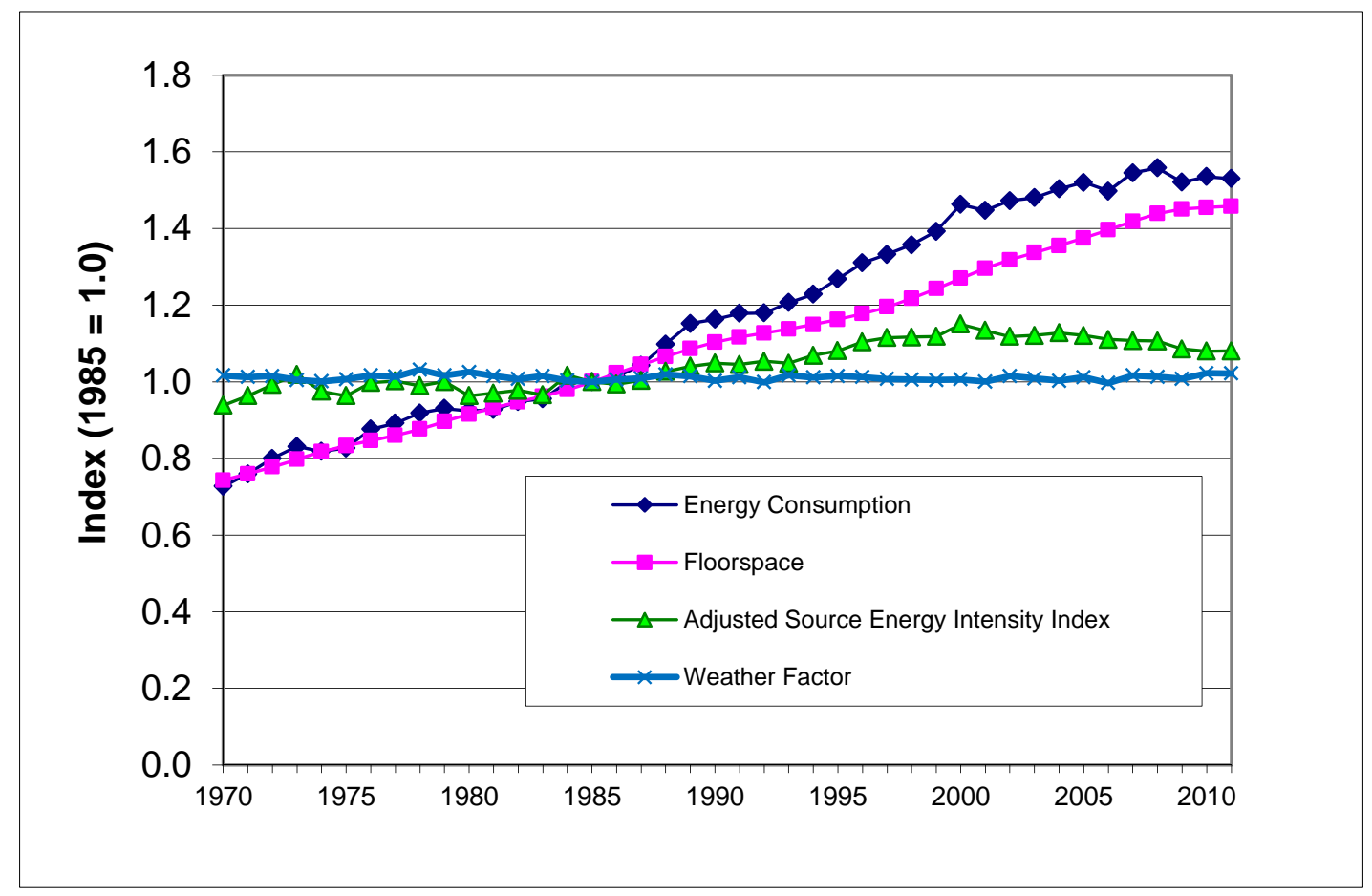

Figure S.4. Energy intensity and related indexes for the U.S. commercial sector, 1970-2011 


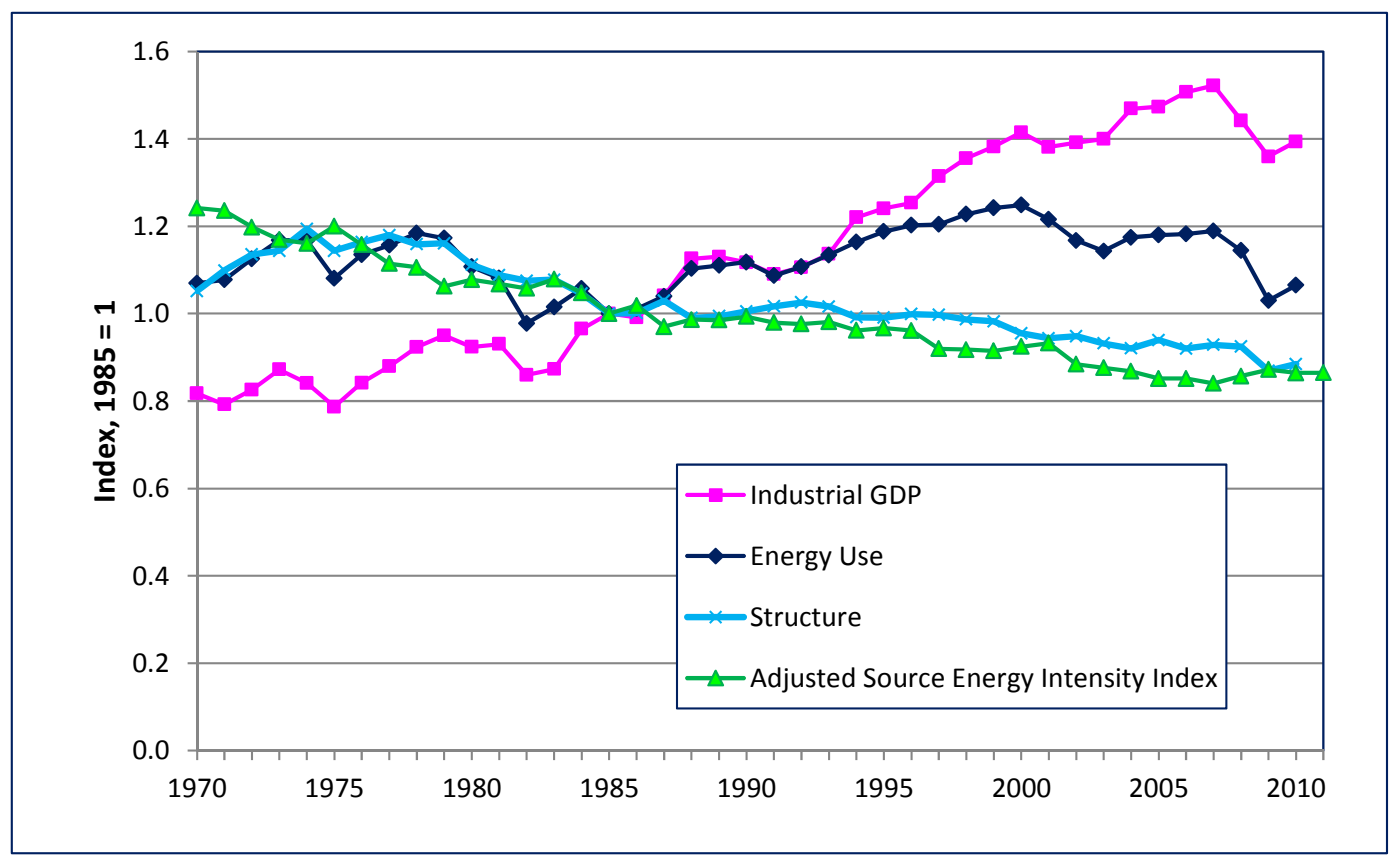

Figure S.5. Energy intensity and related indexes for industrial sector, 1970-2011

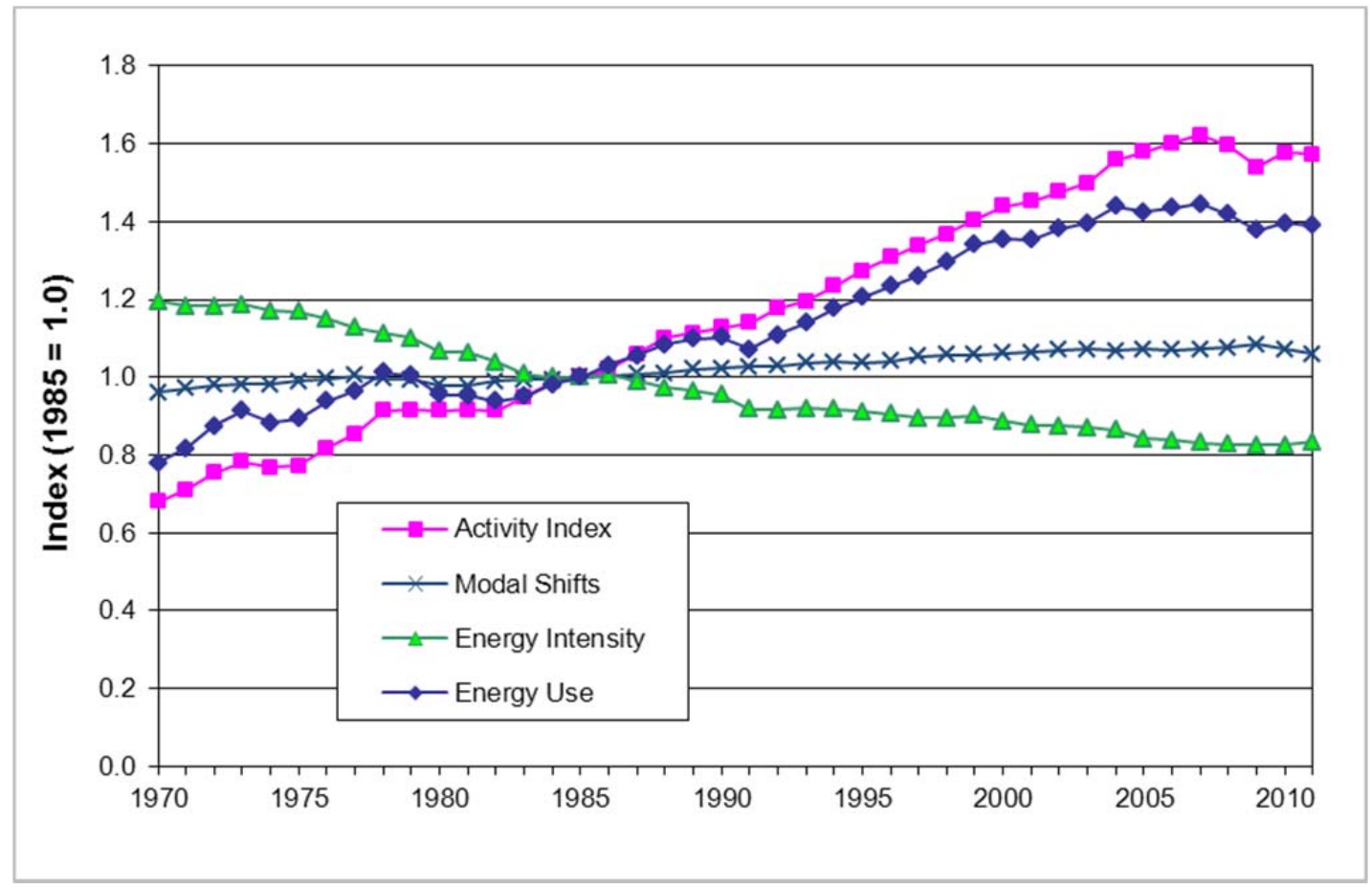

Figure S.6. Overall indexes for the U.S. transportation sector, 1970-2011 
For the industrial sector, separately estimated intensity indexes for manufacturing and nonmanufacturing are combined to form indexes for the industrial sector as whole. As shown in Figure S.5, the structural index reflects structural changes within the two major subsectors, as well as the shift between manufacturing and nonmanufacturing activity. Because manufacturing has a higher absolute intensity per dollar of GDP, the increase in the manufacturing share of industrial GDP is a factor that offsets some of decline from other influences. Relative to 1985, the value of the intensity index in 2011 was about $14 \%$ lower.

Figure S.6 presents the most aggregate indicators for entire transportation sector, combining passenger and freight transportation. The top two indexes show the magnitude of overall transportation activity and energy use relative to 1985. From 1985 to 2011, transportation activity increased about $54 \%$ and energy use about $37 \%$. Both the activity and energy intensity indexes are developed as energy-weighted averages of the respective separate indexes for passenger and freight segments, with the weights changing over time according to the LMDI methodology. The energy intensity index for all of transportation was computed to be 0.83 in 2011, a value closer to the passenger index than the freight index because of the relatively higher amount of energy used for passenger travel (just over $70 \%$ of total transportation energy use in 2011).

The index labeled as "modal shifts," is a sum of these impacts from the passenger and freight modes. (There is no additional structural shift from changes in the ratio of passenger to freight activity because the measures of activity are not the same.) The modal shifts index increased by about $6 \%$ between 1985 and 2011, primarily as result of influence from the highway segment of both passenger (shifts from automobiles to light trucks) and freight transportation (increasing share of freight transported by trucks.) The index reflects the additional amount of energy, compared to 1985 , that is used in transportation from the combined effects of these shifts.

Figure S.7 shows the calculated historical energy intensities, in terms of Btu per $\mathrm{kWh}$, for the electricity-only and combined heat and power (CHP) plants in the electric power sector. Given that electricity-only plants account for over $95 \%$ of electricity generation, the intensity trends in that segment of the electric power sector are much more important from the standpoint of overall energy efficiency in the U.S. Three distinct time periods are clearly delineated in the graph of intensities: 1) a rapid decline in intensities from 1950 through 1960,2) a period of nearly constant intensities between 1960 and 2000, and 3) a slow but steady decline of intensities in the past decade.

The lower graph in Figure S.7 shows the evolution of intensities for CHP plants. Given EIA's imputation methodologies, the absolute intensities for electricity from CHP plants are lower than those in electricity-only plants. The discontinuity in 2004 is caused by a change in the method used by EIA to apportion energy consumption attributable to heat production as compared to electricity generation. Because the energy consumption from CHP plants represents such a small 
percentage of the electric power sector, no effort has been made to adjust the subsequent data for the discontinuity first observed in 2004.

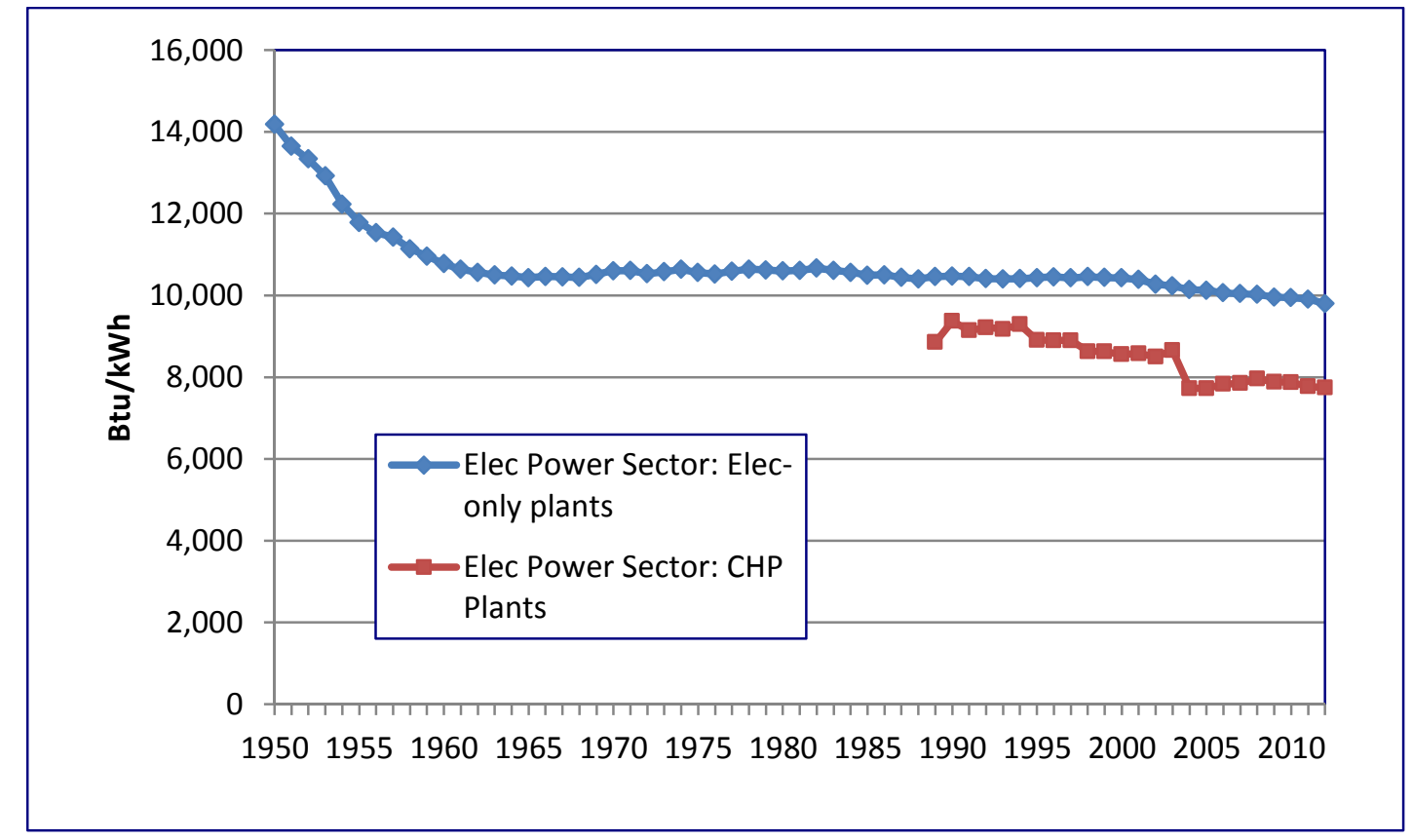

Figure S.7. Energy intensities (Btu/kWh) in electricity-only and CHP plants, 1950-2012

\section{S.6 Suggestions for Future Improvements}

There are several areas related to the system of energy intensity indicators that would represent beneficial improvements. These improvements would lead to more accurate measurement of intensity change, as well as to a greater ability to link the intensity changes to particular technologies or programmatic activities. Several represent further disaggregation within the current set of indicators. A useful study that would complement the economy-wide intensity index involves a partial reconciliation with alternative indexes based upon the energy-GDP ratio. Finally, there are several areas related to closing data gaps that might be pursued. The following bulleted items identify the general nature of these suggested activities:

- Incorporate end-use disaggregation in the residential (and possibly commercial) sectors, with the goal of breaking out space conditioning energy use (and intensity) from other end uses

- Add intensity indexes based upon physical measures of output in selected manufacturing industries 
- Perform a partial reconciliation of the EERE economy-wide intensity index and the energy-GDP ratio

- $\quad$ Fill in missing data gaps for nonmanufacturing that were not addressed in the 2012 update

- Make explicit recognition of "statistical discrepancy" in energy consumption estimates provided by "supply-side" sources (e.g., utilities) and end-user reporting (e.g., MECS). 
xviii 


\section{Contents}

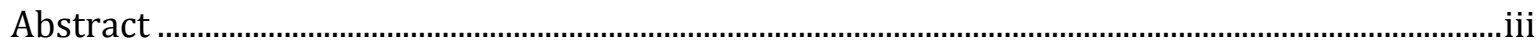

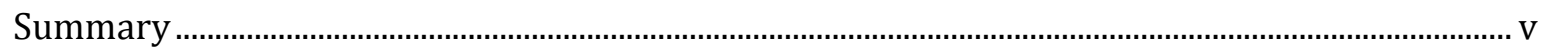

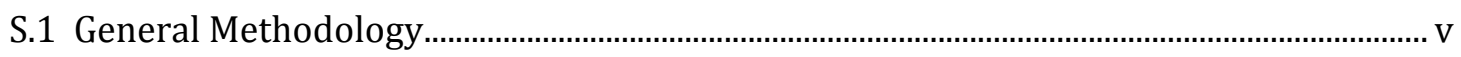

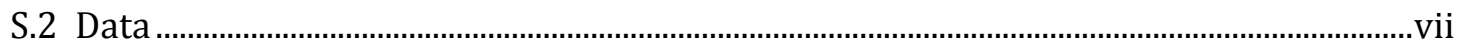

S.3 Economy-wide Indexes of Energy Intensity ....................................................................... ix

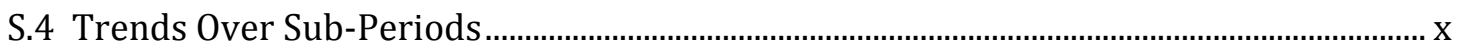

S.5 Key Trends by Sector ......................................................................................................

S.6 Suggestions for Future Improvements....................................................................................

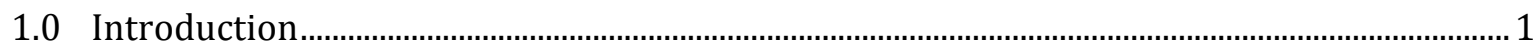

1.1 Energy Efficiency and Energy Intensity ..................................................................... 1

1.2 Background ...................................................................................................................... 2

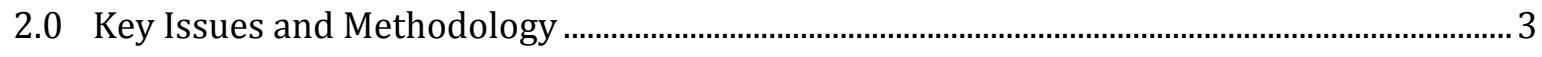

2.1 Source versus Delivered Energy ..................................................................................... 3

2.2 Scope of Energy End Uses and Economic Activity ............................................................. 4

2.3 Hierarchical System of Indicators ................................................................................. 5

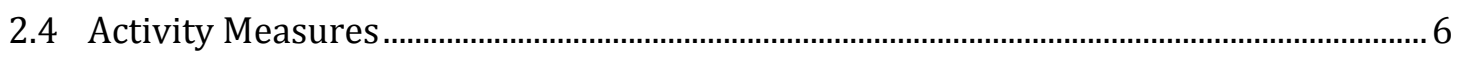

2.5 Aggregate Intensities and Structural Change ...................................................................... 7

2.5.1 Alternative Versions of the LDMI Method ……........................................................ 11

2.6 Electric Utility Energy Efficiency and Source Energy Intensities .................................. 11

2.6.1 One More Structural Factor - "Electrification" ........................................................ 14

2.6.2 Relationship between factors expressed in delivered versus source
electricity.................................................................................................................. 15

3.0 Energy Intensity Indicators for Major End-Use Sectors........................................................ 17

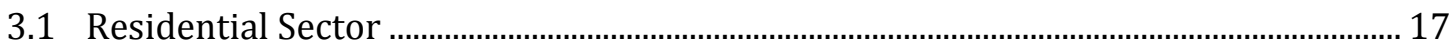

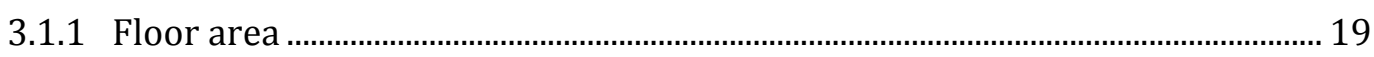

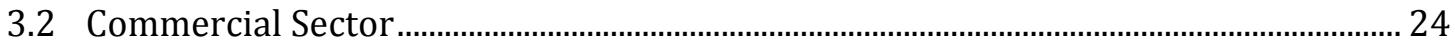

3.2.1 Floor Space Estimates and Other Data Issues ...................................................... 25

3.2.2 Commercial Sector Energy Intensity Trends..................................................... 25

3.3 Industrial Sector ............................................................................................................ 28

3.3.1 Activity Measures and Decomposition Approach................................................ 30

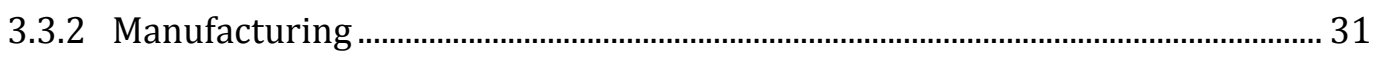

3.3.3 Nonmanufacturing.............................................................................................. 34

3.3.4 Energy Intensity Indexes for the Industrial Sector ................................................ 35

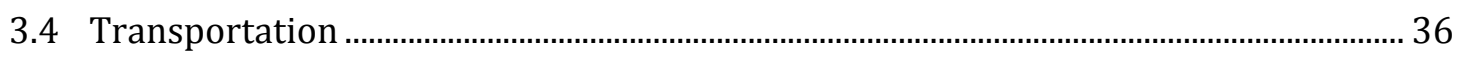

3.4.1 Freight Transportation ....................................................................................... 37

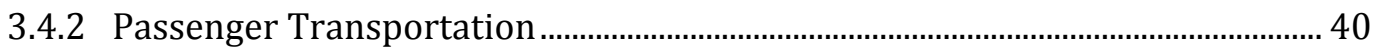




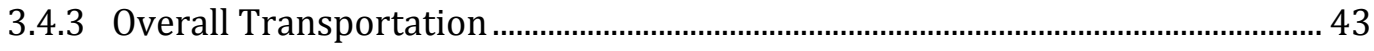

3.5 Electric Power Sector ……………..................................................................................... 45

4.0 Economy-wide Indexes of Energy Intensity........................................................................ 51

5.0 Summary and Suggestions for Future Improvement ............................................................ 55

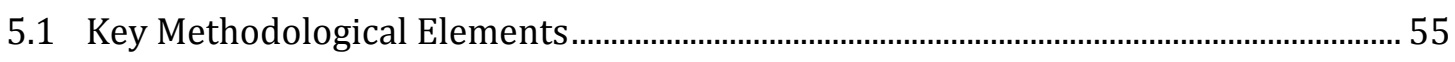

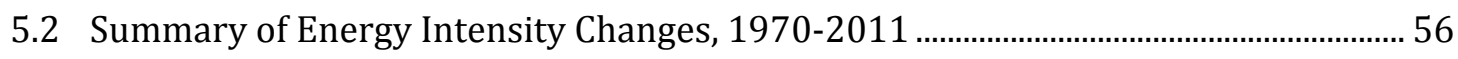

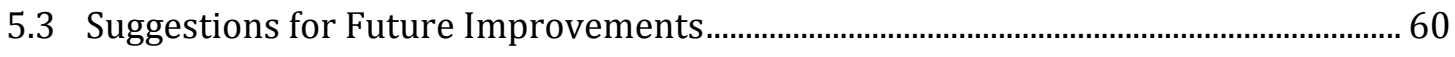

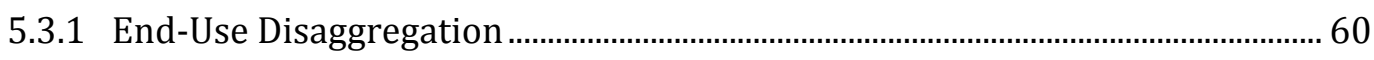

5.3.2 Intensity indexes based upon physical production .............................................. 61

5.3.3 Perform partial reconciliation with the energy-GDP ratio ................................... 61

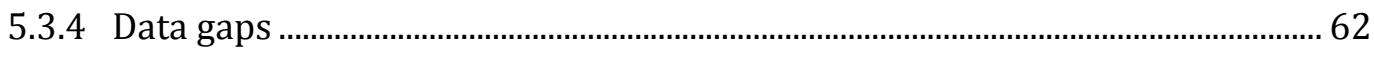

5.3.5 Explicit recognition of "statistical discrepancy" in energy consumption

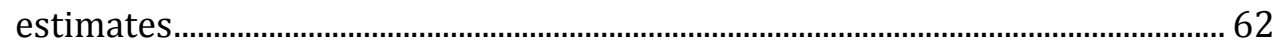

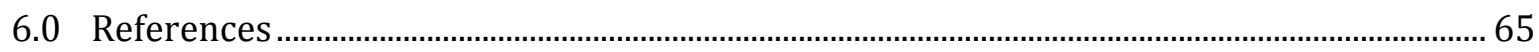

APPENDIX A - Data Sources and Methodology ………………....................................................... A.1

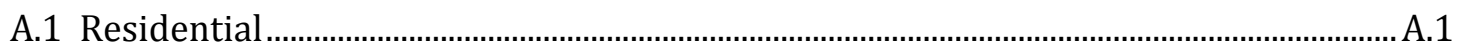

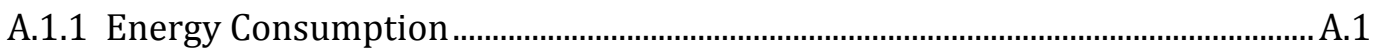

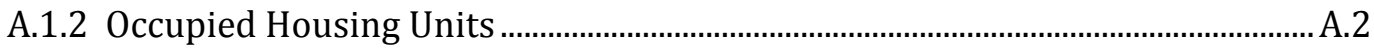

A.1.3 Regional Estimates of Occupied Units...…………………………………….... A.16

A.1.4 Average Size of Residential Housing Units: National.......................................... A.17

A.1.5 Average Size of Residential Housing Units: Regional ........................................ A.21

A.1.6 Housing Stock and Size Estimates, 1970-1984 .................................................. A.23

A.1.7 Weather Adjustment .................................................................................................. A.26

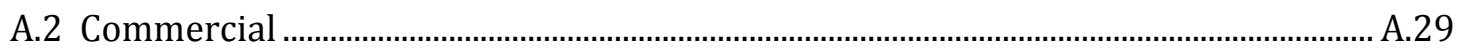

A.2.1 Commercial Buildings versus Commercial Sector ………………………….... A.30

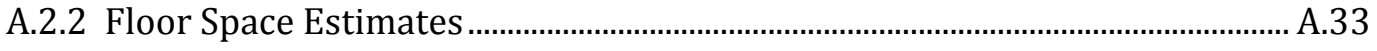

A.2.3 Weather Adjustment ........................................................................................ A.36

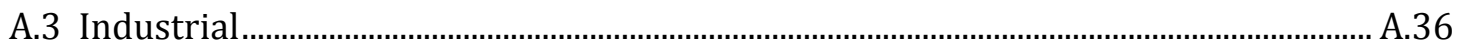

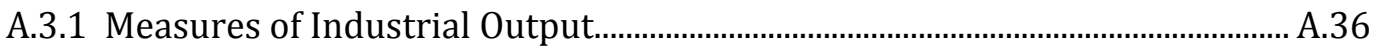

A.3.2 Energy Consumption ..................................................................................... A.40

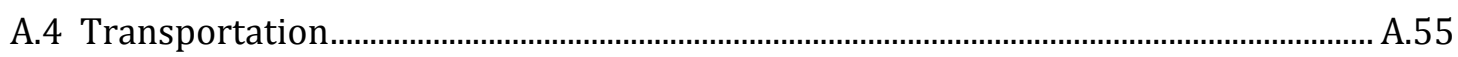

A.4.1 Background and General Data Sources.................................................................. A.56

A.4.2 Recent FWHA Changes Related to Estimates of Vehicle Travel and Fuel Use .................................................................................................................. A.57

A.4.3 Data Sources and Methodology Used for Buses ................................................ A.62

A.4.4 Detailed Sources and Brief Methodology Descriptions..................................... A.73

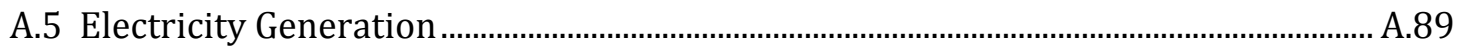

A.5.1 Background and General Data Sources............................................................. A.89

A.5.2 Methodology for intensity indicators for electricity generation...................... A.91 
APPENDIX B - Relationship between Economy-wide Energy Intensity Indexes Based on Source Energy and Delivered Energy …………......................................................................... B.1

APPENDIX C - Energy Consumption Shares Used in the Development of Intensity Indexes.. C.1

C.1 Energy Consumption Shares and LDMI Weights ………….................................................. C.1

C.2 Tables with Energy Consumption Shares ........................................................................... C.3 


\section{Figures}

Figure S.1. Economy-wide indexes of energy intensity, economic activity, and energy use ...........

Figure S.2. Average percentage changes in source energy intensities by sub-period (adjusted source intensities for end-use sectors)

Figure S.3. Energy intensity and related indexes for the residential sector, 1970-2011 _............. xiii

Figure S.4. Energy intensity and related indexes for the U.S. commercial sector, 1970-2011 .... xiii

Figure S.5. Energy intensity and related indexes for industrial sector, 1970-2011 .....................xiv

Figure S.6. Overall indexes for the U.S. transportation sector, 1970-2011 .................................iv

Figure S.7. Energy intensities (Btu/kWh) in electricity-only and CHP plants, 1950-2012 ...........xvi

Figure 2.1. Basic structure of EERE energy intensity indicators (top three tiers) ..........................6

Figure 3.1. Estimates of total residential floor area by housing type, 1970-2011 .......................20

Figure 3.2. Comparison of residential energy intensities (adjusted source energy) based upon

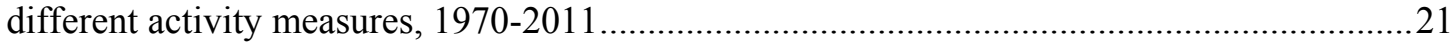

Figure 3.3. Energy intensity and related indexes for the residential sector, 1970-2011 _.............22

Figure 3.4. Decomposition of residential energy intensity based upon published values of source

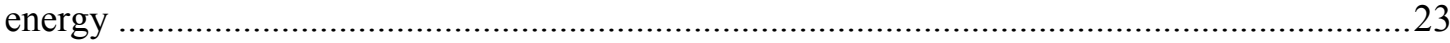

Figure 3.5. Commercial energy intensity indexes by energy type, 1970-2011 ..........................26

Figure 3.6. Energy intensity and related indexes for the U.S. commercial sector, 1970-2011 ......27

Figure 3.7. Decomposition of energy intensity based upon published values of source energy.....28

Figure 3.8. Manufacturing energy intensity indexes by energy type, $1970-2011$.........................33

Figure 3.9. Energy intensity and related indexes for manufacturing, 1970-2011 ........................33

Figure 3.10. Nonmanufacturing (industrial) energy intensity indexes by energy type, 1970-201135

Figure 3.11. Energy intensity and related indexes for industrial sector, 1970-2011 ....................36

Figure 3.12. Energy intensities for freight modes, 1970-2011 ...................................................38

Figure 3.13. Energy intensity indexes, base year 1985, for freight modes, 1970-2011 ...............39

Figure 3.14. Overall indexes for freight transportation, 1970-2011 ..........................................39

Figure 3.15. Energy intensities for major passenger travel modes, 1970-2011 ...........................42

Figure 3.16. Energy intensity indexes for total freight and total passenger transportation

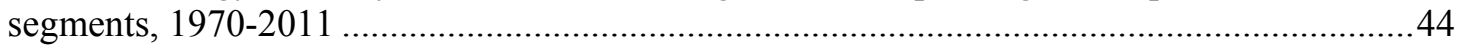

Figure 3.17. Overall indexes for the U.S. transportation sector, 1970-2011 .............................45

Figure 3.18. Energy intensities (Btu/kWh) in electricity-only and CHP plants, 1950-2012 _.........48

Figure 3.19. Energy intensities (Btu/kWh) in electricity-only fossil-fuel plants, 1970-2012 ........49

Figure 4.1. Economy-wide indexes of energy intensity, economic activity, and energy use .........51

Figure 4.2. Decomposition of end-use sector and electric power sector contributions to U.S. energy intensity change

Figure 5.1. Source energy intensity indexes by major end-use sector, 1970-2011, (adjusted for improvements in electricity generation and transmission efficiency)....................................57

Figure 5.2. Average percentage changes in energy intensities by sub-period (adjusted source intensities for end-use sectors). 
Figure A. 1. Estimated survival curve for U.S. single-family housing units

Figure A. 2. Occupied single-family housing units, predicted vs. reported AHS, for U.S. ........A.10

Figure A. 3. Total multi-family housing units, predicted vs. reported AHS, for U.S., $1985-2011$

Figure A. 4. Occupied multi-family housing units, predicted vs. reported AHS, for U.S. .........A.13

Figure A. 5. Estimated survival curve for U.S. manufacturing housing/mobile homes..............A.15

Figure A. 6. Occupied manufactured homes, predicted vs. reported AHS, for U.S. ..................16

Figure A. 7. Predicted and actual average size of occupied single-family housing units, plus extrapolation back to 1985

Figure A. 8. Reported average size of new single-family housing units from the Characteristics of New Housing survey, 1973-2012 (see footnote 9 above)

Figure A. 9. Predicted and actual average size of multi-family housing units, plus extrapolation back to 1985

Figure A. 10. Estimated average size of occupied manufactured housing units, 1970-2011.....A.21

Figure A. 11. Regional/national ratios for single-family housing units, 1999-2009.... A. 22

Figure A.12. Illustration of regional size trend ratio regression and extrapolation, single-family housing units in the Northeast census region

Figure A. 13. Actual and normalized fuel intensities for the South census region .................... A.29

Figure A. 14. Reported commercial and industrial electricity for Minnesota, 1990-2009 .........A.32

Figure A. 15. Estimates of total commercial building floor space in the U.S., 1970-2011 ........A.35

Figure A. 16. Comparison of BEA and BLS gross output series for NAICS Sector 321, Wood Products

Figure A. 17. Ratios of MECS-based costs of purchased fuel to ASM/CM costs of purchased fuels for four selected sectors

Figure A. 18. Predicted prices of natural gas consumed by the chemical sector, NAICS 325 ...A.45

Figure A. 19. Average passenger loads (load factor) and fuel economy (MPG) for transit buses, 1970-2011

Figure A. 20. Estimated energy intensities for domestic waterborne transportation A. 80

Figure B.1. Comparison of economy-wide source and delivered energy intensity indexes 


\section{Tables}

Table S.1 Activity measures by major end-use sector ...............................................................

Table S.2. Listing of major data sources ................................................................................... vii

Table 2.1. Activity measures by major end-use sector...........................................................

Table 3.1. Estimated energy consumption and activity in the residential sector.......................... 18

Table 3.2. Estimated energy and activity (floor space) in the commercial sector.........................24

Table 3.3. Estimated energy use and activity in U.S. manufacturing..........................................29

Table 3.4. Estimated energy use and activity in the nonmanufacturing segment of the industrial

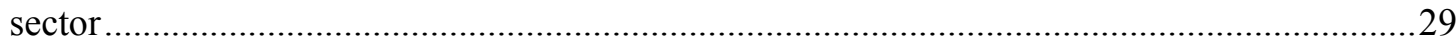

Table 3.5. Estimated energy use and activity in U.S. freight transportation ..................................37

Table 3.6. Estimated energy use and activity in U.S. passenger transportation .............................41

Table 3.7. Electricity generation and energy consumption in electricity-only and CHP plants,

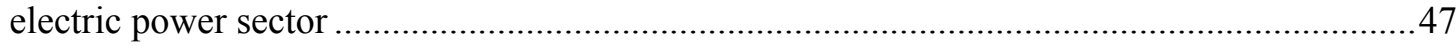

Table 3.8. Electricity generation and energy consumption in electricity-only fossil-fuel plants ....49

Table 5. 1. Annual percentage changes in energy intensity indexes over three sub-periods ..........58

Table A.1. Total number of housing units and number reporting size from the 2009 AHS A.3

Table A.2. Average size, number of occupied housing units, and observations with size data,

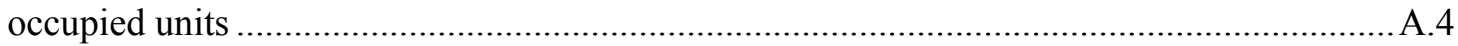

Table A.3. Number of occupied single-family housing units by vintage for various

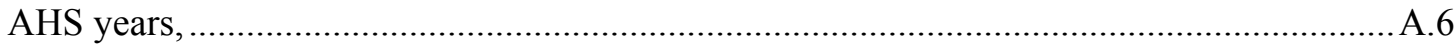

Table A.4. Assigned average years of construction by vintage ............................................. A.7

Table A.5. Number of occupied multi-family housing units by vintage for various AHS years, in

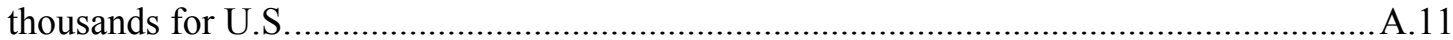

Table A.6. Number of occupied manufacturing housing units (and mobile homes) by vintage for various AHS years, in thousands for U.S.

Table A.7. Regression coefficients for weather adjustment model: fuels intensity, South census region, 1985-2011.

Table A.8. Adjustments in aggregate commercial electricity caused by reclassifications (trillion Btu, site).....

Table A.9. BEA sectors used in industrial energy intensity indicators construction ................. A.38

Table A.10. Sources for mining data by census year ............................................................... A.50

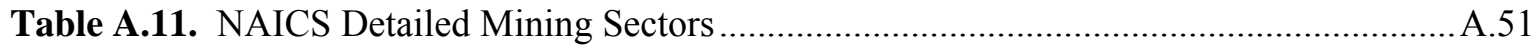

Table A.12. Sources for construction data by census year.....................................................53

Table A.13. Expenditures by fuel type for the U.S. construction, census years ........................ A.54

Table A.14. Estimated energy consumption for the construction sector by fuel type and census

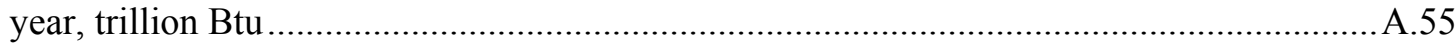

Table A. 15. Summary of extrapolation methodology for car and light truck fuel economy .....A.59

Table A.16. Summary of pre-2007 adjustments for medium and heavy trucks ......................... A.61

Table A.17. Data sources for highway passenger transportation - personal vehicles................ A.82 
Table A.18. Data sources for highway passenger transportation - buses ................................. A.83

Table A.19. Data sources for passenger rail transportation................................................. A.84

Table A.20. Data sources and methodology for airline passenger transportation ...................... A.85

Table A.21. Data sources and methodology for highway freight transportation ....................... A.86

Table A.22. Data sources and methodology for rail and air freight transportation .................... A.87

Table A.23. Data sources and methodology for water and pipeline freight transportation.........A.88

Table A.24. Heat rate values used by EIA to measure energy inputs for electricity generation

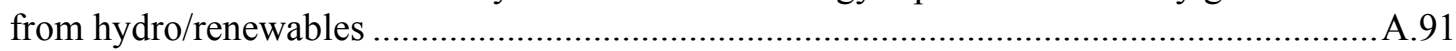

Table A.25. Key electricity-related tables from the Annual Energy Review ............................ A.92

Table A.26. Key AER tables used to construct the detailed energy intensity indexes for the

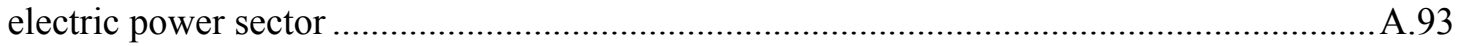

Table A.27. Key AER tables used to construct detailed energy intensity indexes for electricity generation in the commercial and industrial sectors ..........................................................95

Table C. 1. Energy shares and LMDI weights - a numerical example ....................................... 2

Table C. 2. Energy Consumption Shares for Major Sectors ..................................................... C.4

Table C. 3. Energy Shares for Residential and Commercial Sectors ........................................ C.5

Table C. 4. Energy Shares for Industrial Sector, Source Energy ............................................... . 6

Table C. 5. Energy Shares for Industrial Sector, Delivered Energy …...................................... .

Table C. 6. Energy Shares for Transportation Sector ............................................................... C.8

Table C. 7. Energy Shares for Electric Power Sector .............................................................. . .9 



\subsection{Introduction}

Increasing energy efficiency continues to be viewed by policymakers and the public as an important national goal. As has been recognized since the energy crises of the 1970s, energy efficiency can be viewed as an energy resource that can reduce the need for new energy supplies and infrastructure. More recently, energy efficiency has come to be viewed as a major element in efforts to reduce the emissions of carbon dioxide and attendant global climate change. Moreover, for individual consumers of energy services, greater energy efficiency often comes with associated benefits such as more comfortable homes, faster travel options, and better industrial product performance.

This report examines progress toward greater energy efficiency that has taken place in the U.S. over the past four decades. From the outset, it must be noted that issues related to the measurement of energy efficiency are complex. Energy efficiency in its simplest terms refers to the quantity of specific goods or energy services (e.g., lighting or refrigeration) that can be produced with a given amount of energy. It is most accurately expressed at the level of very specific technologies or processes. Examples would include the pounds of aluminum per kWh of electricity or the amount of heat generated per unit of fuel consumption by a gas or oil furnace running at full capacity. The complexity in measuring energy efficiency comes about as one seeks to measure energy efficiency for broader and less-defined measures of output or activity.

\subsection{Energy Efficiency and Energy Intensity}

This report, following the conventional approach of previous studies, focuses upon a metric closely related to energy efficiency, namely energy intensity. At the level of a specific technology or energy service, one can meaningfully refer to energy efficiency as the ratio of output or activity per unit of energy (e.g., miles per gallon). In this situation, energy intensity is the mathematical inverse of energy efficiency, the ratio of energy consumption per unit of output or activity. At higher levels of aggregation across activities involving the production or consumption of goods and services, particularly where physical measures are not available and activity must be measured in value-based units (e.g., inflation-adjusted dollars), energy intensity is the more commonly used construct. Energy intensity, which measures the amount of energy per some fixed level of activity, is more naturally linked to economic savings (i.e., lower expenditures) or environmental benefits that stem from lower levels of emissions.

At higher levels of aggregation, when multiple activities or types of goods are considered, it should be understood that most measures of energy intensity are imperfect proxies for energy efficiency. The broadest level of energy intensity for a particular country or sub-national region is typically the ratio of total energy consumption to aggregate economic activity as measured by the gross domestic product (GDP). Clearly, however, the ratio of energy to GDP is affected not 
only by energy efficiency changes at the technology level, but also by a host of structural and extraneous factors. In broadest terms, the structural factors represent shifts in the mix of activities within the GDP that either increase or decrease the energy-GDP ratio independent of intensity changes at a more detailed level. Examples include changes in the share of energyintensive industries such as primary metals or paper manufacturing, greater transportation demand afforded by higher incomes, and increases in the amount of air conditioning use.

\subsection{Background}

This report draws upon work undertaken to support a system of U.S. energy intensity indicators sponsored by U.S. Department of Energy's Office of Energy Efficiency and Renewable Energy (DOE/EERE). The primary purpose of this activity is to inform policymakers and the public of ongoing progress to improve energy efficiency in the U.S. The intensity indicators were originally developed in response to the May 2001 National Energy Policy that directed DOE to support the improvement of energy efficiency as a national priority for the U.S. After an exhaustive review by means of a 2002 conference including a nationally-recognized panel of economists and other experts (RAND Corporation 2002), indexes of historical energy intensities were constructed that provide measures of changes in energy intensity over time. In particular, the indexes are viewed as providing a detailed look at energy efficiency across various sectors of the U.S. economy. The sector-level indexes are aggregated to an economy-wide metric that can be compared to the more simplistic energy--GDP ratio. The EERE system of energy intensity indicators is an ongoing activity to maintain and consistently track changes in the energy intensity of the U.S. economy and specific economic sectors over time, and to disseminate such changes via a public website. 


\subsection{Key Issues and Methodology}

Any comprehensive system of energy intensity indicators for an entire nation requires addressing a number of methodological and empirical issues. These include: 1) definition of energy units, 2) scope of energy end uses, 3) appropriate sectoral disaggregation, 4) choice of activity measures, 5) distinction between absolute intensities and intensity indexes, 6) method to decompose changes in energy intensity from structural factors, and 7) special consideration of increased energy efficiency in the generation of electricity. Each of these topics will be discussed below.

\subsection{Source versus Delivered Energy}

Energy consumption can be measured in terms of delivered or source energy. Delivered energy is the amount of energy, measured in terms of British thermal units (or joules in metric units), that is consumed at the site of one or more energy-using units of equipment. A common alternative terminology is "site energy." In the treatment here, "delivered" implies a slightly broader connotation. For example, the "site" for an electrified railway is somewhat less defined than a particular building. Source energy, alternatively termed "primary" energy, includes the generation and transmission losses associated with electricity consumption. In the EERE system of energy intensity indicators, the distinction between delivered and source energy applies only to electricity.

These alternative measures of energy translate directly into alternative measures of energy intensity. There continues to be different viewpoints as to which measure of intensitydelivered or source - is more appropriate for tracking progress in energy efficiency. In the 2002 review of EERE's proposed intensity indicators system, there were advocates on both sides of this question.

Several international organizations argue for delivered energy as the preferable metric to assess energy efficiency. In a recent U.N. draft plan to develop a monitoring framework to measure global progress on energy efficiency, there was emphasis on using delivered energy for the more detailed end-use sectors or processes. ${ }^{1}$ Compared to the use of source energy, the plan stated, "it is less meaningful to use primary energy measures for measuring energy intensity at the sectoral or subsectoral level." The draft plan endorsed the use of source energy only for highly aggregated intensity measures. The International Energy Agency also emphasizes "final" or delivered energy as the most relevant measure to be used in tracking energy efficiency at the level of individual sectors (IEA 2008).

\footnotetext{
${ }^{1}$ The United Nations (UN) draft plan was sent to DOE for comment in late October 2012. The chapter on Energy Efficiency is to be included in a document entitled "Sustainable Energy for All Baseline Report." Pacific Northwest National Laboratory (PNNL) received the document on November 2, 2012 via e-mail from DOE's Office of Energy Efficiency and Renewable Energy, Office of Strategic Planning.
} 
On the other hand, source energy metrics are preferred by a number of building energy efficiency programs, including Building America, Environmental Protection Agency (EPA) Energy Star, and Architecture 2030 in the U.S. and Passiv Haus in Germany. As the EPA notes on its Energy Star website, "Source energy represents the total amount of raw fuel to operate the building .... thereby enabling a complete assessment of energy efficiency in a building."

Because the choice of intensity metrics based on either delivered or source energy may depend upon the particular type of analysis being performed, the EERE system of metrics has generally produced four separate types of intensity indexes for each activity: 1) fuels, 2) electricity, 3) delivered energy, and 4) source energy.

Several drawbacks of intensities based upon source energy should be mentioned. First, there is an issue of how to account for the energy losses in the generation of electricity by nuclear, hydroelectric, and renewable technologies. In these instances, there is no commonly accepted method of converting energy inputs to energy (electricity) outputs. Second, changes in the efficiency of electricity generation, brought about by either shifts in the mix of electricity generation technologies or improved efficiencies for specific generation technologies alter the relationship between delivered and source energy, independent of behavior of end users.

With regard to the first drawback, the approach in this report is to adopt the imputation methods used by the Energy Information Administration (EIA) to generate certain types of values. In general, EIA imputes energy consumed by non-fossil fuel electricity generators as the average efficiency of fossil fuel plants, under the assumption that any short-term disruptions in renewable (and hydroelectric) generation would be reflected in higher consumption by fossil fuel plants. More details of EIA's imputation procedures are provided in Appendix A. It should be noted that EIA's imputation procedures are not typically adopted by other countries or international organizations, so any comparison of source energy intensities between the U.S. and other countries should be done with caution.

The second drawback is handled by treating any change in the overall efficiency of the electricity generation as an additional structural factor that needs to be specifically accounted for in any time series of source energy intensity. This topic will be addressed below in the discussion of structural factor decomposition.

\subsection{Scope of Energy End Uses and Economic Activity}

Energy in different forms has a variety of functional uses in an economy. The two most important uses are the combined category of heat and power, and transportation. Energy is also used as material inputs to non-energy activities. In EIA's Manufacturing Energy Consumption Survey (MECS), the distinction is made between fuel use to produce heat, power, and electricity, and "nonfuel" use - raw material input to manufacturing processes. The largest nonfuel use of 
energy falls under the general category of petrochemical feedstocks, but asphalt and lubricants also represent large nonfuel uses of (petroleum) energy.

For purposes of developing efficiency indicators, nonfuel uses of energy are excluded. According to the data available from the 2006 MECS, over 6 quadrillion Btu of energy was consumed by manufacturing for nonfuel purposes, primarily in the chemicals and petroleum refining sectors. One should note that EIA does include nonfuel energy use in their supply-side derived tables of energy consumption for the industrial sector (Table 2.1d in the Annual Energy Review), and so this difference needs to be acknowledged.

For transportation, the estimates of total energy use are developed from sources that report fuel consumption for various segments of the transportation sector. As such, the total fuel, as summed across these segments, does not exactly match the transportation fuel consumption reported by EIA in the Annual Energy Review. Apart from statistical reporting issues, one major element of difference is that the system of energy intensity indicators does not include fuel consumption by military aircraft or for vehicles not primarily used on public roads. Further discussion of data comparability issues is provided in Appendix A.

\subsection{Hierarchical System of Indicators}

The energy intensity indicators developed for EERE's overall system begin with indicators for very disaggregate sectors of the economy and then work up in coverage to eventually apply to the U.S. economy as a whole. This hierarchal structure is similar to various aggregate price indexes maintained by the Bureau of Economic Analysis or the Bureau of Labor Statistics.

Figure 2.1 shows the top three levels of this hierarchy. Just below the economy-wide level at the top of the hierarchy are five sectors - the four major end-use sectors defined by EIA (residential, commercial, industrial, and transportation) and the electric power sector. For these end-use sectors, intensity indexes are defined for both delivered and source energy (as well as electricity and fuels for the buildings and industry sectors). The electric power sector is defined as generating plants owned by firms (or government) whose primary business is to sell electricity or heat to the public. The energy intensity of the electric power sector is defined in terms of Btu per kilowatt-hour $(\mathrm{kWh})$ of electricity generated.

At the third level of the hierarchy, the residential sector is disaggregated by census region, the industrial sector is disaggregated into manufacturing and nonmanufacturing, transportation is split between passenger and freight transportation, and separate indexes for electricity-only and combined heat and power plants are developed as part of the overall electric power sector.

Indicators at lower levels of the hierarchy are constructed for the industrial, transportation, and electric power sectors. Manufacturing is broken out into 18 separate sectors, based upon the North American Industrial Classification System (NAICS) at the "3-digit" level. In 
nonmanufacturing, separate intensity measures are developed for agriculture, mining, and construction.

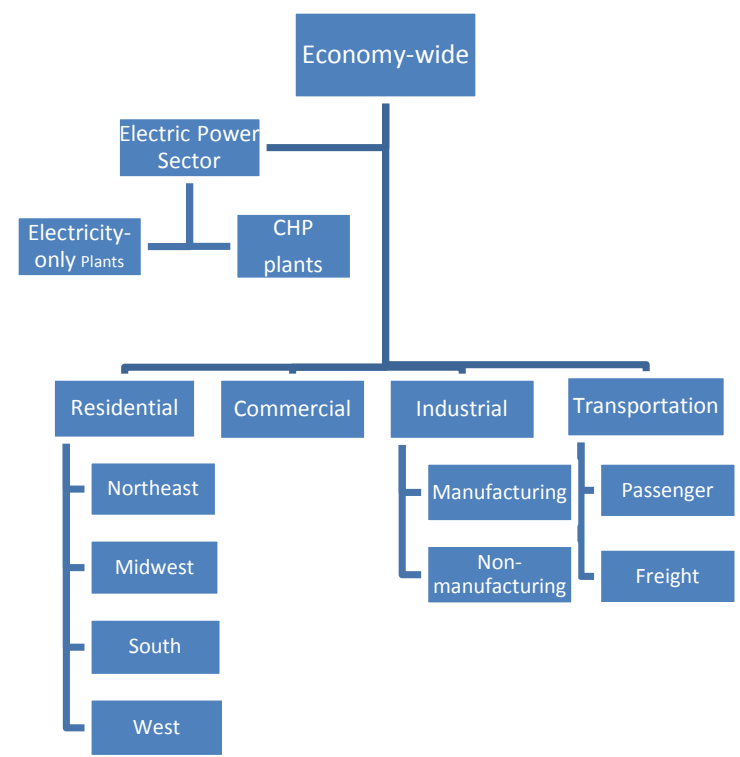

Figure 2.1. Basic structure of EERE energy intensity indicators (top three tiers)

Transportation exhibits the greatest complexity in terms of disaggregate indicators. In general, both passenger and freight segments are disaggregated across major modes: highway, rail, air, and water. Highway transportation is further broken out into passenger cars, light trucks, and buses for passenger travel and into medium and heavy trucks for freight.

In the electric power sector, disaggregated intensity measures, based upon information from EIA, can be constructed for plants using different fuels: coal, natural gas, and petroleum. The part of the sector using these fossil fuels is combined with other data on nuclear, hydroelectric, and renewable electricity generation.

Subsequent sections of this report and Appendix A provide more detail on the disaggregated structure of the overall intensity indicators system.

\subsection{Activity Measures}

As discussed briefly above, measurement of energy efficiency is more accurately done at a technology or process level — ideally with physical measures of activity. However, data limitations prevent any national level system of indicators to be based upon such disaggregation. Thus, a balance must be found between very disaggregated indicators, where data availability 
and quality issues come more into play, and more aggregate indicators, where energy-efficiency changes can be masked in part by structural or other extraneous factors.

Table 2.1 shows the activity measures for each of the five major sectors, the four major end-use sectors plus the electric power sector. The second column of the table gives the preferred activity measure that is used for the most disaggregated indicators in each of these sectors. Column 3 lists some alternative activity measures that can be derived from the system. In general, the activity measures are based upon recommendations from the 2002 conference mentioned above, as well as conventional practice in other countries and international organizations. Further discussion of the choice of particular indicators is provided in the presentation of sector-level indicators in the following section.

Table 2.1. Activity measures by major end-use sector

\begin{tabular}{|c|c|c|}
\hline Sector & Primary Activity Measure & Alternative Measures \\
\hline Residential & $\begin{array}{l}\text { Square feet of occupied housing } \\
\text { units }\end{array}$ & $\begin{array}{l}\text { Number of households } \\
\text { Population }\end{array}$ \\
\hline Commercial & $\begin{array}{l}\text { Square feet of commercial } \\
\text { buildings }\end{array}$ & \\
\hline Industrial & $\begin{array}{l}\text { Real measures of gross output, } \\
\text { (i.e., deflated value of shipments } \\
\text { adjusted for inventory change) }\end{array}$ & $\begin{array}{l}\text { GDP (value added) contributed } \\
\text { from sector - for higher levels of } \\
\text { aggregation, but only to measure } \\
\text { structural change }\end{array}$ \\
\hline Transportation & Passenger-miles, ton-miles & Vehicle-miles in highway modes \\
\hline Electric Power & kWh of electricity generation & \\
\hline
\end{tabular}

\subsection{Aggregate Intensities and Structural Change}

The EERE system of energy intensity indicators includes both absolute intensities and intensity indexes. Absolute intensities are defined in terms of energy per unit of activity or output, as presented in Table 2.1. Absolute intensities can be used for insightful comparison across subsectors of the economy (e.g., comparison of residential energy use per square foot across different census regions), or to make comparisons across countries. 
However, the focus of EERE's system of energy intensity indicators is to measure progress toward greater energy efficiency by means of tracking changes in intensities over time. Following the convention used for measuring changes in the aggregate level of prices, intensity indexes are the most robust method of measuring temporal changes in overall energy efficiency. Typically, such indexes are normalized to a particular year. In this particular study, the objective is to determine to what degree estimated energy savings at the EERE program level are consistent with statistical models that explain long-run changes in these indexes

Indexes that measure changes in energy intensity can be developed in several ways, depending upon the level of aggregation of economic activity and available data. At the most disaggregated level, a time series of absolute energy intensities can be converted to an index simply by dividing intensity in each year by the intensity of given base year. An example of such an intensity might be Btu per passenger-mile in the commercial air transportation sector. Thus, given the selection of the year 1985 as the base year of the index, the value in 1985 would be 1.0 and subsequent years would be higher or lower depending upon the ratio of the intensity in those years to the 1985 intensity. In this simple case, the intensity index and the absolute intensity convey the same information.

However, the situation with regard to the definition of energy intensity changes as one moves to higher levels of aggregation and where the units of activity remain common. In this case, one can still define an absolute intensity in terms of the aggregated (total) energy divided by the aggregated (total) level of activity. An intensity index can be constructed in the same manner by dividing the time series of intensities by the intensity of the selected base year. However, the issue then arises when the composition of sub-aggregates (or subsectors) changes and where the sub-aggregate have markedly different absolute intensities. In this situation, this "compositional" effect will influence the aggregate intensities independent of any changes in the individual intensities of the sub-aggregates. In the parlance of the energy intensity literature, this compositional influence on aggregate indicators is commonly termed a structural factor. Other structural factors include the short-run effects of weather upon measured energy intensities in the residential and commercial buildings sectors.

Some method of accounting for changes in the composition of goods and services has been a long-standing issue in the development of price indexes. Methods for dealing with this problem have included the Laspeyres, Paasch, Fisher, and Divisia index methodologies ${ }^{2}$. The goal of each of these methods is to produce an index of prices that in some way minimizes the influence of structural factors caused by the changing composition of goods and services.

\footnotetext{
${ }^{2}$ Several general discussions of the first three of these types of indicators are available on the web. One is a short discussion by the U.S. Census Bureau: www.census.gov/.../generalinformationaboutpriceindexes.pdf. The second is a very good summary on Wikipedia: http://en.wikipedia.org/wiki/Price index
} 
The case of energy intensity indexes is similar, but not exactly analogous to price indexes. Here, too, the primary goal is to generate an index of energy intensity over time that removes as much of the influence of structural factors as possible. However, because aggregation of like activities is sometimes performed in energy accounting, one can speak of an aggregate energy intensity or index of aggregate energy intensity. For example, an index of aggregate freight energy intensity can be based upon total energy consumption for freight divided by total ton-miles across all modes. In the price index world, there is no counterpart to this this type of aggregation. Typically price indexes at an aggregate level are constructed only by weighting the price indexes of individual goods and services. Given the heterogeneity of goods and services, it simply makes no sense to divide total expenditures by some amorphous number of goods and services.

Given the above discussion, the EERE system of energy intensity indicators is careful to distinguish two types of indexes related to energy intensity. When the index is based upon a normalization of a time series of aggregate energy intensities, the first of these two types is termed an "index of aggregate intensity." This type of index is to be contrasted to an "energy intensity index" that is constructed in a rigorous fashion from similarly-constructed energy intensity indexes at more disaggregated levels. Sometimes this latter intensity index is termed a "component intensity index." Because an energy intensity index is constructed to remove as much of the influence from structural factors as possible, the difference between the "component intensity index" and the "index of aggregate intensity" serves as a measure of those structural factors.

The decomposition of aggregate energy intensity into structural and energy-intensity indexes is performed by the Log Mean Divisia index (LMDI) method, first proposed in by B.W. Ang and K.H. Choi in 1997 (Ang and Choi 1997). ${ }^{3}$ The method can be performed to decompose factors in either an additive or multiplicative fashion. In its multiplicative form, the product of the indexes of the structural factor(s) and the (component) intensity index is identically equal to an aggregate index of intensity. Formally, in the case of two time periods ( 0 and $\mathrm{T})$, we have

$$
(E / Q)^{T} /(E / Q)^{0}=D_{\text {str }} D_{\text {int }}
$$

where

$$
\begin{array}{lll}
E & = & \text { Total energy } \\
Q \quad & =\text { Output or activity measure }
\end{array}
$$

\footnotetext{
${ }^{3}$ A simple explanation of the LDMI approach can also be found in a document prepared by B.W. Ang for the National University of Singapore (accessed on 1/9/2013) http://www.ise.nus.edu.sg/staff/angbw/pdf/A Simple_Guide to LMDI.pdf This explanation relates to the LDMI-I variant of the Divisia index methodology, see text below.
} 


$$
\begin{array}{lll}
D_{\text {str }}= & \text { Structure index } \\
D_{\text {int }}= & \text { Intensity index }
\end{array}
$$

The calculation of the structure and intensity indexes is performing by weighting the log changes in each component (e.g., automobiles and light trucks to construct an overall highway energy intensity index) by a set of weights representing their respective shares of energy use. The weights are computed as the logarithmic mean of the energy shares between successive time periods.

In general terms the logarithmic mean of any two variables is defined as

$$
L(\mathrm{x}, \mathrm{y})=(\mathrm{y}-\mathrm{x}) / \ln (\mathrm{y} / \mathrm{x})
$$

As applied to the energy consumption shares ( $w_{i}$ for component $i$ ) in successive time periods, the logarithmic mean function is defined

$$
L\left(w_{i, 0}, w_{i, T}\right)=\left(w_{i, T}-w_{i, 0}\right) / \ln \left(w_{i, T} / w_{i 0}\right)
$$

The final weights $w_{i}^{*}$ are based upon a normalization that ensures that they exactly sum to one:

$$
w_{i}^{*}=L\left(w_{i, 0}, w_{i, T}\right) / \sum_{i} L\left(w_{i, 0}, w_{i, T}\right)
$$

The structure and intensity indexes are then calculated as

$$
\begin{aligned}
& D_{s t r}=\exp \left[\sum w_{i}^{*} \ln \left(S_{i, T} / S_{i, 0}\right)\right] \\
& D_{\text {int }}=\exp \left[\sum w_{i}^{*} \ln \left(I_{i, T} / I_{i, 0}\right)\right]
\end{aligned}
$$

The most common application of the structure index involves shifts in the composition of total output or activity across components. Thus, in an example using automobiles and light trucks, $S_{i, T}$ would be defined as the share of total activity (passenger-miles) attributed to either automobiles or trucks. The intensities $\left(I_{i}\right)$ are defined straightforwardly as the intensities for each component $i$ of the overall index (i.e. $E_{i} / Q_{i}$ ).

The discussion above is intended to provide only a general overview of the LDMI method. More details of the derivation can be obtained in the original Ang and Choi article and in a methodology write-up posted on the EERE energy indicators website. ${ }^{4}$

Moreover, the above discussion includes only a single structural factor. The method is perfectly extensible to including multiple structural factors. For example, in the residential sector in the EERE system of indicators, structural indexes are computed for compositional shifts in the types

\footnotetext{
${ }^{4}$ The address for the part of the EERE energy-intensity indicators website that contains information on index construction is: http://www1.eere.energy.gov/analysis/eii_methodology.html
} 
of housing units, geographic shifts across census regions, and for year-to-year fluctuations caused by weather. The mathematical construction of the LDMI-based indexes ensures that the product of all the structural indexes and the intensity index is identically equal to the index of aggregate intensity [as shown in the simple case in Equation (2.1)].

\subsubsection{Alternative Versions of the LDMI Method}

In a subsequent journal article, Ang and Liu (2001) point out that the logarithmic mean Divisia method provides perfect decomposition of total energy use but is not consistent in aggregation. They then propose a modification of the Divisia method that satisfies this consistency. In essence, the modification requires the use of the logarithmic mean of the absolute energy use, rather than the shares of energy use in the individual components of the index. This later method has come to be termed the LDMI-I method, whereas the original method is termed the LDMI-II method.

Consistency in aggregation means that the indexes at the highest levels of an index hierarchy are the same regardless of the pattern of aggregation below those levels. Thus, whether total passenger transportation index is built up from the use of an aggregate highway transportation index, or the use of automobiles and light trucks independently, the final result is the same. Unfortunately, this desirable property has an unappealing side effect that is seldom noted. When the LDMI-I method is used, the indexes of aggregate activity are no longer the simple sum of unit measures at the more detailed levels. For example, the index of aggregate transportation activity in this method can no longer be calculated from the sum of passenger-miles across the various components. Because of this deficiency, and to a lesser extent the more complex accounting structure required for the LDMI-I method, the EERE system of intensity indicators utilizes the original Ang and Choi formulation known as LDMI-II.

Some limited testing has compared some of the more aggregate indexes between the two methods and the differences were found to be very small. In one recent test, the index of passenger transportation was calculated by using the separate series for highway modes (automobiles, light trucks, motorcycles, and buses) versus a construction using sub-aggregates for personal vehicles and highway transportation. The results showed only a $0.16 \%$ difference in the 2010 index between the two methods.

\subsection{Electric Utility Energy Efficiency and Source Energy Intensities}

A special case of structural change occurs when dealing with energy intensities defined in terms of source energy intensity as published. As alluded to in Section 2.1, the issue is that improvements in the efficiency of electricity generation are reflected in the intensity indicators for the end-use sectors. Thus, the use of the published source energy to compute these energy 
intensity indicators inappropriately blends efficiency improvements between the end-use sector and the electricity generation sector.

One approach to overcome this problem is to hold constant the efficiency of the electricity generation at some particular base year. That is, the ratio of source to delivered (or site) electricity is maintained at a constant value. While this approach is straightforward, it suffers from the fact that percentage changes in the indexes are dependent to a small degree on the particular year selected for the base period.

However, a more elegant solution is to employ the LMDI method, by constructing an alternative source energy intensity index from separate indexes for electricity and fuels. It is assumed that separate LMDI decompositions have been performed for fuels and electricity separately, such that the following equations hold in index form

$$
\begin{aligned}
& F=Q * D F_{s t r} * D F_{i n t} \\
& E^{d}=Q * D E_{s t r} * D E_{i n t}
\end{aligned}
$$

where

$$
\begin{array}{lll}
F L & = & \text { index of aggregate fuel use } \\
E L^{d} & = & \text { index of aggregate delivered electricity use } \\
Q & \text { index of output or activity } \\
D F_{\text {str, }} D E_{\text {str }} & = & \text { structural indexes for fuels and delivered electricity, respectively } \\
D F_{\text {int }}, D E_{\text {int }} & = & \text { intensity indexes for fuels and delivered electricity, respectively. }
\end{array}
$$

Equation (2.8) can be converted to source energy by multiplying by the time series of the ratios of source to site (or delivered) electricity, and then renormalizing to make the make the index equal to 1 in the desired base year. Denoting the source-to-site ratio for electricity generation as (SSR), we then have

$$
E^{S}=Q * D E L_{s t r} * D E L_{i n t} * S S R
$$

Taken together, Equations (2.7) and (2.9) represent indexes that can be combined to yield an overall source energy decomposition. The appropriate weights for the LDMI method are based upon the shares of fuels and source electricity in total source energy. To simplify the notation from Equation (2.4), let the respective weights be $w_{f}$ and $w_{e}$. Thus, source intensity index, $D_{\text {int }}^{S}$, can be defined as the (log mean) weighted average of the fuels and delivered intensity indexes, 
using the weights as computed from shares of source energy. In this case, we have in the two period case $(\mathrm{t}=0$, and $\mathrm{t}=\mathrm{T})$

$$
D_{\text {int }}^{S}=w_{f} * \ln \left(\left(D F L_{i n t}(T) / D F L_{i n t}(0)\right)+w_{e} * \ln \left(\left(D E L_{i n t}(T) / D E L_{i n t}(0)\right)\right.\right.
$$

The structural factor associated with changes in the source-to-site ratio in electricity, which is denoted as $D_{\text {ssr }}$ is calculated using the same weights:

$$
D_{s s r}=w_{f} * \ln (1 / 1)+w_{e} * \ln ((\operatorname{SSR}(T) / S S R(0))
$$

The first term in Equation (2.11) shows that the effective "source-to-site ratio" for fuels is a constant 1 , normally implied in any calculation of overall source energy. (In some types of analyses, a source-to-site ratio greater than 1 is employed for natural gas, representing transportation and distribution energy. In EIA's computation of source energy by end-use sector, this factor is ignored.) This factor drops out of the equation because $\ln (1 / 1)$ is 0 . The second term develops the index of the electricity generation efficiency, but weights those changes depending upon the share of source electricity in the total source energy used by the particular sector.

The source intensity index developed in this procedure will differ from that of a delivered intensity index in that changes in the use of electricity are magnified in the calculation of source energy (because empirically SSR ranges between 3.1 and 3.4 over the historical period, 1970 2011, in the U.S.) Compared to the use of source energy intensity measured with a constant SSR, the index calculated with the Divisia method is not dependent on the choice of a base year. The procedure provides an exact decomposition between changes in the source energy intensity brought about by behavior of the end users in a particular sector in contrast to improvements in electricity generation in the electric power sector. In the presentation of historical intensity changes in the next section of the report, the source energy intensity adjusted in this manner will be termed source energy intensity, adjusted for electric generation improvement, or more compactly, as adjusted source intensity.

The calculation of an overall structural index for source energy based on the other structural factors $\left(D F_{s t r}, D E_{s t r}\right)$ is computed analogously to the end-use energy intensity and the structural factor representing electricity sector efficiency change.

As a practical matter the overall decomposition shown in this section is reserved for the top-level indexes in each end-use sector. At the economy-wide level, the source energy intensity index is a (LMDI) weighted average of the of the source intensity indexes across the four major end-use sectors. The weights are based upon the end-use sector shares of source energy. Using the same weights, another separate index is calculated for electricity generation efficiency change. Thus, in terms of overall energy intensity improvement in the entire economy, these separate indexes can distinguish between the contribution made by end users of energy and the contribution made by the electric power sector in improving the efficiency of electricity generation. 


\subsubsection{One More Structural Factor - "Electrification"}

One can also use the same basic framework above to show the influence of changing shares of energy use by type on total source energy. An increasing share of electricity consumption with respect to delivered energy use is commonly termed "electrification." The increasing share of electricity comes about by switching to electricity from fuels for the same end uses (e.g., heat pumps replacing gas or oil furnaces for space heating), as well as introduction of new end uses that often favor electricity over fuel consumption.

Using the LDMI decomposition, consider first the derivation of energy intensity and structural indexes for delivered energy, $D_{\text {int }}$ and $D_{\text {str }}$, as depicted in Equation (2.1). Let $(E / Q)^{0}$ from Equation (2.1) be represented by the constant $\mathrm{k}$, which also includes consideration of the units of measurement, energy divided by the units associated with the activity (e.g., Btu/square foot in the base period). Then total delivered energy (electricity plus fuels) can be represented as

$$
\mathrm{E}^{d}=k \mathrm{Q} D_{\text {str }} D_{\text {int }}
$$

Let the shares of electricity and fuels with respect to delivered energy use be represented by ELshr and FLshr. Then delivered electricity and delivered fuel energy can be represented as

$$
\begin{aligned}
& \mathrm{FL}=\left(\begin{array}{ll}
k \mathrm{Q} D_{\text {str }} D_{\text {int }}
\end{array}\right) * E L s h r, \text { and } \\
& \mathrm{EL}=\left(\begin{array}{ll}
k \mathrm{Q} D_{\text {str }} D_{\text {int }}
\end{array}\right) * F L s h r
\end{aligned}
$$

To further break out the effect of utility sector energy-efficiency improvement, the top equation can be multiplied by the source-to-site ratio, defined earlier as SSR. One now obtains a formulation for total source energy, $E^{\mathrm{s}}$, defined as follows

$$
\mathrm{E}^{\mathrm{s}}=\left(\mathrm{k} \mathrm{Q} D_{\text {str }} D_{\text {int }}\right) * F L s h r * 1+\left(\mathrm{k} \mathrm{Q} D_{\text {str }} D_{\text {int }}\right) * E L s h r * S S R
$$

The first and second sums of the products in Equation (2.15) are nothing more than total fuels and total electricity converted to source energy. These shares are used to define the LMDI weights, using Equations (2.3) and (2.4). Given that they are defined in terms of source energy, these weights are the same as those employed in Equations (2.10) and (2.11). Only here we have been more explicit about the derivation of the weights based on energy quantities.

The two terms in the parentheses in Equation (2.15), which are identical in the LDMI process, will simply return the same indexes for $D_{\text {str }}$ and $D_{\text {int }}$ and convert the time series of Q to an index with the same base period. Of most interest is the LDMI weighting of the delivered energy shares, ELshr and FLshr using the same formulation as Equation (2.1). The weighting function for what can be termed the "electrification" effect, $D_{e f n}$, is

$$
D_{\text {efn }}=w_{f} * \ln \left((F L s h r(T) / F L s h r(0))+w_{e} * \ln ((E L s h r(T) / E L s h r(0))\right.
$$


The final (structural) factor is the electric generation efficiency index, computed in exactly the same manner as in Equation (2.11).

The decomposition rendered in this manner yields four separate multiplicative indexes whose product is the same as in the aggregate index of structural intensity $\left[\left(E^{\mathrm{s}} / \mathrm{Q}\right)\right.$ converted to an index]. At this point, it necessary to use superscripts $d$ and $s$ to distinguish between indexes that are derived from either delivered or source energy, respectively. With that complication, the decomposition can be written symbolically as:

$$
E^{s} / \mathrm{Q}=D_{i n t}^{d} D_{s t r}^{d} D_{\text {efn }} D_{s s r}
$$

Again, to be clear, Equation (2.17) says that one can separate an index derived from a straightforward ratio of total (published) source energy divided by total activity in a given sector into four component indexes that represent:

1) A delivered energy intensity

2) One (or more) structural factors, relative to delivered energy

3) An "electrification" factor that measures the impact on source energy intensity from changes in the ratio of delivered electricity to total delivered energy, and

4) An index representing the effect of changes in electricity generation efficiency.

In the sector-specific results for the building sectors, the influence of the electrification index is particularly pronounced. In the commercial sector, for instance, the electrification effect has been sufficiently large to offset a decline in delivered energy use intensity.

\subsubsection{Relationship between factors expressed in delivered versus source electricity}

In general, the more prevalent approach in this report is to view source, rather than delivered, energy intensity as being more relevant for policy and analytical purposes. However, it recognized that in some instances delivered energy intensity can be the more useful metric. While the use of the LMDI is useful for decomposing changes of aggregate energy or intensity into structural and intensity indexes, the measurement of structural factors is not the primary objective of the indicators system. As was mentioned above, structural factors are in a sense only a residual metric, in that they help to illuminate how a more aggregate index of intensity may be different from a more accurate intensity index that is built from the bottom up.

As we have seen, intensity indexes can be constructed in terms of delivered or source energy. Because the weights used to construct these indexes differ, the corresponding structural indexes also are not independent of the energy definition used.

In the two previous sections, two types of decompositions have been described, both dealing with a decomposition of source energy or source energy intensity. The first develops a method 
for measuring the impact of electricity generation efficiency. The second seeks a method to reflect how changes in the relative consumption between electricity and fuels affect source energy intensity - a structural effect termed electrification. The second decomposition also provides a linkage between an aggregate intensity measured in source energy and more specific delivered energy intensity.

Given this background, it may be useful to show several equivalences between the most prevalent types of LMDI decompositions. As can be shown, the index of aggregate source intensity can be expressed in two ways:

$$
\begin{aligned}
& E^{s} / \mathrm{Q}=D_{\text {int }}^{s} D_{s t r}^{s} D_{\text {ssr }}, \text { or } \\
& E^{s} / \mathrm{Q}=D_{\text {int }}^{d} D_{\text {str }}^{d} D_{\text {efn }} D_{\text {ssr }}
\end{aligned}
$$

In both cases, $E^{s} / \mathrm{Q}$ is expressed as index with the same base year as the indexes on the right of the equation. $D_{\text {int }}^{S}$ and $D_{\text {int }}^{d}$ are energy-intensity indexes for source energy and delivered energy intensity, respectively. The index relating to effect of electricity generation efficiency is common to both decompositions. 


\subsection{Energy Intensity Indicators for Major End-Use Sectors}

This section presents key intensity indictors for the four major end-use sectors: residential, commercial, industrial, and transportation. In addition, a summary of major energy intensity trends is provided for the U.S. electric power sector. For each sector, an overview of energy consumption and activity is presented first, followed by graphics that highlight major energy intensity trends. Some discussion of major data sources and methods is included, but detailed treatment of those topics is reserved for Appendix A.

The maintenance of these detailed energy intensity indicators is an ongoing process because the latest data is released from the various organizations on a periodic basis, but with varying lags. An initial draft of this report was released in early 2013, but did not include results from the latest Manufacturing Energy Consumption Survey (MECS) for 2010 (where final data were not released until March 2013). Because the MECS is such an important component in the overall system of indicators, it was deemed highly desirable to incorporate these results. However, by the end of 2013, all data was final for 2011 and could be employed to support updating nearly all the intensity indicators through that year.

The situation as of early 2014 is that final data are available to update some sectors through 2012, but generally data for 2012 is either only preliminary or not yet published. Typically, the data currently used to support updating the complete set of energy intensity indicators is available approximately 18 months after the completion of a calendar year. Given this situation, a somewhat eclectic approach is used to describe the quantitative results for the indicators in this section of the report. In general, the discussion of empirical results will reference the historical trends in the energy intensity indicators and other metrics through 2011. However, in few cases where the data allow, some of the key graphics for the high-level intensity indicators are extended through 2012. The 2012 values for most of these energy intensity indicators are likely to be revised slightly during 2014 , but in most cases do provide a reasonable basis for assessing the most recent changes in the energy intensity indicators.

\subsection{Residential Sector}

Relative to total U.S. energy consumption, the fraction accounted for by the residential sector has grown only modestly over the past four decades, increasing from $20.3 \%$ in 1970 to over $22.0 \%$ in 
2011. ${ }^{1}$ Table 3.1 shows some of key energy and activity metrics associated with the residential sector. The breakdown between electricity and fuels shows a significant increase in electricity use in comparison to fuels. With regard to delivered energy (as the simple sum of electricity and fuels), the share attributable to electricity increased from just over $16 \%$ in 1970 to nearly $43 \%$ in 2011. A number of factors can be cited as responsible for this shift: 1) increased use of electronics and entertainment equipment, 2) greater use of cooling in homes generally, further accelerated by relatively more construction in the southern U.S., 3) lower use of fuels for heating because households have upgraded heating equipment (e.g., condensing gas furnaces) and have reduced heating demand with improved building envelopes, and 4) substitution of electric heat pumps for oil and gas for heating.

Table 3.1. Estimated energy consumption and activity in the residential sector Energy Use, Trillion Btu (TBtu)

\begin{tabular}{|c|c|c|c|c|c|c|}
\hline & \multicolumn{2}{|c|}{1970} & \multicolumn{2}{|c|}{1985} & \multicolumn{2}{|c|}{2011} \\
\hline & (TBtu) & $\begin{array}{c}\% \text { of } \\
\text { delivered }\end{array}$ & (TBtu) & $\begin{array}{c}\% \text { of } \\
\text { delivered }\end{array}$ & (TBtu) & $\begin{array}{c}\% \text { of } \\
\text { delivered }\end{array}$ \\
\hline Delivered & 9,913 & & 9,857 & & 11,354 & \\
\hline Electricity & 1,591 & $16.0 \%$ & 2,709 & $27.5 \%$ & 4,855 & $42.8 \%$ \\
\hline Fuels & 8,322 & $84.0 \%$ & 7,148 & $72.5 \%$ & 6,500 & $57.2 \%$ \\
\hline Source & 13,766 & & 16,041 & & 21,411 & \\
\hline Adjusted Source & 13,545 & & 16,041 & & 22,437 & \\
\hline
\end{tabular}

Activity, Square Feet

\begin{tabular}{lrrr} 
& (Billion) & (Billion) & (Billion) \\
\cline { 2 - 4 } Square Feet (billion) & 92.3 & 129.8 & 211.3 \\
Housing Units (million) & 63.4 & 87.4 & 113.5 \\
Population (million) & 204.0 & 237.9 & 311.6
\end{tabular}

Source: For energy: EIA State Energy Data System and July 2014 Monthly Energy Review, See Appendix A, Section A.1.1 for details and specific references. For activity, see Appendix A for methodology discussion (Sections A.1.2 through A.1.5).

The last two energy consumption values in the table relate to source energy, thus including the electricity generation and transmission losses associated with electricity sales to residential

\footnotetext{
${ }^{1}$ The percentages are based upon the published values of total (source) energy consumption from EIA, as shown in the Annual Energy Review 2011 and the July 2014 issue of the Monthly Energy Review (with revised estimates for the most recent years). The percentages differ from those that would be calculated from the energy considered as part of the system of energy intensity indicators system described in this report. Among the major differences is the exclusion of energy used for petrochemical feedstocks in the industrial sector and the development of an independent total based on non-EIA sources for the transportation sector. After these adjustments, total (source) energy considered in the system of intensity indicators represented about $92 \%$ of total 2011 U.S. energy use published by EIA ( 89.4 quadrillion Btu versus 97.4 quadrillion Btu).

A table of percentages of end-use sector energy consumption based on these revised estimates and used as weights in the calculation of an economy-wide intensity index is shown in Appendix C.
} 
customers. The second (lower) of these two values holds constant the ratio of electricity losses to sales, as derived from EIA's Annual Energy Review 2011, at its 1985 magnitude (2.283). The source energy is recomputed for each year using this ratio. This "adjusted" source energy actually shows that source energy would have grown approximately $6.5 \%$ between 1970 and 2011, had the overall efficiency in the electric power sector remained constant.

The lower portion of Table 3.1 shows the three measures of activity that might reasonably be used to measure "activity" in the residential sector. Floor space has been selected as the primary measure for the development of intensity indicators in this sector. The use of floor space aligns with the same measure in the commercial building sector and reflects the significant increase in average housing size observed since the mid-1980s. However, readily available alternative measures are the number of (occupied) housing units and resident U.S. population.

\subsubsection{Floor area}

Unfortunately, there are no publicly available annual time series estimates of residential building floor area in the U.S. As a result, a set of annual values must be estimated from available information on the historical stock of housing units by type and the average size of those units.

The following section describes this process briefly, with a more detailed discussion in Appendix A.

While no annual publicly available series on residential floor space exists, the residential building surveys (known as the RECS) conducted by the EIA provide major elements for developing a set of annual estimates (Energy Information Administration, various "C"). The RECS cannot be used by themselves for three reasons: 1) the surveys have only been conducted every three to four years, 2) there is a significant degree of sampling variation associated with these estimates, and 3) the methodology used to measure floor area in the RECS sample housing units has varied over the survey years.

The methodology to support the floor space estimate for the system of energy intensity indicators draws upon some aspects of the RECS and the biennial housing survey conducted by the U.S. Census Bureau. The Census Bureau's American Housing Survey (AHS) (U.S. Census Bureau et al. various "B") consists of a detailed survey of some 60,000 households in the U.S. and has been conducted every other year since 1985. Since the late 1990s, the surveys have requested respondents to include the floor area of their housing unit. This number of observations in the survey helps to reduce the sampling errors associated with mean values in successive surveys.

Prior to 1985, data from the Annual Housing Survey (U.S. Census Bureau et al. various "A") were employed to estimate the number of units by housing type and by census region. The Annual Housing Survey was the predecessor survey (using a different and smaller sample frame) and was conducted annually for years 1973 through 1981, followed by one additional survey in 1983. Based upon a written analysis by the Census Bureau included with the 1985 American 
Housing Survey regarding continuity with the 1983 survey, linkages between the 1983 and 1985 time series were developed. Accordingly, a caveat is that the data for the 1970-1985 period are likely have greater uncertainty bounds than those values derived from more recent surveys. Some additional discussion of this issue is provided in Appendix A.

Figure 3.1 shows the estimated amount of floor area in the residential building stock from 1970 to 2011 by type of housing unit. Total floor area increased from about 87 billion square feet in 1970 to 211 billion square feet in 2011 (roughly twice that of all commercial buildings, as presented below). The percentage of total floor area in single-family homes, based upon these estimates, has grown only slightly from approximately $82 \%$ in 1970 to $83.5 \%$ in 2011 . The decline in the share from multi-family units has been roughly offset by the increase in the total floor area of manufactured homes.

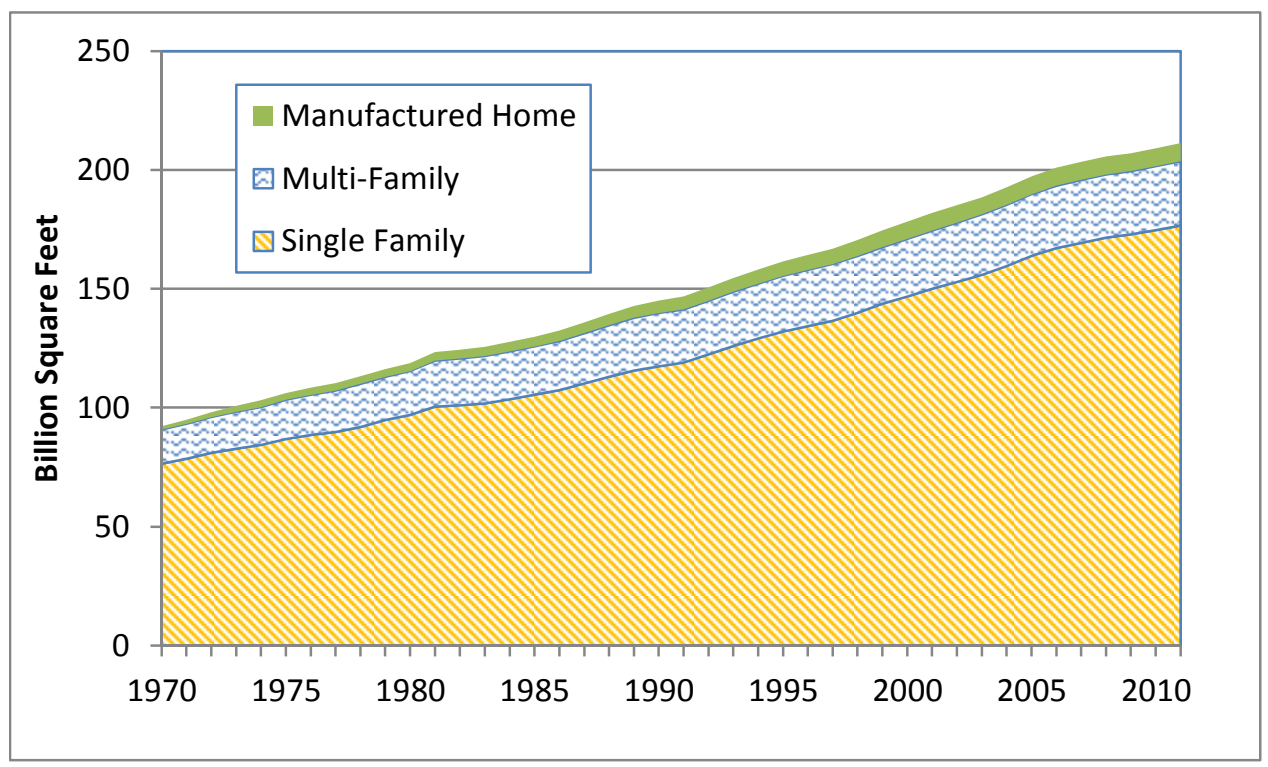

Figure 3.1. Estimates of total residential floor area by housing type, 1970-2011

An interesting set of trends is evident in the underlying data on the number of units by type and associated floor area. Between 1970 and 1985, the average annual rate of growth of the number of housing units was nearly double that of the population, presumably stemming from high household formation by the "baby boom" generation. From 1985 through 2011, the percentage growth rates between households and population are roughly comparable, reflecting little change in average household size. In this later period, the increase in total floor area appears to have been fueled by increased average housing unit size more so than in the previous 15 -year period.

As mentioned earlier in reference to Table 3.1, other reasonable measures of activity in the residential sector are the number of housing units and population. An intensity measured in 
terms of per housing unit has more relevance to end uses such as cooking, refrigeration, lighting, and electronics. A population-based intensity would also be relevant for these uses, as well as for water heating. Floor area is perhaps most relevant to space conditioning and to a lesser extent lighting.

There has not yet been an attempt to try to incorporate EIA's regression-based end-use consumption estimates published as part of the RECS into the intensity indicators system. It is not clear how well that connection could be made; there are serious issues with sampling variability that impact the estimated end-use consumption values from one RECS to the next. Because space conditioning remains the end use (i.e., heating + cooling) with the largest share of energy consumption in the residential sector, floor area, imperfect as it is, is deemed to yield the most robust indictor of energy efficiency change. However, it can still be instructive to look at the national intensity trends across all three measures of activity. These trends are shown in Figure 3.2.

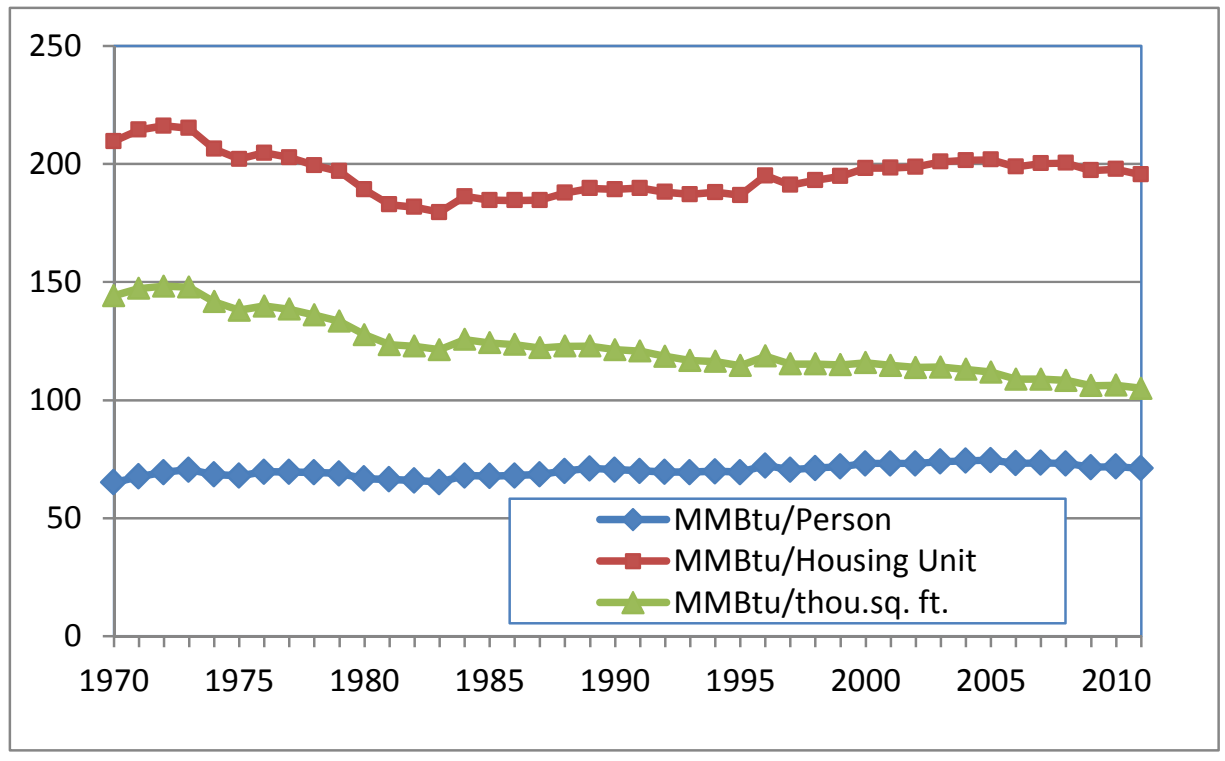

Figure 3.2. Comparison of residential energy intensities (adjusted source energy) based upon different activity measures, 1970-2011

All of the intensities in Figure 3.2 use adjusted source energy so that they reflect the total energy used in the production of electricity consumed in residential buildings. The energy data have also been adjusted for year-to-year weather variation. The population-based intensity at the bottom of the figure shows only modest growth over the entire period, but growth nonetheless. The population-based metric reflects energy intensity improvements in space conditioning and certain major appliances (e.g., refrigerators), but clearly the increases in the (per capita) number of energy-using devices (as well as the increase in floor area per capita) have offset those intensity reductions. 
The housing unit-based intensity shows a dramatic decline from 1970 to 1983, reflecting price induced intensity reductions in space conditioning and likely a number of other end uses. From the mid-1980 on, this intensity has grown somewhat steadily until the mid-part of the last decade (note, prior to the recession years of beginning in 2009). The energy intensity based upon floor area shows decline across the entire time period, although a greater decline in the same 19701983 period as for the intensity based on housing units. ${ }^{2}$

Figure 3.3 shows key indexes related to energy use, activity, and (adjusted) source energy intensity for the residential sector. Since 1985, there has been a significant increase in average housing unit size, estimated to have increased by one-third. The number of housing units has increased by a little over $25 \%$.

Changes in structure include geographic shifts among census regions, shifts in the mix of housing types, and weather. Weather accounts for the most year-to-year variation in the index, fluctuating between plus or minus 3\% relative to the 1985 base year. The long-term change in the mix of housing types has a negligible effect on overall energy use. The geographic shift to more households in the south and west results in about a 1\% decline in energy use. The effect of geographic shifts is muted as result of using source energy (as a result of greater importance assigned to electricity combined with the increase in air conditioning use from higher population growth in the south). The structural indexes (not shown) for geographic shifts associated with fuels shows a reduction of about $4 \%$ and an increase of about $2 \%$ for delivered electricity

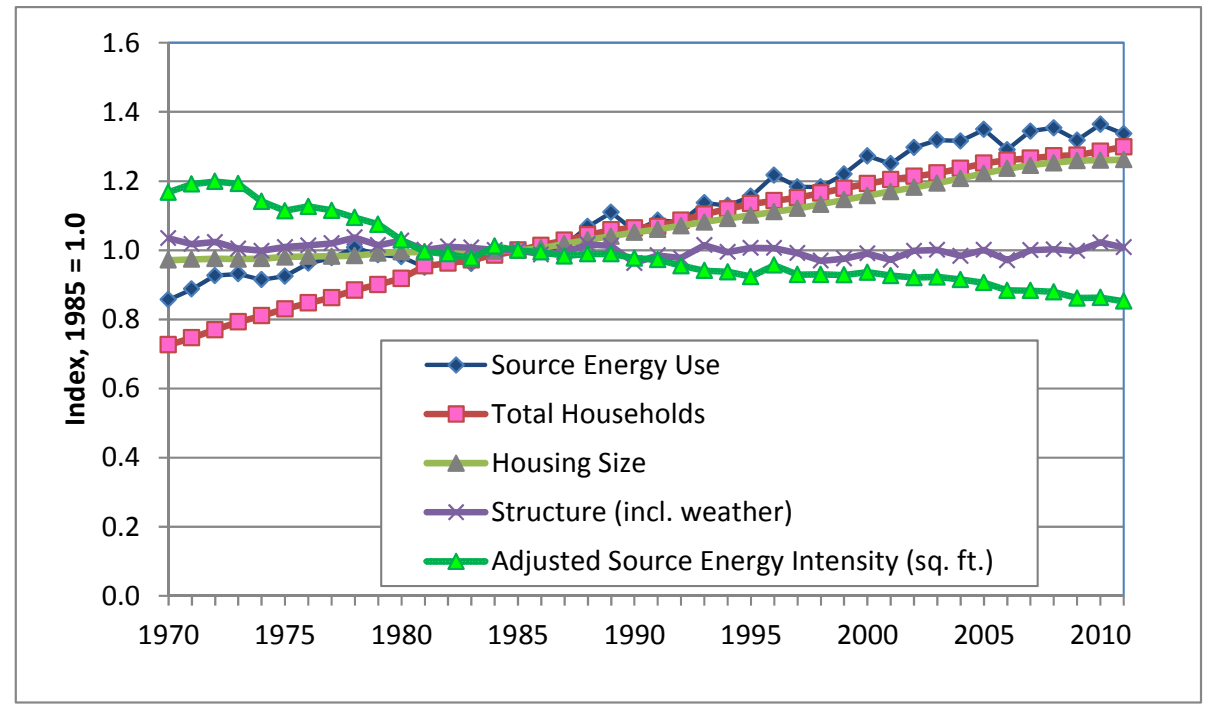

Figure 3.3. Energy intensity and related indexes for the residential sector, 1970-2011

\footnotetext{
${ }^{2}$ The abnormally high values for 1984 and 1996 are most likely caused by the imprecision of the weather adjustment method. As explained in Appendix A (Section A.6), the weather adjustment uses only annual data for degree-days and energy consumption in the statistical models. The energy consumption is generally reported on a billing cycle basis, so that reported consumption for January of a year can reflect the weather conditions in latter part of December. A more rigorous adjustment would require development of degree-day information on a finer time basis by census region.
} 
between 1985 and 2011, reflecting lower heating and higher cooling requirements for residential buildings in the south and west.

The (adjusted) source energy intensity index shown in the figure is computed on the basis of floor area as the activity variable. The 2011 value of the index is 0.852 . Between the two subperiods, 1970-1985 and 1985-2011, the annual average percentage reductions were slightly smaller in the most recent sub-period. Between 1970 and 1985 the intensity declined at an average annual rate of about $1.0 \%$, followed by a decline of $0.6 \%$ per year over the last 26 years.

Figure 3.4 presents three indexes from a decomposition of the energy intensity based on published source energy (as described in the methodology section of Appendix A): delivered energy intensity, the structural effect related to electrification, and the index related to increased electricity generation efficiency. All these indexes are defined relative to total residential square footage. Delivered intensity fell by over $25 \%$ between 1985 and 2011 . However, the impact of electrification offset much of this decline; this factor contributed to about a $20 \%$ increase in the source energy intensity index.

Finally, in terms of the published data for residential source energy consumption from EIA, the effect of improved electricity generation efficiency saved more than 4\% in 2011 relative to 1985.

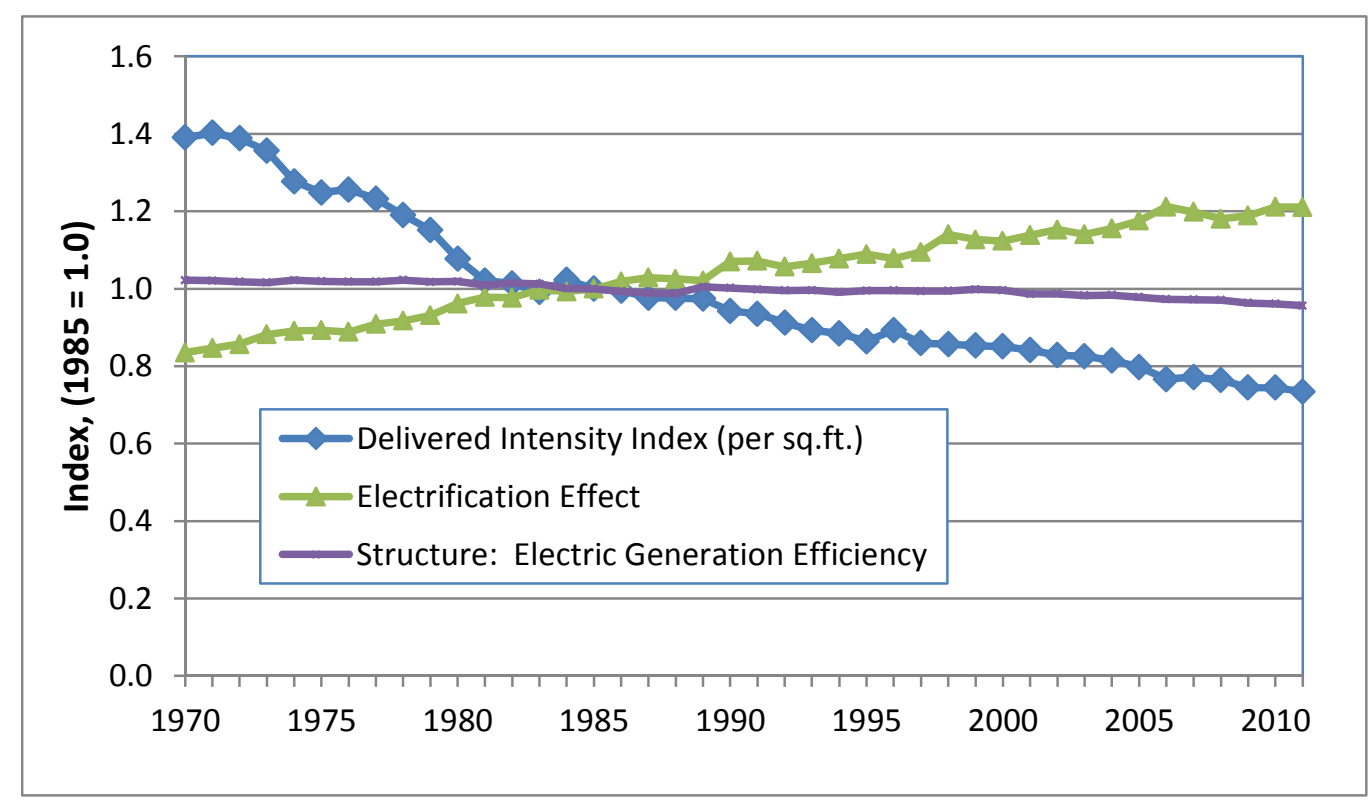

Figure 3.4. Decomposition of residential energy intensity based upon published values of source energy 


\subsection{Commercial Sector}

Of the major end-use sectors in the U.S. economy, the commercial sector showed the greatest growth in overall energy consumption between 1970 and 2011. In terms of source energy, energy consumption in the commercial sector more than doubled between 1970 and 2011. From just over $12 \%$ of the nation's consumption in 1970, the commercial sector accounted for nearly $19 \%$ in 2011. In 2011, commercial energy consumption was estimated to be about 18 quadrillion Btu. $^{3}$

Table 3.2 shows energy consumption in this sector by fuel and under different definitions of energy. Several aspects of the table should be pointed out. The breakdown between electricity and fuels shows the dramatic increase in electricity use in this sector since 1970. As a share of delivered energy (as the simple sum of electricity and fuels), the share attributable to electricity increased from just over $20 \%$ in 1970 to over $50 \%$ in 2011. A number of factors can be cited as responsible for this shift: 1) increased use of computers and office equipment, 2) greater use of cooling in buildings generally, further accelerated by more construction in the southern U.S., 3) lower use of fuels for heating as buildings have upgraded heating equipment (boilers and furnaces) and have reduced heating demand with improved building envelopes, and 4) some small substitution of electric heat pumps for fuel combustion for heating.

Table 3.2. Estimated energy and activity (floor space) in the commercial sector Energy Use, Trillion Btu (TBtu)

\begin{tabular}{lccrrrr} 
& \multicolumn{2}{c}{1970} & \multicolumn{2}{c}{1985} & \multicolumn{2}{c}{2011} \\
& $(\mathrm{TBtu})$ & $\%$ of delivered & $(\mathrm{TBtu})$ & $\%$ of delivered & $(\mathrm{TBtu})$ & $\%$ of delivered \\
\cline { 2 - 6 } Delivered & 5,438 & & 6,093 & & 8,448 & \\
Electricity & 1,201 & $22.1 \%$ & 2,360 & $38.7 \%$ & 4,393 & $52.0 \%$ \\
Fuels & 4,237 & $77.9 \%$ & 3,732 & $61.3 \%$ & 4,055 & $48.0 \%$ \\
Source & 8,346 & & 11,481 & & 17,550 & \\
Adjusted Source & 8,180 & & 11,481 & & 18,478 &
\end{tabular}

Activity, Square Feet

\begin{tabular}{lrrc} 
& (Billion) & (Billion) & (Billion) \\
\cline { 2 - 4 } Floor Space & 43.2 & 58.2 & 84.8
\end{tabular}

Source: For energy data: EIA 2012a, but with adjustment for reclassification of electricity use by utilities between industrial and commercial sectors, see Appendix A, Section A.2.1. For floor space: see Appendix A, Section A.2.2.

\footnotetext{
${ }^{3}$ The EIA published value of commercial source energy use for 2011 is 17,973 TBtu (July 2014 Monthly Energy Review). This value differs slightly from that shown in Table 3.2 as a result of using the most recent data from the State Energy Data System and making an adjustment for reclassifications of electricity use between commercial and industrial customers. See footnote to Table 3.2 and Section A.2.1 for further discussion.
} 
The last two energy consumption values relate to source energy, and thus include the electricity generation and transmission losses associated with electricity sales to commercial customers. As described above with respect to the residential sector, the second ("adjusted source") holds constant the (1985) ratio of electricity losses to sales. Using this procedure, the adjusted source energy actually shows that source energy would have grown almost another $7.5 \%$ between 1970 and 2011, had the overall efficiency in the electric power sector remained constant.

The last line of Table 3.2 shows the estimated amount of floor space in the commercial buildings for the selected years of 1970, 1985, and 2011. The large increase in total floor space is the key driver in the overall consumption in this sector, but that increase is still slightly less than the increase in overall energy use (in terms of source energy).

\subsubsection{Floor Space Estimates and Other Data Issues}

Unfortunately, similar to the residential sector, there are no publicly available time series estimates of commercial building floor space in the U.S. As a result, a set of annual values must be estimated from available information on historical construction activity in the U.S. Appendix A describes the methodology in some detail by which these estimates were constructed. The appendix also shows the distinction between the stock of commercial buildings and the commercial sector, as classified by the available data from electric and gas utilities.

\subsubsection{Commercial Sector Energy Intensity Trends}

Figure 3.5 clearly shows the dramatic differences in energy intensity trends between electricity and fuels. (As also discussed in Appendix A, the intensities shown here are weather-normalized via a regression model estimated at the census region level). The greatest difference occurs prior to 1985 , in which fuels intensity fell by over one-third, while electricity consumption was increased by about $50 \%$. These trends should not be considered as totally independent. During this period, some fuel switching occurred that favored greater use of electric heat pumps and away from combustion of fuels for heating use. Moreover, increased use of electrical equipment, and attendant heat gains in commercial buildings, can offset the need for fuel-generated heat.

Since 1985, two developments stand out. First, for nearly a decade after 1985, the effect of more stable fuel prices is likely to have reduced the rate of intensity reduction observed in the previous decade. However, the intensity reduction accelerated in the wake of energy price increases, particularly natural gas, after 2000. Second, and perhaps more significant, is the sharp change in the trend of increases in electricity consumption since 2000. After 2000, the graphic indicates that electricity intensity has actually declined slightly by 2011 , in sharp contrast to the average annual increase of nearly $2 \%$ between 1980 and 2000 . 


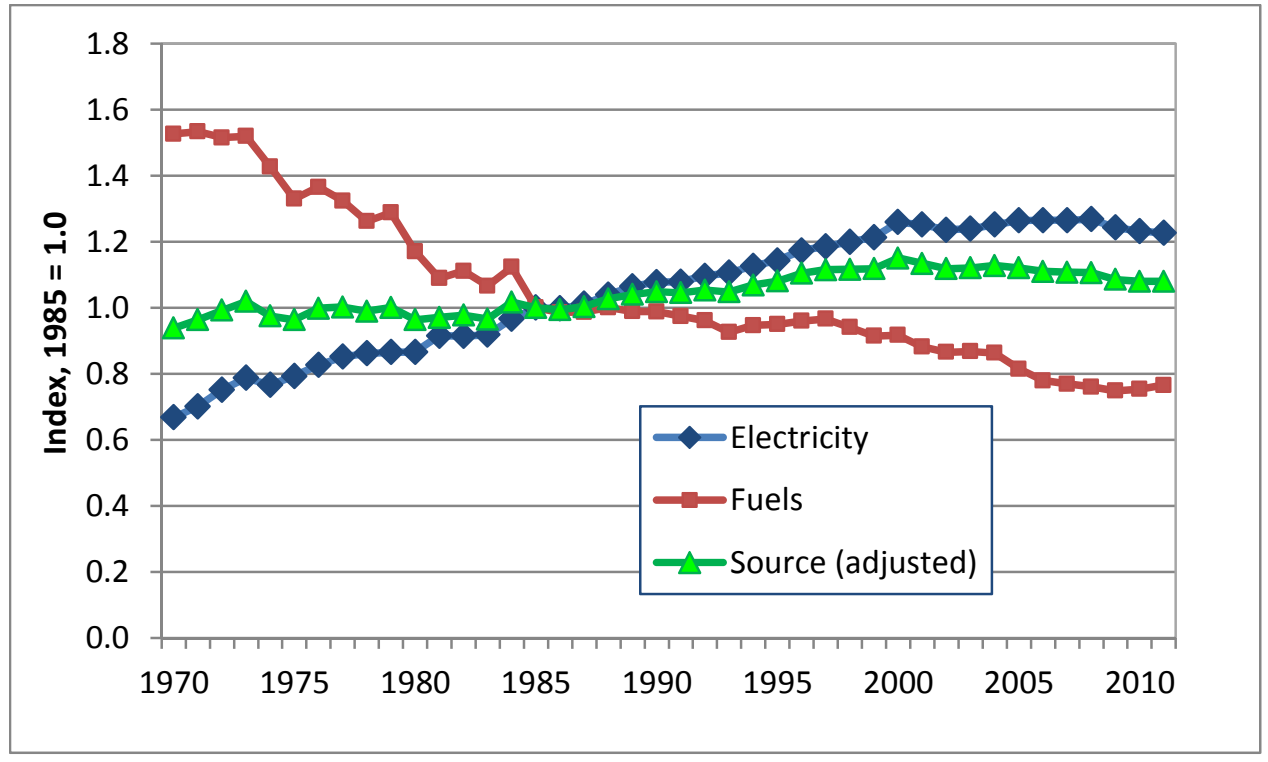

Figure 3.5. Commercial energy intensity indexes by energy type, 1970-2011

The flattening of the trend in electricity intensity in the past decade may be the result of a number of factors, including greater impact from state and utility energy efficiency programs, federal government activities to set energy efficiency standards on some types of commercial equipment and to promote more stringent building energy codes, and the increased general availability of more energy-efficient equipment (e.g., heat pumps, lighting, and computers). The source intensity declines after 2008 may be primarily caused by the depressed economic conditions in those years. (The small increases in fuels intensity in 2010 and 2011 may, in part, reflect lower natural gas prices.)

Between the trend lines for electricity and fuels intensity indexes is the intensity index for source energy. The source energy index captures the fuel switching effects between fuels and electricity. As described in Section 2.6, this index has been adjusted for improvements in the electric power sector that reduce the generation and transmission losses associated with electricity. The source energy intensity index shows different behavior in three distinct time periods: 1) relatively flat up to 1985, 2) increasing from 1985 through 2000, and 3) falling slightly in the past decade as result of declining or flat intensity change in both fuels and electricity.

Figure 3.6 presents the most aggregate indicators for the commercial sector. The top two indexes show the magnitude of commercial floor space and (adjusted source) energy use relative to 1985 . From 1985 to 2011 , commercial floor space increased about $46 \%$ and energy use 
increased about 53\%. The energy intensity index, relative to 1985 , was computed to be 1.080 in 2011 (as repeated from the previous Figure 3.5. The remaining line in the figure shows the estimated weather adjustment factors, normalized to be 1.0 in 1985 . In general, the weather factors show a variation about 4\% over the entire time period. The weather factors for both 2010 and 2011 increase by more than 2\% (compared to 1985), resulting from the two warmest years on record (as measured by cooling degree-days averaged across the U.S.).

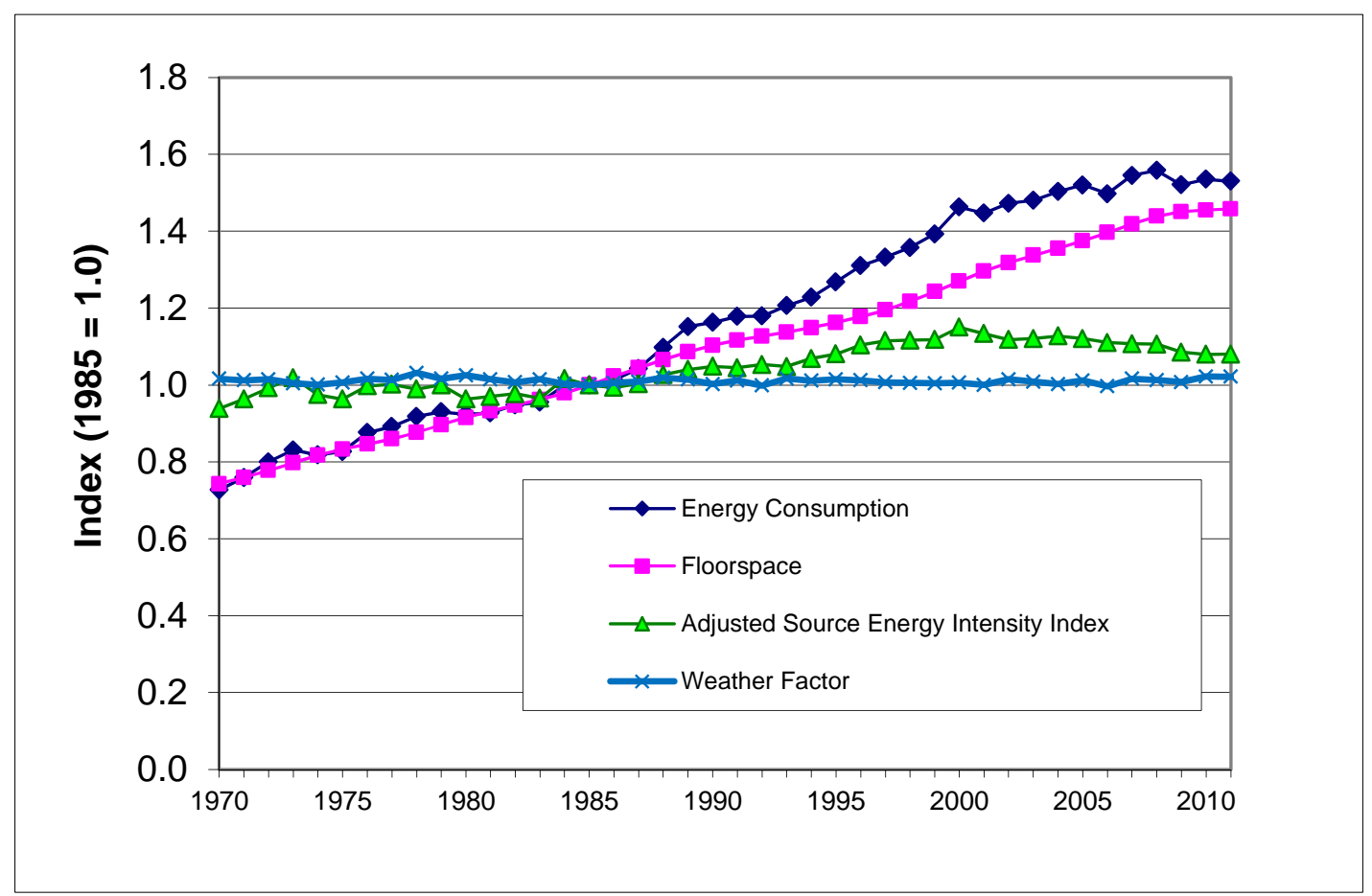

Figure 3.6. Energy intensity and related indexes for the U.S. commercial sector, 1970-2011

Figure 3.7 shows the several indexes that result from a decomposition of published source energy, including the delivered energy intensity index and two structural factor indexes representing electrification and increased electricity generation efficiency. Even though delivered intensity fell approximately 5.5\% between 1985 and 2011, the impact of electrification contributed $16 \%$ additional source energy. In terms of published source energy, the effect of improved electricity generation efficiency saved almost 5\% in 2011 relative to 1985. 


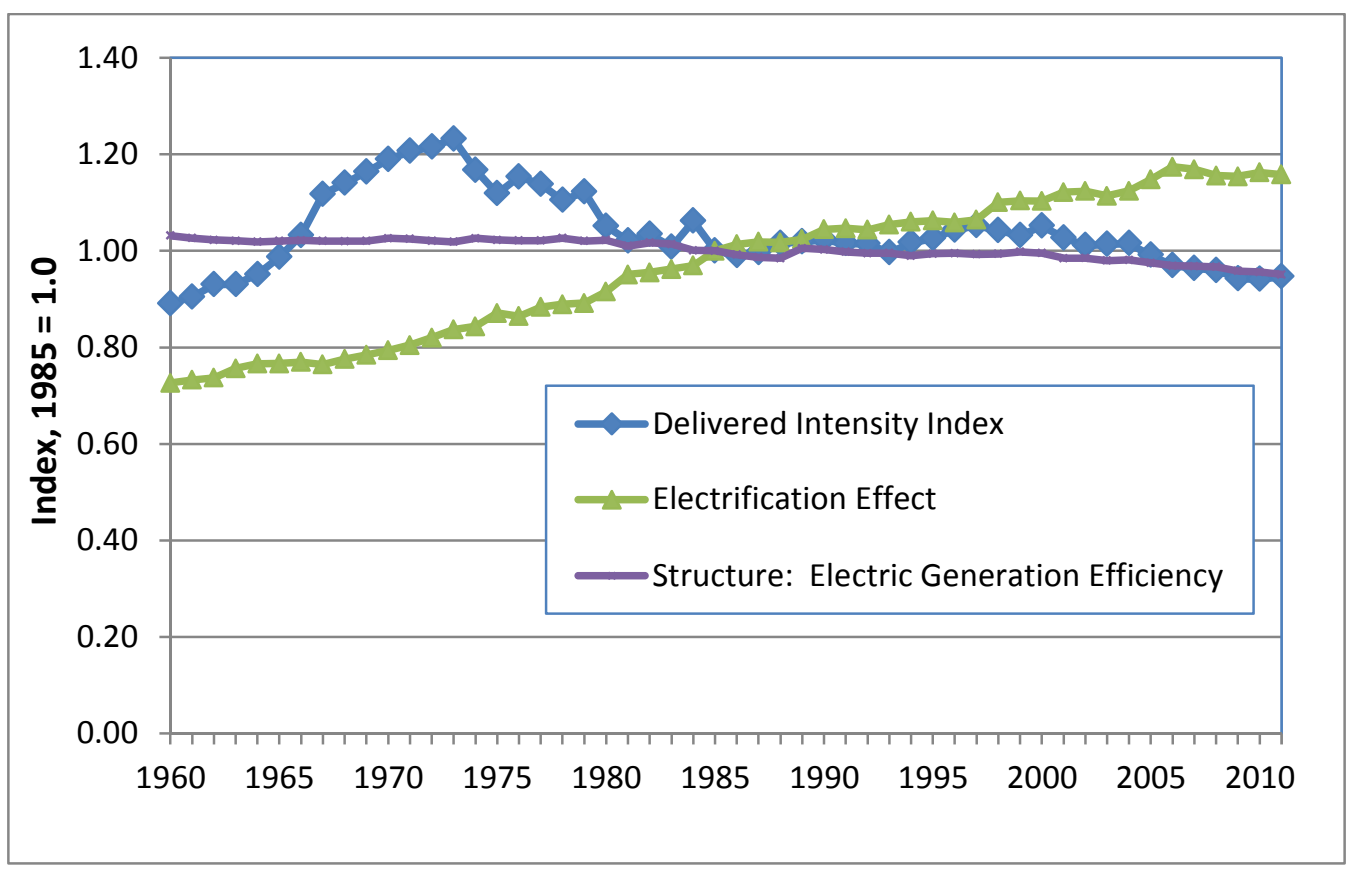

Figure 3.7. Decomposition of energy intensity based upon published values of source energy

\subsection{Industrial Sector}

Overall, the industrial sector has shown the smallest growth in total energy consumption of any of the major end-use sectors. Measured on a total or source energy basis, published industrial energy use was 30.7 quadrillion Btu in 2011, compared to 29.6 quadrillion Btu in 1970. Energy consumption ranged as high as 35 quadrillion Btu in the late 1990s, but has fallen steadily since then, with abnormally low consumption from 2009 through 2011 resulting from the weak economic conditions.

In the EERE system of energy-intensity indicators, the industrial sector is divided into two main subsectors: 1) manufacturing and 2) nonmanufacturing. The main subsectors with nonmanufacturing are agriculture, mining, and construction. Manufacturing was estimated to account for about $86 \%$ of total industrial energy use in 2011 (measured again on a source energy basis).

For the system of energy intensity indicators, consumption estimates for the industrial sector are not based on EIA's published data (as cited above), which rely on energy suppliers (principally electricity and natural gas utilities). A major difference is the use of the various Manufacturing Energy Consumption Surveys (MECS) (EIA various “B”) to estimate energy used for heat, power, and electricity production within manufacturing. Compared to the published estimates of industrial energy use, these alternative sources exclude energy for petrochemical feedstocks. The estimates of energy consumption from these alternative sources for manufacturing and 
nonmanufacturing are shown in Table 3.3 and Table 3.4 and a description of data sources and methods in included in Appendix A, Section A.3.2.

Table 3.3. Estimated energy use and activity in U.S. manufacturing Energy Use, Trillion Btu (TBtu)

\begin{tabular}{lrrrrrr} 
& \multicolumn{2}{c}{1970} & \multicolumn{2}{c}{1985} & \multicolumn{2}{c}{2011} \\
& $($ TBtu $)$ & $\%$ of delivered & (TBtu) & $\%$ of delivered & (TBtu) & $\%$ of delivered \\
\cline { 2 - 7 } Delivered & 16,493 & & 13,627 & & 14,645 & \\
$\quad$ Electricity & 1,701 & $10.3 \%$ & 2,222 & $16.3 \%$ & 2,835 & $19.4 \%$ \\
Fuels & 14,793 & $89.7 \%$ & 11,405 & $83.7 \%$ & 11,810 & $80.6 \%$ \\
Source & 20,611 & & 18,699 & & 20,519 & \\
Adjusted Source & 20,375 & & 18,699 & & 21,117 &
\end{tabular}

Activity, GDP in Billion 2005 Dollars

\begin{tabular}{lrrc} 
& (Billion) & (Billion) & (Billion) \\
\cline { 2 - 4 } GDPman & 501.0 & 802.1 & $1,585.6$ \\
$\%$ of total GDP & $11.7 \%$ & $11.7 \%$ & $12.1 \%$
\end{tabular}

Sources: Energy: various sources from EIA and U.S. Census Bureau, see Appendix A, Section A.3.2.1. For GDP in manufacturing: from Bureau of Economic Analysis, see Section A.3.1.

Table 3.4. Estimated energy use and activity in the nonmanufacturing segment of the industrial sector

Energy Use, Trillion Btu (TBtu)

\begin{tabular}{lr|r|rrrr} 
& \multicolumn{2}{c}{1970} & \multicolumn{2}{c}{1985} & \multicolumn{2}{c}{2011 (see text) } \\
\cline { 2 - 7 } Delivered & (TBtu) & \% of delivered & (TBtu) & $\%$ of delivered & (TBtu) & \% of delivered \\
\cline { 2 - 7 }$\quad$ Electricity & 2,886 & & 2,852 & & 2,126 & \\
Fuels & 318 & $11.0 \%$ & 383 & $13.4 \%$ & 491 & $23.1 \%$ \\
Source & 2,568 & $89.0 \%$ & 2,470 & $86.6 \%$ & 1,635 & $76.9 \%$ \\
Adjusted Source & 3,656 & & 3,726 & & 3,144 & \\
& 3,612 & & 3,726 & & 3,248 &
\end{tabular}

Activity, GDP in Billion 2005 Dollars

\begin{tabular}{lrrr} 
& (Billion) & (Billion) & (Billion) \\
\cline { 2 - 4 } GDP (non-man) & 872.1 & 878.5 & 769.4 \\
\% of total GDP & $20.4 \%$ & $12.8 \%$ & $5.9 \%$
\end{tabular}

Sources: Energy: various sources from EIA and U.S. Census Bureau, see Appendix A, Section A.3.2.2. For GDP in manufacturing: primarily from Bureau of Economic Analysis, see A.3.1. 


\subsubsection{Activity Measures and Decomposition Approach}

The activity measures used to define individual energy indexes in the industrial sector are the gross output measures constructed by the U.S. Department of Commerce, Bureau of Economic Analysis (BEA). ${ }^{4}$ These data measure the output of industrial sectors as the value of sales and other operating income, commodity taxes, and adjustments for inventory change. Chain-type indexes that measure the quantity of gross output are also published. The quantity indexes have been converted to "real" dollars by multiplying the indexes by the value of gross output in a particular base year (now 2005). These measures of real output (termed "chained 2005 dollars") are used as the denominator in the calculation of the intensity indexes, generally the 3-digit level of the North American Industrial Classification System (NAICS). In manufacturing, BEA publishes measures for 18 different sectors based upon this classification. For the nonmanufacturing sector, the measures are published for seven separate subsectors in three groupings: agriculture (3), mining (3), and construction (1).

There is recognition within the overall intensity indicators program that other analyses may be based upon an index of aggregate intensity in the manufacturing or industrial sector computed simply as the ratio of total annual energy consumption divided by the annual gross domestic product attributable to either manufacturing or the industrial sector. ${ }^{5}$ Thus, the system here has been designed to provide an explicit linkage between the detailed energy intensity indexes and a high-level index of aggregate energy intensity constructed from a single ratio.

The key to this linkage is the availability from BEA of value-added estimates that correspond to the gross output measures for individual industry sectors. Value added, as its name implies, represents the value added to any production process from labor compensation and profit-type income (payments to labor and capital), and indirect business taxes. In nominal dollars, the value added is the contribution to GDP from the production side of the national income and product accounts.

Just as for gross output, the BEA has developed quantity indexes of value added. And as for gross output, these quantity indexes can be converted to "real" dollar figures by multiplying the indexes by the dollar magnitude of value added in a chosen base year. Over the past decade or so, BEA has changed its methodology to account for changes in relative prices among subsectors when quantity measures of value added are developed at more aggregate levels. ${ }^{6}$ Before this

\footnotetext{
${ }^{4}$ Two spreadsheet files provide the required data to construct the time series of gross output and value added. The basic historical file is labeled: "GDPbyInd_VA_NAICS_1947-1997.xls" This file can be downloaded from the BEA website: http://www.bea.gov/industry/gdpbyind data.htm

${ }^{5}$ This issue will be discussed further when the economy-wide energy intensity index is compared to the often cited energy-GDP ratio.

${ }^{6}$ The concept behind this change was discussed in an article by J. Steven Landefeld and Robert P. Parker in the May 1997 issue of the Survey of Current Business. This article can be accessed on the BEA website: http://www.bea.gov/scb/account_articles/national/0597od/maintext.htm
} 
change, real value added (real GDP) for any aggregation of sectors (e.g., total manufacturing) was simply the sum of the value-added estimates across the included subsectors. The chained index methodology now being used precludes that identity, and one element of "structural change" in the system of energy intensity indictors can now be viewed as the difference between the sum of real value added and the published estimate based upon the chained quantity index.

The linkage between these differing energy intensity indexes can be derived from a decomposition of the following equation for total energy:

$$
E=\Sigma E_{i}{/ G O_{i}} \cdot{ }^{G O_{i}} /_{V A_{i}} \cdot V A_{i} / \text { VAsum } \cdot V A s u m / V A c h a i n \cdot \text { VAchain }
$$

where

$$
\begin{array}{lll}
E & = & \text { Total energy }, \\
G O_{i} & = & (\text { Real }) \text { Gross output for subsector } i \\
V A_{i} & = & \text { (Real) Value added for subsector } i \\
\text { VAsum } & =\quad \sum V A_{i} \\
\text { VAchain } & = & \text { Chain-weighted real value added for aggregate sector }(=\text { GDP) }
\end{array}
$$

The aggregate energy intensity is found by dividing both sides of this equation by VAchain. The resulting mathematical formulation now clearly expresses that the aggregate energy intensity (i.e., E/VAchain) is related to the sector-specific energy intensities and three additional ratio terms that represent structural and definitional influences included in the aggregate index.

Divisia indexes, relative to a chosen base year (1985), for all of terms on the right side of Equation (3.1) are calculated. The index for the first term is the energy intensity index for the particular aggregation of sectors (e.g., all manufacturing). The next three terms, in turn, represent the effects of changes in the ratio of value added to gross output, changes in the composition of value added (i.e., activity by subsector) within the aggregate sector, and finally the effect of using a chain-weighted measure to calculate value added for any aggregation of sectors.

\subsubsection{Manufacturing}

Table 3.3 above shows energy consumption in manufacturing by major fuel type and under different definitions of energy. The table shows a significant increase in the share of total energy use accounted for by electricity in this sector over the past four decades, but in contrast to buildings, electricity makes up still less than $20 \%$ of delivered energy. Increases in electricity 
use can be attributable to the relatively higher growth of light manufacturing with greater need for building space conditioning, greater use of electricity for steelmaking, and more widespread use of robotics and controls in manufacturing processes. On the other hand, fuel consumption has fallen nearly $20 \%$ since 1970 , reflecting slower (or negative) growth in energy-intensive sectors, better utilization of waste heat, and other efficiency improvements across a range of industries.

Again, the last two entries in the upper portion of the table relate to source energy, thus including the electricity generation and transmission losses associated with electricity sales to commercial customers. The second (lower) of these two values holds constant the ratio of electricity losses to sales at its 1985 magnitude (2.283), as explained earlier in the discussion of the building sectors. For manufacturing, the adjustments to source energy yield an increase in total energy consumption between 1970 and 2011, as compared to the unadjusted estimate.

The last line of Table 3.3 shows the real GDP for this sector, using chained 2005 dollars. In spite of the often-cited decline of U.S. manufacturing sector in recent decades, the BEA estimates indicate that the share of overall U.S. GDP accounted for by manufacturing has remained relatively constant. The tripling of manufacturing output since 1970, and the doubling since 1985, in conjunction with the energy consumption estimates presented at the top of the table, suggests that aggregate energy intensity has declined significantly in manufacturing. As will be shown below, however, a more accurate measure of energy intensity shows a considerably smaller decline.

Figure 3.8 shows the intensity indexes by energy type, based upon the Divisia index methodology and activity measures using real gross output. The most striking feature in the figure is the reduction of more than $30 \%$ in the energy intensity of fuels from 1970 to 1985 . Electricity intensity was relatively constant over the first half of the period, then fell during the latter portion of the 1990s. It has remained relatively constant over the past decade. The composite measure of energy intensity, measured as (adjusted) source energy, is a blend of the behavior of the separate fuels and electricity indexes; by2011, it had declined to a value of about 0.875 relative to 1985 .

The relatively modest changes in the energy intensities, especially since 1985, are in sharp contrast to the implied change in aggregate energy intensities shown by numbers in Table 3.3. This result implies a significant amount of structural change embodied in the aggregate intensity measure. This fact is reflected in Figure 3.9, which shows the indexes for energy, activity, energy intensity, and structural change. 


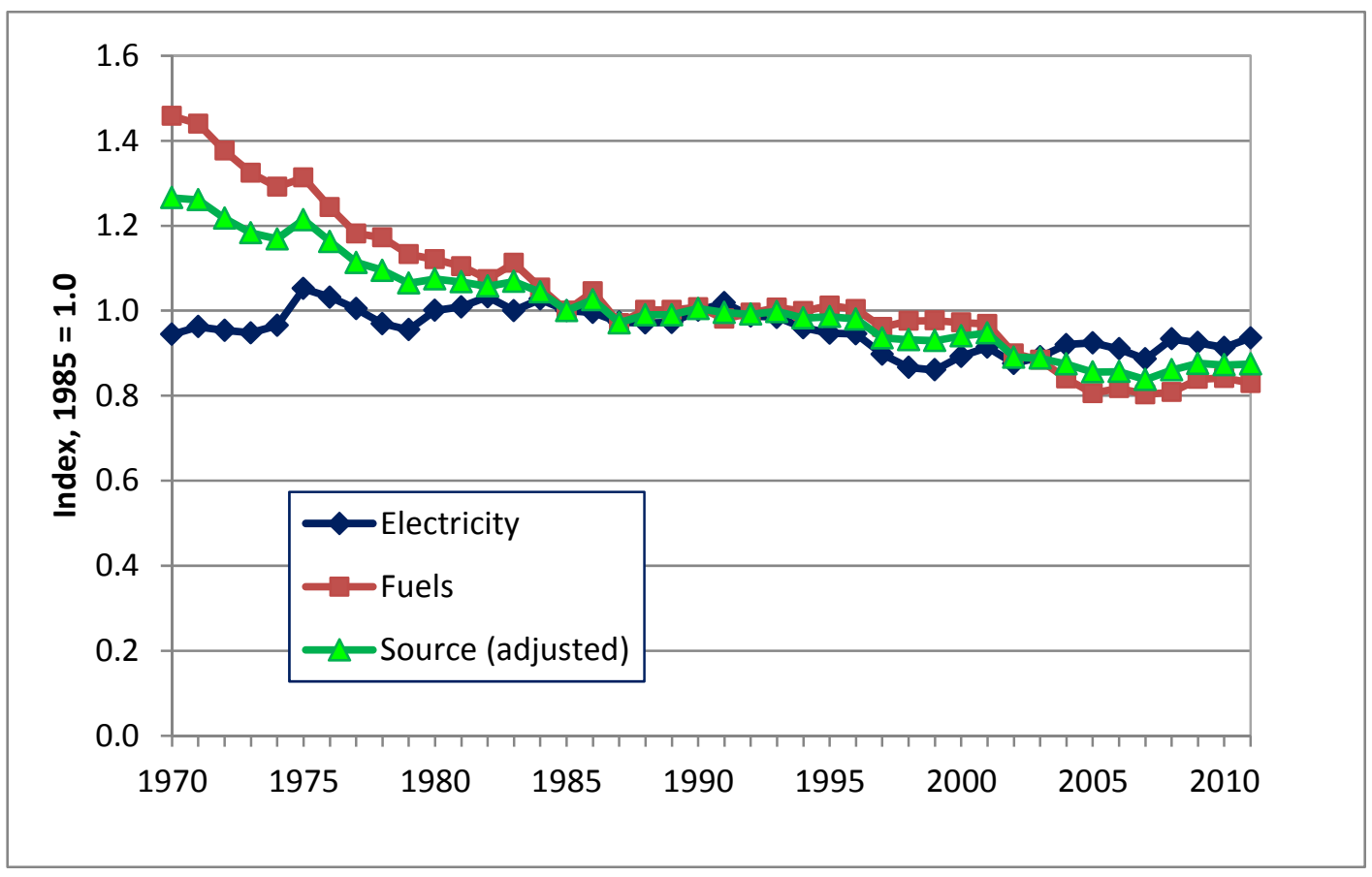

Figure 3.8. Manufacturing energy intensity indexes by energy type, 1970-2011

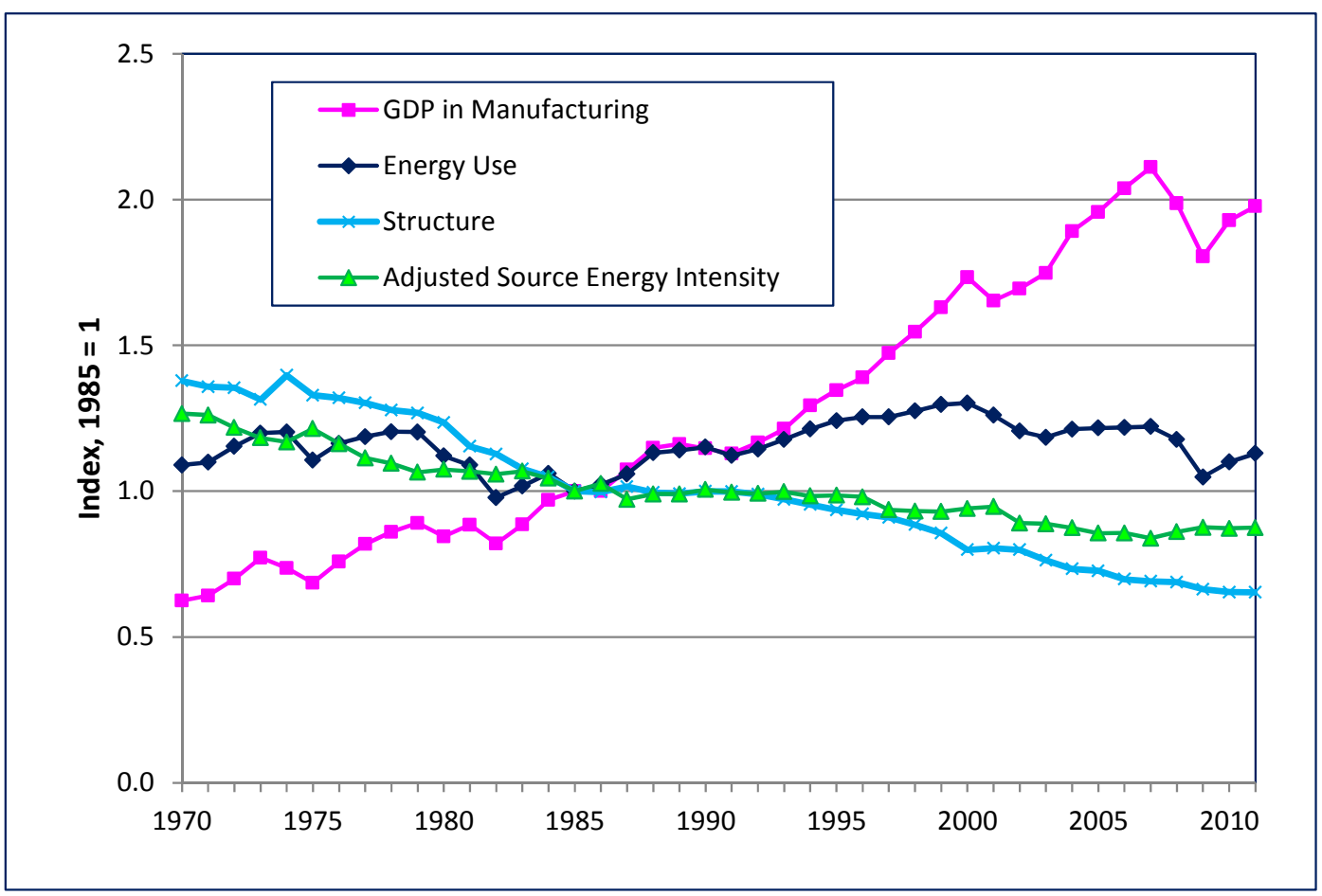

Figure 3.9. Energy intensity and related indexes for manufacturing, 1970-2011 


\subsubsection{Nonmanufacturing}

Energy intensity indexes for the nonmanufacturing portion of the industrial sector were constructed in a manner similar to the manufacturing sector. Activity measures were based upon gross output and value added information provided by BEA and the Bureau of Labor Statistics. Table 3.4 above shows basic energy and activity estimates for the nonmanufacturing segment. ${ }^{7}$ Similar to the industrial sector, electricity consumption has grown relative to fuels, but is still less than one- quarter of total energy use (as measured by delivered energy). Primarily as result of declining mining activity in the U.S. and a weak construction activity in 2011, total GDP in the nonmanufacturing sector was actually lower in 2011 compared to 1970. Representing just over $20 \%$ of total U.S. GDP in 1970, that percentage dropped to $6 \%$ in 2011.

It should be noted that the quality of the energy data used to construct the energy intensity indexes in this sector is below that of manufacturing. Up until this most recent update (through 2011) of the system of the energy intensity indicators, the estimates of energy consumption for nonmanufacturing were based upon a residual calculation - subtracting the establishmentreported energy consumption in manufacturing from total industrial energy use as reported by energy suppliers and published by EIA. This approach was unsatisfactory because it led to very implausible year-to-year estimates of nonmanufacturing energy use (separately estimated for electricity and fuels).

As a result, a preliminary effort was made to construct historical estimates of energy consumption for the primary nonmanufacturing sector. However, while a large improvement over the residual method, this approach is not as robust as a definitive analysis would require. Several of the major shortcomings are 1) economic census year data only for mining and construction, with the need for interpolation and extrapolation to other years; 2) lack of energy quantity data: for many mining sectors (from confidentiality concerns), for all construction sector fuels data, and for electricity consumption by farms; and 3) revision of the industry classification with the 1997 NAICS that defined mining energy services as an separate 3-digit NAICS sector, thus compounding the difficulty in constructing consistent historical series in mining. These issues are addressed more fully in Appendix A. With this caveat, however, it is judged that the current set of energy estimates do reasonably reflect at least the long-term trends in energy use and intensity in these sectors.

Figure 3.10 shows the intensity indexes based upon the estimates of energy consumption derived for the three major nonmanufacturing sectors. As for other major end-use sectors, the energy intensity for fuels has declined significantly since 1970, although the data suggest that there was

\footnotetext{
${ }^{7}$ As explained in Appendix A, Section A.3, the data sources for nonmanufacturing, particularly mining and construction, rely heavily on the periodic economic census. Annual values are generally developed by interpolation between census years. As of this report, data from the 2012 census were not published. Lacking this information, the energy consumption estimates for 2011 are largely based on holding intensities constant for prior years. An exception is an estimate for fuel consumption for agriculture. See Appendix A, Section A.3 for further detail.
} 
no substantially greater decline before 1985 compared to after 1985 . The drop in the fuels intensity in 2003 stems largely from a significant reduction in agricultural fuel use in this year.

Electricity intensity appears to have increased over the period. Detailed data indicate significant increase in electricity consumption between the 2002 and 2007 Census of Construction Industries. ${ }^{8}$ The composite source energy intensity index reflects a weighted average of the separate fuels and electricity indexes; by 2011, it has fallen about $14 \%$ relative to its 1985 value.

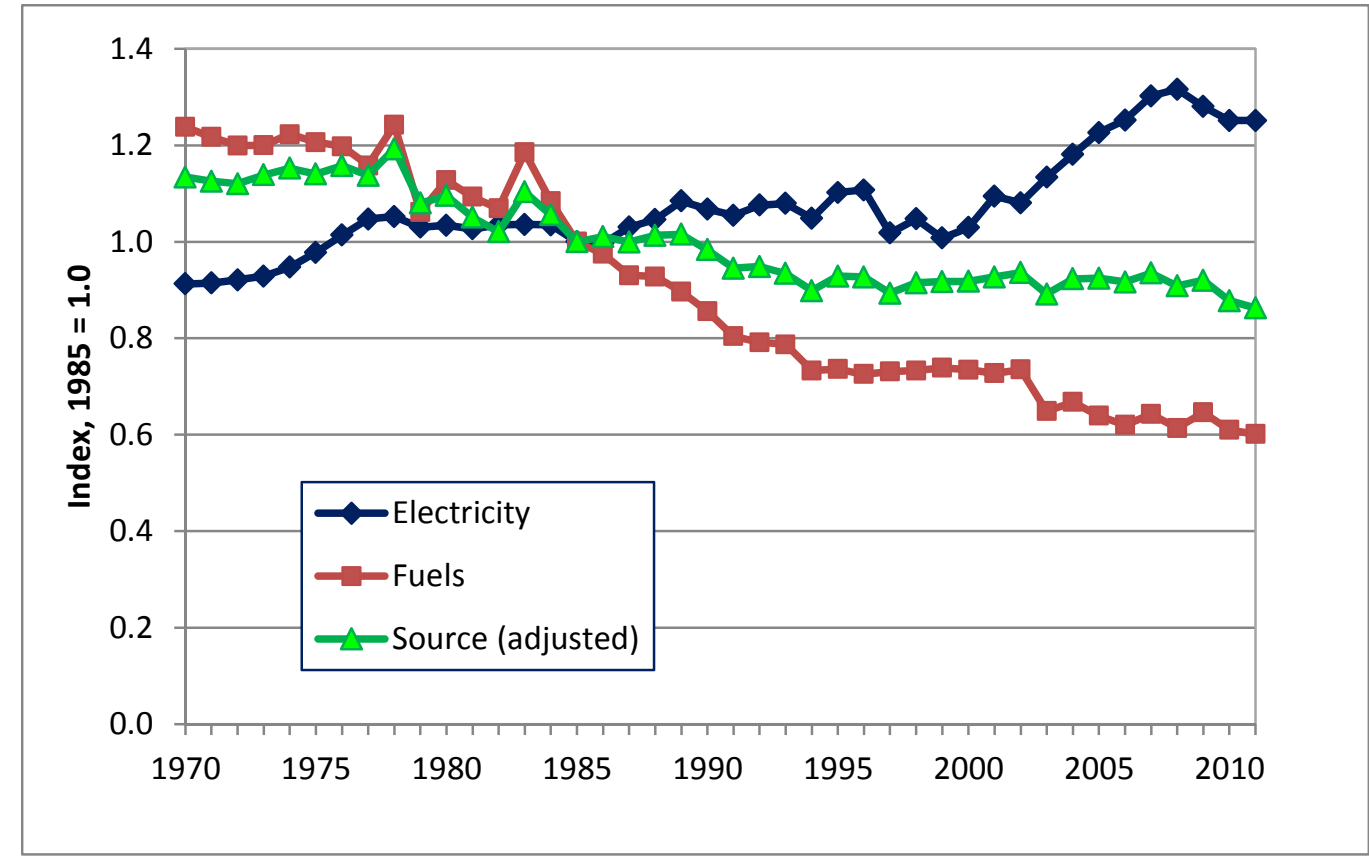

Figure 3.10. Nonmanufacturing (industrial) energy intensity indexes by energy type, 1970-2011

\subsubsection{Energy Intensity Indexes for the Industrial Sector}

The separately estimated intensity indexes are combined to form indexes for the industrial sector as whole. Because the manufacturing sector accounts for the predominant share of industrial energy use (e.g., more than $86 \%$ of source energy in 2011), the energy intensity indexes are very similar to those presented in Figure 3.8. ${ }^{9}$ However, index of activity is somewhat lower because of the negative change in overall nonmanufacturing GDP. The structural index reflects structural changes with the two major subsectors, as well as the shift between manufacturing and nonmanufacturing activity. Because manufacturing has a higher absolute intensity per dollar of GDP, the increase in the manufacturing share of industrial GDP is one factor increasing the

\footnotetext{
${ }^{8}$ The behavior of the electricity index after 2007 is largely a result of compositional shifts within the "Other mining" sector, which includes three separate sub-sectors: a) coal mining, b) metal mining, and c) non-metallic mineral mining. At this point, the indicators system has not yet included a separate decomposition between intensity and structural changes within this sector.

${ }^{9}$ See previous footnote for treatment of nonmanufacturing estimates for 2011.
} 
structural index (compare the 2011 value of the index for manufacturing versus the industrial sector in Figures 3.9 and 3.11).

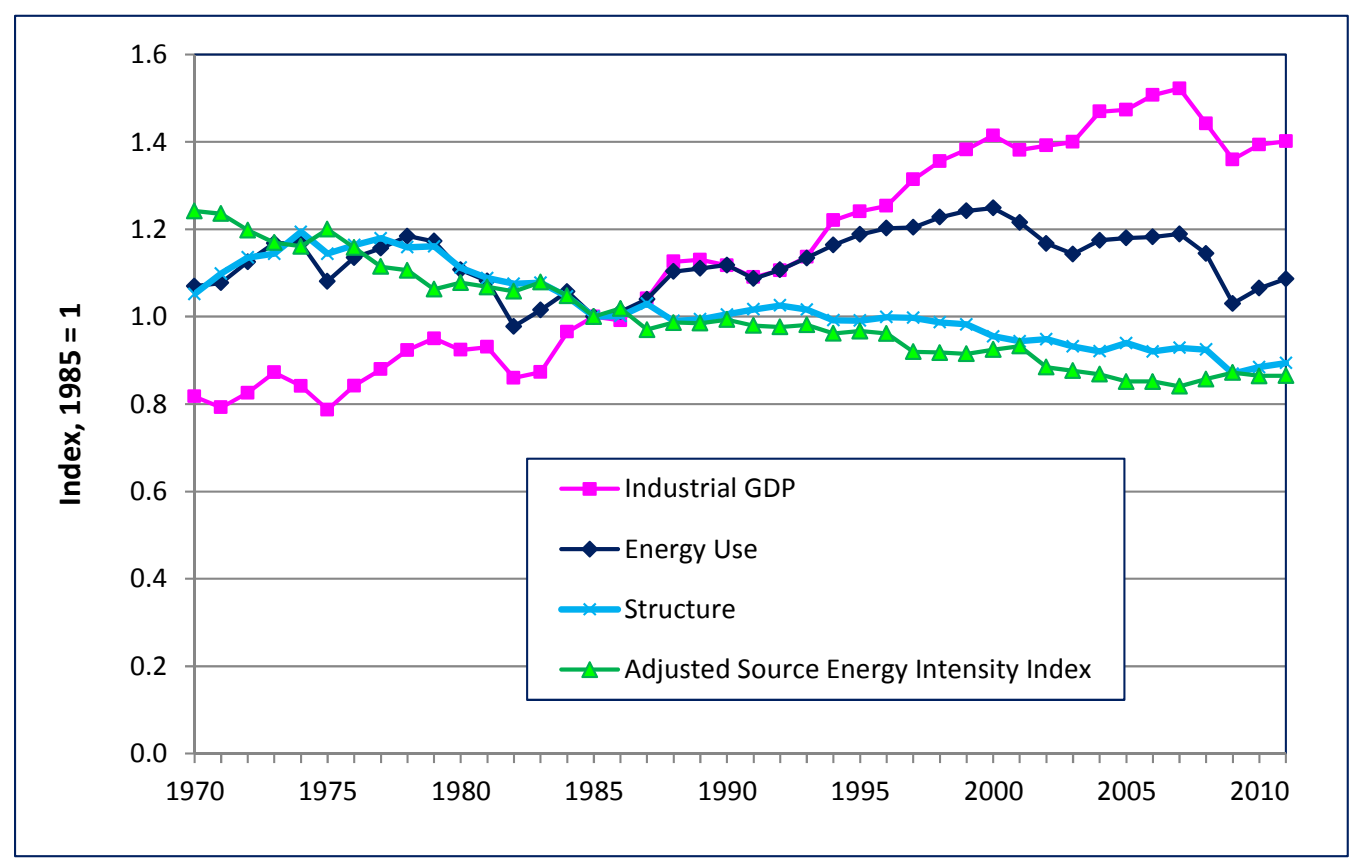

Figure 3.11. Energy intensity and related indexes for industrial sector, 1970-2011

\subsection{Transportation}

Over the 1970-2011 time frame, the transportation sector has shown the second largest percentage increase total energy consumption of any of the major end-use sectors. Total energy consumption, as published by EIA, increased from 16.1 quadrillion Btu in 1970 to 27.2 quadrillion Btu in 2011. Transportation's share of national energy consumption increased from just under $24 \%$ in 1970 to $28 \%$ in 2011.

Similar to the industrial sector, the system of energy intensity indexes relies on a variety of governmental and private sources to develop intensity indicators for various transportation modes. This approach can be contrasted to the use of the single EIA published estimate of total transportation energy consumption cited above. The various indexes are grouped into overall freight and passenger segments. ${ }^{10}$

\footnotetext{
${ }^{10}$ The use of this "bottom-up" approach yields an estimate of total transportation energy use that will differ from the EIA published value developed from supply-side sources (e.g., number of gallons of gasoline or diesel fuel sold to end users). Other than statistical discrepancies, the "bottom-up" approach omits fuel consumption for military aircraft and miscellaneous uses of fuel such as recreational boating. See Appendix A, Section A.4.1 for detailed discussion of data sources and methods. Fuel consumption estimates based upon this approach are shown in Tables
} 


\subsubsection{Freight Transportation}

Energy consumption for freight transportation was estimated to have been 7.6 QBtu in 2011, comprising about $28 \%$ of overall transportation energy use. The share of energy used in transporting freight has been increasing over time. As compared to 2011, in 1970 the estimated share was about $25 \%$; the estimated share in 1985 had grown to nearly $27 \%$.

The EERE system of energy intensity indicators covers five modes in freight transportation, as shown in the top panel of Table 3.5. Table 3.5 shows the dramatic increase in the energy used by trucks in the U.S. over the past 40 years. Trucking energy use increased by a factor of 3 between 1970 and 2011 and now accounts for nearly three-quarters of the nation's energy use for freight transportation. Air freight energy use has a little more than doubled since 1970. Energy consumption in the other three modes is estimated to have actually declined over this same period.

Table 3.5. Estimated energy use and activity in U.S. freight transportation

\begin{tabular}{|c|c|c|c|c|c|c|}
\hline \multirow{2}{*}{ Energy Use, Tril } & \multicolumn{2}{|c|}{1970} & \multicolumn{2}{|c|}{1985} & \multicolumn{2}{|c|}{2011} \\
\hline & (TBtu) & (\%) & (TBtu) & $(\%)$ & (TBtu) & $(\%)$ \\
\hline Trucking & 1,980 & $54.3 \%$ & 3,700 & $72.0 \%$ & 5,803 & $76.5 \%$ \\
\hline Rail & 528 & $14.5 \%$ & 436 & $8.5 \%$ & 515 & $6.8 \%$ \\
\hline Waterborne & 208 & $5.7 \%$ & 268 & $5.2 \%$ & 108 & $1.4 \%$ \\
\hline Air & 150 & $4.1 \%$ & 194 & $3.8 \%$ & 422 & $5.6 \%$ \\
\hline Pipelines (Gas) & 778 & $21.4 \%$ & 543 & $10.6 \%$ & 737 & $9.7 \%$ \\
\hline Total & 3,645 & & 5,141 & & 7,585 & \\
\hline
\end{tabular}

Activity, Ton-miles

\begin{tabular}{lrr|rr|rr} 
& \multicolumn{2}{c}{1970} & \multicolumn{2}{c}{1985} & \multicolumn{2}{c}{2011} \\
& (mill. ton-miles) & \multicolumn{1}{c}{$(\%)$} & (mill. ton-miles) & \multicolumn{1}{c}{ (\%) } & (mill. ton-miles) & \multicolumn{1}{c}{$(\%)$} \\
\cline { 2 - 7 } Trucking & 598,160 & $26.9 \%$ & 909,200 & $31.3 \%$ & $1,467,730$ & $36.3 \%$ \\
Rail & 764,810 & $34.3 \%$ & 876,980 & $30.2 \%$ & $1,729,260$ & $42.8 \%$ \\
Waterborne & 596,200 & $26.8 \%$ & 892,970 & $30.7 \%$ & 499,750 & $12.4 \%$ \\
Air & 3,760 & $0.2 \%$ & 9,050 & $0.3 \%$ & 35,710 & $0.9 \%$ \\
Pipelines (Gas) & 264,070 & $11.9 \%$ & 219,540 & $7.6 \%$ & 310,720 & $7.7 \%$ \\
\cline { 2 - 7 }$\quad$ Total & $2,226,990$ & & $2,907,740$ & & $4,043,170$ &
\end{tabular}

The bottom portion of Table 3.5 shows the same comparisons across modes, but in terms of estimates of ton-miles carried. Rail still accounts for the greatest percentage of nation's freight activity, with over $40 \%$ of total ton-miles in 2011 . The percentage of freight carried by rail has increased since 1970, although its share has fallen relative to trucks. Freight transported on the nation's rivers and lakes and along its coasts has declined by over 30\% compared to the $1980 \mathrm{~s}$ (with most of that decline accounted for by coastal shipping). Air freight has increased 
dramatically in both absolute and percentage terms since 1970. However, it still accounts for only about $1 \%$ of the total U.S. freight activity.

Figure 3.12 shows the absolute energy intensities in terms of Btu per ton-mile for four of the freight modes. (While the intensity for air freight has declined more over this period than any other mode, it is still about 4 times more energy intensive than trucking, and thus is not displayed in the figure.) On a percentage basis, the reduction in energy intensity in the rail sector is the most prominent, falling by more than $50 \%$ since 1970 . As the dominant freight carrier in the U.S., the estimated energy intensity in trucking has changed little since 1985. The available data suggest that intensities during the 1970s may have actually increased (see discussion in data sources section). The estimated intensities for waterborne freight have not changed significantly over the time period in this analysis.

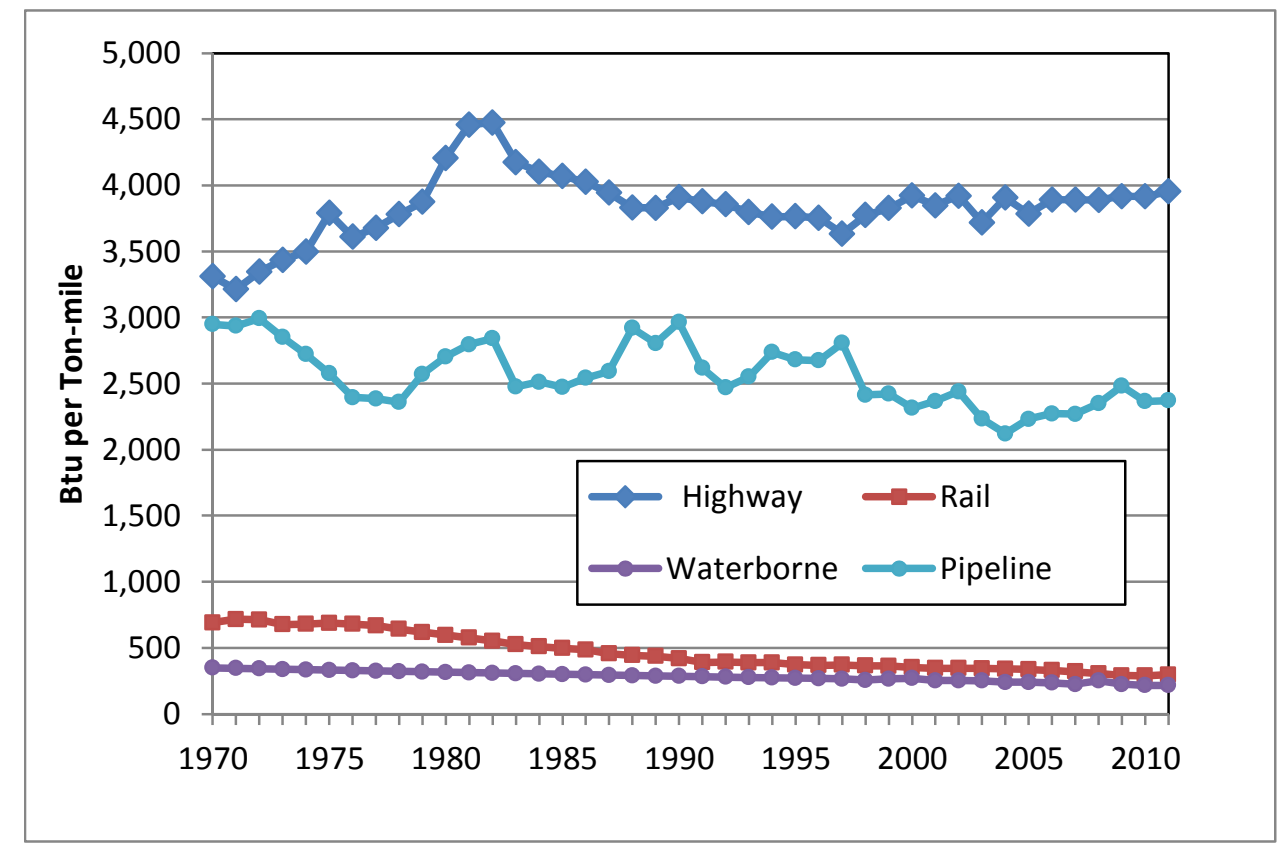

Figure 3.12. Energy intensities for freight modes, 1970-2011

Figure 3.13 shows the energy intensities, including air freight, expressed in index form with a 1985 base year. As just described, this figure clearly illustrates the much greater declines in intensity for rail and air compared to the other three modes. In both cases (rail and air), the declines occurred at a more rapid rate in the period 1970-1985.

Figure 3.14 shows the results of combining data from the various modes into an overall intensity index for total freight transportation. The intensity index (green triangles) is developed from the LMDI methodology described in Section 2.5. The index shows little change from 1970 to 1985. 
After 1985, there is a decline of about $10 \%$ up to the late 1990s, but showing little change over the past decade.

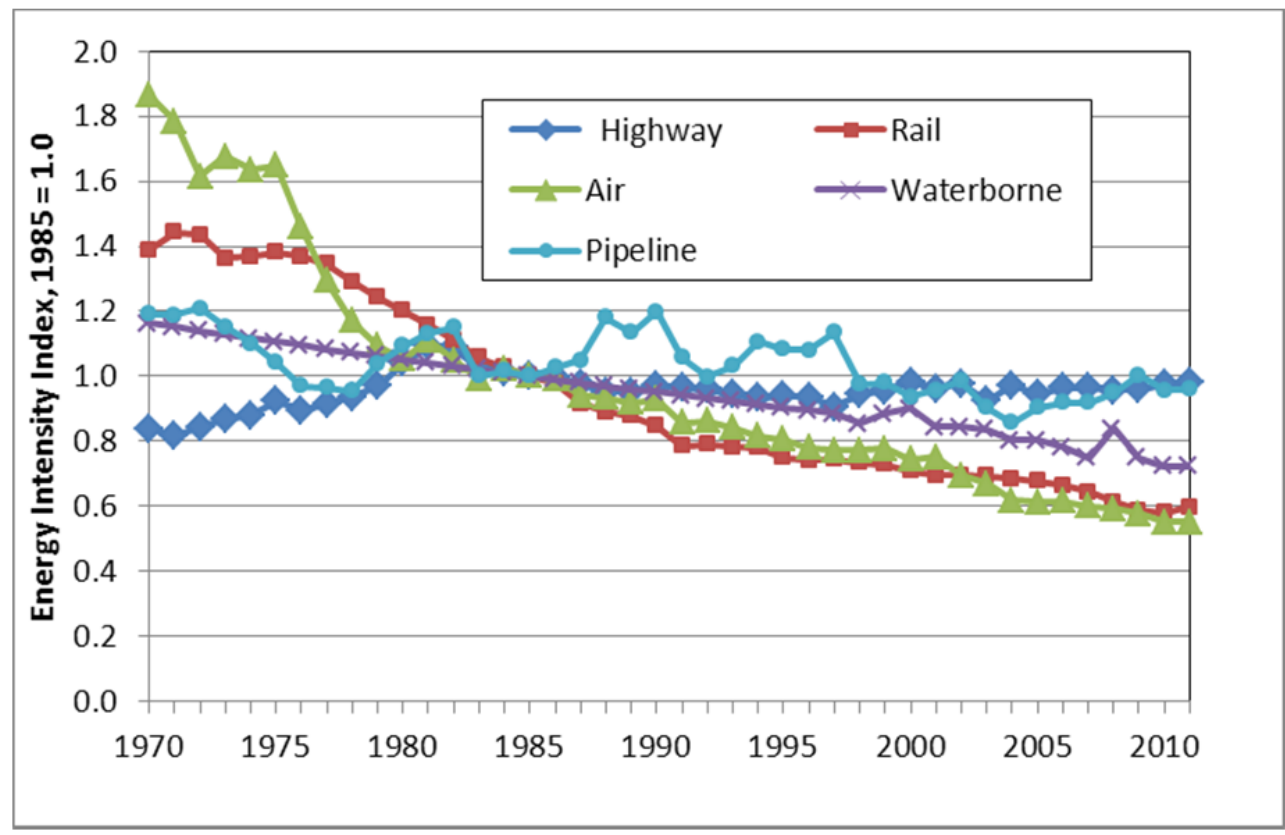

Figure 3.13. Energy intensity indexes, base year 1985, for freight modes, 1970-2011

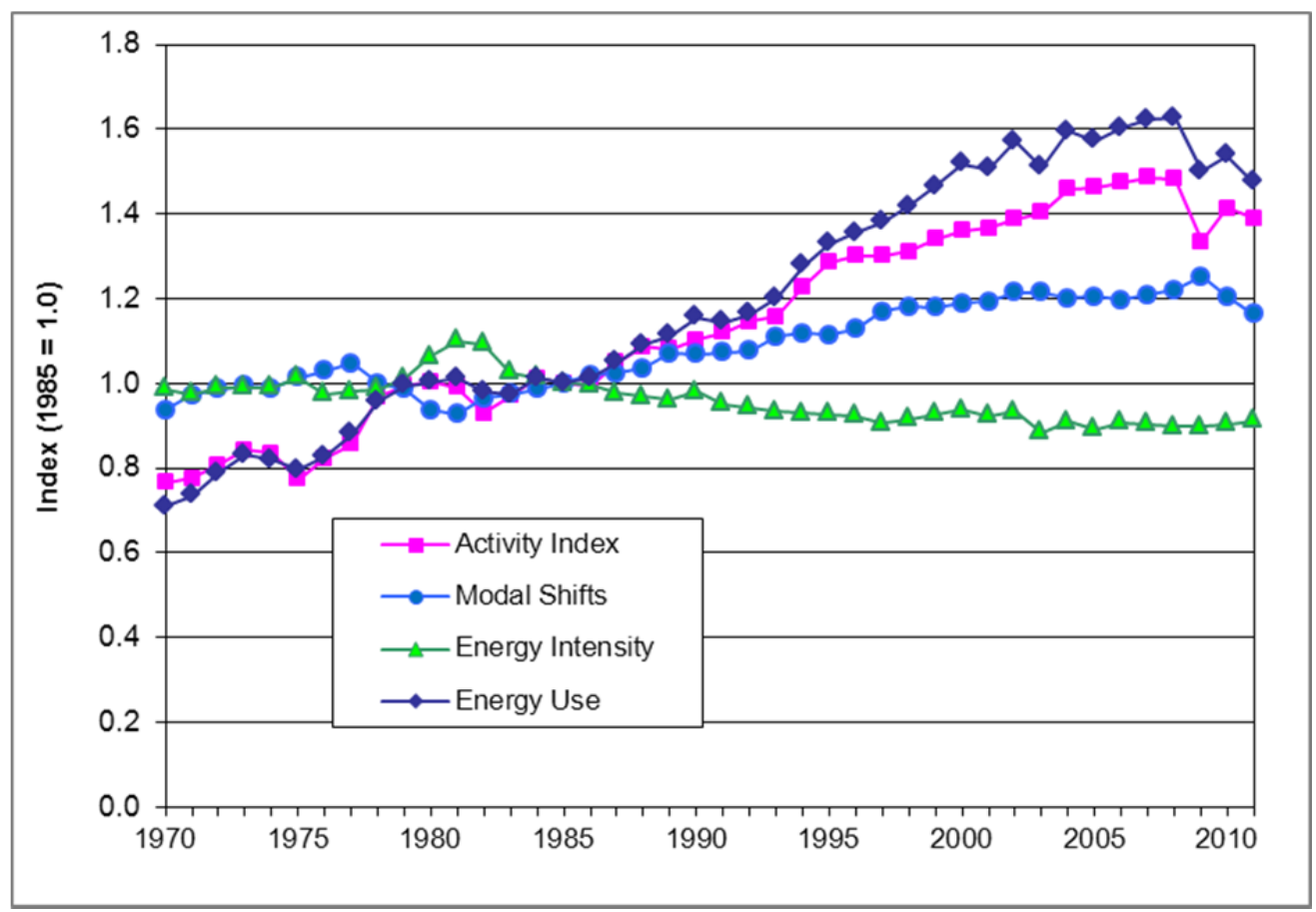

Figure 3.14. Overall indexes for freight transportation, 1970-2011 
The line labeled "modal shifts" shows the effect of the changing shares of ton-miles by mode upon overall energy use. In essence, this curve shows the effects of the changing mix (dominated by the increase in freight carried by trucks) upon an index of aggregate intensity, i.e. total energy divided by total ton-miles. The aggregate intensity measured in this manner (not shown in the figure) increased by about 6\% between 1985 and 2011, which under the LMDI methodology is equivalent to the modal shift index in $2011(=1.16)$ times the energy intensity index for the same year $(=0.91)$. Thus, in terms of energy alone, modal shifts have resulted in the overall freight transportation sector becoming more energy intensive since 1985, in spite of individual modes becoming on balance, less energy intensive. Of course, this observation says nothing about economic efficiency of freight transportation; the increased use of trucks reflects the greater flexibility of that mode in serving diverse locations and in providing scheduling advantages over other modes.

\subsubsection{Passenger Transportation}

Energy consumption for passenger transportation was estimated to have been 19.1 QBtu in 2011, comprising about $72 \%$ of overall transportation energy use. The share of transportation energy used for passenger transportation (as compared to freight) has been slightly decreasing over time. Compared to 2011, in 1970 the estimated share was about $76 \%$.

Data are available to measure passenger travel across three major modes: 1) highway, 2) air, and 3) rail. While cruise ship and riverboat "travel" have increased in recent years, there is no data source that provides information on energy consumption and passenger volume for these activities.

The top portion of Table 3.6 shows the estimated energy consumption across these modes for three selected years: 1970, 1985, and 20110. The dominance of travel by highway is reflected in the energy data, with just under $90 \%$ of all energy consumed for passenger travel. Air travel accounts for a little over $10 \%$ of passenger travel energy use.

The bottom panel of Table 3.6 shows the corresponding estimates for the number of passengermiles traveled by each mode. While highway travel shows dominance in these data as well, the most interesting statistic relates to air travel. As a percentage of overall travel in U.S., airline use more than doubled between 1970 and 2011 (moreover, showing a five-fold increase in overall travel over this same period - no surprise to the frequent travelers who use the nation's congested airports). While rail represents less than $1 \%$ of overall travel, the fraction has remained steady over this period. The overall rail category is actually dominated by commuter rail, which is estimated to account for slightly less than $80 \%$ of the total rail passenger-miles. 
Table 3.6. Estimated energy use and activity in U.S. passenger transportation

Energy Use, Trillion Btu (TBtu)

\begin{tabular}{lrr|rr|rr} 
& \multicolumn{2}{c|}{1970} & \multicolumn{2}{|c}{1985} & \multicolumn{2}{|c}{2011} \\
Highway & $(\mathrm{TBtu})$ & $(\%)$ & $($ TBtu $)$ & $(\%)$ & \multicolumn{1}{c}{$(\mathrm{TBtu})$} & $(\%)$ \\
\cline { 2 - 7 }$\quad$ Automobiles & 10,135 & $88.2 \%$ & 12,530 & $88.0 \%$ & 17,090 & $88.3 \%$ \\
$\quad$ Light trucks & 8,479 & $73.8 \%$ & 8,932 & $62.7 \%$ & 9,029 & $46.6 \%$ \\
Air & 1,539 & $13.4 \%$ & 3,414 & $24.0 \%$ & 7,773 & $40.1 \%$ \\
Rail & 1,306 & $11.4 \%$ & 1,651 & $11.6 \%$ & 2,180 & $11.3 \%$ \\
$\quad$ Total & 48 & $0.4 \%$ & 60 & $0.4 \%$ & 94 & $0.5 \%$ \\
\hline
\end{tabular}

Note: Highway also includes buses, para-transit, and motorcycles, not shown explicitly in table

Activity, Passenger-miles

\begin{tabular}{lrr|rr|rr} 
& \multicolumn{2}{c}{1970} & \multicolumn{2}{c|}{1985} & \multicolumn{2}{c}{2011} \\
& (mill. pass-miles) & $(\%)$ & (mill. pass-miles) & \multicolumn{1}{c}{$(\%)$} & (mill. pass-miles) & $(\%)$ \\
\cline { 2 - 7 } Highway & $2,058,730$ & $92.1 \%$ & $3,028,140$ & $88.7 \%$ & $4,784,970$ & $84.4 \%$ \\
$\quad$ Automobiles & $1,741,730$ & $78.0 \%$ & $2,172,990$ & $63.7 \%$ & $2,505,820$ & $44.2 \%$ \\
$\quad$ Light trucks & 221,910 & $9.9 \%$ & 720,490 & $21.1 \%$ & $2,067,110$ & $36.5 \%$ \\
Air & 160,580 & $7.2 \%$ & 363,370 & $10.6 \%$ & 847,790 & $15.0 \%$ \\
Rail & 15,050 & $0.7 \%$ & 22,100 & $0.6 \%$ & 37,620 & $0.7 \%$ \\
$\quad$ Total & $2,234,360$ & & $3,413,610$ & & $5,670,380$ &
\end{tabular}

Note: Highway includes buses, para-transit, and motorcycles, not shown separately in table. See Appendix A, Section A.4.2 for discussion of data and sources for buses.

The dramatic increase in air travel shown in Table 3.6 in combination with its small share of total energy use reflects its significant improvement in energy efficiency over time. Figure 3.15 illustrates the historical evolution of the aggregate energy intensity in each of the various modes, measured in Btu per passenger-mile. The figure clearly shows the significant and steady improvement in energy intensity by the nation's airlines. This improvement reflects both aircraft energy efficiency as well as operational changes to increase overall load factors. 


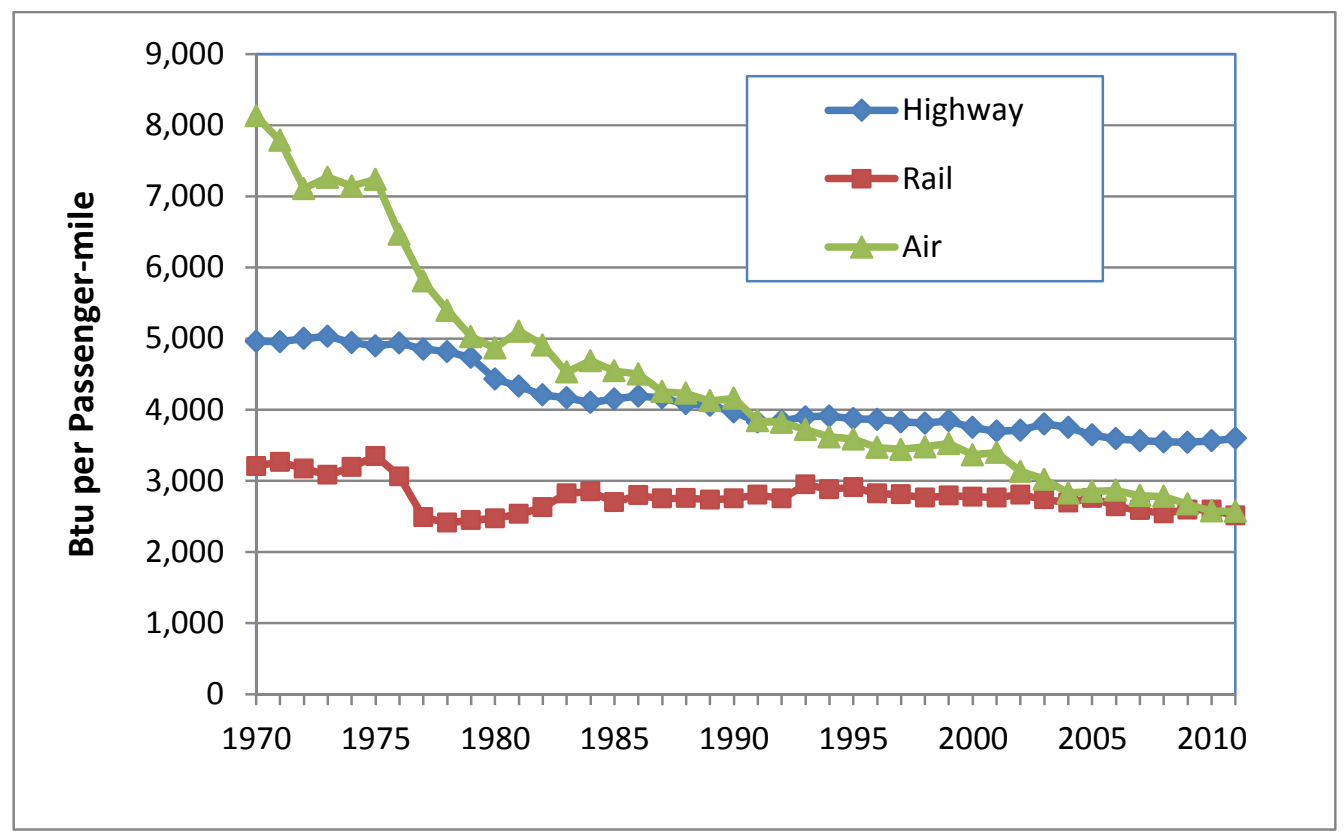

Figure 3.15. Energy intensities for major passenger travel modes, 1970-2011

The greatest reduction in energy intensity in the highway segment occurred over the first half of the data period. Energy intensity across the highway mode declined by $20 \%$ between 1970 and 1990, and declined by $9 \%$ between 1990 and 2011. Several issues should be noted with respect to this high-level look at this energy intensity for highway travel. First, it should be stressed that these estimates are based upon passenger-miles and not vehicle-miles. Thus, for personal passenger vehicles - automobiles and light trucks--the estimated average occupancy (load factor) for each year has been incorporated into the estimates. As explained in Appendix A, the load factors are derived from periodic surveys by the U.S. Department of Transportation (Nationwide Personal Transportation Survey, NPTS, (through 1995) and the subsequent (for 2001 and 2009) National Highway Transportation Survey). ${ }^{11}$ For light trucks (including van and sport utility vehicles) the estimated load factors used to develop the passenger-mile estimates were 1.9, 1.7, and 1.84 in 1970, 1990, and 2009 respectively (with the 1995 NPTS reporting a low of 1.6 in 1995). Thus, for this segment of personal vehicles, the relatively small change over the entire 1970-2011 period indicates that the percentage changes in energy intensity measured in terms of either Btu per vehicle-mile or Btu per passenger-mile are very similar. However, for automobiles there has been a clear long-term trend toward lower load factors. Again, using the NPTS and NHTS data, the load factors for the three marker years are 1.8, 1.6, and 1.55 for 1970, 1990, and 2010, respectively. This reduction in load factor offsets improvements in vehicle

\footnotetext{
${ }^{11}$ All of the data from the NPTS were taken from various editions of Oak Ridge National Laboratory's Transportation Energy Data Book. Section A.4 provides a detailed discussion.
} 
efficiency (i.e., average miles per gallon for all automobiles) by about $18 \%$ over the 4 -decade study period.

The second issue concerns the shift between automobiles and light trucks. As shown in Table 3.6 the percentage of total passenger-miles from light trucks increased significantly between 1970 and 2011. By 2011, the number of passenger-miles accounted for by light trucks was estimated to be just $20 \%$ lower than that in automobiles. In addition to load factors, this shift has also offset improvements in overall vehicle efficiency, given the lower fuel economy of these trucks (plus vans and sport utility vehicles) compared to all automobiles. (Based upon the data shown in Table 3.6 Btu per passenger-mile was 3,603 in automobiles and 3,760 in light trucks in 2011, a difference that has become smaller over time.)

This second issue has a bearing on the intensity indexes calculated for passenger transportation and other aggregate intensity indexes. As mentioned above, the aggregate intensity of the highway mode shown in Figure 3.15 declined by 9\% between 1990 and 2011. However, the aggregate highway intensity includes the structural shift in travel between automobiles and light trucks during this period (as well as insignificant shifts between passenger vehicles and buses). If this (offsetting) structural shift is removed, the energy intensity index actually falls by an additional $20 \%$, or to about $89 \%$ of its 1990 value. While the time series for the intensity index is not shown here, this index is indeed the metric that is carried forward to measure overall energy intensity in the economy as a whole.

\subsubsection{Overall Transportation}

Figure 3.16 compares the derived energy intensity indexes, with a base year of 1985 , for passenger and freight transportation. As explained in Section 2, the intensity indexes seeks to remove as many of the structural influences as possible - in this case, shifts in activity by mode — with the data at hand.

Clearly, the energy crises and attendant fuel price increases of the 1970s had a greater impact on passenger transportation than on freight transportation. The intensity index for passenger transportation fell by about $20 \%$ between 1970 and 1985 , while the freight index was essentially unchanged (with an actually rise in the first few years of the 1980s). In the quarter-century after 1985 , those relative trends have continued--with about a $20 \%$ further reduction in the passenger energy intensity, and about half of that reduction in freight transportation. The graphics in Figure 3.16 also suggest that the recessionary economic conditions since 2008 have slowed further reductions in energy intensity in both transportation segments. 


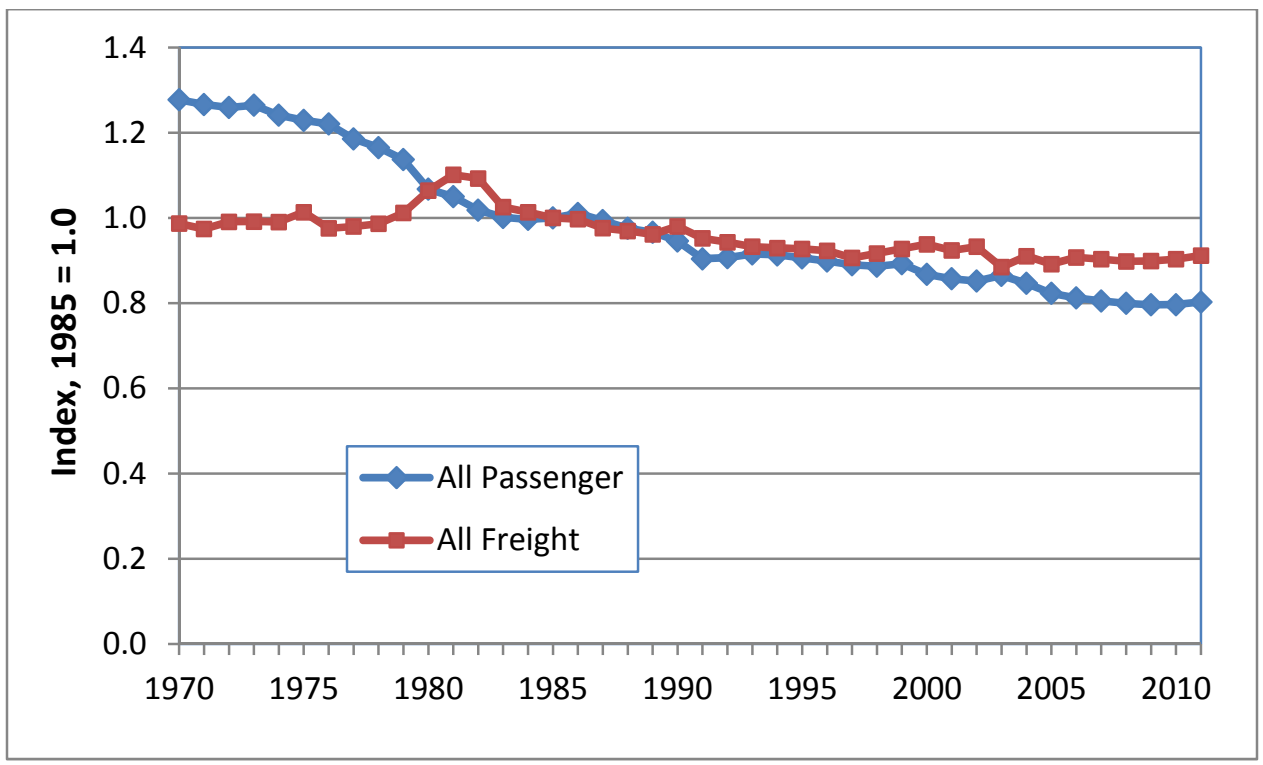

Figure 3.16. Energy intensity indexes for total freight and total passenger transportation segments, 1970-2011

Figure 3.17 presents the most aggregate indicators for transportation as a whole. The top two indexes show the magnitude of overall transportation activity and energy use relative to 1985 . From 1985 to 2011, transportation activity increased about 57\% and energy use about 39\%.

Both the activity and energy intensity indexes are developed as energy-weighted averages of the respective separate indexes for passenger and freight segments, with the weights changing over time according to the LMDI methodology. The energy intensity index for all of transportation was computed to be 0.833 in 2011 , a value closer to the passenger index than the freight index because of the relatively higher amount of energy used for passenger travel (about $70 \%$ of total transportation energy use in 2011).

The index labeled as "modal shifts," is a sum of these impacts from the passenger and freight modes. (There is no additional structural shift from changes in the ratio of passenger to freight activity because the measures of activity are not the same.) The modal shifts index increased by about $6 \%$ between 1985 and 2011, primarily as result of influence from the highway segment of both passenger (shifts from automobiles to light trucks) and freight transportation (increasing share of freight transported by trucks.) The index reflects the additional amount of energy, compared to 1985, that is used in transportation from the combined effects of these shifts. 


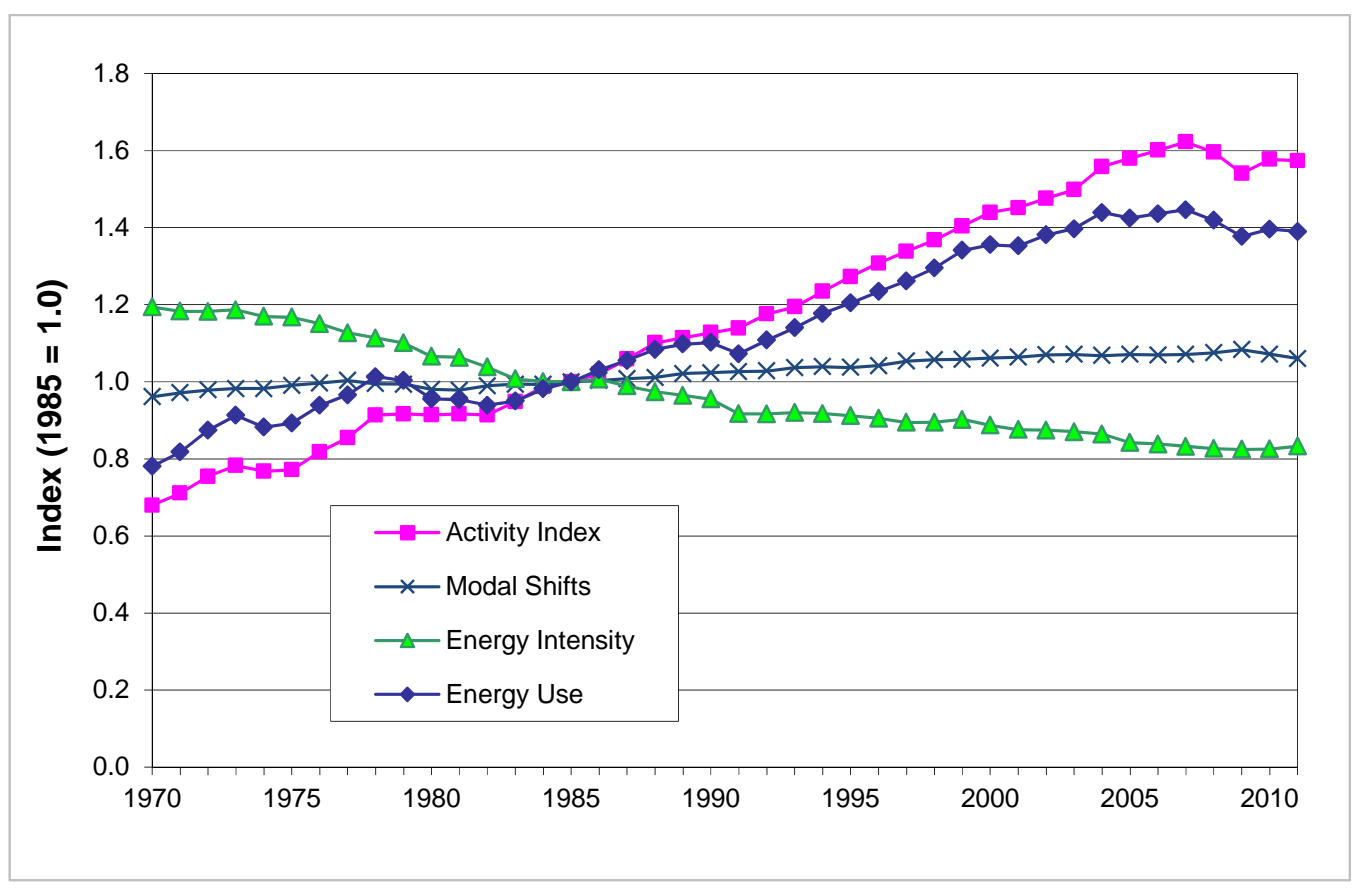

Figure 3.17. Overall indexes for the U.S. transportation sector, 1970-2011

\subsection{Electric Power Sector}

The generation of electricity in the U.S. differs from the other sectors considered above, in that it transforms energy from a variety of fuels and technologies into electricity rather than being an ultimate end use. However, a comprehensive picture of U.S. energy consumption must encompass an overall measure of energy at the primary (or source) level, including fossil fuels, nuclear-generated electricity, and renewable energy. The energy required (or "lost") for generation and transmission of electricity involves approximately $40 \%$ of the nation's total energy consumption. Thus, any change in the efficiency in which electricity is generated and distributed has an important influence on a measure of aggregate energy intensity of the economy.

The DOE Energy Information Administration, using its own surveys and those of other regulatory agencies, maintains a comprehensive data system related to the generation of electricity. EIA distinguishes three major sectors that generated electricity: the electric power 
sector, the commercial sector, and the industrial sector. The electric power sector is defined as those plants owned by firms whose primary business is selling electricity or heat (thermal energy) to the public. EIA also collects information from commercial and industrial establishments where electricity or electricity and heat are produced. Because the fuel inputs used by these two sectors for electricity and heat are already included in those sectors' overall energy consumption, the energy intensity of such electricity generation is not included in the overall system of energy intensity indicators.

In any system seeking to measure the energy intensity of electricity generation, one must address the issue of how to measure the intensity for renewable generation technologies such as solar thermal, photovoltaic, and wind. As explained in Appendix A, for purposes of measuring the energy input for sources other than fossil fuels or biofuels (wood and waste), EIA has adopted thermal conversion factors based upon the annual average heat rate factor for fossil-fueled power plants in the U.S. As discussed in the Annual Energy Review 2011, EIA states that "By using that factor, it is possible to evaluate fossil fuel requirements for replacing those sources during periods of interruption such as droughts." (EIA 2012a).

In 2002, EIA completely revamped its classification of types of power plants within the electric power, commercial, and industrial sectors. Using data from previous surveys and imputation methods, it began to publish separate estimates of electricity generation and fuel inputs for what it termed "electricity-only" plants versus combined heat and power (CHP) plants. The estimates were developed starting in 1989.

In the EERE system of energy intensity indicators, a variety of indicators have been developed for both electricity-only and CHP plants, with further distinction made between fossil fuels and renewables. For the high-level summary here, two distinguishing trends in the electric power sector should be noted: 1) the magnitude and energy intensity of CHP plants, and 2) energy intensities related to fossil-fuel power plants in the electricity-only portion of the sector. Table 3.7 indicates that CHP plants currently account for about $4 \%$ of overall electricity generation in the electric power sector. The absolute magnitude has doubled over the past 20 years, but has remained relatively constant in the past decade. The lower portion of the table suggests that CHP plants in general have lower energy intensities with regard to electricity than do electricityonly plants - the percentage of total energy input for CHP is lower than its percentage of electricity generation. 
Table 3.7. Electricity generation and energy consumption in electricity-only and CHP plants, electric power sector

\begin{tabular}{|c|c|c|c|c|c|c|}
\hline & \multicolumn{2}{|c|}{1990} & \multicolumn{2}{|c|}{2000} & \multicolumn{2}{|c|}{2011} \\
\hline & $(\mathrm{TWh})$ & $(\%)$ & (TWh) & $(\%)$ & (TWh) & $(\%)$ \\
\hline Electricity-Only Plants & 2,844 & $97.9 \%$ & 3,478 & $95.5 \%$ & 3,792 & $96.0 \%$ \\
\hline CHP Plants & 61 & $2.1 \%$ & 165 & $4.5 \%$ & 156 & $4.0 \%$ \\
\hline Total & 2,905 & & 3,643 & & 3,948 & \\
\hline
\end{tabular}

\begin{tabular}{|c|c|c|c|c|c|c|}
\hline \multirow{2}{*}{$\operatorname{rgy} U$} & \multicolumn{2}{|c|}{1990} & \multicolumn{2}{|c|}{2000} & \multicolumn{2}{|c|}{2011} \\
\hline & (TBtu) & $(\%)$ & (TBtu) & (\%) & (TBtu) & $(\%)$ \\
\hline Electricity-Only Plants & 29,779 & $98.1 \%$ & 36,287 & $96.3 \%$ & 37,574 & $96.9 \%$ \\
\hline CHP Plants & 574 & $1.9 \%$ & 1,408 & $3.7 \%$ & 1,212 & $3.1 \%$ \\
\hline Total & 30,353 & & 37,695 & & 38,787 & \\
\hline
\end{tabular}

Source: EIA 2012a, Chapter 8 and unpublished data provided by EIA. (See Appendix A, Section A.5)

Figure 3.18 shows the calculated historical energy intensities, in terms of Btu per $\mathrm{kWh}$, for the electricity-only and CHP plants in the electric power sectors. ${ }^{12}$ Given that electricity-only plants account for over $95 \%$ of electricity generation, the intensity trends in that segment of the electric power sector are much more important from the standpoint of overall energy efficiency in the U.S. Three distinct time periods are clearly delineated in the graph of intensities: 1) a rapid decline in intensities from 1950 through 1960,2) a period of nearly constant intensities between 1960 and 2000, and 3) a slow but steady decline of intensities in subsequent years. As will be dramatically shown below, the most recent downward trend is exclusively attributable to generation of electricity from combined-cycle natural gas plants.

The lower graph in Figure 3.18 shows the evolution of intensities for CHP plants. Given EIA's imputation methodologies (as briefly described in Appendix A), the absolute intensities for electricity from CHP plants are lower than those in electricity-only plants. The discontinuity in 2004 is caused by a change in the method used by EIA to apportion energy consumption attributable to heat production as compared to electricity generation. Because the energy consumption from CHP plants represents such a small percentage of the electric power sector, no effort was made to adjust the later data for the discontinuity first observed in 2004.

\footnotetext{
${ }^{12}$ The electricity data for 2012, developed by EIA and released in November 2013 are expected to be close to final values; accordingly Figure 3.18 plots intensities through 2012.
} 


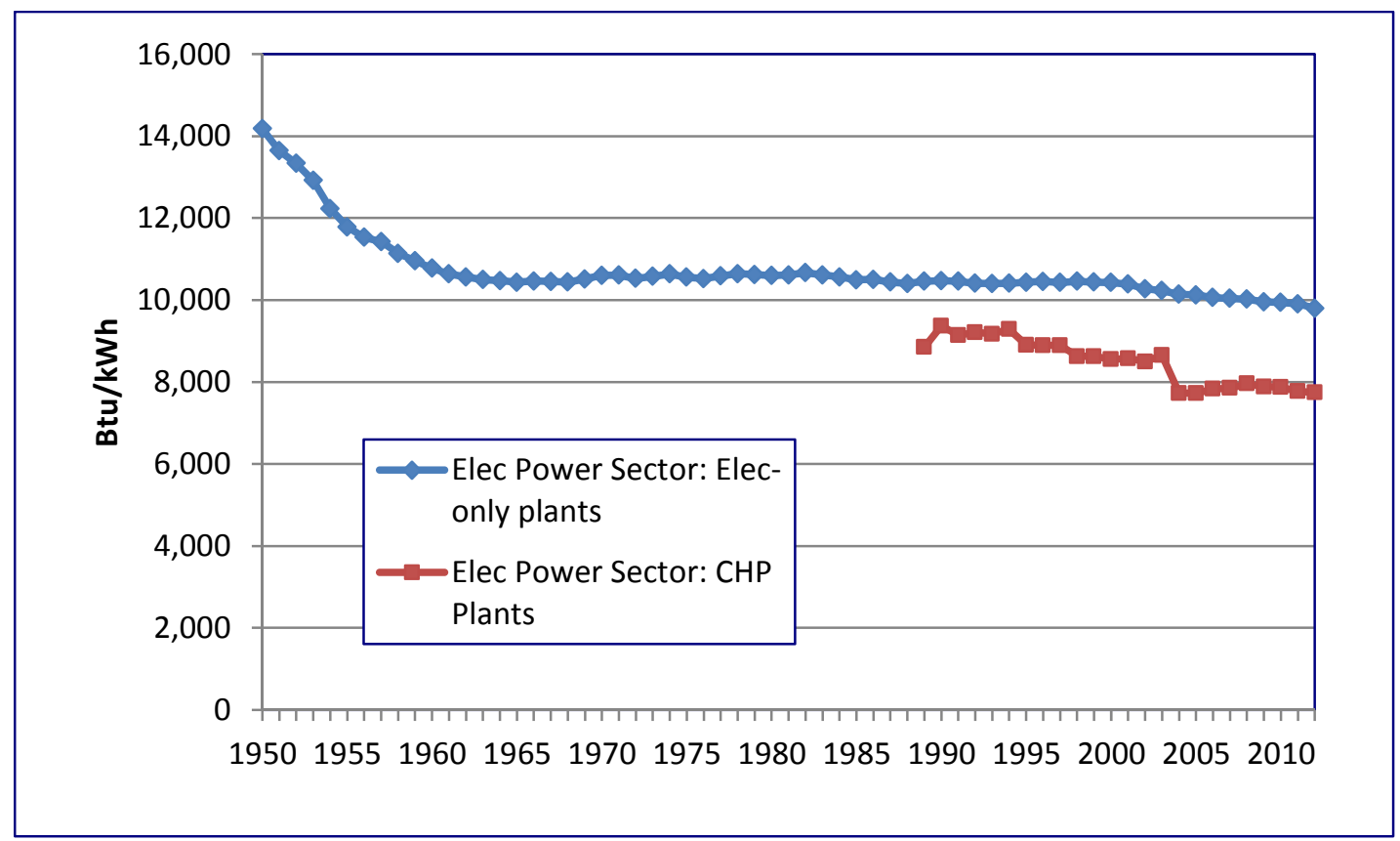

Figure 3.18. Energy intensities (Btu/kWh) in electricity-only and CHP plants, 1950-2012

Table 3.8 shows the generation and energy input for the major generation types in the electricityonly plants. Total generation increased by a factor of two and one-half between 1970 and 2011, because of some significant changes in the composition of generation technologies. Fossilfueled and hydroelectric plants accounted for over $98 \%$ of electricity production in 1970 . By 2011 , that percentage had fallen to $75 \%$. Most of that generation mix was made up by nuclear plants, which contributed $15 \%$ of all generation in 1985 and just over $20 \%$ in 2011 . While still small, the role of renewables in overall electricity generation has been increasing rapidly in recent years, and now accounts for slightly more than $4 \%$ of all generation. ${ }^{13}$

The bottom portion of the table shows the magnitude and composition of fuel use by generation type. In general, the percentage breakdown of energy use by generation (technology) type is very similar to that of the generation itself. This feature stems primarily from the conventions used by EIA to impute fuel use for hydroelectric power and renewables (discussed above and in Appendix A). ${ }^{14}$

Because of the continuing importance of fossil-fuel electricity generation, a picture of the longterm changes in the intensity by fuel type is striking. Figure 3.19 shows the computed energy intensities for three major fossil fuels used to generate electricity in electricity-only plants. ${ }^{15}$

\footnotetext{
${ }^{13}$ In 2010, electricity generation from wind accounted for about three-quarters of all renewable electricity production.

${ }_{15}^{14}$ Appendix A also discusses EIA's method of measuring energy input for nuclear plants.

${ }^{15}$ See footnote 9 for treatment of 2012 values.
} 
Obviously, the intensity for plants using natural gas has shown a dramatic decline in the past decade, primarily because of the penetration of combined-cycle technology. Across all plants using natural gas, the intensity has declined from about 10,500 Btu/kWh in 2000 to just over $8,000 \mathrm{Btu} / \mathrm{kWh}$ in 2011. This development accounts for all the change in the overall intensity decline shown in the top graph in Figure 3.18.

Table 3.8. Electricity generation and energy consumption in electricity-only fossil-fuel plants

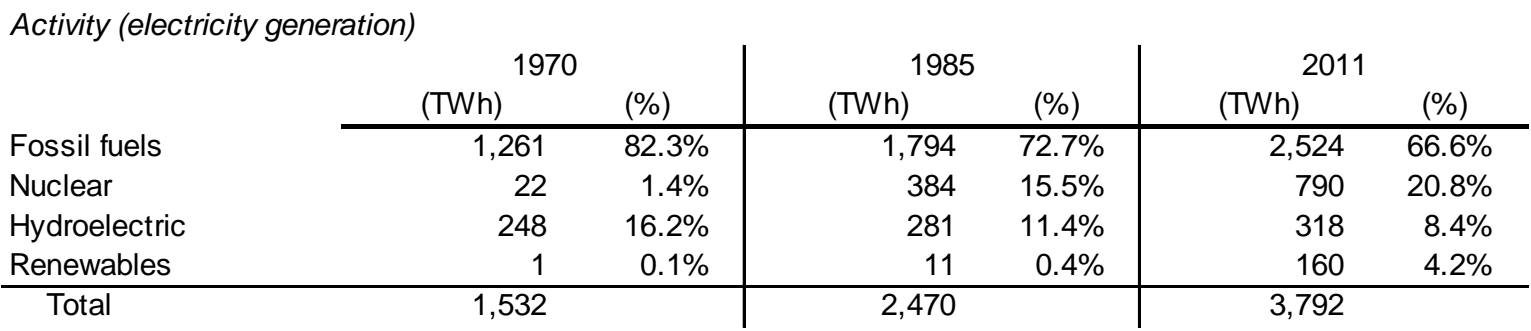

\begin{tabular}{|c|c|c|c|c|c|c|}
\hline \multirow{2}{*}{ ergy Use } & \multicolumn{2}{|c|}{1970} & \multicolumn{2}{|c|}{1985} & \multicolumn{2}{|c|}{2011} \\
\hline & (TBtu) & $(\%)$ & (TBtu) & (\%) & (TBtu) & $(\%)$ \\
\hline Fossil fuels & 13,399 & $82.5 \%$ & 18,792 & $72.5 \%$ & 24,521 & $65.3 \%$ \\
\hline Nuclear & 239 & $1.5 \%$ & 4,076 & $15.7 \%$ & 8,270 & $22.0 \%$ \\
\hline Hydroelectric & 2,600 & $16.0 \%$ & 2,937 & $11.3 \%$ & 3,085 & $8.2 \%$ \\
\hline Renewables & 9 & $0.1 \%$ & 112 & $0.4 \%$ & 1,698 & $4.5 \%$ \\
\hline Total & 16,247 & & 25,917 & & 37,574 & \\
\hline
\end{tabular}

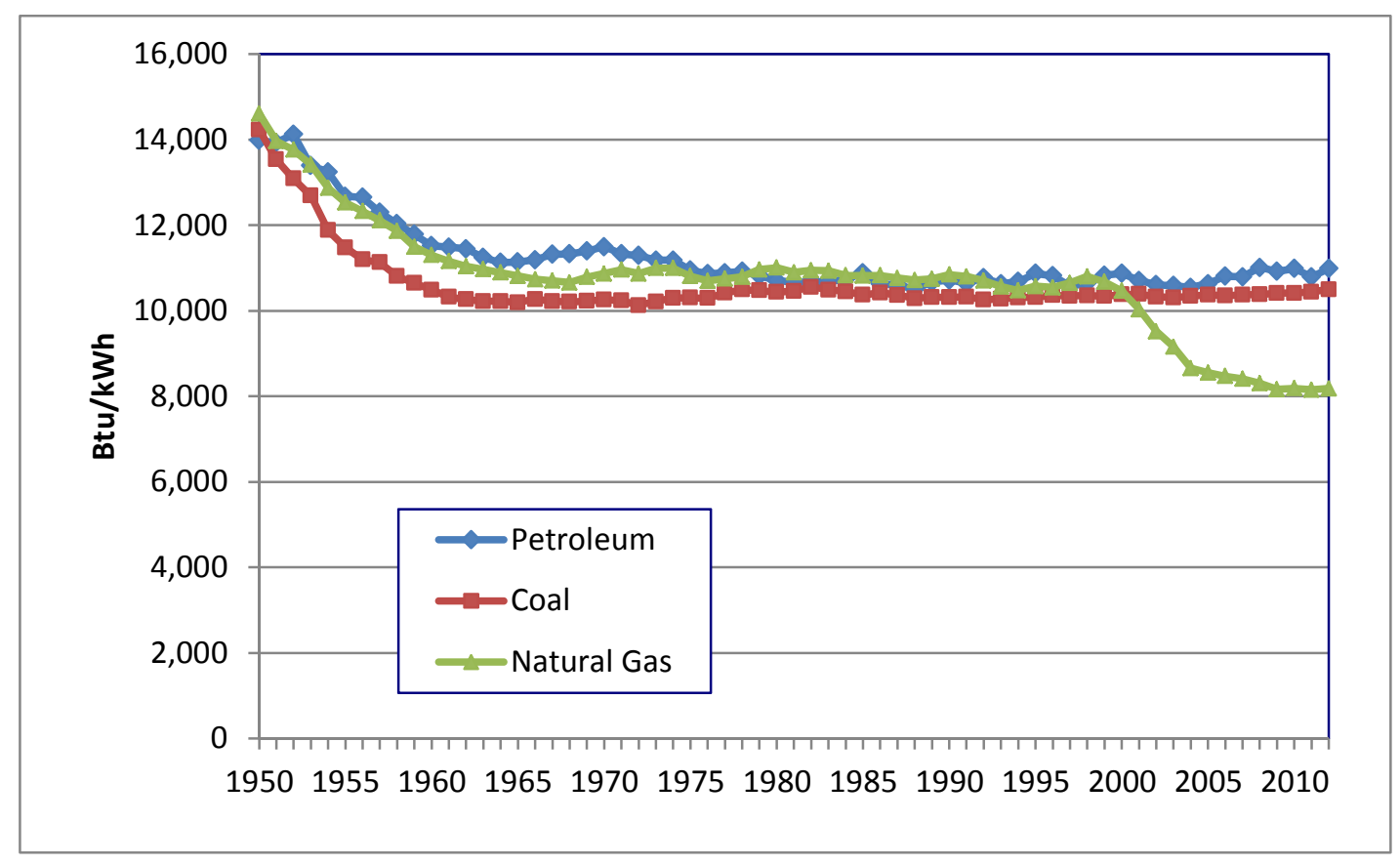

Figure 3.19. Energy intensities (Btu/kWh) in electricity-only fossil-fuel plants, 1970-2012 


\subsection{Economy-wide Indexes of Energy Intensity}

An energy intensity index for the entire U.S. economy is constructed as a weighted average of the (adjusted) source energy indexes for the four major end-use sectors. The LDMI approach facilitates this construction. Even though the measures of activity vary by sector, an aggregate index can be developed by using the shares of energy use to weight the component indexes. In this sense, the economy-wide energy intensity index is similar to the Department of Labor's total consumer or wholesale price indexes.

A natural comparison is suggested between the intensity index constructed in this bottom-up fashion to an index based upon the energy-GDP ratio. Figure 4.1 shows this comparison, with 1985 once again selected as the base year of the index. Because total energy and GDP data are available back to 1950 , the energy-GDP index begins in that year. ${ }^{1}$

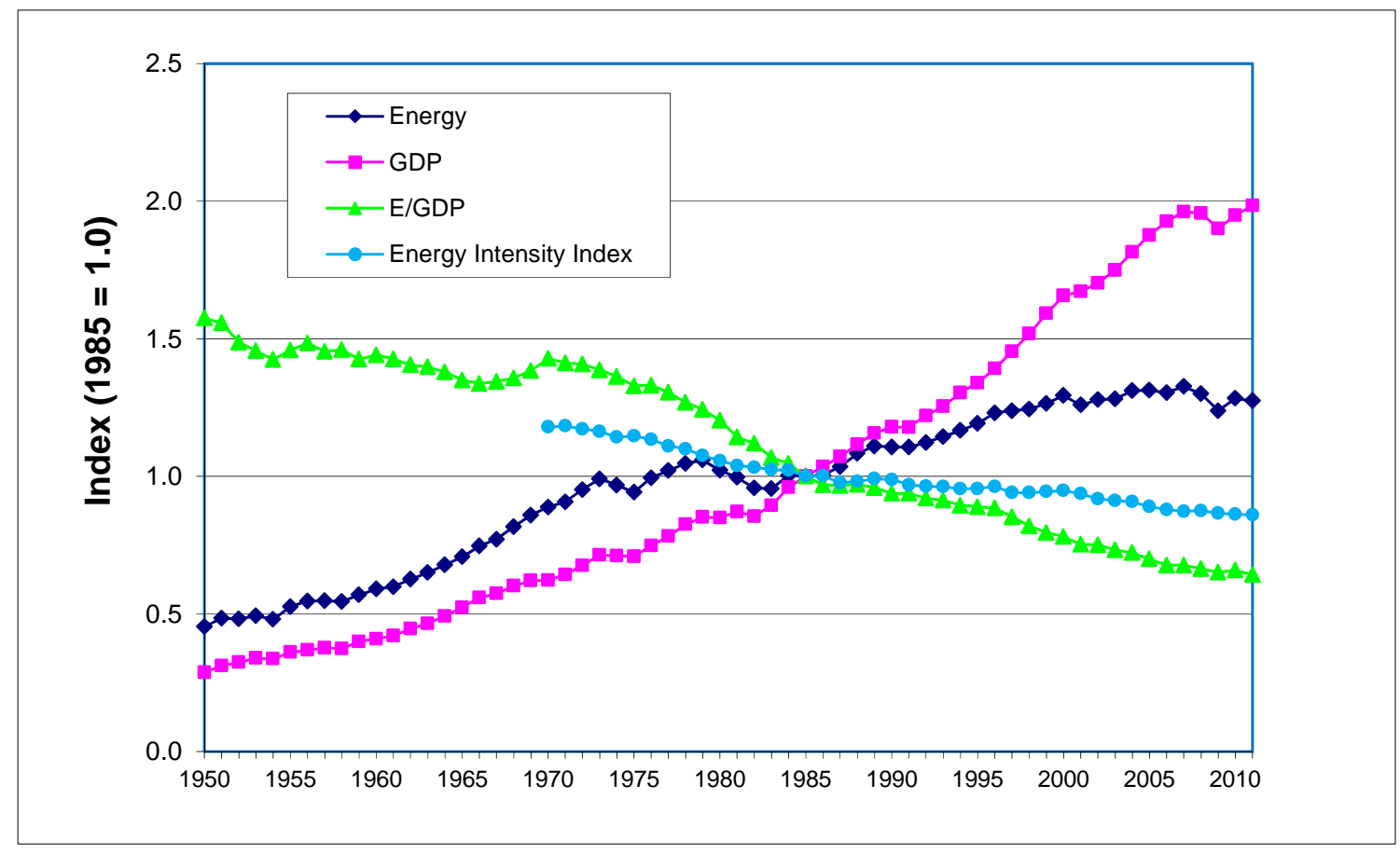

Figure 4.1. Economy-wide indexes of energy intensity, economic activity, and energy use

\footnotetext{
${ }^{1}$ The energy data from the EIA's Annual Energy Review actually begin in 1949.
} 
The economy intensity index clearly shows a smaller long-run trend reduction than the energyGDP index. In the past quarter-century (1985-2011), the economy-wide energy intensity index fell about $14 \%$, while the energy-GDP index fell by more than double that amount approximately $36 \%$.

As was argued at the outset of the report, the energy-GDP ratio suffers from number of limitations. While the amount of energy used in the numerator of this ratio is similar to that used across the intensity indicators developed here, the measure of activity is decidedly different. Moreover, the GDP is influenced by a variety of structural factors that will affect energy consumption independent of underlying changes in energy efficiency.

A key example of the effect of structural factors is in the industrial sector. In the development of intensity metrics at the end-use sector level, aggregate activity in the industrial sector is represented by the GDP attributable to industrial sector output. Thus, this intensity measure has basic similarity to the energy-GDP ratio, but where GDP represents only the industrial segment of the economy. The results described in Section 3.4 above indicate that the index of aggregate energy intensity in the industrial sector fell by approximately $23 \%$ from 1985 to 2011 . However, the component-based, bottom-up energy intensity index declined just slightly more than one-half of that amount, or about $13 \%$. In manufacturing, the shift toward less energy-intensive industries, as well as structural changes within industries (e.g., GDP, or real value added, increases relative to the gross output measures upon which energy intensities are calculated) both contribute to the lower energy use and are reflected in larger changes in the index of aggregate energy intensity.

Outside the industrial sector, there is only limited correspondence between the activity measures used in the intensity indexes in this report and elements of GDP. The transportation sectors do have the potential to be measured along the lines of the industrial sector. On the production side of GDP accounts, there are GDP (real value added) data for rail, airline, and water transportation sectors. However, there is only a rough correspondence between GDP (as some measure of labor and capital inputs measured in real terms) and energy use. Given the availability of data (at least for rail and air), it is much more natural to measure energy intensity in terms of energy per passenger-mile or per ton-mile of freight. Activity in commercial (for-hire) trucking is also measured in the GDP accounts, but given the use of trucks for hauling freight by many other sectors (including manufacturing, wholesale trade, and agriculture), there is no way to reliably link the economic activity in the trucking sector, narrowly defined as commercial trucking, and total energy use. ${ }^{2}$

\footnotetext{
${ }^{2}$ This discussion suggests that the periodic input-output tables might contain the appropriate information to develop energy intensity indexes. Thus, for example, the commercial trucking sector is represented by a column in the tables, whose entries indicate the values of purchased inputs. Among such entries would be the estimate of expenditure for fuels in the year of the table. Unfortunately, the issues associated with any effort to infer energy quantities from the estimated expenditures data, as well as the infrequency of the published tables, prevent this source from being a reliable means of generating energy intensity metrics.
} 
GDP data for the services sector, broadly defined to cover all sectors outside transportation and industry, might also be considered as an activity measure for an intensity indicator. Such an indicator would increase the correspondence between overall energy-GDP ratio and the economy-wide measure. Such data are readily available from the same sources as the industrial GDP data used in the present system of indicators. Clearly, GDP originating in the service sector has likely increased relative to floor area in that sector. However, much of the increase in output can be linked to the increased use of computers, the internet, and other electronic equipment. As a question for an energy analyst, should the decrease in energy intensity based on such activity measures be considered as a true measure of greater energy efficiency? Roughly half of the energy use in this sector continues to be space conditioning, ventilation, and lighting in buildings. Thus, the more robust measure of energy efficiency would still seem to be better represented by an intensity based upon floor area.

Finally, perhaps the largest limitation related to the use of GDP as a measure of output for an aggregate energy intensity index relates to the residential sector. In conventional national income accounting, household production of energy services is not included in GDP as measured on the production side of the national accounts. Personal consumption expenditures include electricity and fuels for both home and vehicle use, but there is no corresponding measure of activity anywhere in the accounts. Thus, while household energy use is included in the numerator of the energy-GDP ratio, GDP in the denominator contains only traces of influence from the household activity (an unmeasurable fraction of GDP from the energy supply sectors caused by household energy consumption).

Given these considerations, the contention of this report is that the economy-wide intensity index provides a more robust indicator of national energy efficiency than an index based on the energyGDP ratio. While there is always ambiguity about the most appropriate measures of activity (and energy) for particular sectors of the economy, it seems on balance that combining these metrics across various sectors provides a reasonable measure of energy intensity change for the nation as a whole. Just as the consumer price index and wholesale price index are subject to a myriad of assumptions about data sources and methods, they are still regarded as providing valuable guidance to the public and to policymakers about broad trends related to prices in the economy. The development of the economy-wide intensity index in the system described here has the same general intent.

Figure 4.2 breaks out the economy-wide energy intensity index (as shown in Figure 4.1) into two components: 1) an index associated energy-efficiency actions attributable to the end-use sectors, and 2) an index associated with improvements in the efficiency of the electric power sector. This decomposition of source energy was previously discussed in Section 2.6. 


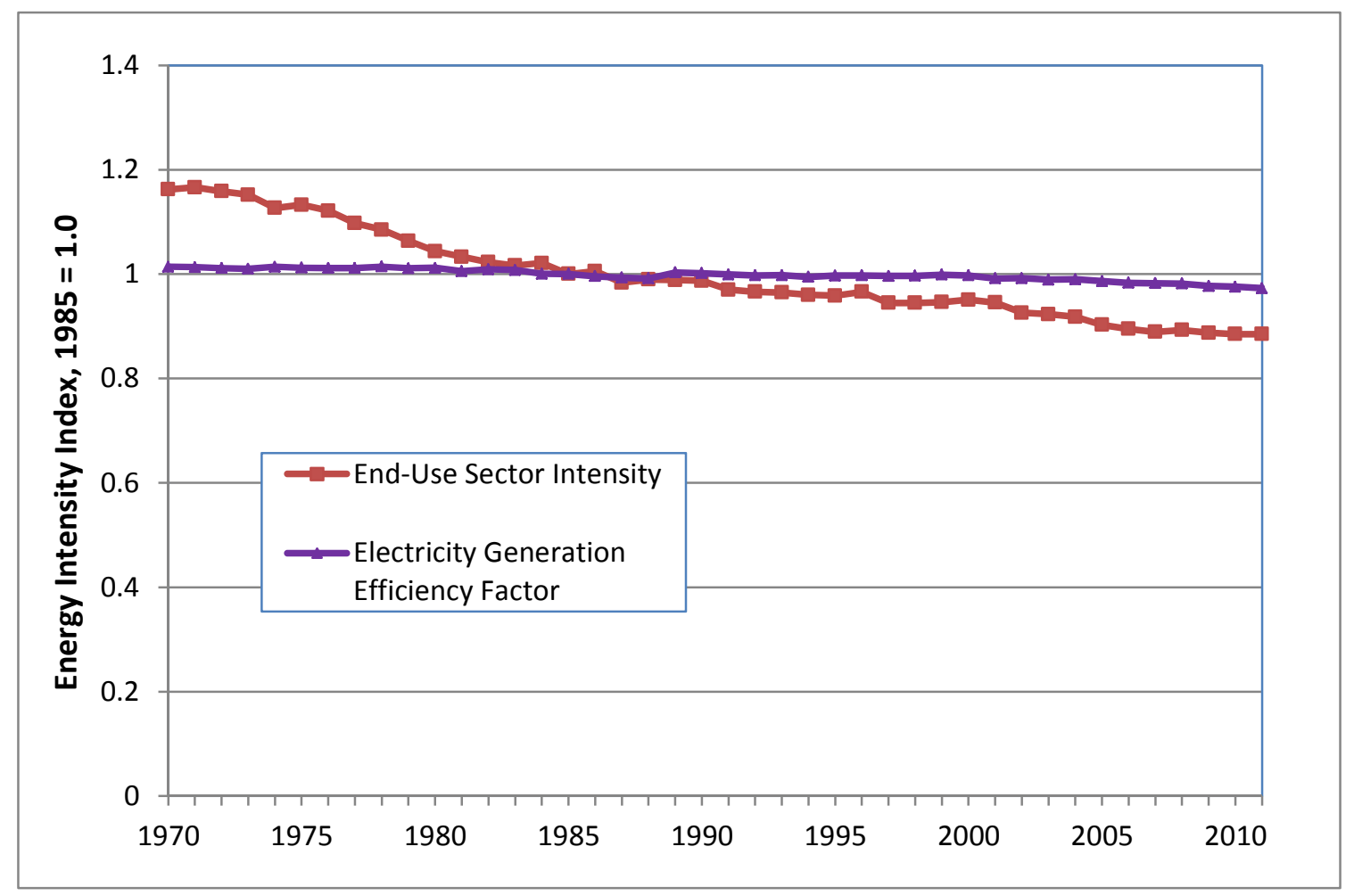

Figure 4.2. Decomposition of end-use sector and electric power sector contributions to U.S. energy intensity change

Over the entire U.S. economy, the flatter line in the figure shows that increases in electricity generation efficiency contributed to about a 1\% decline in overall energy intensity between 1970 and 1985, and an additional $2.7 \%$ reduction in the years since 1985 . The most recent changes are primarily related to the use of more efficient combined-cycle natural gas plants, as explained in Section 3.5.

The steeper line in the graphic shows the source intensity index associated with end users of energy, excluding changes in electricity generation efficiency. In 2011, the value of the index was about $12 \%$ lower than in 1985 .

The total change in the energy intensity index between 1985 and 2011 was a decline of about $14 \%$-- implied by the value of the index $(2011=0.861)$ shown in Figure 4.1. Of that change, about $5 / 6$ of the change was caused by efficiency actions taken by end users of energy and about $1 / 6$ of the change coming from the improved electricity generation efficiency in the electric power sector. Because electricity now plays such an important role in the nation's use of energy, changes in generation efficiency now have a magnified impact on overall energy intensity trends in the U.S. 


\subsection{Summary and Suggestions for Future Improvement}

The system of energy intensity indicators developed for DOE's Office of Energy Efficiency and Renewable Energy provides a comprehensive picture of the nation's progress toward greater energy efficiency. The system seeks to provide annual measures of energy intensity for detailed sectors, which are then combined to generate intensity indexes for more aggregate sectors. At the top of the indicators hierarchy is an index for the entire U.S. economy. The economy-wide index of energy intensity provides a single measure that can be used to monitor the impacts of energy-efficiency improvements throughout the economy.

This system was prompted by response to the May 2001 National Energy Policy that directed DOE to support the improvement of energy efficiency as a national priority for the U.S. Energyefficiency improvement continues to be an important element in addressing public policy concerns relative to energy security and climate change. EERE's system of indicators is intended to provide metrics that show the most recent changes in energy intensity, as well as sector detail that can assist in the broad development of energy policy.

\subsection{Key Methodological Elements}

The system of energy intensity indicators recognizes major implications of distinguishing energy consumption by end users either in the form of direct (fossil) fuel consumption or in the form of electricity. Energy intensity indexes are constructed separately for both forms of energy consumption. Separate estimates for fuels and electricity consumption permit more aggregate analyses to be conducted with either one of two commonly used definitions of total energy: 1) delivered, the sum of fuels and electricity use, and 2) source (or primary), where electricity losses from electricity generation and transmission are assigned to the end user and added to delivered energy. With regard to source energy intensity, the EERE system takes into account improvements in the electricity generation efficiency that have occurred over time. The source energy from which these improvements have been removed has been termed (for convenience) "adjusted" source energy.

The interpretation of energy intensity indexes as indicators of changes in energy efficiency in large part depend upon the choice of activity for each sector. In general, the preferred procedure is to use physical-based measures of activity, such as floor area in buildings, passenger-miles of travel, and ton-miles of freight. For the industrial sector, the current approach is to use gross output in real dollars as the measure of activity because measures of physical output are not available across the entire sector. Perhaps the most vexing issue concerns the appropriate choice of activity for the residential sector. For the indicators system here, the preferred metric is total floor area of occupied housing units because that measure best correlates to space conditioning energy use and is consistent with the approach for the commercial sector. However, alternative choices are the number of occupied housing units and population. 
To the extent that the availability of data permits, the system of intensity indicators includes as much detail at the lowest level of the indicators hierarchy as possible. The most detail is included in the industrial and transportation sectors. In manufacturing portion of the industrial sector, energy intensity measures are available for 18 individual industries. At the lowest level of the transportation hierarchy, the system includes energy intensity indexes for 12 segments of passenger transportation and 6 segments of freight transportation. The least disaggregation is available in the residential and commercial buildings sectors. The residential sector includes separate indexes for census regions because data for the number of occupied housing units and residential housing floor space can be estimated at that level. Similar estimates (floor space) for the commercial sector have not been yet developed by region, so a single national intensity index has been constructed for this sector.

The EERE system uses a rigorous mathematical methodology to distinguish those changes in energy use that can be attributed to energy efficiency (or intensity) from those that result from structural factors. Structural factors include those changings aspects of the economy that are not (or only indirectly) related to improvements in energy efficiency. Classic among previous studies of energy use in manufacturing in the U.S. and other countries has been the consideration of changes in the composition of industrial output and its effect on energy intensity measures based upon aggregate data. That is, a major structural factor behind reductions in aggregate energy intensity in manufacturing in many developed countries has been the relative decline of energy-intensive industries (e.g., primary metals, chemicals, and paper). The EERE system uses the log mean Divisia index (LMDI) method to decompose changes in energy use (and energy intensities) for aggregate sectors into separate indexes for energy intensity and other indexes that represent various types of structural factors.

\subsection{Summary of Energy Intensity Changes, 1970-2011}

As reflected in Figure 4.1, the U.S. economy has made steady improvement in lowering overall energy intensity over the past four decades. The EERE index of overall U.S. energy intensity declined $27 \%$ over the period 1970-2011, an average annual percentage decline of $0.8 \%$. By contrast, the energy-GDP ratio declined slightly more than $50 \%$ over the same period, or about $1.9 \%$ per year. This report has argued that there are serious limitations to the use of energy-GDP ratio as a means of measuring energy efficiency improvement on a national scale. While the amount of energy used in the numerator of this ratio is similar to that used across the intensity indicators developed in this report, the measure of activity is, for the most part, decidedly different. Moreover, the GDP is influenced by a variety of structural factors that will affect energy consumption independent of underlying changes in energy efficiency.

Using the definition of "adjusted" source energy, Figure 5.1 shows history of the intensity indexes for the four major end-use sectors. The figure suggests that the overall pattern and declines have been reasonably comparable across the sectors, with the notable exception of the 
commercial sector. Up through the beginning of the last decade, (adjusted) source energy intensity actually increased in the commercial sector. That trend has been reversed over the past decade, with the 2011 intensity estimated to be about $6 \%$ lower than its value in 2000 .

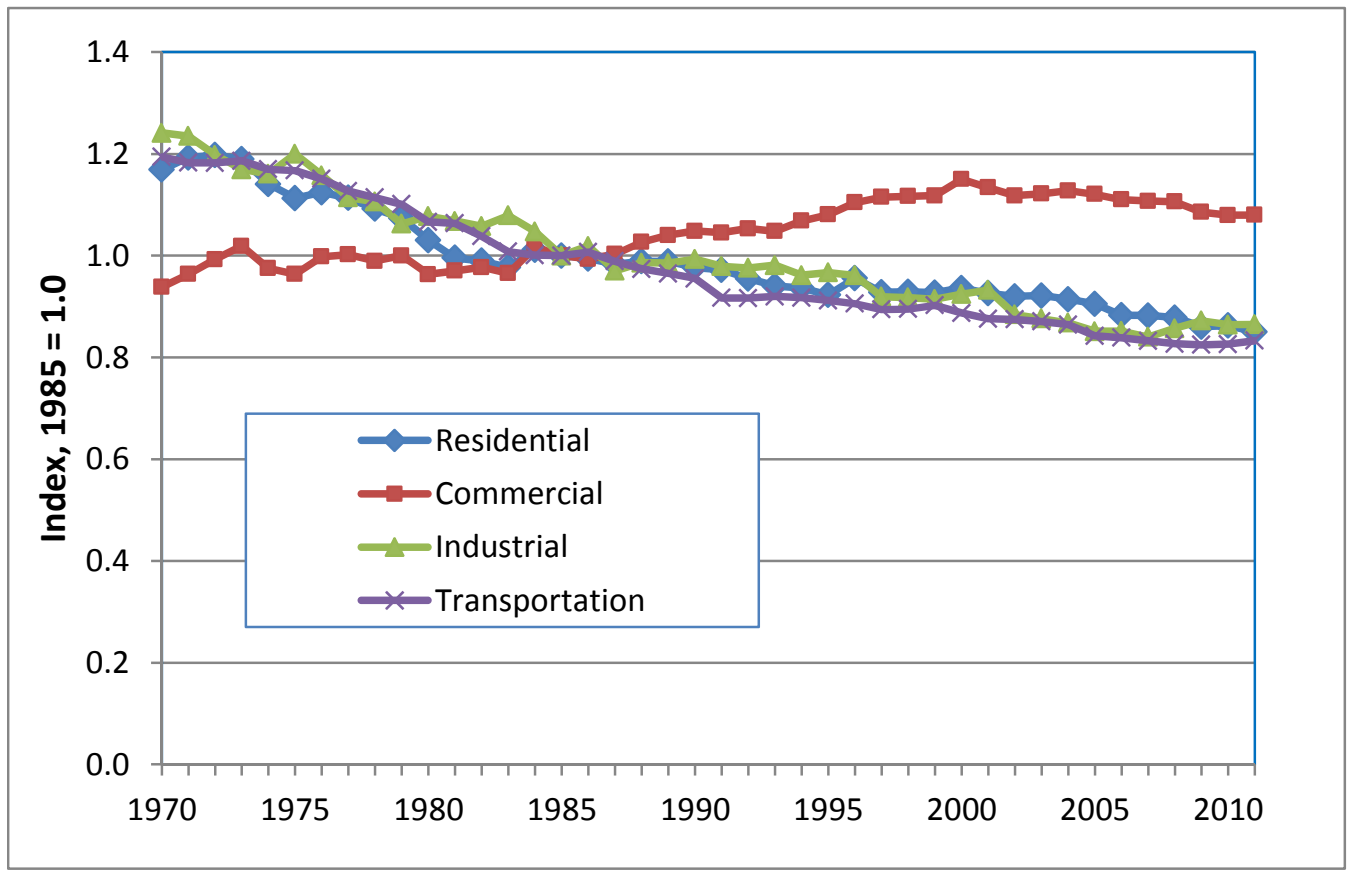

Figure 5.1. Source energy intensity indexes by major end-use sector, 1970-2011, (adjusted for improvements in electricity generation and transmission efficiency)

It is illuminating to explore the changes in energy intensity by sector across sub-periods. In Table 5.1, the entire period has been divided in three sub-periods: 1970-1985, 1985-2000, and 2000-2011. Because the time periods are of unequal length, the values in the table are normalized to show annual percentage changes (between the initial and terminal years of each sub-period).

The top line in each panel shows the annual percentage changes in delivered energy intensity. For the electricity sector, the intensity has been measured in terms of total energy consumption divided by total electricity generation. In the initial 1970-1985 period, the average declines were largest in the residential and industrial sectors, $2 \%$ per year. The economy-wide index is based upon a (Divisia index) weighted average across all five sectors. (The energy "weight" for the electric utility sector in making up this index is based upon the generation and transmission losses.) Over this initial 15 -year period, the index fell about $1.4 \%$ per year. 
Table 5. 1. Annual percentage changes in energy intensity indexes over three sub-periods

\begin{tabular}{|c|c|c|c|c|c|c|}
\hline & Residential & Commercial & Industrial & Transportation & $\begin{array}{l}\text { Electric } \\
\text { Utilities }\end{array}$ & $\begin{array}{c}\text { Economy } \\
\text { wide }\end{array}$ \\
\hline \multicolumn{7}{|l|}{$1970-1985$} \\
\hline Delivered & $-2.2 \%$ & $-1.1 \%$ & $-2.0 \%$ & $-1.2 \%$ & \multirow[t]{3}{*}{$-0.4 \%$} & $-1.4 \%$ \\
\hline Source & $-1.2 \%$ & $0.3 \%$ & $-1.5 \%$ & $-1.2 \%$ & & $-1.1 \%$ \\
\hline Adj. Source & $-1.0 \%$ & $0.4 \%$ & $-1.4 \%$ & $-1.2 \%$ & & \\
\hline \multicolumn{7}{|l|}{$1985-2000$} \\
\hline Delivered & $-0.6 \%$ & $0.2 \%$ & $-0.3 \%$ & $-0.5 \%$ & \multirow[t]{3}{*}{$0.0 \%$} & $-0.3 \%$ \\
\hline Source & $-0.3 \%$ & $0.5 \%$ & $-0.3 \%$ & $-0.5 \%$ & & $-0.2 \%$ \\
\hline Adj. Source & $-0.3 \%$ & $0.6 \%$ & $-0.3 \%$ & $-0.5 \%$ & & \\
\hline \multicolumn{7}{|l|}{$2000-2011$} \\
\hline Delivered & $-1.4 \%$ & $-1.0 \%$ & $-1.1 \%$ & $-0.6 \%$ & \multirow[t]{3}{*}{$-0.8 \%$} & $-0.9 \%$ \\
\hline Source & $-1.2 \%$ & $-1.0 \%$ & $-0.8 \%$ & $-0.6 \%$ & & $-0.9 \%$ \\
\hline Adj. Source & $-0.9 \%$ & $-0.6 \%$ & $-0.6 \%$ & $-0.6 \%$ & & \\
\hline
\end{tabular}

The second two lines report the average declines in the intensity indexes based upon a source energy definition, with and without including efficiency changes in the electric utility sector. The largest differences are in the buildings sectors, where there was a substantial increase in electricity use compared to direct fuel consumption. In the first sub-period with regard to these sectors, the use of source energy offsets the decline in delivered energy by between $1.0 \%$ and $1.4 \%$ per year. This offset yields an actual increase in source energy intensity in the commercial sector over this period. When increases in the efficiency of the electric power sector are also removed, as reflected in the "adjusted source" values, the average intensity change is further reduced in the residential sector (from $-1.2 \% / \mathrm{yr}$ to $-1.0 \% / \mathrm{yr}$ ) and increased by similar percentage $(\sim 0.1 \% / \mathrm{yr})$ in the commercial sector.

The bottom two panels show similar metrics for the 1985-2000 and 2000-2011 periods. The most notable aspect of examining the comparable cells in these panels to those from the 19701985 period is that the average rates of decline were dramatically smaller in the 1985-2000 period, but then generally fell by a larger and more consistent degree over the last decade (i.e., 2000-2011) sub-period. The most significant examples of this pattern were in the industrial and commercial sectors. Using the results for delivered energy intensities, the average annual percentage decline in the industrial sector slowed from $2.0 \%$ per year over the $1970-1985$ period to just $0.3 \%$ per year (decline) in the next 15 years. In the most recent decade, the rate of decline increased to about one-half of its downward trend during the 1970-1985 period (i.e., 1.1\%/year). A somewhat similar pattern is observed in commercial sector; but in this case, the recent rate of decline in delivered energy intensity is near what was during the first sub-period (approximately $1 \%$ per year). The same general pattern was observed in the residential sector, but with a somewhat smaller relative decline in the middle time period. The transportation sector, as well, 
showed the greatest rate of decline in the 1970-1985 period, and the average annual reductions in both sub-periods since 1985 have been much smaller.

The economy-wide intensity indexes reflect the general behavior of the sector-specific results over these same sub-periods. The source intensity index is the most appropriate index from an aggregate point of view (highlighted in yellow, see Appendix B for further discussion). From an annual rate of decline of just over 1\% per year during the 1970-1985 period, the rate slowed to just $0.2 \%$ (decline) over the next 15 years. However, over last 11 years of the data period, source energy intensity declined at nearly the same rate as in the initial period.

While it is beyond the scope of this report to provide an explanation of the behavior of the energy intensity indexes, several general observations can be made. The important role of energy prices in influencing behavior with regard to energy use is clearly evident in the subperiod results. The first sub-period represents one in which energy prices rose dramatically in response to the two oil-related crises of the 1970s (1973-1974, and 1979-1980). After the collapse of the petroleum market in 1986, the ensuing 15 years or so were marked by general energy price stability. Finally, the run-up in energy prices, particularly natural gas and oil, in the last decade likely spurred renewed activity to achieve greater energy efficiency.

However, responses to energy prices are likely not the only factors yielding progress toward greater energy efficiency. Public policies and programs at all levels — states, utilities, and federal - contributed to lower energy consumption, particularly in the buildings and industrial sectors. At the federal level, mandatory equipment efficiency standards, promotion of more stringent building energy code, as well as targeted R\&D to support industrial energy efficiency have all yielded energy savings, particularly since 1995. ${ }^{1}$ Many electric utilities around the U.S. have aggressively promoted energy efficiency programs dealing with improved lighting and space conditioning in residential and commercial buildings. These programs have taken on renewed vigor in the latter portion of the previous decade, and thus, may be a measureable influence on the more robust intensity reduction trends identified in this study.

Figure 5.2 presents graphically the sub-period annual percentage changes from Table 5.1 related to the (adjusted) source intensity indexes for the end-use sectors, the electric utility sector, and for the economy as a whole. The figure clearly shows the slowdown in intensity reductions that were observed over the 1985-2000 period. Compared to the previous 30 years, the period from 2000 and forward shows the most consistent declines across the various sectors.

\footnotetext{
${ }^{1}$ EERE has recently sponsored a statistical study to examine its historical role in supporting energy-efficiency improvements in the residential, commercial, and manufacturing sectors. The report is scheduled to be released in the spring of 2014.
} 


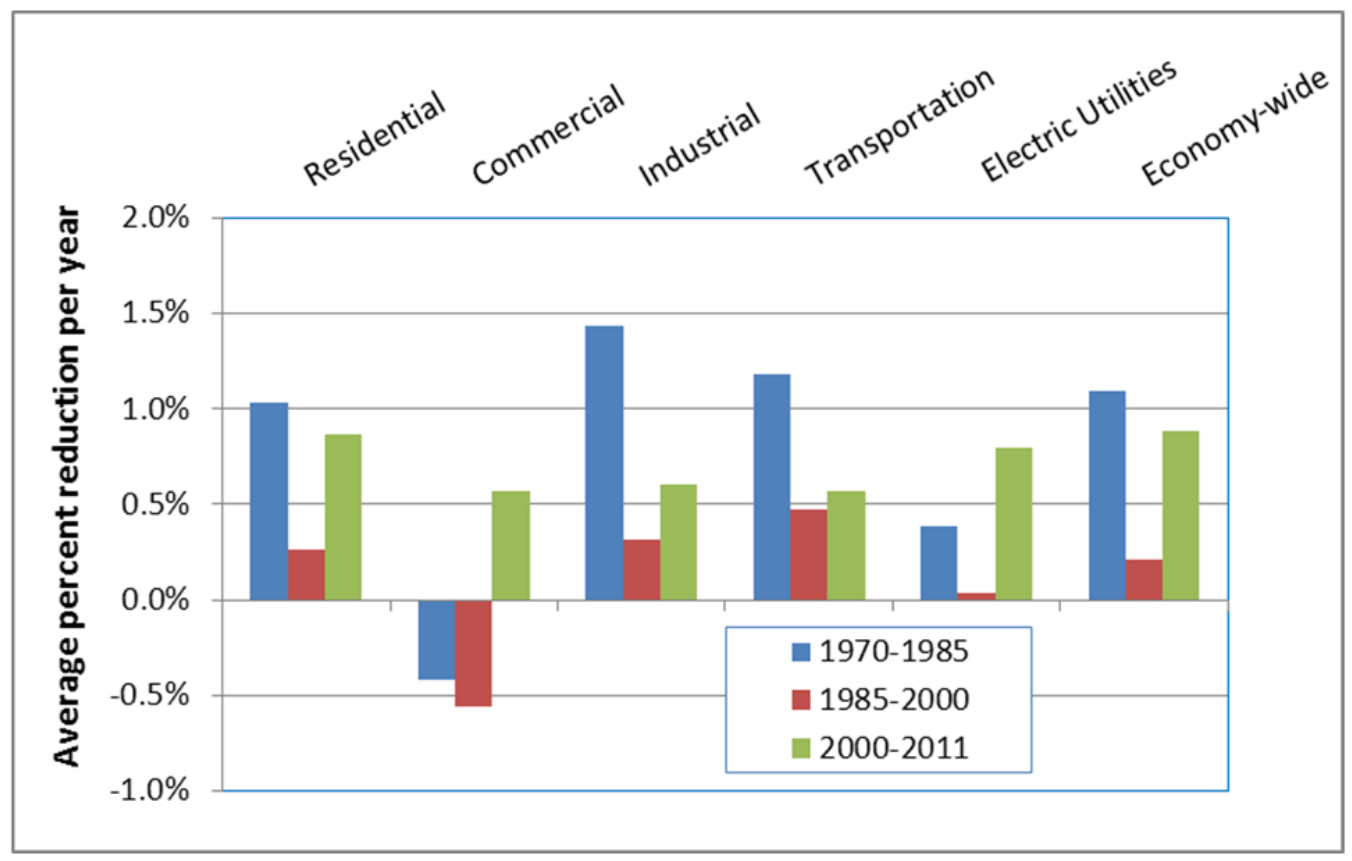

Figure 5.2. Average percentage changes in energy intensities by sub-period (adjusted source intensities for end-use sectors)

\subsection{Suggestions for Future Improvements}

There are several areas related to the system of energy intensity indicators that would represent beneficial improvements. The first two represent further disaggregation within the current set of indicators. A useful study that would complement the economy-wide intensity index involves a partial reconciliation with alternative indexes based upon the energy-GDP ratio. Finally, several areas in which data gaps persist are discussed briefly.

\subsubsection{End-Use Disaggregation}

As discussed in Section 3.1, a particular issue with regard to the residential sector is the choice of activity measure. While floor space lends itself to be an appropriate activity measure for space conditioning, it is more problematic for other end uses. In particular, increasing electricity use in residential buildings comes more from additional devices and equipment, rather than traditional end uses such as lighting, refrigeration, water heating, washing, and so on. It is improbable that one can define a metric that somehow measures the energy intensities of these newer uses of electricity. However, having some indication of their importance over time would be valuable in terms of defining intensities for the more conventional end uses.

The EIA has developed estimates of major end-use consumption for its Residential Energy Consumption Survey (RECS) (EIA various “C”). The end uses are heating, cooling, water 
heating, and lighting and appliances. The consistency of such estimates across various surveys is a natural question, particularly whether reasonable consistency could be achieved for the historical RECS surveys by census division. With consistent measures of end-use consumption, it would be possible to use alternative measures of activity for different end uses. Thus, one might define energy intensities for heating and cooling in terms of energy use per square foot and consider the energy intensity for other end uses on a per capita basis. Some major empirical issues relate to the differences between energy consumption measured in the RECS and the measures of energy consumption based upon supply-side sources that are currently used for the intensity indexes. There is an issue of how to integrate weather adjustment into a system based upon both data sources. Finally, a method to interpolate (and extrapolate) estimates for nonRECS years would be required.

In the commercial sector, there would be benefit in isolating heating, cooling, and ventilation (HVAC) energy use from other end-use consumption. Unfortunately, the available estimates of

end-use consumption from the Commercial Building Energy Consumption Surveys (CBECS) are much more limited than for the residential sector. End-use consumption estimates have been developed for four CBECS (1992, 1995, 1999, and 2003), but there has not been a consistent methodology applied to derive the estimates. Thus, the historical consistency is problematic. Finally, the next set of end-use estimates associated with the CBECS (for 2012) is not expected before 2015 .

\subsubsection{Intensity indexes based upon physical production}

In the first few years of the energy intensity indicators development in the early 2000 s, energy intensity measures for selected manufacturing industries were developed from physical production data. The industries included: 1) pulp and paper, 2) cement, 3) steel, and 4) primary aluminum. The physical units of production were compared to the (real) dollar gross output data for the corresponding sectors. Ideally, one would find commonly-accepted measures of energy intensity employed by the industry itself and then integrate such measures in the overall EERE system of indicators. It would be important to report the share of manufacturing energy use that would be represented by physical-based intensity indexes.

\subsubsection{Perform partial reconciliation with the energy-GDP ratio}

While the economy-wide energy intensity index can be considered a more accurate and robust measure of improved energy efficiency in the U.S., the energy-GDP continues to be often cited as an appropriate metric with the same objective. One suggestion for a future study is to perform a partial reconciliation of the intensity index generated in this report with the energy-GDP ratio. Currently, the industrial sector employs GDP data at the aggregate level to decompose changes in energy consumption over time. While there are no detailed energy consumption data for individual service industries, one could develop measures of overall GDP in the service sector 
compared to the floor space estimates. The goal would be to estimate the impact on the overall energy-GDP ratio from increases in service sector GDP per square foot of floor area.

This analysis would also lend itself to determine the impact on the energy-GDP ratio from the relative change in service sector GDP compared to industrial GDP. Finally, some means of representing the energy consumption for residential housing and personal transportation in the energy-GDP framework. This type of analysis might be able answer the question of how much of the decline in the energy-GDP ratio stems from compositional change among sectors represented in the national accounts and how much of the decline is the result of an inappropriate inclusion of residential (plus personal transportation) energy use. As part of such a study, the quantitative impact of the extremely large increase in GDP associated with computer manufacturing would be investigated.

\subsubsection{Data gaps}

As described in Appendix A, there was a significant increase in scope during 2012 related to the underlying data to construct several energy intensity indexes. The primary area where new data were collected was in the nonmanufacturing industrial sector. A medium-priority task in future work is to seek to fill in some of the existing weaknesses in the new estimates first made in 2012. These would likely involve 1) finding new information for electricity in agriculture, 2) obtaining the detailed data for the 1977 and 1982 Census of Minerals, and 3) looking for additional data sources to improve the intensity indicators for construction.

In transportation, another activity may include working more closely with Oak Ridge National Laboratory (ORNL) to improve some of the metrics associated with transportation indicators (e.g., buses, pipelines, medium and heavy trucks).

\subsubsection{Explicit recognition of "statistical discrepancy" in energy consumption estimates}

As mentioned above, considerable effort was devoted in 2012 to develop independent historical estimates of energy consumption in the nonmanufacuring sector. These estimates were based upon available reporting by the Census Bureau and other sources from users of energy in these sectors. As explained in Appendix A, this approach replaced the previous method of estimating energy use in this sector as a residual - the difference between supply-side estimates of industrial energy use and estimates from the MECS and Census Bureau for manufacturing energy use. The current approach (initiated in 2012) yields much more plausible estimates of nonmanufacturing energy intensity, but at the expense of leaving unexplained small differences between the total industrial energy consumption as estimated from end-user information and energy consumption data, as collected from suppliers and reported by EIA in Table 2.1c of the Annual Energy Review. Transportation is another sector where there is some difference between the sum of the 
energy reported by different modes and the estimates provided by EIA. From the discussion in Appendix A, it is expected that the supply-side estimate from EIA would be higher than that from the indicators system because the EIA fuels estimates would include military sales of jet fuel (and perhaps diesel).

The work suggested by these issues would essentially mimic the approach used the Bureau of Economic Analysis in the National Income and Product Accounts, where an explicit statistical discrepancy is published as a measure of the difference between GDP measured from the production side and GDP measured from the expenditure side. Before accepting the current values of discrepancies, a first step in this activity would be to engage with EIA staff, and perhaps staff at the Census Bureau, in an effort to better understand the reasons and statistical problems related to these discrepancies. This step could be expected to yield some improvement in the way the current sources are employed and may suggest possible modifications in future data collection activities. 


\subsection{References}

Ang, B.W. and K.L. Choi. 1997. "Decomposition of Aggregate of Energy and Gas Emission Intensities for Industry”, Energy Journal, 18(3), pp. 59-73.

Ang, B.W. and F. L. Liu. 2001. "A new energy decomposition method: perfect in decomposition and consistent in aggregation. Energy, 26, pp. 537-547

Belzer, D.B. 1995. "Energy Use and Intensity in the Industrial Sector", paper presented at the 1995 American Council for an Energy Efficient-Economy (ACEEE) Summer Study on Energy Efficiency in Industry, August 1-4, 1995 in Grand Island, New York. Paper can be accessed in ACEEE website: http:/www.aceee.org/conferences/1995/ssi/program, (accessed on 2/20/2013).

Belzer, D.B. 2007. Estimates of U.S. Commercial Building Energy Intensity Trends: Issues Related to End-Use and Supply Surveys. PNNL-18820, Pacific Northwest National Laboratory, Richland, WA.

Bureau of Transportation Statistics. 1993. National Transportation Statistics, Annual Report, September 1993, Historical Compendium 1960-1992. U.S. Department of Transportation, Washington, D.C.

Energy Information Administration. 2002. Annual Energy Review 2001, DOE/EIA-0384(2001), U.S. Department of Energy, Washington, D.C.

Energy Information Administration. 2012a. Annual Energy Review 2011, DOE/EIA0384(2011), U.S. Department of Energy, Washington, D.C.

Energy Information Administration. 2012b. Commercial Demand Module of the National Energy Modeling System: Model Documentation 2012. DOE/EIA-M066 (2012), Washington, D.C. Accessed on EIA website on 1/12/2012:

http://www.eia.gov/forecasts/nemsdoc/commercial/pdf/m066(2012).pdf

Energy Information Administration. 2014. Monthly Energy Review July 2014, DOE/EIA$\underline{0035(2014 / 07)}$

Energy Information Administration. Various “A”. Commercial Building Energy Consumption Survey DOE/EIA, Washington, D.C. Data from the 1992, 1995, 1999, and 2003 CBECS is available through EIA website: http:/www.eia.gov/consumption/commercial/data/2003/ (accessed 2/18/2013). 
Energy Information Administration. Various "B". Manufacturing Consumption of Energy DOE/EIA-M0512, Reports issued from the periodic Manufacturing Energy Consumption Survey (MECS), Washington, D.C. Data from the various MECS are available through the EIA website: http://www.eia.gov/emeu/mecs/contents.html

Energy Information Administration. Various "C". Residential Energy Consumption Survey (RECS) DOE/EIA, Washington, D.C. Data from the various RECS is available through the EIA website:

http://www.eia.gov/consumption/residential/data/2009/ (accessed 2/18/2013)

Energy Information Administration. 1995. Residential Energy Consumption Survey 1993. DOE/EIA-0555 (93/2)

Eno Transportation Foundation. 2002. Transportation in America. $19^{\text {th }}$ edition, Washington, D.C.

Eno Transportation Foundation et al.. 2007. Transportation in America. $20^{\text {th }}$ edition, Washington, D.C.

International Energy Agency. 2008. Worldwide Trends in Energy Use and Efficiency: Key Insights from IEA Indicator Analysis. International Energy Agency, Paris, France.

Oak Ridge National Laboratory. 2012. Transportation Energy Data Book. 31 edition, Oak Ridge, TN.

Pierce, Barbara. 1994. Office of Buildings and Technologies Evaluation and Planning Report, BNL-52426. Prepared for U.S. DOE, Office of Energy Efficiency and Renewable Energy, ice of Office of Building Technologies by Brookhaven National Laboratory, Upton, New York.

RAND Corporation. 2002. "E-Vision 2002, Shaping Our Future by Reducing Energy Intensity in the U.S. Economy." In Volume I: Proceedings of the Conference, Prepared by David S. Ortiz and Jerry M. Solinger, Rand Corporation. Report obtainable from Rand website: http://www.rand.org/pubs/conf_proceedings/CF184.html

U.S. Census Bureau et al.. Various "A". (1973-1984). "Annual Housing Survey for the United State. Part A General Housing Characteristics. Current Housing Reports, Series H150, U.S. Government Printing Office, Washington, D.C..

U.S. Census Bureau et al.. Various "B". (1985-2009 bienniel). "American Housing Survey for the United State. Part A General Housing Characteristics. Current Housing Reports, Series H150, U.S. Government Printing Office, Washington, D.C.. 
U.S. Department of Agriculture (USDA). 2009. 2007 Census of Agriculture, United States, Summary and State Data, AC-07-A-51, Washington, D.C. Available on USDA website:

http://www.agcensus.usda.gov/Publications/2007/Full_Report/Volume 1, Chapter 1 US/, accessed on $2 / 20 / 2013$. 
APPENDIX A

Data Sources and Methodology 



\section{APPENDIX A - Data Sources and Methodology}

This appendix describes the primary data sources that are used to support EERE's system of energy intensity indicators for the U.S. economy. The discussion of methodology essentially involves how the various sources are combined or adjusted to represent consistent historical time series. A broad key issue relates how to interpolate and extrapolate those data series that are not available on an annual basis. Other more specific issues involve: 1) how to integrate major changes in reported data from federal statistical agencies (e.g. EIA's complete revision of statistics related to combined heat and power facilities in 2002, the Federal Highway Administration reclassification of vehicles in 2007, etc.), 2) the adjustment of building sector energy consumption for weather variation, and 3) differences between reported consumption between end users and supply-side sources. For the residential and the commercial building sectors, there are extensive discussions of the methods used to develop historical annual time series of floor area.

Many of these procedures are implemented in the publicly available spreadsheets for each of the major end-use sectors (plus electric utilities) and the U.S. economy as a whole. The material in the appendix should aid users of these spreadsheets to better understand some of the adjustments that are required to develop consistent historical measures of economic activity and energy consumption that underlie the specific intensity indexes.

\section{A.1 Residential}

As described in the text, the primary energy intensity for the residential sector is based upon energy consumption per square foot. However, alternative energy intensities based upon occupied housing units or population can be useful in some applications

\section{A.1.1 Energy Consumption}

The data for energy consumption were principally taken directly from Table $2.1 \mathrm{~b}$ in the Annual Energy Review 2011 (EIA 2012a) and the State Energy Data System (SEDS). ${ }^{2}$ Because EIA did not publish an Annual Energy Review 2012 (in 2013), the most recent energy consumption through 2012 was derived from the July 2014 edition of the Monthly Energy Review (whose online version contained annual data from 1949 through 2013), (EIA 2014).

\footnotetext{
${ }^{1}$ The Annual Energy Review 2011 can be accessed from: http://www.eia.gov/totalenergy/data/annual/previous.cfm. (accessed 10/3/2012).

${ }^{2}$ The State Energy Data System (SEDS)can be accessed from: http://www.eia.gov/state/seds/seds-datacomplete.cfm. The consumption data by state is derived from the downloadable file: use_all_btu.csv, located under the headings on the webpage, "Consumption Estimates"/"Data Files 1970-2010." (last accessed on 10/3/2012).
} 
There are some small differences between the national energy consumption totals from the SEDS and the recent editions of the Annual Energy Review (AER) and Monthly Energy Review (MER) cited above. These differences most likely relate to the timing of the publications. The MER will contain the most recent energy use data processed by EIA, and thus contain any ongoing revisions to the historical data. The SEDS is updated only on an annual basis. For the residential sector, the approach has been to scale proportionately the (national) sum of the regional energy consumption estimates from the SEDS to match the most recent national estimates shown in the MER. The scaling is performed separately for electricity and fuels. Through 2011, the electricity consumption estimates between the SEDS and the MER matched perfectly. For fuels, the national estimates from the MER slightly exceeded those derived from SEDS. The differences were generally only a few tenths of a percent - an average difference of only $0.19 \%$ from 1970 through 2011. The calibration is used to make the national estimates more transparent, by ensuring that the residential energy consumption matches the most readily available EIA sources. The differences between the EIA sources have negligible effect on the trend of the energy intensity indicators over all time periods.

\section{A.1.2 Occupied Housing Units}

In late 2011, an assessment of the feasibility of using the American Housing Survey (AHS) to develop measures of residential housing stock and residential floor space was undertaken. ${ }^{3}$ It was concluded that AHS data would be a more stable source of information to estimate the growth of the residential housing stock and average housing unit size compared to the EIA's Residential Energy Consumption Surveys (RECS). The sample size of the AHS through 2009is roughly an order of magnitude greater than in the RECS ( 60,000 vs. 6,000$)$, and thus provides in many cases more reasonable estimates of the change in housing stock over short time intervals. ${ }^{45}$ Such differences can be especially noticeable in the reported changes in successive RECS in the number of multi-family and manufactured homes at the census region level. Furthermore, while there is an issue with self-reporting of housing unit size in the AHS, the data collection format has remained the same over time. The RECS suffers from changes in the methodology used to estimate floor space and sampling variation related to the smaller sampling sizes.

\footnotetext{
${ }^{3}$ Data and the published reports from the American Housing Survey can be accessed from the Census Bureau webpage: http://www.census.gov/housing/ahs/ The report from which much of the discussion below is based was for 2009 (U.S. Census Bureau, various “B”)

${ }^{4}$ The sample size in the 2009 RECS was approximately doubled from previous surveys. However, this improvement does not solve the problem of sampling variability associated with the older surveys.

${ }^{5}$ The sample size in the 2011 American Housing Survey was increased substantially to include over 180,000 units. This increase resulted from the inclusion of a separate sample of units in strictly metropolitan areas, which had previously been reported separately from the national sample. As will be explained in the text below, this change appears to result in some incomparability with the AHS from 2009 and earlier years.
} 
Many of the main data elements required for development of the time series of housing stock and size can be derived from several published tables in the American Housing Survey. These tables are termed "Introductory Characteristics" and are shown for both "All Housing Units" and "Occupied Housing Units." The other relevant tables used in the analysis here are entitled "Size of Unit and Lot." These published tables display: 1) number of rooms, 2) number of bedrooms, 3) complete bathrooms, 4) square footage of unit by various size ranges, plus the median over all units, and 5) lot size by various size ranges, in acres.

Unfortunately, the square footage data from table, "Size of Unit and Lot" refer only to a combined category of "single detached and manufactured/mobile homes." That restriction, together with the limitation of data presented only in size categories, prompted the need to use the available micro data files from the AHS. In addition, the published tables provide no means of calculating unit size at the census region level. Fortunately, these micro datasets are readily available from the Department of Housing and Urban Development. ${ }^{6}$

Of course, the key element of interest is the data related to the size of the unit. By the 2009 edition of the AHS, the size information was available for a very high percentage of the sampled housing units (U.S. Census Bureau et al. various "B"). Table A.1 shows the total national number of units (All Housing Units - occupied and vacant) by type of unit and the number (and percentage) of units for which size in square feet was reported.

Table A.1. Total number of housing units and number reporting size from the 2009 AHS (thousands of units)

\begin{tabular}{lrrr} 
& \multicolumn{1}{c}{$\begin{array}{c}\text { Total } \\
\text { Housing } \\
\text { Units }\end{array}$} & $\begin{array}{c}\text { Total, with } \\
\text { size data }\end{array}$ & $\begin{array}{c}\text { Percentage } \\
\text { with size }\end{array}$ \\
\hline $\begin{array}{l}\text { Single-family } \\
\text { detached }\end{array}$ & 82,472 & 77,678 & $94.2 \%$ \\
Single-family attached & 7,053 & 6,053 & $85.8 \%$ \\
Multi-family & 31,817 & 27,625 & $86.8 \%$ \\
Manufactured homes & 8,769 & 8,034 & $91.6 \%$
\end{tabular}

Source: Derived from micro data from the 2009 American Housing Survey

\footnotetext{
${ }^{6}$ The relevant website is: $\mathrm{http}: / /$ www.huduser.org/portal/datasets/ahs.html.
} 
For the purpose of imputing square footage to those units in which size was not reported, it was assumed that the average size of such unit was the same as reporting units with the same vintage and census region. Tables with vintage-specific results were used to impute the amount of square footage for those units where size information was not supplied. An example of this table, based on the 2009 AHS, is provided as Table A.2 below. Table A. 2 was developed from national-level data for occupied housing units.

\section{Annual Estimates of Occupied Housing Units - National}

While the AHS provides more accurate measures of the various elements of the U.S. housing stock over time, several issues remain that must be resolved before the published data can be directly used for residential intensity indicators. First, the AHS is conducted only on a biennial basis, and some means of interpolating estimate for non-AHS must be conducted. Second, even though the AHS has relatively large sample size, as a survey, it is still subject to sampling errors that sometimes lead to implausible changes in the number of units from one survey to the next.

Table A.2. Average size, number of occupied housing units, and observations with size data, occupied units

\begin{tabular}{|c|c|c|c|c|c|c|c|c|c|}
\hline & $<1940$ & $1940-49$ & 1950-59 & $1960-1969$ & $1970-1979$ & 1980-1989 & 1990-1999 & 2000 \& later & All Vintages \\
\hline \multicolumn{10}{|c|}{ Average Size, square feet } \\
\hline SF,MH & 2,150 & 1,737 & 1,790 & 2,034 & 2,064 & 2,158 & 2,422 & 2,640 & 2,158 \\
\hline SF-detach & 2,153 & 1,747 & 1,793 & 2,072 & 2,164 & 2,309 & 2,606 & 2,749 & 2,221 \\
\hline SF-attach & 1,900 & 2,074 & 2,101 & 1,738 & 1,731 & 1,798 & 1,873 & 1,816 & 1,837 \\
\hline Multi-Fam & 1,130 & 1,170 & 869 & 956 & 974 & 1,025 & 1,133 & 1,211 & 1,043 \\
\hline Man. Home & 1,485 & 860 & 1,219 & 1,156 & 1,215 & 1,291 & 1,671 & 1,698 & 1,456 \\
\hline All Units & 1,879 & 1,656 & 1,682 & 1,781 & 1,721 & 1,811 & 2,205 & 2,370 & 1,899 \\
\hline & & & & & & & & & \\
\hline \multicolumn{10}{|c|}{ Number of Units, thousands } \\
\hline $\mathrm{SF}, \mathrm{MH}$ & 11,267 & 5,163 & 9,740 & 9,649 & 13,590 & 8,888 & 10,895 & 10,725 & 79,918 \\
\hline SF-detach & 11,218 & 5,109 & 9,684 & 9,248 & 12,094 & 7,522 & 8,625 & 9,580 & 73,079 \\
\hline SF-attach & 853 & 297 & 352 & 444 & 1,038 & 1,112 & 815 & 1,062 & 5,973 \\
\hline Multi-Fam & 4,762 & 1,285 & 1,680 & 3,232 & 6,620 & 4,025 & 2,110 & 2,198 & 25,912 \\
\hline Man. Home & 49 & 54 & 56 & 401 & 1,496 & 1,366 & 2,270 & 1,146 & 6,839 \\
\hline All Units & 16,882 & 6,745 & 11,771 & 13,326 & 21,248 & 14,025 & 13,820 & 13,986 & 111,803 \\
\hline \multicolumn{10}{|c|}{ Number of Observations (with size information) } \\
\hline $\mathrm{SF}, \mathrm{MH}$ & 3,920 & 1,819 & 3,552 & 3,472 & 4,758 & 3,138 & 4,004 & 4,126 & 28,789 \\
\hline SF-detach & 3,903 & 1,806 & 3,534 & 3,345 & 4,275 & 2,739 & 3,506 & 3,802 & 26,910 \\
\hline SF-attach & 358 & 108 & 128 & 156 & 393 & 431 & 343 & 440 & 2,357 \\
\hline Multi-Fam & 1,655 & 419 & 560 & 1,138 & 2,286 & 1,611 & 859 & 832 & 9,360 \\
\hline Man. Home & 17 & 13 & 18 & 127 & 483 & 399 & 498 & 324 & 1,879 \\
\hline All Units & 5,933 & 2,346 & 4,240 & 4,766 & 7,437 & 5,180 & 5,206 & 5,398 & 40,506 \\
\hline
\end{tabular}

Source: National estimates derived from micro data from 2009 AHS 


\section{Single-Family Housing Stock}

As a means of overcoming these issues, the methodology here employs a very simple modelingbased approach to essentially fill in and smooth the published data series. The model assumes a vintage stock model of the following form:

$$
\text { Stock }_{\mathrm{t}}=\text { Stock }_{\mathrm{t}-1}+\text { New Units } \mathrm{t}-\text { Retirements }_{\mathrm{t}}
$$

Data for the number of new units was taken from the Characteristics of New Housing $(\mathrm{CNH})$ website maintained by the Census Bureau. ${ }^{7}$ Retirements can be based upon the development of a vintage survival curve estimated from the vintage data extracted from the AHS micro data, as exemplified by the columns in Table A.2.

The vintage models were based upon examining the decline of the housing stock built in 1999 and earlier years across the AHS datasets from 1999 through 2009. The data were aggregated into the same vintages shown in Table A.2. Table A.3 below shows the total U.S. stocks of single-family housing units by vintage over the seven AHS years from 1999 through 2011. As one might expect, the greatest number of retirements on a percentage basis are for the oldest vintage of units, built prior to 1940 .

However, as can be expected with empirical data, expected patterns are not evident throughout the entire set of AHS results. Several anomalies stand out. First, there is an unexplained increase in the numbers between 1999 and 2001 (which show up in the total ("all units") national numbers as an increase of nearly 4 million units, far exceeding new units built over these two years). Second, the 1950-1959 vintage shows an uncharacteristically low relative number of retirements between 1999 and 2009, compared to the adjacent vintages. Third, the number of units in all but the oldest vintage display implausible behavior between 2009 and 2011 . For all vintages after 1950, the published number of occupied units is higher in the 2011 AHS as compared to the 2009 AHS. As noted above (footnote 5), the 2011 AHS contains many more observations than the previous 2009 and earlier surveys, a result achieved by incorporating the previous metropolitan area sample with the national sample. ${ }^{8}$ Unfortunately, it appears that this larger sample is now inconsistent in some respects with the previous editions of the AHS, even after accounting for the sampling variability observed in the older and smaller AHS editions.

\footnotetext{
${ }^{7}$ The home page for the Characteristics of New Housing website is at http://www.census.gov/construction/chars/ (accessed 2/2/2013). The table for median and average size of new single-family units can be selected from the webpage: http://www.census.gov/construction/chars/completed.html

${ }^{8}$ For the 2011 AHS, the inclusion of the metropolitan sample added over 116,000 units to the national sample. See Census Bureau explanation at website: http://www.census.gov/housing/ahs/files/Appendix\%20B-National.pdf
} 
Table A.3. Number of occupied single-family housing units by vintage for various AHS years, in thousands

\begin{tabular}{|r|r|r|r|r|r|r|r|r|}
\hline AHS Year & $<1940$ & $1940-49$ & $1950-59$ & $1960-1969$ & $1970-1979$ & $1980-1989$ & $1990-1999$ \\
\cline { 2 - 8 } & 13,732 & 5,891 & 10,394 & 10,272 & 12,849 & 8,834 & 9,528 \\
\hline 1999 & 13,789 & 5,829 & 10,536 & 10,346 & 13,274 & 8,933 & 9,912 \\
\hline 2001 & 13,783 & 13,166 & 5,593 & 10,019 & 9,859 & 12,808 & 8,871 & 9,835 \\
\hline 2005 & 12,481 & 5,438 & 9,806 & 9,712 & 12,481 & 8,840 & 9,825 \\
\hline 2007 & 12,078 & 5,429 & 9,803 & 9,557 & 12,361 & 8,673 & 9,577 \\
\hline 2009 & 12,071 & 5,406 & 10,036 & 9,692 & 12,132 & 8,634 & 9,440 \\
\hline 2011 & 11,850 & 5,266 & 10,165 & 9,694 & 13,331 & 8,789 & 9,583 \\
\hline
\end{tabular}

Source: tabulations using micro data from the AHS from 1999 through 2011

In spite of the anomalies observed for the AHS through 2009, a simple survival curve was estimated using the data as it was tabulated from the AHS micro data. Data from the 2011 AHS were not included. The form of the survival curve is same as that used in the commercial energy demand module in EIA's National Energy Modeling System (NEMS) (EIA 2012b). The specification of this curve is as follows

$$
\text { Surviving proportion in year } \mathrm{t}=1 /\left(\left(\mathrm{t}-\mathrm{t}_{\mathrm{v}}\right) / \mathrm{L}\right)^{\gamma}
$$

where

$$
\begin{aligned}
& \mathrm{t}=\text { current year } \\
& \mathrm{t}_{\mathrm{v}}=\text { average year of construction for building in vintage } \mathrm{v} \\
& \mathrm{L}=\text { median lifetime of buildings (estimated as parameter) } \\
& \gamma=\text { survival parameter (gamma) }
\end{aligned}
$$

To implement this formulation here, only aggregate vintage level data are taken from Table A.3. The variable $t$ takes on the current year of the AHS, namely odd-numbered years from 1999 through 2009. The average year of construction for each vintage was assigned judgmentally, as follows in Table A.4. 
Table A.4. Assigned average years of construction by vintage

\begin{tabular}{|c|c|}
\hline Vintage & $\begin{array}{c}\text { Average year } \\
\text { of construction }\end{array}$ \\
\hline$<1940$ & 1910 \\
\hline $1940-1949$ & 1948 \\
\hline $1950-1959$ & 1955 \\
\hline $1960-1969$ & 1965 \\
\hline $1970-1979$ & 1975 \\
\hline $1980-1989$ & 1985 \\
\hline $1990-1999$ & 1995 \\
\hline
\end{tabular}

The median lifetime, L, is a parameter to be estimated, as well as the survival (or "shape" parameter, $\gamma$. The survival parameter determines the uniformity of the declines in the stock over short periods of time. A value near 1.0 is yields a curve similar to an exponential decay, that is constant percentage declines in each year. A high value of this parameter yields a curve in which retirements are very low in the first years, then accelerate rapidly during a "middle" set of years, and then return to slow decline for the very oldest buildings.

The estimation of the median life and survival parameter was performed via the Solver nonlinear optimization tool in Excel. The objective function was to minimize the sum of squared errors across all the entries shown in Table A.3. In other words, the logistic function was used to make predictions for all of the cells in Table A.3, based upon the difference between the year of the survey and the assumed average construction year for the particular vintage. A calibration parameter was estimated, along with the other two parameters, as a means of moving the entire curve up or down to better correspond with empirical data. The result of this process yielded the following parameter estimates:

$$
\begin{array}{ll}
\text { Median life }(\mathrm{L}) & =85.9 \text { years } \\
\text { Survival parameter } & =2.49 \\
\text { Calibration parameter } & =1.01 .
\end{array}
$$

These parameters yield a survival curve (function) as shown in Figure A.1. As one can see from the graphic, the median life, where $50 \%$ of the stock has been retired, is approximately 85 years. Given the small declines in the stock data shown in Table A.3 for houses built after 1980, the 
curve reflects some fall in the number of homes in any given vintage after about 15 years (perhaps because of fires and natural disasters).

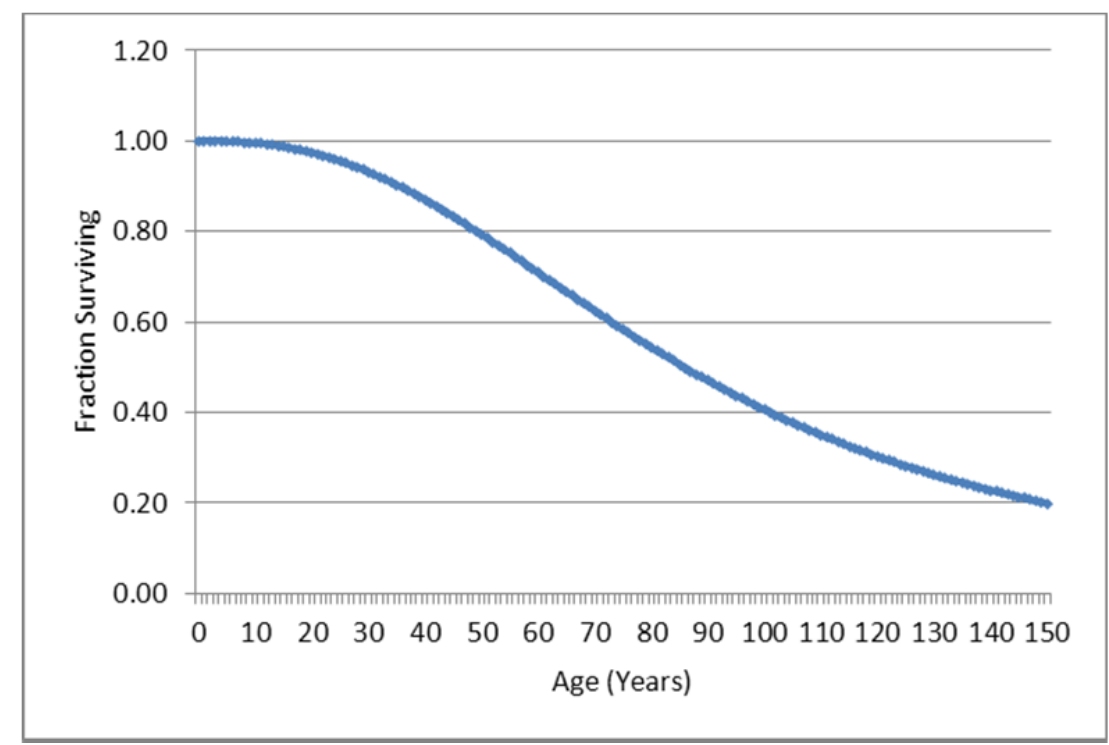

Figure A. 1. Estimated survival curve for U.S. single-family housing units

After estimation of the survival curve, the next step is to use that curve to develop annual estimates of total retirements. For the "base" year of 1999 used in the survival curve estimation process, total retirements were estimated to be about 500,000 units, or about $0.7 \%$ of the 1999 stock.

Given the annual estimates of retirements based upon the survival curve and new units completed (from the Census Bureau's Characteristics of New Housing (CNH) website ${ }^{9}$ ), one can employ the vintage stock model in Equation (A.2) to develop an annual series of housing stock. A base year for the vintage model must be selected; again 1999 is used as the base year because it formed the starting year for the survival curve estimation.

The estimated survival curve was based upon occupied housing units rather than total housing units. In an attempt to calibrate the vintage stock model, the number of new housing units was reduced by $5 \%$ to account for houses that would be used on either a seasonal or occasional basis (e.g., "vacation homes").

\footnotetext{
${ }^{9}$ The data come from the Characteristics of New Housing webpage: http://www.census.gov/construction/chars/completed.html
} 
Somewhat unexpectedly, the data from the AHS on total occupied stock, new units from the $\mathrm{CNH}$, and estimated retirements based upon the survival function in Eq. (A.2) above, do not appear to be internally consistent. The estimates for total stock in years prior to 1999 were based upon subtracting the new units from the $\mathrm{CNH}$ and then adding back the estimated retirements. When this process is carried back to 1985 , the estimated stock is roughly 4 million units higher than the published value in the AHS.

An alternative approach was then applied to develop an annual occupied housing stock series that better corresponded with the published data. For this approach, the data from American Housing Survey for 2011 were included. Several adjustments to the initial model were made for this approach. First, the vintage stock model was calibrated to total stock, rather than only occupied. Thus, the new data from the $\mathrm{CNH}$ was not adjusted by the $5 \%$ factor cited above. Second, the numbers from the $\mathrm{CNH}$ were smoothed by weighting the current and previous year's construction levels equally. The rationale behind this step was that the published stock numbers from any given year of the AHS only partially reflect the new units built in that year.

Third, the estimated retirements taken directly from the survival curve described above were not employed. Instead, the retirements were assumed to depend upon both the existing stock and the number of the new units constructed in any year. The rationale for this change is that retirements (demolitions or conversions) are likely to be higher in periods in which new housing construction is relatively robust. The dependency is expressed as a simple scalar that is applied to the product of both the existing stock and the number of new units. This step was implemented in terms of a simple non-linear least squares model (again, using Excel Solver tool) that uses one parameter to adjust a preliminary estimate of retirements that is set as a fraction of new units constructed in the same year. The preliminary estimate of retirements, based upon this fraction, was adjusted manually and the Solver routine was re-run to search for the smallest sum of squared residuals with regard to the total number of units for the AHS years. In the final estimation, the estimated number of retirements ranged from 95,000 units in the recession year 2010 to a high of 186,000 units in 2006. As a percentage of the existing stock, the implied retirement rates over the period 1985 through 2011 averaged about $0.17 \%$ per year.

As mentioned above, the predicted values from this alternative approach apply to all housing units, including unoccupied units. To develop a time series of occupied units, the overall observed vacancy rate was applied directly in the AHS years; that is, the number of occupied units (predicted) is calculated as total predicted units multiplied by ( 1 - vacancy rate). The vacancy rates for non-AHS (even-numbered) years were obtained by a simple interpolation between the adjacent AHS years. ${ }^{10}$

\footnotetext{
${ }^{10}$ For example, the total vacancy rate from the AHS for 2001 was 0.091 and for 2003 was 0.099 . The interpolated value for 2002 was 0.95 . Unfortunately, this procedure does not carefully acknowledge cyclical behavior in the housing market, but the development of a more robust method remains as a topic for future work.
} 
Figure A.2 displays the results of the final methodology to predict occupied single-family housing units by year. Clearly, the approach yields a change in the predicted overall number of occupied units that corresponds well with the AHS published values. Moreover, predicted values appear to follow a smoother pattern in comparison to the "actual" AHS data, particularly over a few short intervals within overall time series. This behavior is especially evident in the data over the period 1999 through 2003, where the published 2001 data may be viewed as abnormally high relative to the adjacent AHS years (1999 and 2003).

Accordingly, for purposes of constructing the energy intensity indicators, the predicted, rather than the published, values of the number of national occupied single-family housing units, as shown in Figure A.2 are used. These values would seem to be the most robust over short periods of time, and clearly would not lead to distortion of any long-term intensity trends.

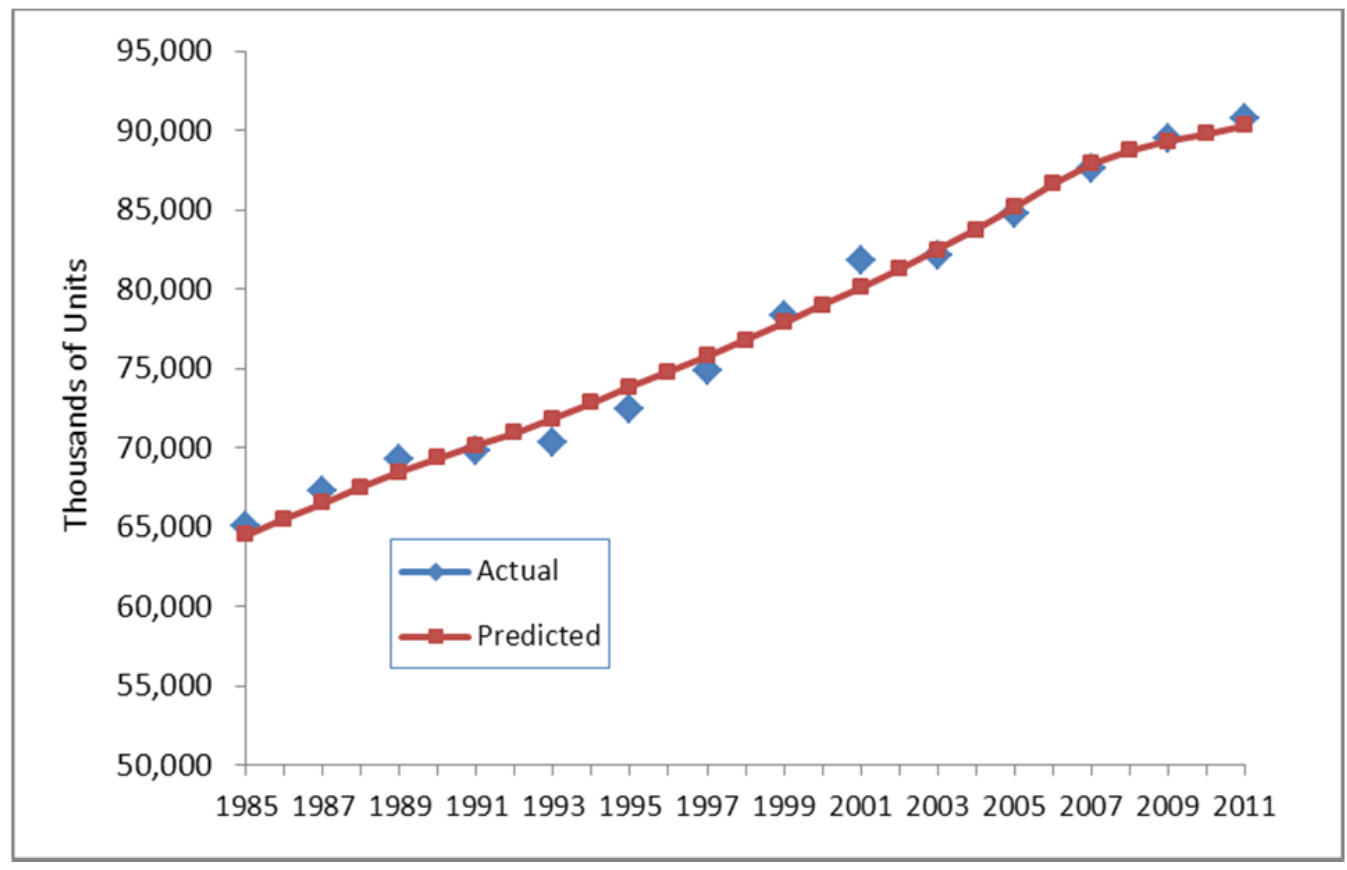

Figure A. 2. Occupied single-family housing units, predicted vs. reported AHS, for U.S.

\section{Multi-Family Housing Stock}

A similar methodology for the estimation of annual housing stock was followed for multi-family units. Similar to the single-family data shown earlier, Table A.5 shows the total U.S. stocks of multi-family units by vintage over the seven AHS years from 1999 to 2011 . Here, as for the single-family units, the largest percentage declines in the stock are for the oldest vintage of units, built prior to 1940. However, as can be expected with empirical data, expected patterns of slow 
declines in the stock are not evident throughout the entire set of AHS results. In this case, anomalous data appear in the 1970-1979 vintage, where the totals for both 2005 and 2007 are higher than either of the first two survey years. But the most implausible results appear with the most recent data from the 2011 American Housing Survey. Across all vintages, the number of occupied units in 2011 from this survey exceeds the number of units in the prior (2009) survey. Because most multi-family units can be expected to be located in metropolitan areas, the inclusion of the metropolitan area sample as part of the national sample in 2011 appears to be partially responsible to this unexpected result.

Table A.5. Number of occupied multi-family housing units by vintage for various AHS years, in thousands for U.S.

\begin{tabular}{|r|c|c|c|c|c|c|c|}
\hline AHS Year & $<1940$ & $1940-49$ & $1950-59$ & $1960-1969$ & $1970-1979$ & $1980-1989$ & $1990-1999$ \\
\hline 1999 & 5,760 & 1,519 & 1,798 & 3,354 & 5,660 & 4,403 & 2,021 \\
\hline 2001 & 5,375 & 1,426 & 1,865 & 3,456 & 5,550 & 4,366 & 2,190 \\
\hline 2003 & 5,276 & 1,489 & 1,836 & 3,396 & 5,764 & 4,240 & 2,141 \\
\hline 2005 & 5,065 & 1,352 & 1,699 & 3,334 & 5,719 & 4,157 & 2,159 \\
\hline 2007 & 5,136 & 1,353 & 1,652 & 3,454 & 5,891 & 4,017 & 2,100 \\
\hline 2009 & 4,762 & 1,285 & 1,680 & 3,232 & 5,620 & 4,025 & 2,110 \\
\hline 2011 & 5,026 & 1,313 & 1,673 & 3,480 & 6,513 & 4,203 & 2,225 \\
\hline
\end{tabular}

Source: tabulations using micro data from the AHS from 1999 through 2011

Again, an initial step in developing a model to predict annual estimates of housing stocks was to estimate a survival function based on the vintage AHS data for multi-family units. Excluding the data from the 2011 AHS, a survival function was estimated along the lines of that for singlefamily units, using the general form of the logistic in Eq. (A.2). In this case, the parameter estimates yielded by the Excel non-linear optimization tool (Solver) were:

$$
\begin{array}{ll}
\text { Median life }(\mathrm{L}) & =86.0 \text { years } \\
\text { Survival parameter } & =4.26 \\
\text { Calibration parameter } & =1.00 .
\end{array}
$$

The estimation process resulted in about the same median age for the survival curve for multifamily as it did for single-family units. However, the shape parameter was considerably higher, resulting in curve where retirements are very small over the first three decades.

However, as in work related to single-family units, the survival function estimated on the 19992009 time period did not work well in modeling the entire period. Thus, a simpler approach was to use a retirement fraction that was estimated as part of data fitting approach. Following the approach for the single-family units, retirements in any year were assumed to be linked to the number of new units built in that year. Along with the parameters used to represent retirements, another parameter was used to adjust the reported new units from the CNH survey. Again, it is 
important to note that the data-fitting (calibration) approach was applied to the total stock of multi-family units, rather than just occupied units. ${ }^{11}$ The results of this calibration procedure are shown in Figure A.3. As implied in the figure, the data series on new construction and estimated retirements, leading to predicted changes in the overall stock, does not seem to be compatible with the published AHS stock data over the entire time period $(1985-2011)$. The actual AHS estimates, particularly in the 1997-2003 period, are somewhat lower than that indicated by the stock model (with absolute declines from 1997 to 2001). The calibration procedure does yield close correspondence in beginning and ending (particularly 2009) years of the time series, and so the use of predicted series to generate energy intensity indicators will not bias any inferences about long-term trends.

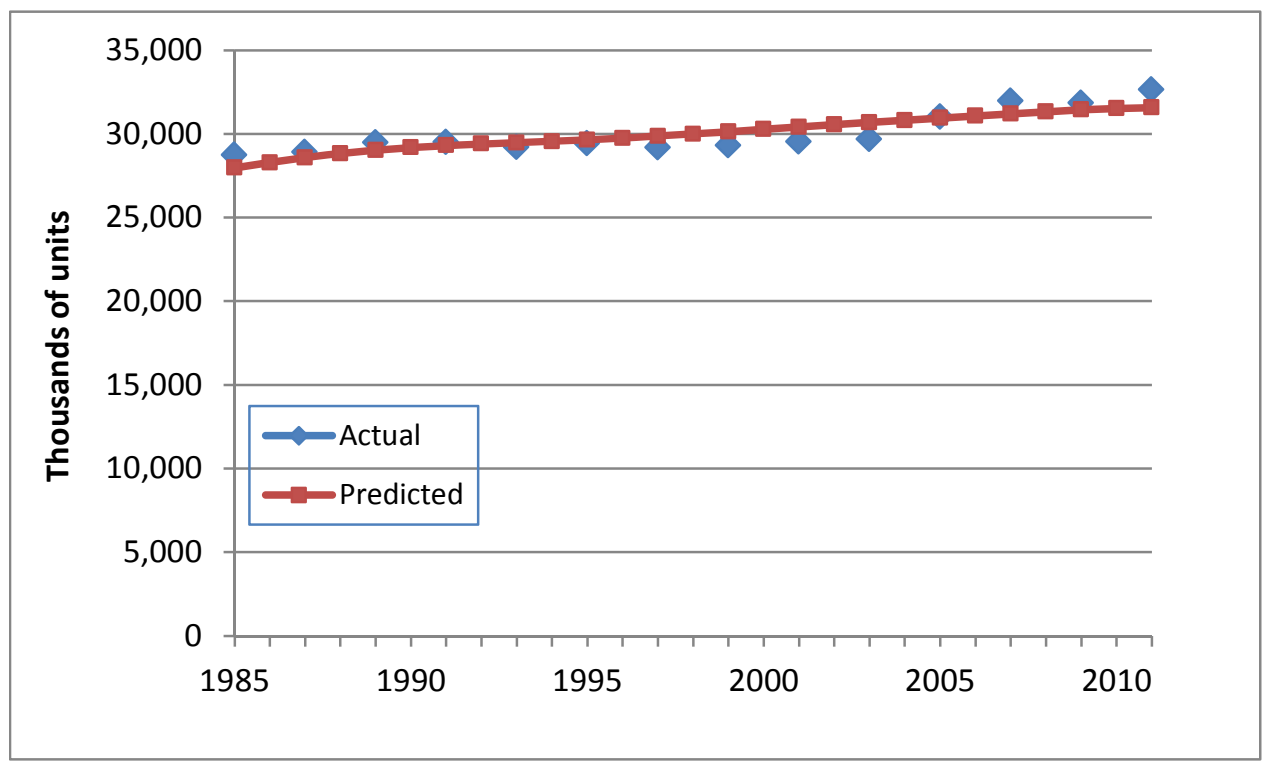

Figure A. 3. Total multi-family housing units, predicted vs. reported AHS, for U.S., 1985-2011

Similar to the procedure for single-family units, the predicted annual values of the total stock of multi-family units were adjusted to reflect (predicted) estimates of occupied units by applying the reported overall vacancy rates from the AHS. For non-AHS years, the vacancy rates were typically linearly interpolated between the adjacent AHS years. The series for occupied multi-

\footnotetext{
${ }^{11}$ For the calibration procedure, the 2011 data for the total stock of multi-family units were included in the estimation. Between 2009 and 2011 as reported in the two (AHS) surveys, the total stock of multi-family increased by just over 800,000 units. This increase is still implausible in light of new construction activity, but was considered to be reasonable in light of the previous history of sampling variation. By contrast, the reported number of occupied units between these 2 years increased by approximately 1.3 million units, indicating a significant reduction in the overall vacancy rate of these types of units. As shown in Figures A.3 and A.4, the predicted values of both total and occupied units increased between 2009 and 2011, but both values are lower than the reported values in the 2011 AHS. The predicted (smoothed) values are deemed to better represent the actual increases over this period and thus are more suitable for use in computing changes in energy intensity for the residential sector.
} 
family housing units shows somewhat more cyclical variation than does the series for total units, as could be expected from higher vacancy rates that might be expected during economic downturns. The reported and predicted (i.e., smoothed) series for occupied multi-family units is shown in Figure A.4.

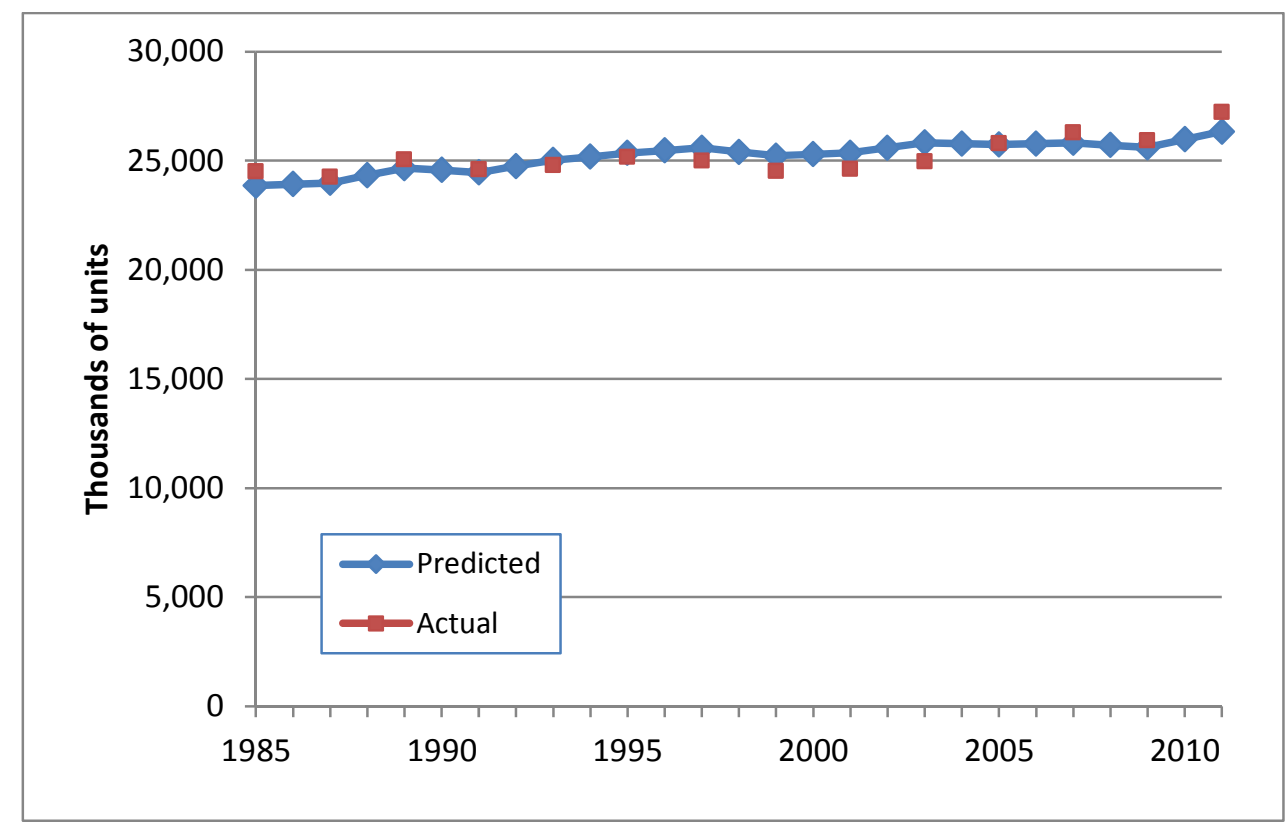

Figure A. 4. Occupied multi-family housing units, predicted vs. reported AHS, for U.S.

The smallest segment of the housing stock is manufactured housing and mobile homes. Table A.6 displays the numbers of manufactured housing unit by vintage across the past six housing surveys. As shown by the data, these units were predominantly built after World War II.

The general approach to calibrating a stock model to track the published data returned to that used for the single-family sector. First, the vintage data from the 1999 through 2009 AHS were used to estimate a survival curve (as for the previous housing categories, data from the 2011 AHS were not included). This curve was used to develop the approximate number of retirements (likely, all demolitions) beginning in 1985. 
Table A.6. Number of occupied manufacturing housing units (and mobile homes) by vintage for various AHS years, in thousands for U.S.

\begin{tabular}{|r|r|r|r|r|r|r|r|}
\hline AHS Year & $<1940$ & $1940-49$ & $1950-59$ & $1960-1969$ & $1970-1979$ & $1980-1989$ & $1990-1999$ \\
\hline 1999 & 38 & 16 & 102 & 602 & 2,104 & 1,518 & 2,400 \\
\hline 2001 & 56 & 24 & 101 & 594 & 2,093 & 1,530 & 2,439 \\
\hline 2003 & 44 & 17 & 78 & 526 & 1,901 & 1,463 & 2,289 \\
\hline 2005 & 50 & 30 & 49 & 453 & 1,651 & 1,495 & 2,380 \\
\hline 2007 & 56 & 38 & 42 & 384 & 1,585 & 1,496 & 2,300 \\
\hline 2009 & 49 & 54 & 56 & 401 & 1,496 & 1,366 & 2,270 \\
\hline 2011 & 48 & 44 & 67 & 422 & 1,496 & 1,502 & 2,362 \\
\hline
\end{tabular}

Source: tabulations using micro data from the AHS from 1999 through 2011

Because the survival model for manufactured housing may be of general interest to readers, the results are briefly discussed. As one might expect, the median life for manufactured homes is considerably shorter than for site-built structures, just under 40 years compared to the approximately 85 years for site built. The two parameters defining this curve are:

$$
\begin{array}{ll}
\text { Median life }(\mathrm{L}) & =37.5 \text { years } \\
\text { Survival parameter } & =3.95 .
\end{array}
$$

The graph of the estimated survival curve is shown in Figure A.5.

Data for placements of new manufacturing housing units was available from the U.S. Census Bureau's Manufactured Homes Survey website. ${ }^{12}$ The data from this survey are based on from monthly estimates of manufactured (mobile) homes either placed for residential use or added to dealer inventories. The survey is conducted by the Census Bureau, but funded by the Department of Housing and Urban Development.

\footnotetext{
${ }^{12}$ The website for the Census Bureau's Manufactured Homes Survey is http://www.census.gov/construction/mhs/placed.html (accessed 2/2/2013)
} 


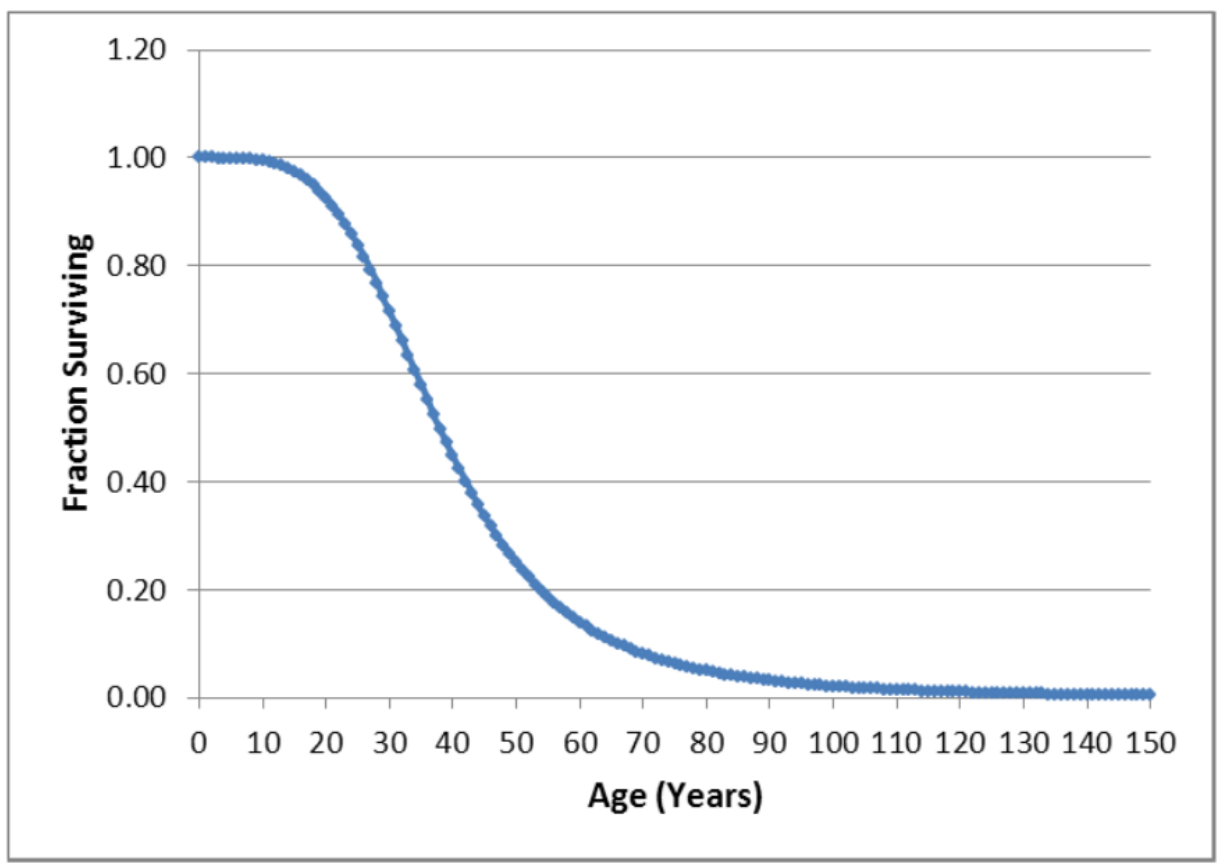

Figure A. 5. Estimated survival curve for U.S. manufacturing housing/mobile homes

Similar to the approach for the single-family housing sector, a calibration procedure using the stock adjustment formulation in Equation (A.1) was used to fit the biennial AHS data on the U.S. total number of existing manufacturing homes. The data from the most recent AHS were not included in the calibration. In this case, this approach yielded very reasonable coefficients to adjust the placement data from the Census Bureau (coefficient $=1.03$ ) and a second coefficient to adjust the estimated retirements derived from the survival curve shown in Figure A.5 (coefficient $=0.87$ ). A third parameter was used to simply adjust the initial 1985 stock level (59.3 [thousand] units). Similar to the approach for the single- and multi-family models, the predicted total stock was adjusted by the actual data on the occupancy rate to yield annual predicted values of occupied units.

Figure A.6 shows the results from using the calibrated stock model, with the subsequent adjustment for the overall vacancy rate. One can see that the model tracks the general patterns of the occupied manufactured home stock very well, especially with regard to capturing the decline over the 2001-2003 period, and the relatively unchanged level of the stock in subsequent years of the last decade. The value from the 2011 AHS is higher than the predicted value, a result not unexpected from the pattern observed for single- and multi-family housing units. At this point, the predicted value for 2011 is deemed to represent a more plausible change from 2009 than that reported by the 2011 AHS. 


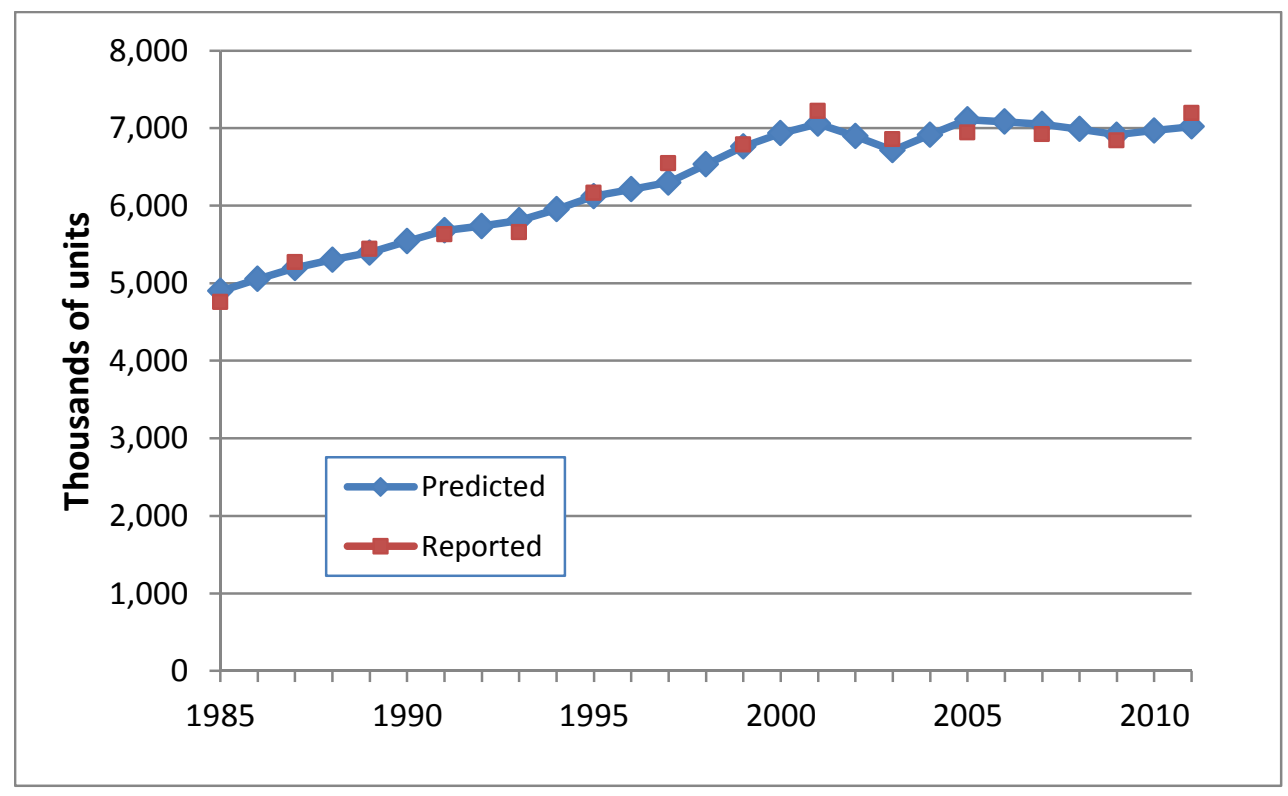

Figure A. 6. Occupied manufactured homes, predicted vs. reported AHS, for U.S.

\section{A.1.3 Regional Estimates of Occupied Units}

The estimation of the number of occupied housing units by type and by census region was based upon sharing out the national estimates. While the approach of developing calibrated stock models that was applied to the national data could be extended to the regional data, the complexities encountered in the national analysis suggested that that approach may be challenging at the regional level. Thus, a more straightforward approach, using the regional shares of reported AHS stock numbers, was undertaken. ${ }^{13}$

As seen above, the reported values of occupied housing units from the 2011 AHS appear to be implausibly high relative to those from the 2009 survey. However, for purposes of allocating national totals to the census regions, one may assume that the factors contributing to the 20092011 differences may be at least consistent across regions. In examining the regional shares from the 2011 AHS, they appear to generally follow prior historical trends for single-family and multi-family occupied housing stocks. Thus, the shares for these categories of housing units employed the 2011 AHS values. However, this result was not observed for manufactured

\footnotetext{
${ }^{13}$ For non-AHS years, regional shares were linearly interpolated between the adjacent AHS years.
} 
housing units. ${ }^{14}$ For manufactured housing units regional shares were maintained at the 2009 values for both 2010 and 2011.

\section{A.1.4 Average Size of Residential Housing Units: National}

Of primary concern in the work to support intensity indicators was a means to develop robust historical estimates of the total floor space of the residential housing stock. Total floor space is derived in a straight forward manner by multiplying the number of units by the average size per unit. Total floor area at the national level is the sum of the regional floor space estimates.

Similar to the process used to estimate the number of regional housing units, the approach was to first estimate average size at the national level and then to apply regional ratios to develop average sizes for the census regions. This approach as applied to average size is further motivated by the lack of credible housing size data prior to 1999 .

The first step thus becomes one of developing a simple model to estimate national average size for each of the three major housing types. This model is used to both estimate (i.e., backcast) the housing size for years prior to 1999 and to smooth any sampling errors in the surveys in subsequent years.

\section{Single-family}

Because both the first AHS (American Housing Survey, then termed the Annual Housing Survey) and the base year of the intensity indicators are 1985, the focus was to estimate housing size from 1985 forward. The model used to predict average size used the size data from new houses constructed (from Characteristics of New Housing), as well as a procedure to distinguish the total floor area in the pre-1985 stock from the post-1985 additions to that stock.

Figure A.7 shows the actual and predicted average sizes of occupied single-family housing units for the period 1997 and later, as well as the predicted values of average size for 1985 through 1997. The predicted values for the earlier years suggest that the growth of average size has been relatively constant, at least up to the most recent housing recession years. According to the stock model, the average size increased about $8.4 \%$ in the $1985-1995$ period and about $9.7 \%$ in the 1995-2005 period. As seen in the figure, the rate of increase slows in the period after 2005.

\footnotetext{
${ }^{14}$ For example, the share of occupied manufacturing housing units for the Midwest census region declined from 0.167 to 0.152 between the 2009 and 2011 AHS. This change was roughly twice as great as the calculated change between any two sequential surveys in the previously history from 1999 through 2009.
} 


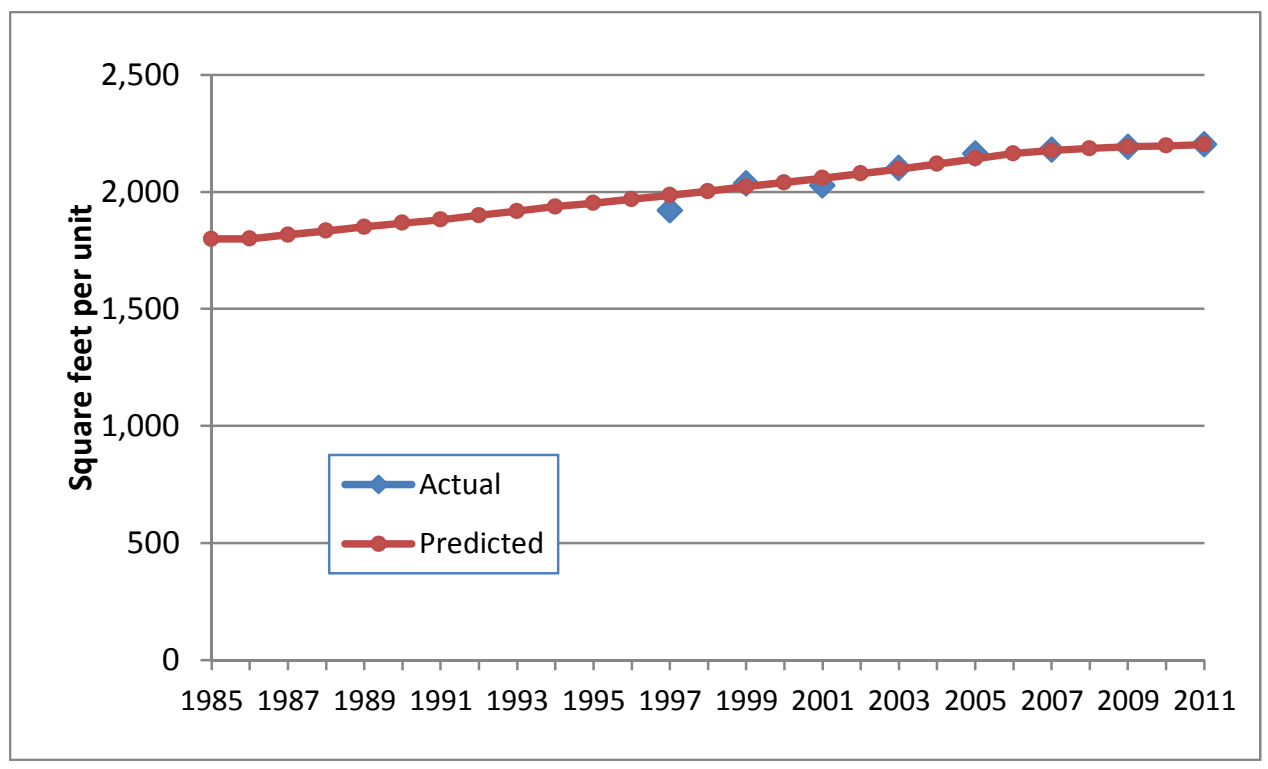

Figure A. 7. Predicted and actual average size of occupied single-family housing units, plus extrapolation back to 1985

It may be of interest to look at the historical series of the size of average new single-family homes based upon the CNH. This series is shown in Figure A.8. The figure clearly shows a correlation of incremental changes in average size and general economic conditions. The economic shocks caused by oil prices and the recessionary period of the early 1980s dampened the increase in average new home size over the first 10 years of the survey (1973-1983).

Average new home size grew significantly during the robust economy over the remainder of the 1980 s, up to the slowdown in economic growth at the early 1990s. The trend toward larger home sizes resumed in the mid-1990s up until the 2002-2003 recession. The last spurt in average home size occurred during the housing boom from 2004 through 2007. The decline in average home size in the subsequent three years was the largest of any experienced over the past four decades. The upturn in average size in new homes for the latest two years (2011 and 2012) likely reflects a greater percentage of custom-built homes within a much smaller overall construction market. 


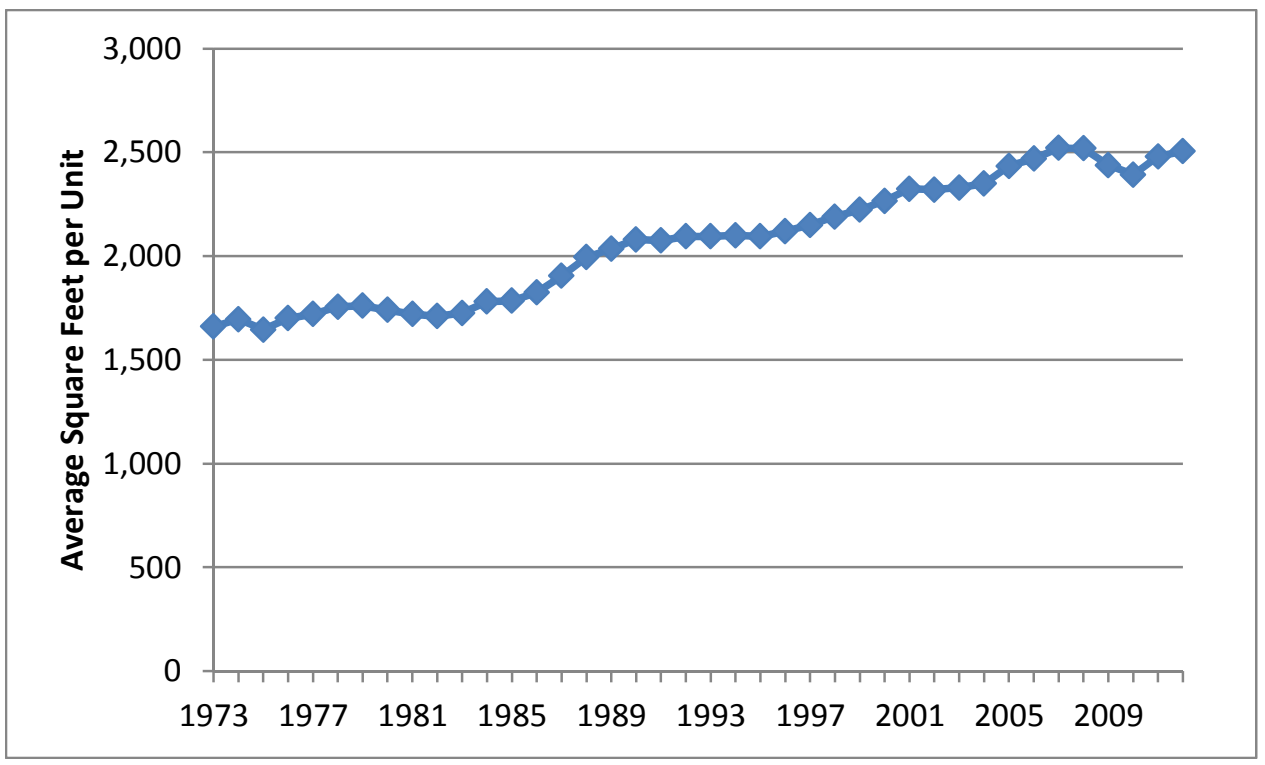

Figure A. 8. Reported average size of new single-family housing units from the Characteristics of New Housing survey, 1973-2012 (see footnote 9 above)

\section{Multi-family}

As an element in the mathematical model to estimate average housing size, one parameter was used to represent the increase in the average size of the pre-1985 stock. That parameter captures additions to the stock in the form of newly constructed floor area to existing units. For multifamily units, however, this parameter much more likely reflects differential retirement rates across and within various vintages of units. Table A.2 above clearly shows that the average size of pre-1950 units is considerably higher than those built in the succeeding three decades. But, even if retirement rates are greater in the oldest vintages, as borne out in the data in Table A.5, one can have a strong supposition that smaller units (less desirable in more robust economic conditions) would be retired before larger units. Thus, there may be a natural tendency for average size to increase within the same vintage of units in later surveys.

Because of the uncertainty surrounding the parameter reflecting the annual increase in the pre1985 stock, and a desire to err on the side of conservatism with regard to the growth in the average size, this parameter was adjusted downward by 25\% in backcasting the 1985-1997 data points. This adjustment has the result of increasing the estimated average size of the total stock in 1985 from the 815 square feet to 848 square feet. The predicted vs. actual values of average size for 1999 and later surveys, as well as the model-generated average size for prior years is shown in Figure A.9 (with the adjusted 1985-1997 series denoted as "Predicted-Alt").

There is some hesitancy to use the model-generated values over the period 2007-2011 period. The model reflects to a lesser degree the peculiar behavior of the AHS reported overall average size of multi-family units over this period, rising from 1,021 square feet in 2007 to 1,042 square feet in 2009, and then falling back to 1,026 square feet in the most recent (and much larger) 2011 
AHS. At a minimum, it can be assumed that the increase over the 2007 to 2011 was not large, even if the intervening years may display some unexpected behavior. At this point, there appears to be no alternative other than to employ the AHS data over the entire period.

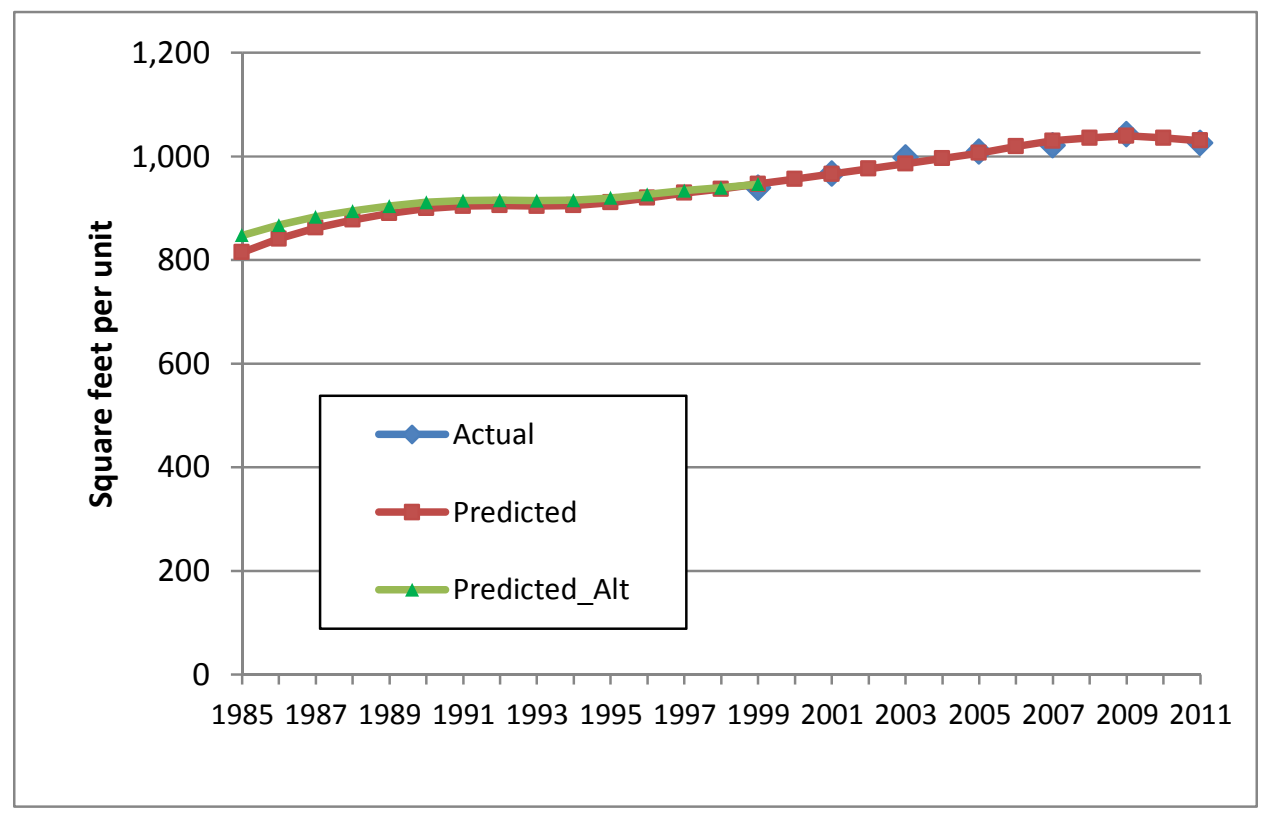

Figure A. 9. Predicted and actual average size of multi-family housing units, plus extrapolation back to 1985

\section{Manufactured Homes}

As discussed in the main text, the values of average size from the AHS were deemed to be implausibly high. Moreover, models to estimate changes in the average size over time were also viewed as unsatisfactory. In this case, the RECS data were used exclusively to estimate average sizes of the national stock of these units. The values for non-RECS years were generally obtained by simple linear interpolation between adjacent RECS years. For 2010 and 2011, the average annual incremental increase was based upon adjusting the RECS reported annual change between 2005 and 2009. The adjustment reduced the annual change for these 2 most recent years by $40 \%$, reflecting the relative magnitude of manufactured home placements in these years compared to the 2005-2009 average.

For years prior to the first RECS (in 1980), the size was based upon vintage data derived from the 1984 and 1987 RECS. Data from these two surveys were combined as simple averages, as a means of estimating the average size among existing homes from three (constructed) vintages: 1950-1969, 1950-1974, and 1950-1979. (There were no data earlier than 1950 related to manufactured homes reported by the RECS.) The ratio of the average size from the first two of these vintage categories was compared to the average size of the third vintage. (As an example, 
the average size for the 1950-1973 period was 765 square feet and the average for the 1950-1979 period was 810 square feet. The ratio between these two numbers $(0.944)$ was applied to the reported average size from the 1980 RECS ( 826 square feet) to predict the average size for the stock in 1974 (yielding 780 square feet) An analogous procedure was used to estimate the average size of the stock in 1970. The average size data derived from the 1984 and 1987 RECS were used rather than that from the earlier surveys because the vintage data were deemed to be more robust. Figure A.10 displays the average size estimates derived from the RECS and the methodologies used to generate annual values for non-RECS years.

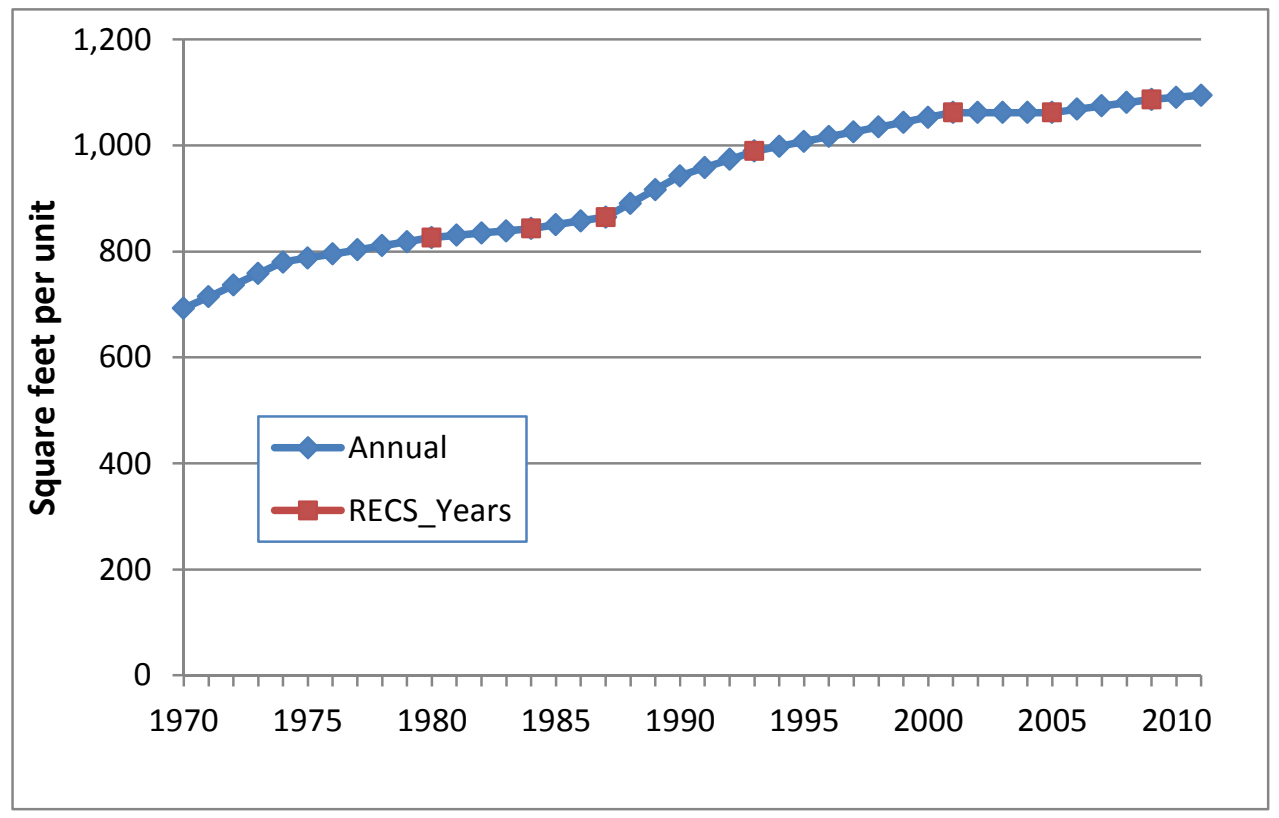

Figure A. 10. Estimated average size of occupied manufactured housing units, 1970-2011.

\section{A.1.5 Average Size of Residential Housing Units: Regional}

For estimates of the average size of housing units at the regional level, the similar ratio approach was used as was employed for regional estimates of the number of units. Trend regression models were used to estimate the average change in the ratio of the average size of the regional stock to the average size of the national stock. These models could be estimated for the AHS data over the years 1997 through 2009 (for the six years in which larger sample sizes in the AHS were utilized; but excluding the most recent 2011 AHS with somewhat incomparable data). Figure A.11 presents the regional/national size ratios for single-family housing units for the data derived from the AHS. 


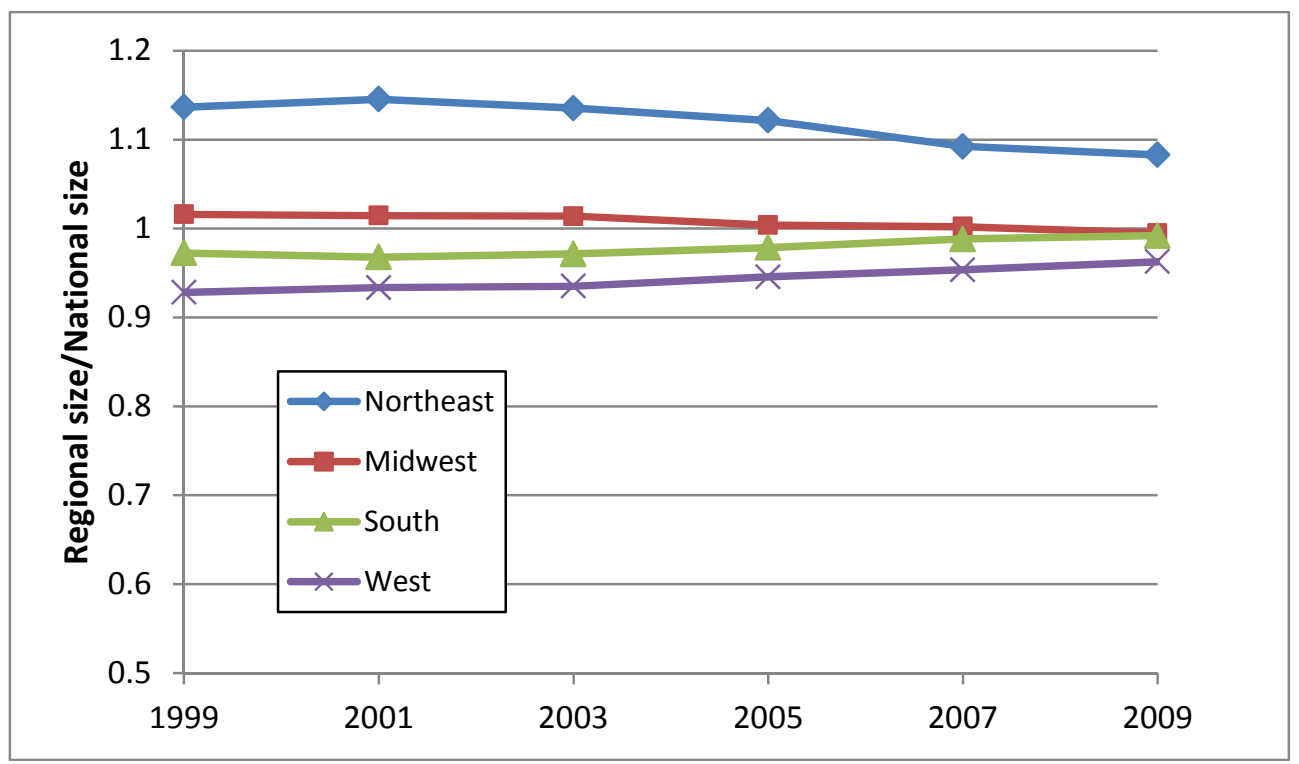

Figure A. 11. Regional/national ratios for single-family housing units, 1999-2009

The more difficult question is whether to assume that the trends reflected in these simple models were present in the years prior to 1997. For this purpose, data from the RECS were to calibrate general rates of change (of the regional/national size ratio) in the period 1985 to 1997 . The approximate calibration compared trends in total square feet by region between the RECS and the methodology using the AHS data (and the use of extrapolated trend ratios of regional to national average unit size).

For purposes of extrapolating the ratios for 2010 and 2011, the annual rates of change were adjusted to reflect the lower volume of activity in construction for these years. Adjustment factors were based upon the relative number of new housing units constructed over the 20102011 period, as compared to the 2005-2009 average. For example, for single-family homes in the Northeast, the relative construction volume in the 2010 and 2011 was about $40 \%$ of that in the prior 4 years, so the annual change in the size ratio for these 2 years was reduced $40 \%$ relative to its earlier trend. Figure A.12 illustrates the results of the 1997-2009 regression on the size ratios for single-family units for the Northeast census region, and the modified extension of that trend to both earlier and later years. 


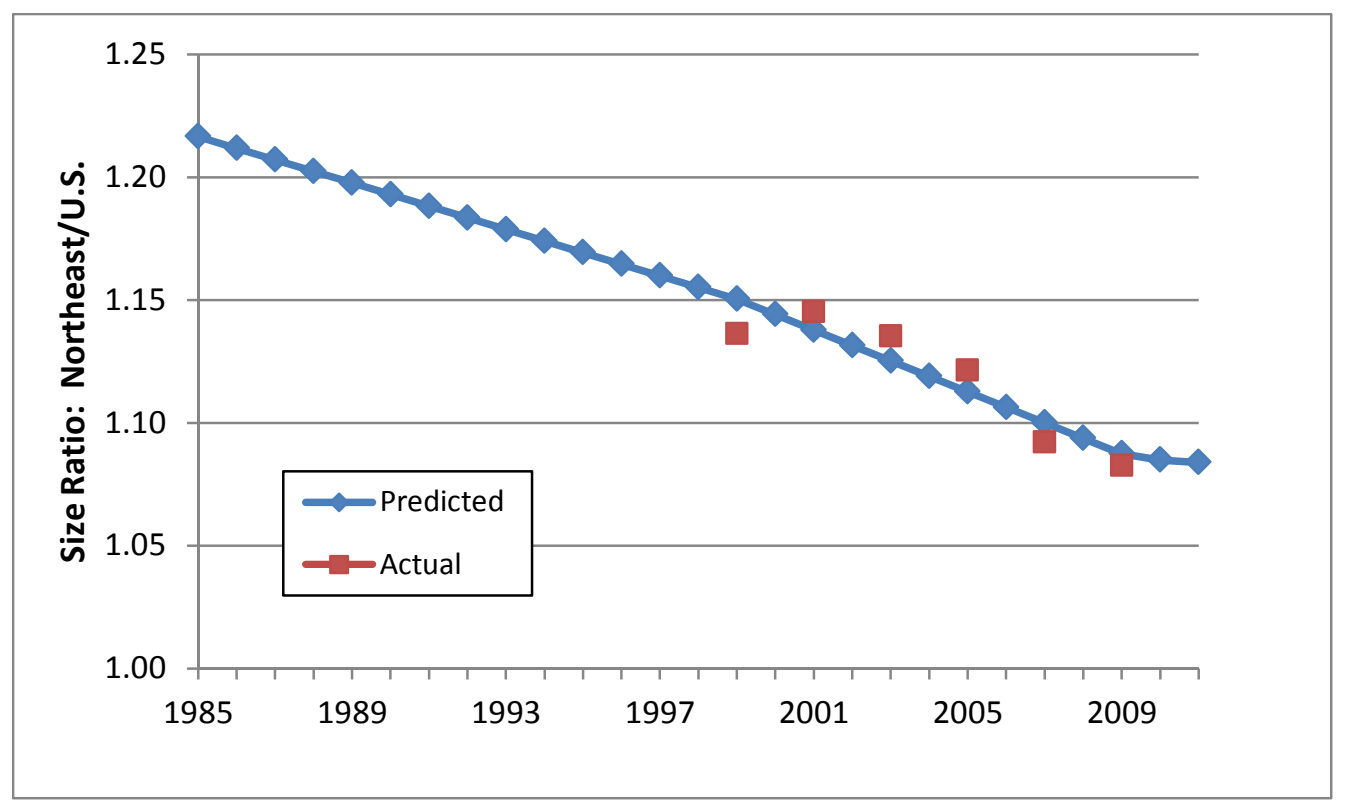

Figure A.12. Illustration of regional size trend ratio regression and extrapolation, single-family housing units in the Northeast census region

\section{A.1.6 Housing Stock and Size Estimates, 1970-1984}

In late 2012, an effort was made to develop residential floor area estimates for the period 19701984. The primary motivation for this work was to support a statistical analysis of residential energy intensity and consumption over the 1970-2011 period. The work followed the same general approach as described in the previous subsections; separate estimates were developed for the stock of housing units by type and for the average size of the units in each year.

\section{Stock of Housing Units, 1970-1984}

With regard to the number of housing units, the primary source was the Annual Housing Survey, the predecessor survey to the American Housing Survey. The Annual Housing Survey was conducted in each year from 1973 through 1982, and then finally in 1983. The initial American Housing Survey, with an expanded sample frame, was conducted in 1985. Because of the differences in sample frame and other elements between the two surveys, the stock estimates by region and housing type were not always consistent between the 1983 Annual Housing Survey and the 1985 American Housing Survey. Some discussion of these differences, and a partial reconciliation of national estimates, was provided in a technical note that accompanied the 1985 American Housing Survey.

The estimation method for this earlier data was carried out in several steps. The first step was to extrapolate the previously calculated housing stock estimates for 1985 back to 1983 . To begin the process, the data on total completions by housing type (single-family and multi-family) for 
1984 through 1986 was used to compute growth factors. These factors were calculated as the number of new units in one year divided by the new units built in the previous year. The factor for 1985 to 1986 was then applied the absolute incremental increase in housing units developed from the estimates discussed in Section A.1.1 above.

For example, the factor calculated from the completions data for single-family units in the Northeast for 1985 and 1986 was 0.88 . This factor was assumed to be the relative change in the stock between 1984 and 1985 compared to the change between 1985 and 1986. This factor was multiplied by the estimated change in the stock between 1985 and 1986 based on the American Housing Survey data (where the national estimates are shown in Figure A.2). For the Northeast the change in the stock between 1985 and 1986 was approximately 98 thousand units. This value was multiplied by 0.88 to yield 85 thousand units as an approximate change in the stock between 1984 and 1985. The 1984 stock was then calculated as the 1985 stock less 85 thousand units. A similar extrapolation method was used to get back to 1983.

This process just described yielded estimates roughly consistent with the American Housing Survey for 1983. The values could then be compared with those from the last Annual Housing Survey in 1983. In some instances, the correspondence was quite good. For example, for singlefamily units in the Northeast, the 1983 Annual Housing Survey estimate was 10,411 (thousand) units and the extrapolated American Housing Survey estimates was 10,568 (thousand) units. The correspondence was generally not as close for multi-family units. In the Midwest, the Annual Housing Survey estimate for 1983 was 5,241 (thousand) units and the extrapolated American Housing Survey estimate was 5,606 (thousand) units.

The tables published in the Annual Housing Survey for numbers of occupied housing units all include comparable values from the 1970 census. Thus, if one simply scales the entire time series from the Annual Housing Survey to match 1983 estimate derived from the American Housing Survey in 1983, then the 1970 values will not match those from the 1970 census. The approach in the next step was to assume that the reason for the mismatch in the 1983 estimates was the result of sample "drift" associated with Annual Housing Survey. Thus, a set of multiplicative adjustment factors were computed by means of linearly interpolating between a value of 1 (in 1970 and 1973) to the ratio of the American Housing Survey divided by the Annual Housing Survey estimate in 1983. Thus, for example, in the above case for the Northeast census region, the 1983 factor was calculated as 10,568/10,411 or 1.015. The adjustment factor was assumed to be 1 in 1973, the first year of the Annual Housing Survey. Between 1973 and 1983, the adjustment factors (as multipliers on the Annual Housing Survey values) were interpolated between the values of 1 and 1.015 .

As mentioned above, the Annual Housing Survey did not contain estimates for 1971, 1972, and 1982. Absolute values for 1971 and 1972 were estimated by linear interpolation between 1970 and 1973. Because of the depressed housing market, the data on new units completed from $\mathrm{CNH}$ were used in the method to interpolate the stock between 1981 and 1983. The objective was to 
better represent the initial recovery in 1983, so that the resulting estimates of the stock do not show identical increments in both 1982 and 1983.

Average Size of Housing Units, 1970-1984

While the Annual Housing Survey provides sufficient information to construct estimates of housing stocks by type of unit and by census region for the earlier period, there is no explicit data source that related to housing size. Even with the American Housing Survey, there were inadequate data on housing size prior to the late 1990s. As the previous section (A.1.3) discusses, it was necessary to extrapolate the more recent data to provide estimates back to 1985 .

The earliest data that pertain to the size of residential come from the RECS, in particular the 1984 and 1987 surveys. Lacking explicit data on the average size of stock housing units for the years in question (1970-1984), the approach must utilize vintage data for later points in time. The approach used for the intensity indicators was to examine the patterns of average size by vintage.

In both the 1984 and 1987 RECS, the average floor area for new single-family and multi-family homes was given for the following vintages: 1939 or before, 1940-49, 1950-59, 1960-69, 197079, and 1980-1984. Combining the two surveys and the vintages, the following average sizes were obtained on a national basis:

- 1969 and earlier: 1,704 square feet

- 1979 and earlier: 1,751 square feet

- 1984 and earlier: 1,750 square feet.

These absolute changes were imposed on the 1985 average size, estimated (via extrapolation) from the American Housing Survey. The changes in the size in the intervening years were based on a smoothing method. Based upon the RECS results, the 1985 average size 1,691 square feet was extrapolated back to 1979 by annual factor of 0.999 and from 1979 back to 1970 by a factor of 0.997 . That is, during the $1970 \mathrm{~s}$, the average size in year (t-1) was assumed to be 0.997 times the average in year $(t)$. At the national level, the estimated average size of occupied units was estimated to be 1,691 square feet in 1985 (as in Figure A.6), by use of this backward extrapolation procedure, estimated to be 1,633 square feet in 1970. These (negative) growth factors were selected to yield the approximate change in square footage estimated by the RECS.

The limitations of this approach should be pointed out. First, by using only information from a point in time, there is no recognition of the increases in average size of single-family homes from additions. Second, there still seems to be a bias in the average sizes of home reported by the 
RECS and those reported by the American Housing Survey ${ }^{15}$. At this point, a more complete reconciliation of sources and more thorough analysis of this earlier period await further research.

The same general approach of examining the 1984 and 1987 vintage data was followed for multi-family units. In this case, the calculated values showed no increase from the average size in the pre-1970 stock, compared to the stock including the 1970s vintage. This result was deemed implausible, and so the annual growth factor (or, more properly, the reciprocal) in average size was assigned a value of 0.998 between 1970 and 1979.

For manufactured homes, as explained at the end of Section A.1.4, the vintage data from the 1984 and 1987 RECS also were used. The average size from all vintages through 1969 , compared to the size computed from all vintages through 1979, increased by 130 square feet. Such an increase is likely caused by a larger share of double-wide mobile homes sold over that period.

The discussion above was entirely devoted to constructing national estimates of the average size of housing units. Similar to the approach used for the post-1985 estimates, the average unit sizes by region were based upon ratios applied to the national estimates. The change in the ratio between 1985 and 1986 was computed and multiplied by 0.5 . The 0.5 reflected a middle position between assuming no change in the relative size of the regional stock compared to the national stock and assuming the change would be equal to the estimated values from the post1985 period. Because of the uncertainty of using the RECS data to impute changes in the national average size, it seemed infeasible to try to use the same approach at the regional level

An honest assessment is that there are few data sources available to support robust pre-1985 measures of floor area in the residential sector. The discussion above should make clear that a number of strong assumptions are required to develop these estimates. Thus, at this point, the estimates should not be viewed as definitive, but provisional until a more focused research effort can be directed toward this topic.

\section{A.1.7 Weather Adjustment}

Weather adjustment of the energy intensity indexes was performed by linear regression models. These models were estimated separately for fuels and electricity, using as dependent variable energy consumption per square foot of floor area. Models were estimated for each census region and for two separate time periods: 1970-1984, and 1985-2011.

Because energy consumption in buildings can be considered additive across end uses, the regression models followed a linear, rather than logarithmic, specific. In other words, because space conditioning is likely to have changed more than other end uses since 1970, it was deemed

\footnotetext{
${ }^{15}$ The data in Table A.1 would suggest an average size of homes built through 1980, in the 2009 stock, to be larger
} than the RECS values cited here. 
inappropriate to consider space conditioning as constant fraction of total energy use, with only weather variation affecting that fraction from one year to the next. ${ }^{16}$ To account for varying levels of impacts over the regression period, cross-product term involving degree-days and time was included in the specification. To account for time intervals with varying degrees of intensity changes, the time trend variable was augmented to include squared and cubed terms of time. The resulting specification for fuels intensity (heating) was formally:

Intensity $=b_{0}+b_{1} \mathrm{HDD}+b_{2} \mathrm{HDD} *$ Time $+b_{3}$ Time $+b_{4} \mathrm{Time}^{2}+b_{5} \mathrm{Time}^{3}+e$

where

$\begin{array}{lll}\text { Intensity } & = & \text { energy use }(\mathrm{kBtu}) \text { per sf of residential floor area in census region } \\ \text { HDD } & = & \text { heating degree-days for census region, from weighted HDD for } \\ & \text { census divisions } \\ \text { Time } & = & \text { annual time trend (year } 1=0, \text { year } 2=1, \text { year } 3=2, \text { etc. }) \\ e & \text { stochastic error term }\end{array}$

The HDD data are taken from the Table 1.9, Heating Degree-Days by census division, in the Annual Energy Review 2011 (EIA 2012a). To calculate HDD for census regions, the HDD values by census division are combined with weights that approximate the relative shares of heating consumption at a period roughly at the midpoint of the time series. These shares were based upon heating end-use consumption estimates by census division developed for the 1993 Residential Energy Consumption Survey (RECS), (EIA 1995).

The most recent (2011) degree-day data from the Annual Energy Review 2011 were revised (very slightly) on the basis of data derived from the primary source, the National Climatic Data Center (NCDC) in the U.S. Department of Commerce's National Oceanic and Atmospheric Administration (NOAA). Heating and cooling degree-day data by census division are published in NCDC's Historical Climatology Series (Series S-1 for heating degree-days and Series S-2 for cooling degree days). ${ }^{17}$

For electricity intensity a similar regression specification was used, but with the emphasis on cooling degree-days (CDD). In this case, both CDD and HDD variables are included in the

\footnotetext{
16 To elaborate, if one uses the log of the dependent variable in a specification that include degree days as one of the independent variables, then a given change in degree days always leads to the same percentage change in consumption. This would be a misspecification if the fraction of overall energy use attributable to space conditioning were decidedly different in the early periods of the regression compared to later periods.

${ }^{17}$ The historical heating and cooling degree-day data from NCDC can be accessed from http://www.ncdc.noaa.gov/oa/documentlibrary/hcs/hcs.html
} 
specification, although there is no cross product with time for the HDD variable. The final regression model specification for electricity is:

Intensity $=b_{0}+b_{1} \mathrm{HDD}+b_{2} \mathrm{CDD}+b_{3} \mathrm{CDD} *$ Time $+b_{4}$ Time $+b_{5}$ Time $^{2}+b_{6}$ Time $^{3}+e(\mathrm{~A} .4)$

The CDD data are taken from the Table 1.10, Cooling Degree-Days by Census Division, in the Annual Energy Review 2011. The weighting methodology is the same, except that the weights related to the electric heating and cooling consumption estimates that were developed for the 1993 RECS.

After the estimation of the regression models, two measures of predicted intensity were used to calculate a weather normalization factor. The first is simply the predicted values of the regression model using the actual HDD and CDD values. For the second set of predicted values, the long-term normal values of HDD and CDD are used instead of the actual values. The longterm normal values are taken directly from Tables 1.9 and 1.10 in the Annual Energy Review 2011 (and according to the footnote in the 2011 edition, the normalized values are an average over the 1971-2000 period). Thus, if the predicted intensity with actual degree-day values is denoted as Intensity ${ }^{\mathrm{P}}$ and the predicted intensity using the long-term normal values of degree day is denoted as Intensity ${ }^{N}$, then the weather adjustment factor for that year is simply:

$$
\text { Weather Adjustment Factor }=\text { Intensity }^{\mathrm{P}} / \text { Intensity }^{\mathrm{N}}
$$

As defined in this manner, the weather factors are divided into the nominal fuels and electricity consumption data prior to constructing the intensity indexes.

To help illustrate the methodology, the coefficients for the fuels regression for the South census region over estimation period 1985-2011 are shown in Table A.7.

Table A.7. Regression coefficients for weather adjustment model: fuels intensity, South census region, 1985-2011

\begin{tabular}{|l|c|c|c|c|c|c|}
\hline & Constant & HDD & HDD*Time & Time & Time $^{2}$ & Energy Price \\
\hline Coefficient & 36.8 & 0.009301 & -0.0001204 & -1.407 & 0.0183 & -2.988 \\
\hline (t-statistic) & 5.46 & 4.03 & -1.51 & -5.37 & 4.54 & -2.02 \\
\hline
\end{tabular}

A graph of the actual and normalized fuels intensities is shown in Figure A.13. The coefficients from Table A.7 were used for the adjustments in the years 1985 and later. The adjustment 
reflects unusually warm (calendar) years experienced in 1974 and 1990, and the very cold winters in the eastern portion in the U.S. over the 1976-1978 period. ${ }^{18}$

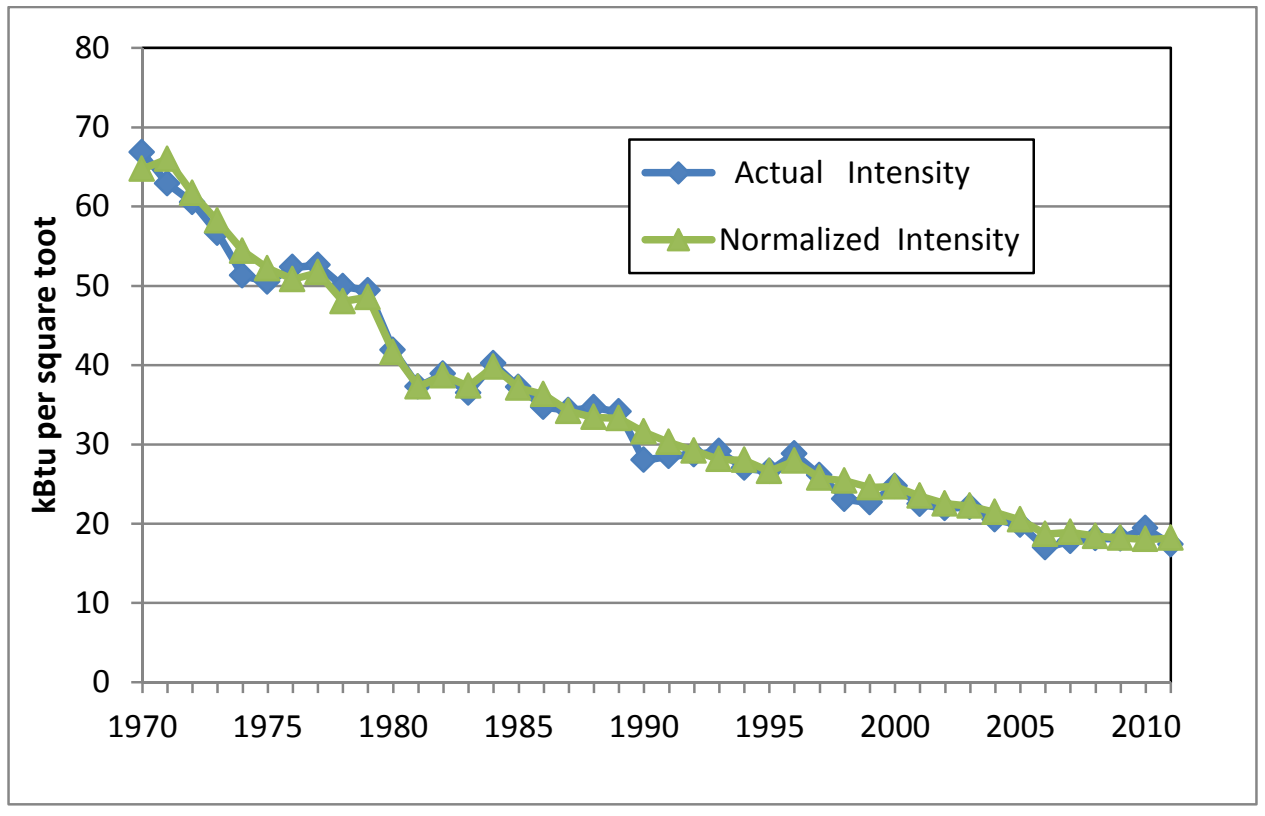

Figure A. 13. Actual and normalized fuel intensities for the South census region

\section{A.2 Commercial}

The energy intensity indicator in the commercial sector is restricted to a single index for all commercial energy use across the U.S. As for the residential sector, the index relies heavily on the supply-side derived estimates of energy consumption, as published by EIA in the Annual Energy Review. ${ }^{19}$ However, there are two issues related to the use of this data. The first involves the distinction between commercial sector energy use, which includes energy used by equipment outside of buildings, and a more restricted scope of the energy used solely in commercial buildings. The second issue relates to significant changes in the published estimates of commercial electricity use that stem from utilities reclassifying customers as commercial that were formerly some other classification (typically industrial), and vice versa.

\footnotetext{
18 The Potomac River froze over in early 1977. According to Table 1.7 of the Annual Energy Review 2010, January 1997 had the highest number of national heating degree-days of any month over the period 1970 through 2010.

${ }^{19}$ The latest data on commercial energy use are taken from Table 2.1c in the Annual Energy Review 2011 (EIA 2012a) and from the EIA website for the Monthly Energy Review July 2014 (EIA 2014). Annual commercial energy consumption data in spreadsheet form for Table 2.3 were found online: http://www.eia.gov/totalenergy/data/monthly/index.cfm
} 
Perhaps the main issue involved in the development of a robust energy intensity indicator for the commercial sector is the lack of consistent time series information on the stock of commercial floor space in the U.S. The discussion below will address this issue in some detail.

The final issue involves adjustment of the intensity measures to account for year-to-year weather variation. Following the approach in the residential sector, a set of single-equation regression models was developed to make these adjustments.

\section{A.2.1 Commercial Buildings versus Commercial Sector}

The commercial sector in the EIA's energy accounting for broad end-use sectors encompasses more than commercial buildings. The most important non-building uses of energy in the commercial sector are water and sanitary services, street lighting, and outdoor communication equipment. A 2007 PNNL study estimated that about 9\% of 2005 electricity use in the commercial sector was outside of buildings (Estimates of U.S. Commercial Electricity Intensity Trends: Issues Related to End-Use and Supply Surveys, Belzer 2007). No study has been made of commercial fossil fuel use outside of buildings. One might presume that outdoor amusement facilities would be consumers of diesel fuel (e.g., isolated ski areas), as well as electricity, but the magnitude of such use is unknown.

At present, the energy intensity indicators for the commercial sector for all fuels are based on an intensity based upon dividing total commercial sector energy use by total square footage of buildings. The 2007 PNNL study estimated that the growth in electricity consumption for these non-building uses was less than that in buildings over the period 1983-2005. Accordingly, the computed increase in energy intensity up to 2000 (as shown below) may slightly understate the actual increase in commercial building energy intensity. The lack of annual estimates of nonbuilding energy use prior to 1983 and after 2005, together with an objective to include as much of the U.S. energy consumption as possible in the energy intensity indicators system, motivated the decision to include the total commercial energy use (building and non-building) in the energy intensity indicator for this sector.

\section{Reclassifications of Commercial and Industrial Customers by Electric Utilities}

The electricity consumption data by end-use sector published in Table $2.1 \mathrm{~b}$ of the Annual Energy Review 2011 relies almost exclusively on the EIA-861 survey that is mandatory for the nation's electric utilities (more than 3,000 reporting entities). A potential contributing factor in the very large growth in commercial electricity sales reported in the EIA-861 survey over the period up through the mid-2000s may have been that some customers who formerly purchased electricity under a residential or industrial rate were subsequently switched to a "general service" or commercial rate. Typically, industrial rates are lower than commercial rates and are reserved to those customers with large (and relatively constant) electricity demands. Restructuring rate 
classes that put more customers into a "general service" class generally will increase utility revenue without the need for explicitly raising rates. Without trying to give a normative interpretation of this phenomenon, it may be that any shift to a rate class that is reported as commercial under EIA-861 is simply an effort to better align the utility's cost of service with its revenue. $^{20}$

The problem posed by these reclassifications was treated in detail in the 2007 PNNL report (Belzer 2007). The discussion below is taken largely from that report, but stops short of showing all of the individual reclassifications that were identified in the report.

In analyzing the historical data by state based on the EIA-861 survey, it appears that there have been significant reclassifications of accounts in recent years, particularly between the commercial and industrial sectors, in a number of states. To help identify the most significant changes, 1990-2004 data on the number of industrial and commercial customers were plotted together for each state. Evidence of reclassification was judged, in part, on the basis of clear discontinuities in the customer counts, where the change in the number of industrial customers was roughly matched by an opposite change in commercial customers. In a few cases, however, there were significant (and opposite) changes in consumption, but where the customer count changes were modest.

An examination of the state-level data for both customer counts and electricity sales resulted in the identification of a dozen states where there appeared to be a significant reclassification between industrial and commercial accounts. Over the period up to 2005, reclassifications between these two end-use sectors tended to increase commercial sector sales and reduce industrial sector

Although a small share of national electricity, the published state-level data for Minnesota provide a clear example of a reclassification, as shown in Figure A.14. The reduction in industrial electricity between 2000 and 2001 is mirrored with a similar increase in commercial use between the same two years.

\footnotetext{
${ }^{20}$ One must admit as well that without direct investigation as to how utilities respond to the 861 survey, it may be just that over time utilities have reported the consumption from more rate classes as "commercial" and fewer as "industrial." Thus, a reclassification in the context of this report need not involve customers actually facing a different rate schedule over time, but that the rate schedules are classified and aggregated differently for reporting to EIA.
} 


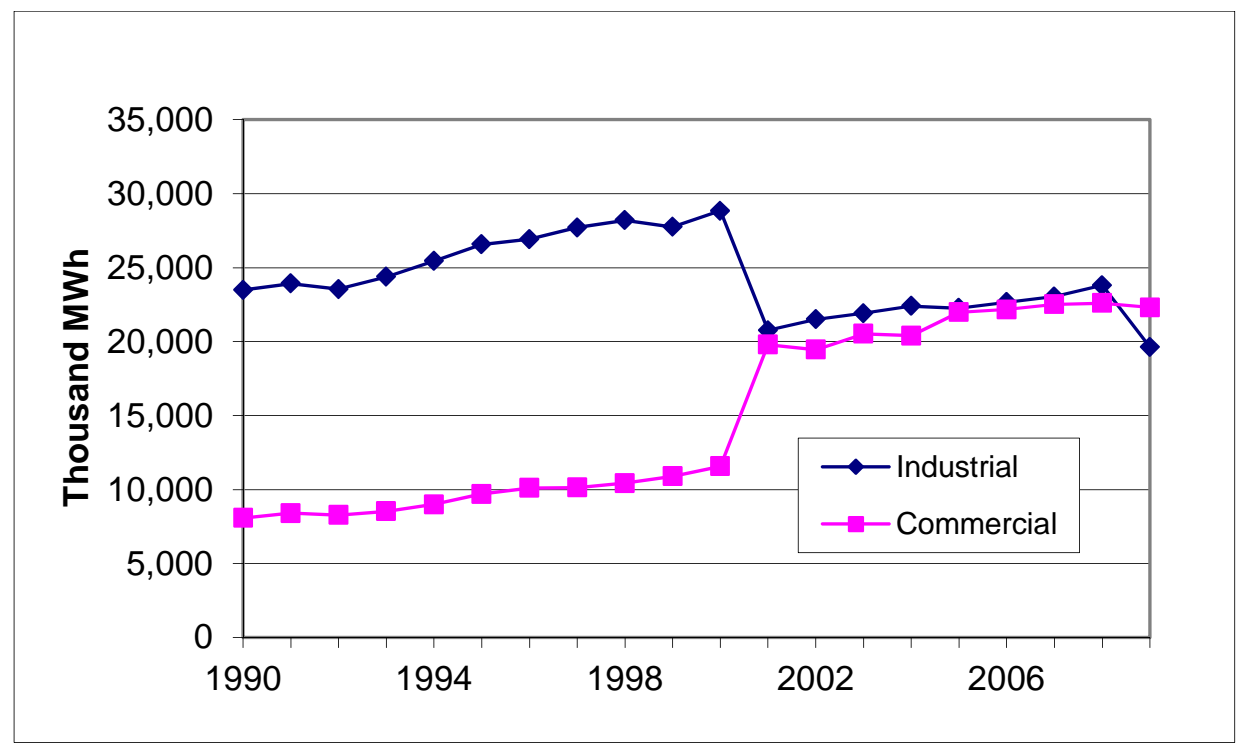

Figure A. 14. Reported commercial and industrial electricity for Minnesota, 1990-2009

The purpose of examining these major reclassifications primarily was to determine if they played any significant role in explaining the very high growth in commercial sector electricity sales over the period 1990-2005. To meet that objective, one must try to maintain what would have been a consistent classification framework over time. We can meet the second objective by trying to keep the commercial sales consistent with the classification framework either before or after the reclassification. For example, for Minnesota, one either shows that commercial sales over the period up to 2001 are greater by about 9 terawatt-hours (TWh), consistent with the post-2000 classification, or that the sales are about $12 \mathrm{TWh}$ in 2001 and grow along a smooth path after that (consistent with the pre-2001 classification).

Ideally, we would like to identify the choice that would yield a closer match to the amount of electricity actually used by commercial buildings. Unfortunately, without detailed examination of the specific utilities for which these reclassifications took place and how their rate classes are defined, there is no clear evidence on which to make a particular choice. For the 2007 study, an attempt was made to estimate the consumption series using two methods. In method A, the approach was to maintain the commercial time series consistent with the earlier classification. This has the advantage that one need only adjust the more recent commercial sales data, rather than going all the way back to the early and mid-1980s to construct a consistent time series.

For the second method (B), an effort was made to estimate what commercial and industrial sales might have been in earlier years using the most recently observed classification. Because many of the reclassifications occurred in the mid to late 1990s, this method is likely to involve more uncertainty because we need to adjust more years of data. Nevertheless, if we presume that the most recent reporting of commercial and industrial sales portrays a more accurate distribution 
between these two sectors, then method B is to be preferred, in spite of the need to make adjustments over a longer time period.

The 2007 study ultimately produced two sets of estimates at the national level, corresponding to the methods A and B just described. For purposes of the energy intensity indicators work here, the estimates from method A were selected. ${ }^{21}$ Method A approximates what electricity consumption would have been had the 1985-1990 classifications of customers remained constant over time. It is presumed to reflect a conservative estimate of the reclassification adjustment. Method A estimates the amount of reclassification in the year that it occurred and then holds the magnitude of that adjustment constant in subsequent years. Without detailed information (and analysis) by utilities, there is really no basis on which one can rigorously estimate how commercial (or industrial) electricity consumption under current classifications (or rate schedules) would be altered should customers be classified under a system in place decades earlier.

Subsequent to the 2007 study, the state-level electricity data based on EIA's 861 survey have been reviewed to detect recent reclassifications that yield abnormal changes in the commercial electricity consumption. The two major reclassifications in the years after those covered by the 2007 study occurred in Maryland in 2006 and in Massachusetts in 2009. Table A.8 shows the adjustments to the national commercial electricity consumption that have been estimated through the application of method A. In 2010, the reduction in reported electricity use in the commercial sector from these adjustments is $3.0 \%$.

\section{A.2.2 Floor Space Estimates}

Unfortunately, similar to the residential sector, there are no publicly available time series estimates of commercial building floor space in the U.S. As a result, a set of annual values must be estimated from available information on historical construction activity in the U.S. The following section describes briefly this process.

While no annual publicly available series on floor space exists, the various commercial building surveys conducted by the EIA provide the primary basis for developing a set of estimates. ${ }^{22}$ Because these surveys have only been conducted every 4 three to four years and because there is a significant degree of sampling variation associated with these estimates (blurring the changes from one survey to the next), a more robust measure of the stock of commercial floor space for each year is required.

\footnotetext{
${ }^{21}$ The District of Columbia showed a large reclassification in 1994 that resulted in a 90\% decline in industrial use, and $50 \%$ increase in commercial. In this one particular case, method B was followed; a constant amount of electricity use was added to the pre-1994 commercial consumption values (9.2 TBtu of site electricity).

22 EIA conducted what was published as the Nonresidential Building Energy Consumption Survey (NBECS) for 1979, 1983, and 1986. Beginning with the 1989 survey, the title was changed to Commercial Building Energy Consumption Survey (CBECS). Subsequently, the CBECS was published for 1992, 1995, 1999, and 2003.
} 
Table A.8. Adjustments in aggregate commercial electricity caused by reclassifications (trillion Btu, site)

\begin{tabular}{|r|r|r|r|}
\hline & $\begin{array}{c}\text { Adjustment } \\
\text { (Tbtu) }\end{array}$ & & $\begin{array}{c}\text { Adjustment } \\
\text { (Tbtu) }\end{array}$ \\
\cline { 2 - 4 } & 9.2 & 2001 & -162.6 \\
\hline 1986 & 9.2 & 2002 & -136.3 \\
\hline 1987 & 9.2 & 2003 & -108.9 \\
\hline 1988 & 9.2 & 2004 & -126.0 \\
\hline 1989 & 9.2 & 2005 & -126.0 \\
\hline 1990 & 9.2 & 2006 & -164.0 \\
\hline 1991 & 9.2 & 2007 & -164.0 \\
\hline 1992 & 29.8 & 2008 & -164.0 \\
\hline 1993 & 10.2 & 2009 & -138.0 \\
\hline 1994 & 1.7 & 2010 & -138.0 \\
\hline 1995 & -40.6 & 2011 & -138.0 \\
\hline 1996 & -40.6 & & \\
\hline 1997 & -117.7 & & \\
\hline 1998 & -117.7 & & \\
\hline 1999 & -117.7 & & \\
\hline 2000 & -117.7 & & \\
\hline & & & \\
\hline
\end{tabular}

Source: Based upon examination of state-level electricity sales by state for industrial and commercial sectors. See Belzer (2007).

These estimates are based on a combination of data from the EIA commercial building surveys (NBECS/CBECS) and floor space additions provided by the F.W. Dodge Division of the McGraw-Hill publishing company. The "Dodge" construction data are published in the Statistical Abstract of U.S. ${ }^{23}$ Given the lack of detailed Dodge data by building type from this source, the estimates thus far have been developed only for aggregate commercial floor space in the U.S. The estimation of floor space follows a perpetual inventory approach: stock in any given year is based on the previous year's stock, new additions, and estimated retirements from the stock. $^{24}$ Based on previous PNNL work, the current series of historical commercial floor space

\footnotetext{
${ }^{23}$ For example, recent data through 2007 were taken from the U.S. Census Bureau's Statistical Abstract of the U.S.: 2009, Table No. 924, "Construction Contacts-Value of Construction and Floor Space of Buildings by Class of Construction: 1980:2007." Classes of construction are very broad: commercial (includes office, retail, lodging, and warehouse), educational, health, public buildings, religious, social and recreational, and miscellaneous. The data are published only in the hard copy version of the Statistical Abstract, and are not available on the Census Bureau's website: http://www.census.gov/compendia/statab/

${ }^{24}$ The estimates of retirements are based on the two-parameter logistic survival curve, using the same functional form as that used by EIA in the commercial NEMS model (EIA 2012b). The parameters of this curve were estimate by finding the best statistical fit to four data points corresponding to the percentage of surviving stock for four vintages $(<1920,1920-1945,1946-1959,1960-1986)$ as implied by the 1999 CBECS in comparison to the 1989 CBECS. The median lifetime for all commercial buildings from this estimation was 59 years. For recent years, the survival curve generates an average retirement rate of about $0.7 \%$ per year.
} 
is benchmarked to the $1989 \mathrm{CBECS}^{25}$ Unfortunately, new floor space additions from F.W. Dodge are very likely to underestimate the actual amount of new floor space. ${ }^{26}$ An adjustment of this Dodge-based underestimate for the period 1960-1989 is based on the amount of floor space estimated by the 1989 CBECS to have been built during this period. This adjustment increases the Dodge floor space additions numbers by about $20 \%$ to account for this underreporting.

Figure A.15 compares the annual floor space developed from this perpetual inventory approach and the estimates of national floor space from the various CBECS. The CBECS numbers in the figure have been adjusted to approximately match the definitional scope of buildings included in

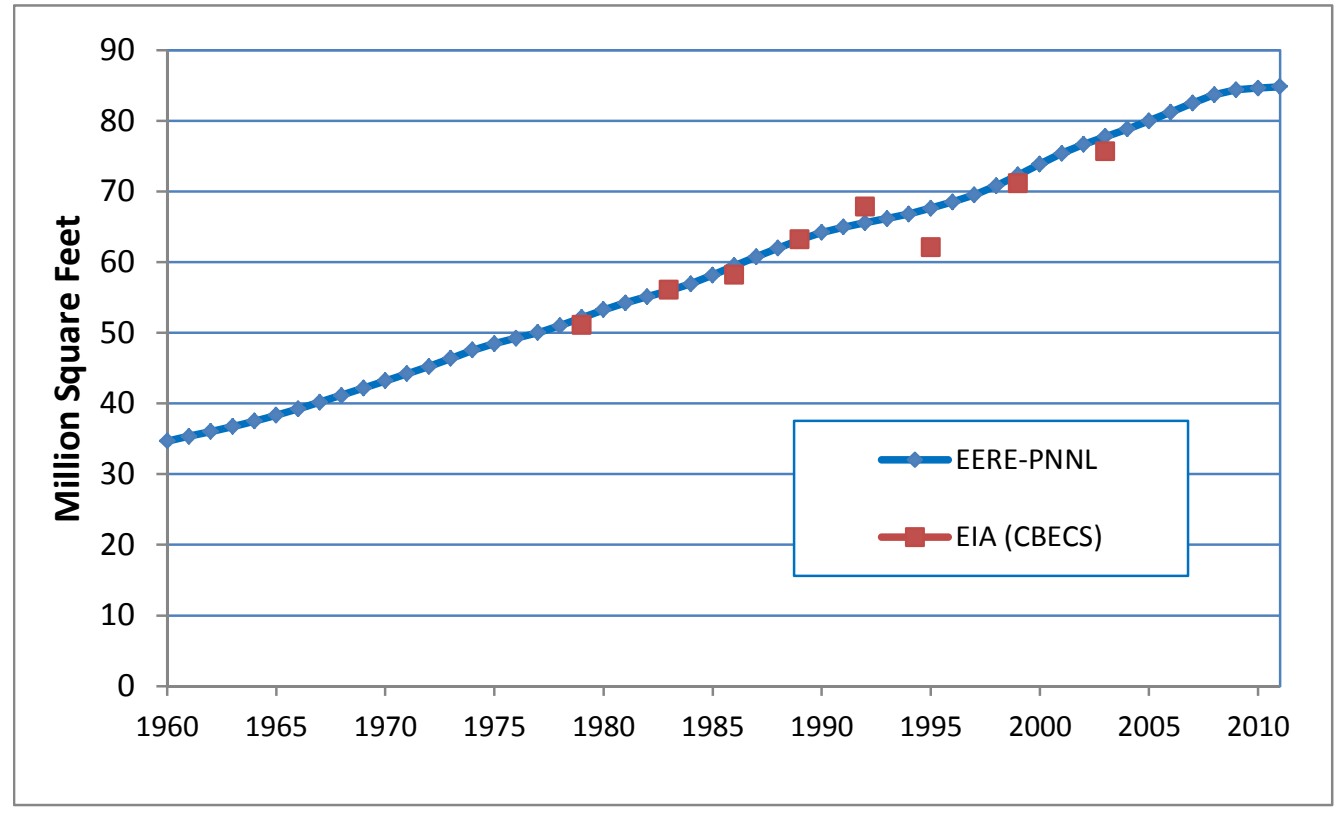

Figure A. 15. Estimates of total commercial building floor space in the U.S., 1970-2011

the CBECS for 1986 through 1992. This definition includes parking garages and commercial buildings in manufacturing complexes (buildings that are presumed to be included in the Dodge construction data).

\footnotetext{
${ }^{25}$ The floor space stock is periodically updated by PNNL. The general approach to developing the historical time series of floor space was documented by PNNL in a 1994 evaluation report prepared by Brookhaven National Laboratory for the EERE/Buildings Technology office (Pierce 1994).

${ }^{26}$ This assertion is based primarily on the methodology used by the U.S. Census Bureau to estimate the value of new nonresidential construction. In the current methodology, the Census Bureau increases the value of construction from a sample of Dodge construction projects by $25 \%$ to "account for undercoverage of construction projects not covered by MHC" (McGraw-Hill Construction). The specific factor is based on periodic comparison of data from Dodge and from building permits. This methodology is discussed in an appendix to the reports related to the value of new construction put in place: http://www.census.gov/const/C30/methodology.pdf. In years prior to 2003, the adjustment factor used by the Census Bureau was $28 \%$. Unfortunately, the Census Bureau is concerned only with the value of new construction and so the adjustment factors cannot be assumed to apply equally to floor space.
} 


\section{A.2.3 Weather Adjustment}

The weather adjustment for the commercial sector followed the same overall methodology as for the residential sector. Separate regression models for the 1970-1984 and the 1985-2011 time periods were estimated for the four census regions, both for electricity and fuels. The regression models employ approximate measures of energy intensity by census region. The energy data were taken from most recent version of EIA's State Energy Data System (see Section A.1.1). Approximate measures of floor space were derived from allocating national floor space on the basis of regional shares of floor space in previous editions of EIA's Commercial Building Energy Consumption Survey (CBECS), (EIA various "A"). Annual ratios were developed based on regression models linking regional shares of commercial floor space to regional shares of total occupied housing units. The purpose of the intensity measures was to facilitate the weather adjustment models by census region and energy type. They are not deemed sufficiently robust to accurately represent regional trends in energy intensity for use in disaggregating national trends.

\section{A.3 Industrial}

The energy intensity indicators for industrial sector are developed separately for 18 separate industries in manufacturing sector and for three subsectors in nonmanufacturing: agriculture, mining, and construction.

The available data sources for historical energy consumption differ between manufacturing and nonmanufacturing. The principal data source for manufacturing is the periodic Manufacturing Energy Consumption (MECS), conducted by EIA. This information is supplemented for nonMECS years with estimates derived from the Annual Survey of Manufactures (ASM) and Census of Manufacturing $(\mathrm{CM})$. In the non-manufacturing sectors, the primary data sources include the Census of Mining, Census of Construction, and surveys of farms conducted by the U.S. Department of Agriculture.

For years prior to 1985, a primary data source is the National Energy Accounts (NEA), a project sponsored by the Department of Energy and the Department of Commerce until the mid-1980s. The energy consumption data in the manufacturing and nonmanufacturing sectors were based upon ASM and other economic census data over the period up through 1985.

\section{A.3.1 Measures of Industrial Output}

As described in the body of the report, the primary energy intensity indicators for the industrial are defined in terms of energy consumption per unit of industry gross output (GO). Linkages to more aggregate sector intensity are obtained by the use of value added (VA), where value added is the particular sector's contribution to gross domestic product (as defined below). 
Two spreadsheet files provide the required data to construct the time series of gross output and value added. The basic historical file is labeled: "GDPbyInd_VA_NAICS_1947-1997.xls" This file can be downloaded from the BEA website: http://www.bea.gov/industry/gdpbyind data.htm

The following text is taken from the "ReadMe" tab of this spreadsheet (see below) used to disseminate the gross output and value added estimates from BEA. Formally, BEA defines value added and gross output as:

Value added (VA) is the contribution of each private industry and of government to the gross domestic product (GDP) of the United States. VA is equal to an industry's gross output (sales or receipts and other operating income, commodity taxes, and inventory change) minus its intermediate inputs (consumption of goods and services purchased from other industries or imported). Current-dollar value added is calculated as the sum of distributions by an industry to its labor and capital, which are derived from the components of gross domestic income. [Gross Output capitalized here to improve clarity].

While the file is labeled with 1947 as a starting year, only value added (and associated price index) data for about 20 aggregate industry sectors is provided for the years 1947 through 1976. These aggregate industry sectors are defined in terms of the North American Industrial Classification System (NAICS). Beginning in 1977, value added estimates are provided for more detailed NAICS sectors, expanded to more than 60 industry sectors across the U.S. economy. Estimates of gross output for the same level of industry detail are not available until 1987 and later. From these tables, 24 detailed sectors are extracted for use in the development of the industrial energy intensity indicators. These sectors, along with the corresponding NAICS codes, are shown in Table A.9.

The most current estimates from 1998 forward are also available from the same website. The more recent appropriate spreadsheet file is GDPbyInd_VA_NAICS_1998_2011.xls.

All of the value added and gross output data provided by BEA are in terms of current dollar and chained quantity indexes. The chained quantity indexes are indexed to be 100.0 in 2005 . For purposes of the indicators calculations, the real values of both value added and gross output are obtained by multiplying the 2005 estimates by the corresponding time series of quantity index values (and dividing all subsequent values by 100 to account for value of the index in 2005).

In mid-2012 additional work was undertaken to extend the activity measures for the industrial sectors back to 1970. To support this effort, gross output estimates by industry sector were derived from data provided by the U.S. Bureau of Labor Statistics (BLS), as part of their inputoutput model used to project employment by occupation. The website where the historical industry data can be accessed is: http://www.bls.gov/emp/ep_data industry_out and emp.htm. On this webpage, the relevant data files are listed under the heading "Data Files (in ASCII format)." The actual data file is obtained the link under this heading, "Industry Output [DAT]." 
Table A.9. BEA sectors used in industrial energy intensity indicators construction Industry Title NAICS Code

Manufacturing

Durable goods

Wood products

Nonmetallic mineral products $\quad 327$

Primary metals 331

Fabricated metal products $\quad 332$

Machinery 333

Computer and electronic products $\quad 334$

Electrical equipment, appliances, and components $\quad 335$

Motor vehicles, bodies and trailers, and parts $336, \mathrm{pt}$.

\begin{tabular}{l} 
Other transportation equipment $336, \mathrm{pt}$. \\
\hline
\end{tabular}

\begin{tabular}{|l|l|}
\hline Furniture and related products & 337
\end{tabular}

\begin{tabular}{|l|l|}
\hline Miscellaneous manufacturing & 339
\end{tabular}

Nondurable goods

$\begin{array}{ll}\text { Food and beverage and tobacco products } & 311,312\end{array}$

\begin{tabular}{l|l} 
Textile mills and textile product mills & 313,314
\end{tabular}

\begin{tabular}{|l|l}
\hline Apparel and leather and allied products & 315,316
\end{tabular}

\begin{tabular}{|l|l|}
\hline Paper products & 322 \\
\hline
\end{tabular}

\begin{tabular}{|l|l|}
\hline Printing and related support activities & 323
\end{tabular}

\begin{tabular}{|l|l|}
\hline Petroleum and coal products & 324 \\
\hline
\end{tabular}

Chemical products $\quad 325$

\begin{tabular}{|l|l|l|}
\hline Plastics and rubber products & 326
\end{tabular}

Nonmanufacturing (defined for intensity indicators)

Agriculture, forestry, fishing, and hunting

Farms

111,112

Forestry, fisheries, and related activities (not in indicators) $\quad 113-115$

Mining

Oil and gas extraction $\quad 211$

Mining (except oil and gas) $\quad 212$

Support activities for mining $\quad 213$

Construction

23

The BLS gross output estimates cover 195 sectors across the U.S. economy, 77 of which are in manufacturing. The values for these 77 sectors (in terms of "chained" 2005 dollars) were aggregated to the 18 (3-digit NAICS) manufacturing sectors included in the energy intensity indicators system. The BLS estimates of industry outputs begin in 1972.

There is an obvious connection between the BLS and BEA gross output measures, because the sum of the BLS detailed sector outputs within a BEA (3-digit NAICS) sector typically match the value in the BEA dataset. In many of the BEA sectors, the historical series match each other exactly or are very close to each other. Up to this point, there has been no dedicated effort to understand and perhaps reconcile these series. Instead, the approach is to use the BLS estimates as a means of extrapolating the BEA series over the period 1972-1986, the years in which the BEA series are not published. The extrapolation procedure involves first the estimation of a simple log-log regression model for each BEA sector of the following form: 


$$
\operatorname{Ln}\left(\mathrm{Q} \_ \text {BEA }\right)=b_{0}+b_{1} \ln \left(\mathrm{Q} \_ \text {BLS }\right)
$$

Q_BEA and Q_BLS are the gross output estimates taken from the BEA and BLS datasets, respectively. The estimated model was then applied to project (historically) the BEA estimates back to 1972. For 1970 and 1971, the estimated BEA output series were extrapolated back from the 1972 estimate on the basis of the percentage changes in the Federal Reserve Board indexes of industrial production within the most comparable 2-digit SIC (Standard Industrial Classification) industry

In some cases, the regression model omitted the most recent two years, 2009 and 2010, as there were distinct differences in the data series between BLS and BEA. As an illustration, Figure A.16 compares the BLS and BEA estimates of real gross output for NAICS 321, Wood Products. In this case, the last two years, 2009 and 2010, were deleted from the regression model. The estimated value of the coefficient, $b_{1}$, was 0.87 , suggesting that over the period 1987 through 2008 , a $1 \%$ change in output measured by BLS was reflected in a $0.87 \%$ change in the BEA output measure. Applying the model to the pre-1987 period, the estimated value of the BEA output variable in 1972 was $\$ 79,137$ (million chained 2005 dollars). By contrast, the value obtained by simple proportional (backward) extrapolation of the 1987 BEA estimate would have been $\$ 76,407$. The higher value for 1972 is of course caused by the estimated elasticity having a value less than one.

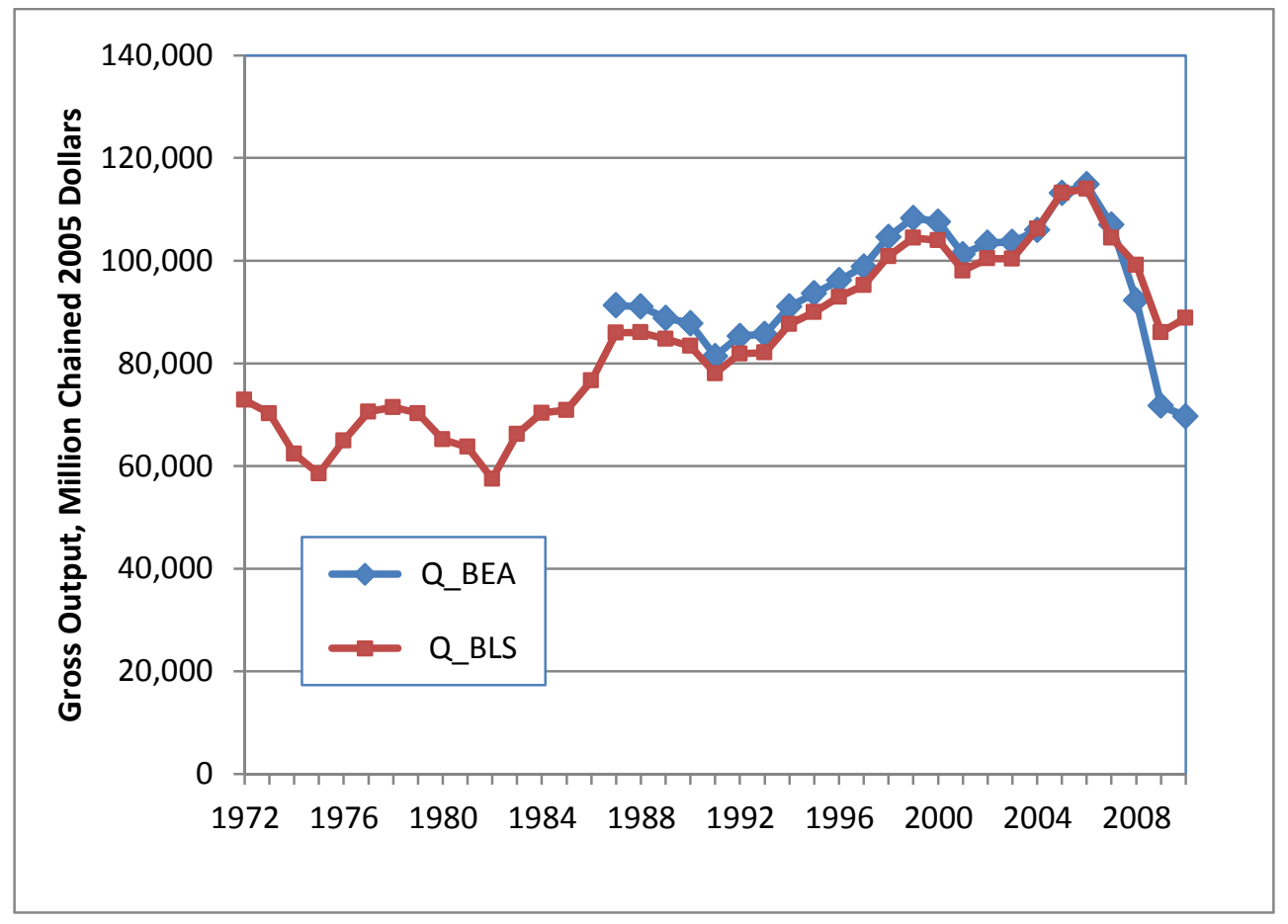

Figure A. 16. Comparison of BEA and BLS gross output series for NAICS Sector 321, Wood Products 
As described in the body of the report, the intensity indicators for the industrial sector are designed to provide a linkage between the intensity index, defined in terms of a Divisia index aggregation of intensities based on gross output, and an index of aggregate intensity defined in terms of total energy divided by total industrial value added (i.e., GDP). To implement this linkage, both value added and gross output measures are required at the detailed sector level. The previous discussion described the methodology by which the gross output measures were estimated back to 1970. Because the detailed value added estimates were available only from 1977 forward, estimates of value added for the 1970-1976 period were estimated by applying the calculated ratio of value added to gross output for 1977 to the earlier gross output values. This procedure has no effect on the primary variable of interest, the energy intensity index for the aggregate manufacturing or industrial sectors, but would impact any decomposition of "structural change" over this earlier period.

\section{A.3.2 Energy Consumption}

The sources for historical energy consumption estimates differ between the manufacturing and nonmanufacturing sectors. In addition, most of the work has focused upon the period 1985 and later. Recent work has sought to extend those time series of energy consumption back to 1970 , and will be discussed at the end of sections below.

\section{Manufacturing}

The primary data source for manufacturing energy consumption since 1985 is the Manufacturing Energy Consumption Survey (MECS). The MECS has been conducted by EIA in 1985, 1988, 1991, 1994, 1998, 2002, 2006, and 2010 (EIA various “B”). To develop annual estimates of energy consumption, the MECS data is supplemented with data from the Annual Survey of Manufactures (ASM) and the Census of Manufactures (CM), both conducted by the U.S. Census Bureau. The ASM and CM collect data on the cost and quantity of purchased electricity and the cost of purchased fuels. Because these census sources represent a larger sample (in the case of the ASM) of manufacturing establishments than the MECS, the electricity estimates (quantity in $\mathrm{kWh}$ purchased) are used directly in the system of energy intensity indicators. These census sources thus provide data for all years from 1985 through 2011, for the 18 manufacturing sectors included in the system.

The ASM and CM data also include a data item labeled "Generated less sold". This information is not used for the energy intensity, because it involves a "double counting" of total energy. Electricity generated by manufacturing is using purchased fuels and other fuels that are already included in total energy consumption.

The MECS produces several tables related to quantity of fuel consumption: a) total for all purposes, b) non-fuel use (e.g., feedstocks), c) fuel use (for heat, power, and electricity generation), and d) offsite-produced fuel consumption. For purposes of the energy intensity 
indicators work, the appropriate table involves the fuel use in item c), fuel consumption for heat, power, or electricity, irrespective of whether the fuel is purchased from offsite suppliers or is derived as a by-product of the manufacturing process. As an indicator of energy efficiency, fuels used as materials such as feedstocks or asphalt are not relevant. Beginning in 1998, the MECS reported this fuel use in its Table 3.2. (In prior MECS, the relevant table was Table A4).

The major issue with regard to fuel use is how to estimate fuel consumption for non-MECS years. As stated earlier, the ASM and CM report only the cost of purchased fuels, with no information about quantities. As a result, the following seven-step methodology was followed in an effort to best characterize the fuel consumption in those years for which MECS data are not available.

Step 1. Estimate total cost of purchased fuels (offsite-produced) in MECS years.

Over its 25-year history, the MECS has generally published estimates for several aggregates concerning total fuel use as listed in items a) through d) above. For the last item (d), EIA indicates that this value can be related to historical data collected by the U.S. Census Bureau as part of its Annual Survey of Manufactures and Census of Manufactures. As stated in Appendix A of the 1988 MECS, EIA describes "Energy consumed onsite as a fuel and produced offsite" as:

This derived value represents onsite consumption of fuels that were originally produced offsite. That is, they arrived at the establishment as the result of a purchase, or were transferred to the establishment from outside sources. As such, this derived value is definitionally equivalent to "consumption of purchased" fuels reported by the Census Bureau for the years 1974-1981. The Census Bureau defines "purchased fuels" to include those actually purchased plus those transferred in from other establishments (EIA 1991, p. 139)

While dropping the request for quantity information on purchased fuels after 1981, the ASM and $\mathrm{CM}$ have continued to include the question related to total cost of such fuels. What the method here seeks to do is develop a MECS-based "cost of purchased fuels" that can be compared to the cost of purchased fuels obtained from the census data. From that point, the ASM purchased fuel data can be used to interpolate the definitionally-equivalent MECS values for non-MECS years and then finally apply a composite fuel cost (\$MMBtu) to derive quantity estimates.

This first step is to bring into a spreadsheet the quantities under item c) above, by fuel and 3-digit NAICS industry. Over time, the MECS table numbers providing this information have changed. In the most recent MECS, these data, converted to Btu, are in Table 4.2. Unfortunately, some small quantities of some fuel types are not published for some sectors. Using the row (NAICS sector) totals and quantity totals (total consumption by fuel), as well as any recent MECS where such data were not withheld, judgmental estimates of the missing fuels must be made. In general, this imputation process is not likely to affect the overall intensity estimates to any large degree because the withheld information usually appears to involve small quantities. 
Next, the information on prices paid by fuel is obtained. In each of the historical MECS information on fuel prices by fuel and sector have been published. In the recent MECS, the prices in terms of dollar per MMBtu are in Table 7.2. The prices are really the average costs paid, as they are the quotient of expenditures for purchased energy sources (Table 7.9 in the recent MECS) and total quantity of purchased energy sources (Table 7.6). Some of the purchased energy sources are not used for heat and power (i.e., feedstocks or material inputs). However, it is assumed that the average price paid is the same for all uses of the fuel.

With quantities and prices in hand, a synthetic estimate of the total cost of purchased fuels for "heat, power, and electricity production" is developed for each 3-digit NAICS sector. For most sectors, this estimated value is very close to the published figures for total cost of purchased energy sources (Table 7.9), because most, if not all, of the purchased energy sources are used as fuel.

A bridge between the NAICS sectors (1998 and later) and the 2-digit Standard Industrial Classification (used in the MECS from 1985 through 1994) was developed based on a detailed analysis of electricity quantity data. From this bridge, fuel quantities for all MECS were put on a NAICS classification. Prices based on the SIC were assigned to NAICS as appropriate. (Some weighting for the "new" NAICS sector, computer manufacturing was performed to generate what might be expected to reasonably representative set of fuel prices. In general, the variance across 3-digit NAICS sectors in equipment manufacturing is not large).

Step 2. Estimate total cost of offsite-site produced fuels for non-MECS years

To estimate the total expenditure on offsite-produced fuels for non-MECS years on a consistent basis, the ASM and CM cost of purchased fuels information was used for interpolation purposes, and applied to each 3-digit NAICS sector. For each MECS year, the following ratio was computed:

Estimated cost of fuels from Step 1 (MECS)/Cost of purchased fuels (ASM, CM)

Between the successive ratios for MECS years (beginning in 1985), the ratios for intervening years were calculated by linear interpolation. The interpolated ratios were then applied to the ASM or CM cost data for the non-MECS years to provide an estimate of the MECS-defined costs for these years. Figure A.17 shows the cost ratios for the MECS years and the interpolated ratios for four different 3-digit NAICS sectors. The ratios for the years beyond 2010 will be retained at the 2010 values.

Step 3. Estimate annual costs per MMBtu for each fuel for each NAICS sector. 


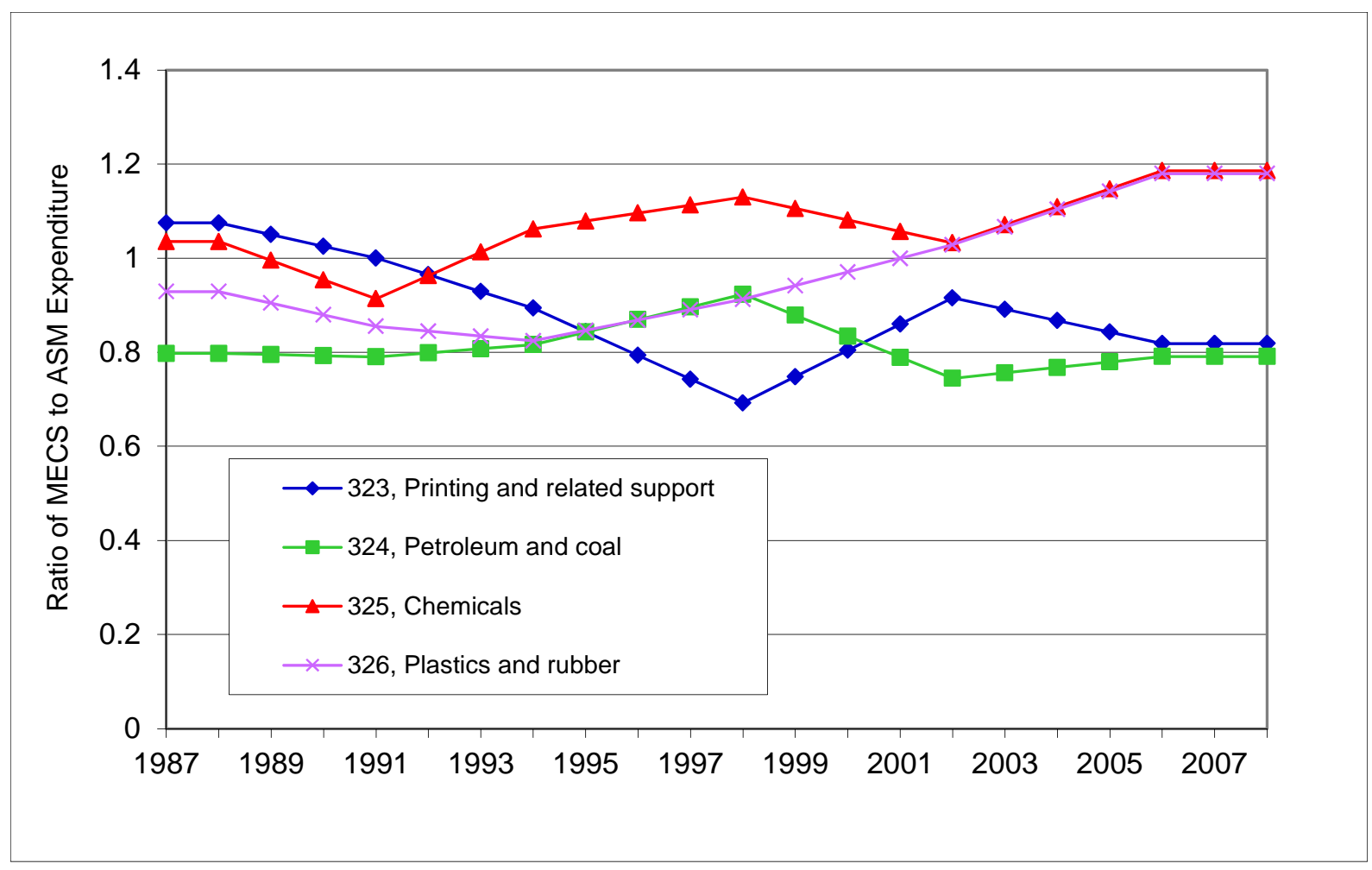

Figure A. 17. Ratios of MECS-based costs of purchased fuel to ASM/CM costs of purchased fuels for four selected sectors

Estimates of cost per MMBtu by fuel for each sector were developed for all years. Individual fuel price models were estimated over the period 1988 through 2011 for each 3-digit NAICS sector and fuel type. For MECS beginning in 1998, the seven major fuels reported in the survey were used: 1) residual fuel oil, 2) distillate fuel oil (diesel), 3) natural gas, 4) LPG, 5) coal, 6) coke and breeze, and 7) other. For the earlier MECS, data for coke and other fuels were not published.

The purpose of these models was to try to ascertain any historical trends between the implied costs per unit from the periodic MECS and the various annual series of fuel prices published by EIA in the Annual Energy Review, Monthly Energy Review, or elsewhere available on the EIA website. These models must be judged as only very approximate in a process to impute how the published fuel prices are reflected in the variation of average fuel cost shown in the MECS; the uncertainty in these models primarily stems from the presence of only six (MECS) data points. The specification of the fuel price models was as follows.

$$
\operatorname{MECS\_ Cost}(y m)=a \text { Price_Ind }(y m)+b \text { Price-Ind }(y m-1)
$$

where MECS_Cost $(y m)=$ published cost per MMBtu in MECS year ym $(1985,1988,1991,1994$, 1998, 2002, 2006, and 2011) 
Price_Ind $(y m)=$ Aggregate industrial price for fuel in MECS year ym, as published by EIA in the Annual Energy Review or on its website (see below).

The motivation for including both the current and lagged price was that the actual cost (price) paid by industrial customers could involve a long-term supply contract or be the result of fuel held at the manufacturer's site.

The tables for the industrial price series based upon the most recent Annual Energy Review (AER), Monthly Energy Review (MER), or alternative EIA table on its website are:

Natural gas - AER Table 6.8, MER Table 9.10; Natural gas prices by sector Distillate fuel oil - No.2 Distillate, Sales to end users, industrial, accessed on http://www.eia.gov/dnav/pet/pet_pri_dist_dcu_nus_a.htm

Residual fuel oil - AER Table 5.23, MER Table 9.5; Sales price to end users for residual fuel oil

Coal - Bituminous and anthracite prices from AER Table 7.8

Wood/Waste - AER Table 3.4, Industrial biomass price.

Based upon the estimated parameters, $a$ and $b$ from Equation (A.6), prices were predicted for each year between 1983 and 2011. The regression residuals at the eight MECS years (actualpredicted) were computed. Between the MECS years, values were computed that were linear interpolations of these residuals between successive pairs of MECS years. These "interpolated" residuals for the non-MECS year, as well as the residuals for the MECS years were added back to raw predictions from the regression. The procedure ensures that the actual prices for all MECS years are the actual values corresponding to each MECS.

An illustration of the methodology is given in Figure A.18. In this case, the regression model was applied to natural gas consumed by the chemicals sector. The top line in the figure shows the price for all industrial sales of natural gas. The lower graph shows the predicted, or perhaps more accurately, interpolated values of the natural gas price, consistent with the observed values in the MECS. The (red) squares in the background denote the MECS years and show how the regression errors have been adjusted to yield the MECS. Not surprisingly, the average price paid for natural gas is lower for the chemical sectors than it is for the entire industrial sector. The regression coefficients in this case were $a=0.66$, and $b=0.11$, suggesting some support for the lag in the overall market price for natural gas to be fully reflected in prices paid by the chemicals sector.

Step 4. Estimate composite fuel prices

Step 4 involved weighting the predicted fuel prices (actual prices in MECS years) to derive an overall price per MMBtu of fuel consumption. Weights were developed from fuel quantity shares derived from the MECS data on offsite-produced fuel consumption, and then linearly 


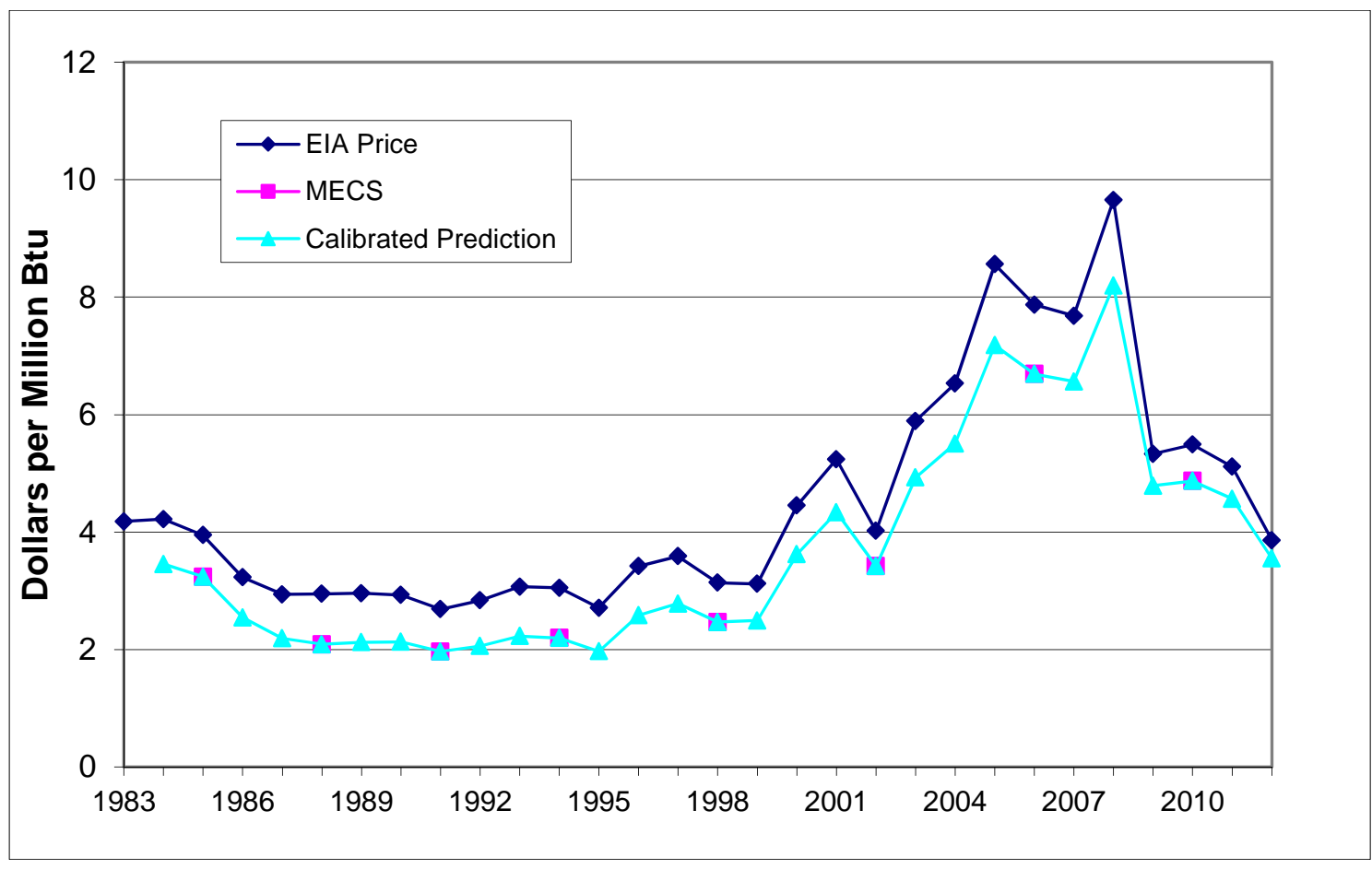

Figure A. 18. Predicted prices of natural gas consumed by the chemical sector, NAICS 325

interpolated between MECS years. Until data from the next (2014) MECS is released, the fuel shares are expected to be maintained at the observed levels for 2010 .

Composite prices (i.e., \$/MMBtu) were computed as the cross products of the weights (shares) in each year with the predicted MECS prices. For the period 1985 through 1998, the composite prices were based upon the five fuels for which sector-level prices were available in the MECS. For 1998 through 2011, the composite prices were developed from prices for each of the seven fuels. For 1998, composite prices were based on both five and seven fuels, as a way of bridging between the years just before and just after 1998 .

Step 5. Estimate annual offsite-produced fuel quantity consumption, consistent with the MECS.

This step is straightforward. The estimates of the total cost of purchased (offsite-produced) energy are divided by the corresponding composite price of energy for each NAICS sector. By construction, the total cost values and the composite prices match those that can be calculated directly from the MECS in the years the MECS has been published.

Step 6. Include onsite produced fuel consumption

The efforts in all the previous steps were employed to generate an estimate of fuel consumption that is consistent with ASM and CM data on "cost of purchased fuels." In terms of the MECS, the quantity of energy consistent with this definition, as mentioned above, is labeled offsiteproduced energy consumption. The MECS data on total fuel consumption include both offsite- 
produced and onsite-produced energy. Sectors that have a large fraction of total fuel consumption from onsite sources include wood products, paper, petroleum refining, chemicals, and primary metals.

Typically, the onsite-generated fuel consumption shows up in the "other" column of MECS tables for total fuel consumption (Table 3.1 in the most recent MECS). However, some of this energy also is purchased (or transferred) from offsite sources. For example, in 2010, the MECS reported other fuel use, from offsite sources, for the Food industry (NAICS 311) to be 54 trillion Btu (TBtu). Total fuel consumption for the "other" category, on the other hand, was 99 TBtu Btu. The ratios of fuel consumption between offsite and onsite may be volatile from one MECS to the next, owing to the particular structure of the industry and underlying technologies. For purposes of the intensity indicators methodology, it was assumed that the ratios of total energy consumption to total offsite-produced energy consumption would be the most stable over time. Thus, for each MECS year, this ratio was calculated. For example, in the Food industry, the ratio in 2010 was calculated as $902 / 855(\mathrm{TBtu})=1.055$. For non-MECS years, the ratios were interpolated linearly between successive MECS years. Again, taking Food as an example, the corresponding ratio was 1.071 in 2006 . Thus, the ratio of total/offsite fuel consumption was gradually reduced from the 2006 value in each of the intervening non-MECS years, 2007 through 2009. These ratios were then applied to effectively "inflate" the offsite-produced estimates of fuel consumption derived in Step 5.

Step 7. Perform final interpolation with annual values from Step 6.

Generally, the derived total fuel consumption estimates from Step 6 match the values from the MECS directly in the MECS years. In the years beginning with the 1998 MECS, this is particularly the case. Some small differences may result from slight adjustments made to one or more fuel consumption or expenditure data values in the course of estimating the composite fuel price. In the years prior to 1998 MECS, there is the issue of data comparability from the change from the SIC to the NAICS. As mentioned in the discussion of Step 1, an effort to try to rigorously adjust consumption and expenditures for each fuel type from its value under the SIC to its value under the NAICS was not performed. Thus, the interpolating series were based upon a rough cross-walk at the 2-digit SIC and 3-digit NAICS sector levels. The actual (preferred) estimates of NAICS-based total fuel consumption (i.e., including onsite as well as offsiteproduced fuel) for the MECS for 1985, 1988, 1991, and 1994 were developed with a more detailed mapping procedure based upon EIA's published data from the 1998 MECS on both an SIC and NAICS sector basis. The final interpolation procedure involves imputing the deviations from a hypothetical linear interpolation between the estimated total fuel quantities for successive MECS years from the annual series produced in Step 6. 


\section{Pre-1985 Energy Consumption Estimates}

For the energy consumption estimates over the period 1970-1984, the data series from the National Energy Accounts (NEA) was utilized. The NEA was a major analytical effort that was conducted over the period 1975 through 1984. The NEA developed two major sets of accounts, the first dealing with energy sources (for some 50 energy products), as well as an end use account that measured the disposition of each energy product throughout the U.S. economy. The NEA was funded initially by the Federal Energy Administration and later by the Department of Energy. The final study that updated the data through 1985 was sponsored by the Department of Energy. All of the work under four separate studies was performed by Jack Faucett Associates, an economic consulting firm located in Chevy Chase, Maryland. ${ }^{27}$

PNNL obtained computer files of the NEA files in the late 1980s. The data series in the final set of files extended from 1947 through 1985, although complete detail was lacking prior to 1958. The NEA formed the basis of work done by PNNL for the U.S. Department of Energy in the mid-1990s that examined trends in manufacturing energy use (Belzer 1995). With regard to industrial energy consumption, the NEA contained 17 sectors in nonmanufacturing (agriculture, mining, and construction) and 72 sectors in manufacturing (3- and 4-digit SIC detail). The manufacturing sectors were aggregated to conform to the extent possible to 3-digit NAICS sectors. These series, separately calculated for electricity and total fuel consumption, were then used to extrapolate the corresponding 1985 estimate based on the MECS back to 1970 .

The NEA data in manufacturing were based exclusively on data from the ASM and CM for this earlier period. For the years 1974 through 1981, the fuel information is more robust compared to other years, because the Census Bureau collected data on both the cost and quantity of various fuels.

\section{Nonmanufacturing}

Nonmanufacturing covers agriculture, mining, and construction. Prior to 2012, total manufacturing energy consumption (electricity and fuels) was estimated as a residual between the supply-side estimates of industrial consumption published by EIA and the end-user estimates based upon the MECS (supplemented by census-based data, as described above). The residualbased method produced very unsatisfactory results; year-to-year changes in energy consumption were implausible in a large number of instances. A complicating factor for fuels is that industrial consumption estimates published by EIA include energy products used as chemical feedstocks and other nonfuel purposes. As a result, a preliminary effort was undertaken in mid-2012 to estimate energy consumption from the user side for these sectors. The following paragraphs briefly describe the data sources and methods used.

\footnotetext{
${ }^{27}$ The final report citation is: Jack Faucett Associates, Inc., National Energy Accounts, JACKFAU-84-316, submitted to U.S. Department of Commerce, under contract 50-SABA-4-06114, December 1984. The report itself contained few tables of data; the computer files were obtained from the office in the Department of Commerce that funded the last round of this work.
} 


\section{Agriculture}

The principal data source for agriculture built on a set of estimates developed by John Miranowski, a professor at Iowa State University. Miranowski developed annual estimates of energy by fuel for the farm sector for the period 1965-2002. ${ }^{28}$ These data were later employed by Randy Schnepf at the Congressional Research Service, who was kind enough to send the spreadsheet-based Miranowski consumption estimates to PNNL. ${ }^{29}$

Data beyond 2002 were developed from the survey of farm expenses conducted by the National Agricultural Statistics Service (NASS). Information on the expenses for fuels were derived from downloaded data from: http://www.nass.usda.gov/Statistics_by_Subject/index.php. This same website was also accessed for data for average prices paid. Estimates for fuel expenses were available for four fuel types: diesel, gasoline, LPG, and "other" (assumed to primarily consist of natural gas). The expenses data were downloaded for year 2000 through 2011. Data for average prices paid were available for diesel, gasoline, and LPG up through 2008. Estimates for 2009 and 2010 were based upon extrapolating the series with fuel price data from EIA. Estimates of annual fuel consumption were derived by straightforward division of the expenditure data by the price estimates.

The "other" fuel category was assumed to consist primarily of natural gas. Expenditure data were converted to fuel quantities with the use of the natural gas prices for the commercial sector published by EIA. ${ }^{30}$

Diesel fuel represents the majority ( $\sim 65 \%$ ) of fuel used by farms in the U.S. The consumption estimates by fuel type for 2010 were: diesel - 449 TBtu, gasoline - 114 TBtu, LPG - 71 TBtu, and natural gas/other - $61 \mathrm{TBtu}$.

Unfortunately, the NASS survey of farm expenses does not separately identify electricity expenditures or quantities. The Census of Agriculture includes electricity expenses as part of "utilities." The following definition is supplied in an Appendix B to the 2007 Census of Agriculture (USDA 2009):

"These data show the farm share cost of electricity, telephone charges, internet fees, and water purchased in 2007. Included in the water cost is water purchased for irrigation purposes, livestock watering, etc. Household utility costs were excluded from these items." Given the likely increase in internet usage by 2007, there appears to be no reliable method of breaking out electricity expenditures, as either an absolute magnitude or as a stable share of the overall expenditures in this category. Accordingly, the computed intensity electricity in farms has been maintained at its 2002 level for the current edition of the energy intensity indicators. In 2002 the estimate

\footnotetext{
${ }^{28}$ These estimates are displayed graphically in a PowerPoint presentation made by Miranowski to a Farm Foundation conference (Agriculture as a Producer and Consumer of Energy), June 24, 2004. This presentation file was accessed on the web through www.farmfoundation.org/news/articlefiles/370-miranowski.ppt, 10/11/2012.

${ }^{29}$ Personal communication with Randy Schnepf, Congressional Research Service, August 7, 2012.

${ }^{30}$ Table 3.4 in the 2011 Annual Energy Review (EIA 2012a)
} 
developed by Miranowski was less than 120 TBtu, or less than $12 \%$ of total energy used by farms in that year. Thus, the assumption of a constant intensity for electricity since 2002 is deemed to have little impact the trend of overall energy intensity by farms, as total energy use is dominated by fuels. ${ }^{31}$

The Miranowski energy consumption estimates and subsequent updates all relate to farms, both livestock and crops. The other segment of agriculture in its broadest sense includes forestry and fisheries, and agricultural services. Based upon the National Energy Accounts data, these activities accounted for less than $4 \%$ of total agricultural fuel use, and about $6 \%$ of agricultural electricity use, in 1985. A review of NEA documentation suggests that these estimates are based upon a limited set of data sources, including one-time surveys. The energy estimates for the agricultural services sector appear to be based on Volume 3 of the 1978 Census of Agriculture, which covers the activities of this sector. A perusal of the USDA website with historical census data indicates that 1978 was the last year that agricultural services were covered by the census.

Given the relatively small amount of energy that is consumed in these other agricultural sectors, they are currently excluded as a part of the energy intensity indicators system. It should be noted, however, that the electricity and gas consumption in agricultural services is likely included in the commercial sector reporting of energy use by electric and gas utilities (and thus captured in the energy intensity indicators for the commercial sector). Thus, for example, a building that serves as a field office for employees of a large pesticide or fertilizer company would likely be classified by utilities as a commercial account.

\section{Mining}

The energy consumption estimates for mining depend entirely on the various editions of the periodic census (ending in years with ' 2 " and " 7 " since 1967). Up through 1987, the information for mining was collected under the title "Census of Mineral Industries." From 1992 forward, the same information is part of the mining segment of the Economic Census (which now is the broad term for all the census surveys in the census years).

Table A.10 shows the website data sources for the mining sector. For the most recent census in 2007, the data were selected from a flexible download procedure that allows the user to select key data elements for each specific NAICS sector. The specific data items were 1) "quantity of electricity purchased" and 2) fuels consumed by type: a) quantity, and b) delivered cost. For the previous years, the data were derived from downloaded industry series reports (or selected pages). In these reports, the cost and quantity of electricity is found in Table 3 (Detailed

\footnotetext{
${ }^{31}$ As yet, there has been no attempt to try to ascertain the source and methodology behind the Miranowski electricity estimates. Another potential source for more recent data would exploit the work done to estimate the greenhouse gas emissions from the agricultural sector. For example, see http:/www.usda.gov/oce/climate_change/index.htm. These activities will be pursued for future editions of the energy intensity indicators as resources permit.
} 
Statistics by Industry) and Table 7 (Selected Supplies, Minerals Received for Preparation, Purchased Machinery, and Fuels Consumed by Type). ${ }^{32}$

Table A.10. Sources for mining data by census year

\begin{tabular}{|c|c|}
\hline Year & Source \\
\hline 2007 & $\begin{array}{l}\text { From printout of selected data items from table on Census Bureau (factfinder) website: } \\
\text { http://factfinder2.census.gov/faces/tableservices/jsf/pages/productview.xhtml?pid=EC } \\
\text { N 2007 US 21SG12\&prodType=table }\end{array}$ \\
\hline 2002 & $\begin{array}{l}\text { Downloadable pdfs of industry reports: extracted Table } 3 \text { and Table } 7 \text {. List of pdfs } \\
\text { available at https://www.census.gov/econ/census02/guide/INDRPT21.HTM }\end{array}$ \\
\hline 1997 & $\begin{array}{l}\text { 1997: Downloadable pdfs of industry reports: extracted Table } 3 \text { and Table } 7 . \text { List of } \\
\text { pdfs available at: http://www.census.gov/prod/www/abs/ec1997mining-ind.html }\end{array}$ \\
\hline 1992 & $\begin{array}{l}\text { Downloadable pdfs of industry reports: extracted Table } 3 \text { and Table } 7 . \text { List of pdfs } \\
\text { available at: } \mathrm{http}: / \mathrm{www} . \text { census.gov/prod/1/manmin } / 92 \mathrm{mmi} / 92 \mathrm{minif} . \mathrm{html}\end{array}$ \\
\hline
\end{tabular}

Since 1997, the mining industries have been classified under three major 3-digit NAICS sectors: 211, Oil and Gas Extraction; 212, Mining (except oil and gas); 213 Support Activities for Mining. Unfortunately, there are no aggregations of energy data from the more detailed industries to this level. Thus, an estimation of electricity and fuel consumption must begin with the more detailed mining sectors, essentially 6-digit NAICS since 1997 and 4-digit SIC in earlier years. At the NAICS level, there are 29 specific industries as shown in Table A.11 (the word "mining" has been omitted from most of the official NAICS titles in the table).

For the most part, there was a one-to-one translation between the 4-digit SIC sectors and the 6digit NAICS sectors. That permits a reasonable transition between the pre- and post-1997 data. As shown in Table A.11, the mining support sectors were all collapsed into a broad (3-digit) NAICS sector, whereas under the SIC the support industries were classified with their production counterpart industries. The only other notable change was the reclassification of oil and gas well drilling to be a part of this overall support sector.

${ }^{32}$ In the 1992 and prior Censuses of Mineral Industries, the purchased fuels data was shown in Table $7 \mathrm{~b}$. 
Table A.11. NAICS Detailed Mining Sectors

\begin{tabular}{|r|l|}
\hline NAICS & \multicolumn{1}{|c|}{ Industry } \\
\hline 211111 & Crude Petroleum and Nat. Gas \\
\hline 211112 & Natural Gas Liquid Extraction \\
\hline & \\
\hline 212111 & Bituminous, surface \\
\hline 212112 & Bituminous, underground \\
\hline 212113 & Anthracite \\
\hline & \\
\hline 212210 & Iron Ore \\
\hline 212221 & Gold Ore \\
\hline 212222 & Silver Ore \\
\hline 212231 & Lead \& Zinc Ore \\
\hline 212234 & Copper \& Nickel \\
\hline 212291 & Uranium/Radium/Vanadium \\
\hline 212299 & All Other Metal Ores \\
\hline & \\
\hline 212311 & Dimension Stone \\
\hline 212312 & Crushed and Broken Limestone \\
\hline 212313 & Crushed and Broken Granite \\
\hline 212319 & Other Crushed and Broken Stone \\
\hline 212321 & Construction Sand and Gravel \\
\hline 212322 & Industrial Sand \\
\hline 212324 & Kaolin \& Ball Clay \\
\hline 212325 & Clay \\
\hline 212391 & Potash, Soda, \& Borate \\
\hline 212392 & Phosphate Rock \\
\hline 212393 & Other Chem. \& Fertilizer Minerals \\
\hline 212399 & All Other Nonmetallic Minerals \\
\hline 213111 & Drilling Oil and Gas Wells \\
\hline 213112 & Support Activities for Oil and Gas \\
\hline 213113 & Support Activities for Coal Mining \\
\hline 213114 & Support Activities for Metal Mining \\
\hline 213115 & Support Activities for Nonmetallic Minerals \\
\hline & \\
\hline & \\
\hline & \\
\hline & \\
\hline & \\
\hline & \\
\hline & \\
\hline &
\end{tabular}

There is no major difficulty in assembling the electricity quantity data, as quantities (kWh) were asked of respondents as part of the census survey in all years. The situation with fuels is quite another matter. The census forms ask for both cost and quantity information for specific fuels. The overall set of data throughout the years is plagued by missing values resulting from "withheld" information, i.e., data "withheld to avoid disclosing data of individual companies." A variety of methods were employed to try to work around this problem. In some cases, an approximate value could be derived on the basis of subtracting the cost of those fuels for which data were published from total cost. (This residual approach yields a control total for the two or more fuels with missing data). Because of the cyclical nature of the mining industry and the 
fluctuations in the industry structure, estimates (or proportions) missing for one census year could sometimes be imputed on the basis of a previous census.

In addition, there are two categories that complicate the estimation of fuel quantities, both of which only present information on total cost. The first is "Other fuels - liquefied petroleum gas, coke, wood, etc." and the second is "Undistributed fuels." "Undistributed" as defined by the Census Bureau "represents cost for establishments that did not report detailed data, including establishments that were not mailed a form."

With regard to "Other fuels", the assumption was that the dominant fuel was propane. The cost estimates were converted to quantities by the use of the price of propane published by EIA. ${ }^{33}$ For undistributed fuels, the assumption was that the average price of the unreported fuels was the same as the reported fuels. Operationally, this assumption was implemented as follows. The cost and quantity of reported fuels was estimated. Then the ratio of the total cost of all fuels with respect to the cost of reported fuels was calculated. This ratio $(>1.0)$ was then used as multiplicative adjustment factor applied to the quantity of all reported fuels.

Unfortunately, only the cost of fuels was reported for the 2007 census. The quantity estimates for 2007 were based upon extrapolating the 2002 quantity estimates by means of the 2007/2002 total cost ratio divided by a factor representing the percentage change in the appropriate fuel price between 2007 and 2002.

The consumption estimates for years up through 1985 were based upon the National Energy Accounts. The NEA estimates were also based upon prior editions of the Census of Mineral Industries. For non-census years the NEA interpolated the energy intensities between the successive census years. This same approach is followed in the current work using the more recent census data.

Further work is required to refine the estimates of energy consumption during some time periods. The recent updating work has not included electricity data for the 1987 census (and thus interpolates intensities between 1985 and 1992). Another activity for future work is to use the 1982 census data directly to estimate energy consumption. The NEA data for years beyond 1982 did not utilize the 1987 information in its post-1982 extrapolation methods. Overall, however, the efforts to construct estimates of total energy consumption for the mining sector is deemed to be a significant improvement over the previous methodology, which included this energy as part of the difference between total industrial and total manufacturing.

\footnotetext{
${ }^{33}$ Energy prices to end users, as published in Table 5.23, Annual Energy Review 2011, accessed at http://www.eia.gov/totalenergy/data/annual/index.cfm
} 


\section{Construction}

Data for expenditures for various types of energy are available from the various editions of the Economic Census. For 1992 and earlier years, the census went under the title Census of Construction Industries, and the data were collected (and classified) under the SIC. Since 1997, the collection of data from the construction is subsumed under the general Economic Census with Construction as one of industry groups. As elsewhere, the construction sectors have been classified under the NAICS since 1997.

For the energy intensity indicators system, energy consumption and intensity is estimated for construction as a whole. Thus, the approach here is to aggregate across all of the detailed construction sectors when necessary (26 4-digit SIC sectors, and 29 5-digit NAICS sectors).

The data for energy expenditures is included in tables for "detailed statistics" for all years. Conveniently, Table 2 in the 1992 Census (Detailed Statistics for Establishments with Payroll: 1992 and Earlier Census Years) contained information for 1992 and for three previous census years,: 1977, 1982, and 1987. These data were obtained from individual 4-digit SIC industry reports. The source of the 1992 information, as well as the census data for subsequent years, is shown in Table A.12.

Table A.12. Sources for construction data by census year

\begin{tabular}{|l|l|}
\hline Year & Source \\
\hline 2007 & $\begin{array}{l}\text { 2007: Construction: Industry Series: Preliminary Detailed Statistics for } \\
\text { Establishments: 2007, downloadable spreadsheet from: } \\
\text { http://factfinder2.census.gov/faces/tableservices/jsf/pages/productview.xhtml?pid=EC } \\
\text { N_2007_US 23I1\&prodType=table. }\end{array}$ \\
\hline 2002 & $\begin{array}{l}\text { 2002: Construction Industry Series: Detailed Statistics for Establishments, } \\
\text { downloadable spreadsheet from: } \\
\text { http://factfinder2.census.gov/faces/tableservices/jsf/pages/productview.xhtml?pid=EC }\end{array}$ \\
\hline $\begin{array}{l}\text { N2002_US 23I04A\&prodType=table } \\
1997\end{array}$ & $\begin{array}{l}\text { 1997: Industry Summary, 1997 Economic Census, Construction, Subject Series } \\
\text { EC97C23S-IS, downloaded from: } \underline{\text { http://www.census.gov/epcd/www/97EC23.HTM }}\end{array}$ \\
\hline 1992 & $\begin{array}{l}\text { 1992: Industry Series (CC-92I), with downloadable pdf files for each 4-digit SIC } \\
\text { construction industry. Downloadable from: } \\
\text { http://www.census.gov/prod/www/abs/cciview.html }\end{array}$ \\
\hline
\end{tabular}


All of the census information for construction shows expenditures for four fuel types: 1) electricity, 2) natural and manufactured gas, 3) gasoline and diesel fuel, and 4) other, including lubricating oils and greases. Beginning with the 1987 census, category 3) was broken out into "on highway use" and "off highway use).

Because "on highway use" is covered in the transportation sector, the focus in this work was on "off highway use." For the years prior to 1987 (1977 and 1982), the share of total gasoline/diesel use for off-road activity, averaged between 1987 and 1992, was applied to estimate off-road consumption. This imputation was done for each of the 26 4-digit SIC construction industries.

The energy expenditures estimates from the available census data are shown in Table A.13. Clearly, the increase in construction activity and overall increases in fuel prices lead to a large change between 2002 and 2007.

Table A.13. Expenditures by fuel type for the U.S. construction, census years millions of dollars

\begin{tabular}{|c|c|c|c|c|c|}
\hline & & & \multicolumn{2}{|c|}{ Gasoline and diesel } & \\
\hline & Electricity & Natural Gas & On-Road & Off-Road & Other/Lubricants \\
\hline 1977 & 468 & 227 & 2,573 & 779 & 472 \\
\hline 1982 & 823 & 266 & 4,534 & 1,417 & 407 \\
\hline 1987 & 1,089 & 304 & 4,125 & 1,602 & 519 \\
\hline 1992 & 1,469 & 464 & 4,480 & 1,761 & 517 \\
\hline 1997 & 1,741 & 515 & 5,336 & 2,117 & 548 \\
\hline 2002 & 2,596 & 1,025 & 8,024 & 2,886 & 868 \\
\hline 2007 & 5,774 & 1,713 & 17,977 & 5,703 & 1,198 \\
\hline
\end{tabular}

Source: Census publications listed in Table A.12

Note: On-road and off-road values for 1977 and 1982 are imputed (see text).

The expenditures by fuel type were converted to quantities using fuel prices published by EIA. The sources for fuel prices are:

Electricity: Table 3.4, Consumer Price Estimates for Energy by End-Use Sector, commercial sector, in the Annual Energy Review 2011 (EIA 2012)

Natural gas: Same source as for electricity.

Gasoline: Table 5.23. All Sellers Sales Prices for Selected Petroleum Products, Sales Price to End-Users, Conventional motor gasoline, Annual Energy Review 2011

Diesel: Table 5.23. All Sellers Sales Prices for Selected Petroleum Products, Sales Price to EndUsers, No. 2 Diesel Fuel, Annual Energy Review 2011. 
For the off-road category of expenditures, it was assumed that the majority of equipment would be powered by diesel (road construction equipment, large compressors, etc.). Therefore, the composite price for off-road fuel was calculated with $30 \%$ weighting applied to gasoline and $70 \%$ weighting to diesel. There is no EIA published price for lubricants. Here the assumption was that lubricants were 3 times more expensive than the composite gasoline/diesel price.

Using these sources (and assumptions) for fuel prices, Table A.14 shows the estimated electricity and fuel consumption by census year.

Table A.14. Estimated energy consumption for the construction sector by fuel type and census year, trillion Btu

\begin{tabular}{|c|c|c|c|c|c|}
\hline & Electricity & Natural Gas & $\begin{array}{c}\text { Off-road } \\
\text { Gasoline/Diesel }\end{array}$ & $\begin{array}{c}\text { Other/ } \\
\text { Lubricants }\end{array}$ & Total Fuels \\
\hline 1977 & 39.0 & 113.5 & 326.9 & 99.0 & 539.4 \\
\hline 1982 & 40.9 & 56.5 & 259.9 & 37.3 & 353.7 \\
\hline 1987 & 53.3 & 65.4 & 389.3 & 63.1 & 517.8 \\
\hline 1992 & 66.3 & 97.7 & 360.3 & 52.9 & 510.9 \\
\hline 1997 & 79.0 & 90.8 & 385.3 & 49.9 & 526.0 \\
\hline 2002 & 113.8 & 157.9 & 451.2 & 67.9 & 677.0 \\
\hline 2007 & 204.2 & 156.0 & 328.1 & 34.5 & 518.5 \\
\hline
\end{tabular}

Source: Expenditures in Table A.13 converted to quantities via cost estimates described in text.

The values in Table A.14 were used to develop energy intensity estimates for electricity and total fuels for each of the census years. Similar to mining, the energy intensities were then interpolated for the non-census years (and held constant at the 2007 level through 2011).

For years prior to 1977 , the consumption estimates were extrapolated back to 1970 by use of the National Energy Accounts series for construction sector electricity and fuel use.

\section{A.4 Transportation}

The indicators for the transportation sector are classified under two major segments-passenger transportation and freight transportation. Indicators of energy intensity in the passenger segment are defined in terms of energy per passenger-mile. For freight, the intensities refer to energy per ton-mile of freight transported. To construct an energy intensity index for the entire transportation sector, the Divisia index methodology combines the overall indexes for each segment on the basis of the relative quantities of energy used in each segment. 


\section{A.4.1 Background and General Data Sources}

The available data sources for historical energy consumption for transportation rely extensively on data sources other than EIA. The published transportation energy consumption data from EIA is based upon data sources for the supply of transportation fuels, and thus are not focused on the particular sectors and end uses pertaining to those fuels.

In the original development of the energy intensity indicators in 2002, Oak Ridge National Laboratory (ORNL) provided the basic methodology and underlying data sources for the construction of energy intensity indicators in the transportation sector. This activity grew out of ORNL's long history in supporting the Department of Energy in R\&D and policy analysis related to the U.S. transportation sector. In subsequent years, some minor modifications to this structure have been made, primarily in response to changing data sources.

One of the primary ongoing activities at ORNL has been the publishing of the Transportation Energy Data Book (TEDB). In the introduction to the TEDB, a statement of purposes as part of ita original motivation is provided as follows, "The major purposes of the Data Book were to draw together, under one cover, transportation data from diverse sources, to resolve data conflicts and inconsistencies, and to produce a comprehensive document" (ORNL 2013). In the summer of 2013 ORNL released the $32^{\text {nd }}$ edition of the Data Book. ${ }^{34}$ The TEDB primarily relies on published sources, although in terms of the TEDB, "these data may be reformatted for presentation."

Another comprehensive secondary source of transportation data is the Bureau of Transportation Statistics (BTS) within the Research and Innovative Technology Administration (U.S. Department of Transportation). The BTS is responsible for compiling and publishing a variety of statistics via the ongoing publication, National Transportation Statistics. According to the BTS website, this report presents "statistics on the U.S. transportation system, including its physical components, safety record, economic performance, the human and natural environment, and national security. This is a large online document comprising more than 260 data tables plus data source and accuracy statements, glossary and a list of acronyms and initialisms." The BTS National Transportation Statistics (BTS-NTS) report is available as a downloadable (pdf) file or as separated downloadable spreadsheet tables (updated quarterly) on the BTS website. ${ }^{35}$

\footnotetext{
${ }^{34}$ For purposes of citation in the remainder of this report, this edition of the Data Book will be identified as "TEDB-32." The most recent TEDB is available on the web at: http://cta.ornl.gov/data/index.shtml

${ }^{35}$ The BTS-NTS can be accessed at: http://www.bts.gov/publications/national transportation_statistics/
} 
In addition to these comprehensive secondary sources, primary data are available via a number of sources, either from government statistics-gathering or regulatory agencies or from trade associations. Most of the sources can be accessed via websites managed by these organizations.

During the periodic updates of the EERE system of energy intensity indicators over the past decade, all three of these sources (TEDB, BTS-NTS, and primary sources) have been utilized at one time or another. In general, the use of any particular source depends upon the timing of the update and the desire to obtain the most recently available data. In some cases, the primary data sources have been used because they contain other additional information needed to develop the intensity index. However, in some cases, the particular source has been used just out of convenience in the way the data can be accessed or how it must be further processed for use in the indicators system.

In the documentation of the data source in the tables in remainder of this section, the goal will be to present the available sources for a data item. The source or sources actually used in the most recent edition of the energy intensity indicators will be indicated by highlighted cells in the tables. Because the data sources often present information related to transportation activity along with energy consumption data, both activity and energy use will be cited together for each individual transportation segment.

\section{A.4.2 Recent FWHA Changes Related to Estimates of Vehicle Travel and Fuel Use}

Before turning to the individual tables summarizing the data sources and methodologies for detailed segments of the transportation sector, a major issue with regard to the highway segment of transportation warrants discussion. The Department of Transportation's Federal Highway Administration (FHWA) substantially changed its methodology for estimating vehicle travel and fuel use beginning in 2007. As part of their VM-1 series published in their principal publication regarding highway travel (Highway Statistics), the separate estimates for cars and light trucks (including SUV's and vans) were discontinued after 2008. In its place, the FWHA began to report travel (vehicle-mile) and fuel consumption estimates for short wheel-base (SWB) and long wheel- base vehicles (LWB). Most SUV's, vans, and small trucks were moved into the category with cars, and the resulting series after 2007 had no continuity with those from 2006 and earlier. However, as FHWA had previously published estimates under its old system through 2008, there are two years where there is an overlap between the old and new classification systems. ${ }^{36}$

Because of the ongoing need for many analytical purposes that require individual trends for both cars and light trucks, in early 2012 ORNL developed a special vehicle travel model that was used to extrapolate the $2006 \mathrm{VM}-1$ estimates consistent with the previous FHWA methodology. These estimates were shown in (previous) Edition 31 of ORNL's Transportation Energy Data

\footnotetext{
${ }^{36}$ This overlap is attainable only through use of ORNL's databook. For 2007 and 2008, FHWA only includes estimates under its new classification on its website.
} 
Book released in the summer of 2012. Unfortunately, the detailed vehicle registration data used to inform the ORNL model was not available to generate the same quality of estimates for Edition 32 of the databook. ORNL's published estimates for average fuel economy related to cars and light trucks for years 2009 through 2011 contain a disclaimer that the estimates are not comparable to the prior history. The average fuel economy values shown in Edition 32 of the TEDB appear to be inconsistent with the recent trends displayed in the most recent editions of FHWA's Highway Statistics. For the present study, an extrapolation procedure was developed to generate average fuel economy estimates for the years 2009 through $2011 .^{37}$

The extrapolation procedure involves several key assumptions:

- FHWA's SWB category can be separated into sub-categories, cars (SWB-1), and small trucks and SUVs (SWB-2). Metrics associated with the older category of light trucks can represented by a combination of SWB-2 and LWB.

- The percentage change from 2008 in fuel economy (mpg) for the SWB-2 category is a simple average of changes for cars (SWB-1) and LWB vehicles.

- The percentage change in the fuel economy for pre-2007 category of light trucks is a weighted average of the changes for SWB-2 and LWB, the weights based upon estimates of vehicle-mile for these categories.

Many of the quantitative aspects of the procedure are shown in Table A.15. The top panel of the table shows the vehicle-miles travelled (VMT) by the various categories of personal vehicles. Based on the VMT estimated by FHWA under both old and new systems, the VMT averaged $3.5 \%$ higher under the old system as compared to the new. The VMT shown in Table 4.1 (cars) and Table 4.2 (light trucks) in TEDB-32 from 2009 through 2011 were scaled to match the totals from FHWA (plus the 3.5\% adder). The estimates for these years are shown in highlighted portion of the top panel of the table.

The middle panel of the table shows the fuel economy estimates by vehicle category. It is clear from a comparison of the fuel economy for cars under the old system and the fuel economy for short-wheel base vehicles under the new system that FHWA did more than simply reclassify vehicles in their methodology change. One would expect that the addition of small trucks and SUVs to cars to make up the SWB classification would reduce overall fuel economy. However, that expectation is contradicted by the published FHWA estimates. In 2008, for instance, the fuel economy for cars was $22.60 \mathrm{mpg}$, as compared to the value of 23.66 for SWB vehicles. Given this situation, extrapolation to years after 2008 for cars and light trucks can be made only by assuming that percentage changes in fuel economy are reasonable proxies for changes in fuel economy under the previous methodology.

\footnotetext{
${ }^{37}$ It should be noted that ORNL is continuing to try to develop a robust methodology that will maintain historical consistency with previously published fuel economy estimates for cars and light trucks. Thus, in subsequent updates of the energy intensity indicators for this segment, revised estimates for 2009 and later should not be unexpected.
} 
Table A. 15. Summary of extrapolation methodology for car and light truck fuel economy

\begin{tabular}{|c|c|c|c|c|c|c|c|c|}
\hline \multicolumn{9}{|c|}{ Vehicle-miles (billions) } \\
\hline & \multicolumn{3}{|c|}{ Old (Pre-2007) Classification } & \multicolumn{3}{|c|}{ New (Post-2006) Classification } & \multicolumn{2}{|c|}{ Imputed Categories } \\
\hline & Cars & Light Trucks & Total & SWB & LWB & Total & SWB-1 & SWB-2 \\
\hline 2006 & $1,690.5$ & $1,082.5$ & $2,773.0$ & $\mathrm{NA}$ & $\mathrm{NA}$ & NA & & \\
\hline 2007 & $1,672.5$ & $1,112.3$ & $2,784.7$ & $2,104.4$ & 586.6 & $2,691.0$ & 1672.5 & 431.9 \\
\hline 2008 & $1,615.9$ & $1,108.6$ & $2,724.5$ & $2,024.8$ & 605.5 & $2,630.3$ & 1615.9 & 408.9 \\
\hline 2009 & $1,622.1$ & $1,104.2$ & $2,726.3$ & $2,015.7$ & 617.5 & $2,633.2$ & 1622.1 & 393.6 \\
\hline 2010 & $1,617.3$ & $1,123.8$ & $2,741.1$ & $2,025.7$ & 622.7 & $2,648.4$ & 1617.3 & 408.4 \\
\hline 2011 & $1,616.7$ & $1,123.4$ & $2,740.1$ & $2,043.4$ & 603.2 & $2,646.6$ & 1616.7 & 426.7 \\
\hline \multicolumn{9}{|c|}{ Average fuel economy (miles per gallon) } \\
\hline \multicolumn{9}{|l|}{2006} \\
\hline 2007 & 22.49 & 17.99 & & 22.87 & 17.07 & & & \\
\hline 2008 & 22.60 & 18.11 & & 23.66 & 17.34 & & & \\
\hline 2009 & 22.47 & 18.06 & & 23.53 & 17.29 & & & \\
\hline 2010 & 22.29 & 17.93 & & 23.34 & 17.18 & & & \\
\hline 2011 & 22.02 & 17.81 & & 23.08 & 17.08 & & & \\
\hline & & & & & & & & \\
\hline \multicolumn{9}{|c|}{ Percentage change from 2008 for fuel economy } \\
\hline & \multicolumn{2}{|c|}{ (Imputed changes) } & & \multicolumn{3}{|c|}{ (calculated changes) } & \multicolumn{2}{|c|}{ (Imputed changes) } \\
\hline 2008 & & & & 0 & 0 & & 0 & 0 \\
\hline 2009 & $-0.56 \%$ & $-0.31 \%$ & & $-0.53 \%$ & $-0.26 \%$ & & $-0.56 \%$ & $-0.39 \%$ \\
\hline 2010 & $-1.39 \%$ & $-1.00 \%$ & & $-1.34 \%$ & $-0.92 \%$ & & $-1.39 \%$ & $-1.13 \%$ \\
\hline 2011 & $-2.56 \%$ & $-1.70 \%$ & & $-2.44 \%$ & $-1.51 \%$ & & $-2.56 \%$ & $-1.98 \%$ \\
\hline
\end{tabular}

The middle portion of the lowest panel of the table shows the percentage changes in fuel economy under FWHA's new methodology, using 2008 as a base year. Thus, for example, the percentage change in fuel economy for SWB vehicles between 2008 and 2011 is shown to be $2.44 \%$ and for LWB vehicles, $-1.51 \%$. For the extrapolation methodology, it is assumed that the percentage change in fuel economy for small trucks and SUVs (labeled here as SWB-2) is somewhere between the percentage change for SWB as a whole and LWB vehicles. It should be noted from the estimates from the top panel of the table, the VMT in the SWB category appears to be dominated by cars. (For instance, given the simple approach here, cars are estimated to account for $80 \%$ of the total VMT of the SWB category in 2011.) Without specific information for guidance, the simplifying assumption is that the percentage change of the SWB-2 category is a simple average of the changes in fuel economy for SWB and LWB vehicles. (Thus, yielding for example, a change of $-1.98 \%$ for SWB-2 vehicle, as shown in the last row and column of the table.) Given this assumption and using the relative weights from the VMT estimates, the percentage changes in fuel economy for SWB-1 (= cars) can be calculated. 
The percentage changes in the various categories (SWB-1, SWB-2, and LWB) can be reconstituted to generate approximate changes for the original FHWA classification (SWB-1 = cars, SWB-2+LWB $=$ light trucks). The percentage changes are shown in the left-most columns in the last panel of the table. These percentage changes are finally applied to extrapolate 2008 values of fuel economy for cars $(22.60 \mathrm{mpg})$ and light trucks $(18.11 \mathrm{mpg})$. The extrapolated values are shown in the highlighted cells in the middle panel of the table. In 2011, average fuel economy for cars is estimated to $22.02 \mathrm{mpg}$ and $17.81 \mathrm{mpg}$ for light trucks. The average fuel economy estimates are divided into the estimates of total VMT to calculate total gallons of fuel consumed for both cars and light trucks.

\section{Methodology for Medium and Heavy Trucks}

The change in FHWA's overall methodology with regard to highway travel and fuel consumption data also impacted medium and heavy trucks. More formally, these trucks are classified by the Department of Transportation as 1) Class 3-8, Single-Unit, and 2) Class 7-8 Combination. Unfortunately, the FWHA methodological changes result in an implausible reduction in the overall energy intensity of the trucking segment of freight transportation starting in 2007. As compared to the immediately preceding years (2004 to 2006), the reduction in energy intensity in this segment falls between 5 and $8 \%$, considerably greater than the trends in the previous decade would suggest. Of course, this discontinuity impacts both the overall freight transportation sector (because trucking accounts for about $75 \%$ of freight energy use), as well as the energy intensity index for all transportation.

The decision was made to adjust the prior 1970-2006 data to be consistent with the more recent data published by the FWHA. While no perfect adjustment is possible, the adjustment of the earlier was deemed preferable to including this discontinuity in the overall intensity indicators structure and distorting the overall changes in many of the aggregate indicators for the 20072011 period. $^{38}$

Table A.16 provides a summary of the procedure by which the earlier (pre-2007) data were adjusted. Beginning with data for single-unit trucks, the top panel of the table shows that the change in the FHWA methodology changed the vehicle travel for medium trucks by almost $50 \%$ (less the change in actual travel that would have been measured under the old system). Fuel use

\footnotetext{
${ }^{38}$ 1. Provide direct technical assistance, training and web-based tools to agencies engaging in institutional/behavior change programs in support of achieving goals of EO 13514

2. Develop and implement technical assistance tools to assist agencies in designing effective institutional and behavior change programs needed to implement Strategic Sustainability Performance Plans required by E.O. 13514. 3. Collaborate with agencies identify the best practice metrics and measurement methodologies to evaluate the effectiveness of institutional and behavior change programs, focusing on significance and persistence of energy and environmental impacts. This is the opposite approach to that taken by ORNL with regard to passenger vehicles. However, ORNL employed a detailed model to recast the more recent data in terms of the old vehicle categories, an approach not feasible here. Whether ORNL eventually tries to adjust the trucking data to be consistent with the pre2007 time series is not clear. It should be noted that the actual vehicle categories for trucks was not changed by FHWA, rather it seems that changes in their overall statistical methodology are responsible for the different estimates.
} 
also was increased substantially, such that fuel economy in terms of miles per gallon fell by about $10 \%$, from 8.16 to 7.35 . The values for 1985 are included in the table for context and the fact that the intensity indicators are normalized to that year.

Table A.16. Summary of pre-2007 adjustments for medium and heavy trucks

\begin{tabular}{|l|r|r|r|}
\hline \multicolumn{2}{|l|}{ Single-Unit Trucks } & & \\
\hline & Vehicle travel & Fuel use & Fuel economy \\
\hline & (million miles) & (million gallons) & (miles/gallon) \\
\hline 1985 (Old) & 45,441 & 7,399 & 6.14 \\
\hline 2006 (Old) & 80,344 & 9,852 & 8.16 \\
\hline 2007 (New) & 119,979 & 16,314 & 7.35 \\
\hline & & & \\
\hline Scale Factor & 1.47 & NA & 0.90 \\
\hline 1985 (Revised) & 66,814 & 12,071 & 5.53 \\
\hline 2006 (Revised) & 118,133 & 16,073 & 7.35 \\
\hline 2007 (New) & 119,979 & 16,314 & 7.35 \\
\hline & & & \\
\hline & & & \\
\hline Combination Trucks & & & \\
\hline & Vehicle travel & Fuel use & Fuel economy \\
\hline 1985 (Old) & 78,063 & 14,005 & (miles/gallon) \\
\hline 2006 (Old) & 142,169 & 28,107 & 5.57 \\
\hline 2007 (New) & 184,199 & 30,904 & 5.96 \\
\hline & & & \\
\hline Scale Factor & 1.28 & NA & 1.18 \\
\hline 1985 (Revised) & 99,585 & 15,163 & 6.57 \\
\hline 2006 (Revised) & 181,365 & 30,430 & 5.96 \\
\hline 2007 (New) & 184,199 & 30,904 & 5.96 \\
\hline
\end{tabular}

Source: See text. Shaded values designate values for 2006 assumed to be equal to 2007 to facilitate linkage of series

For combination truck data, shown in the lower portion of the table, the increase in travel was less pronounced than that for single-unit trucks, and overall fuel consumption was increased by less than $10 \%$. This resulted in an improvement in the fuel economy of about $18 \%$.

To adjust the data series for travel and fuel use for previous years, there was no choice but to assume that the proportional changes under the old system adequately reflected the appropriate trends. Thus, the procedure becomes one of the estimating the values for 2006 under the revised methodology and extrapolating proportionately back to previous years according to changes in the "old" estimates. 
For the magnitude of vehicle travel, it was assumed that that change in the constant-dollar value of the output of the trucking industry [provided by the Bureau of Labor Statistics for their occupation projections input-output model (BLS 2012) ${ }^{39}$ ] would mirror the change in vehicle miles, at least over short time intervals. Thus, the 2006 estimates for miles travelled in both trucking segments were increased by $1.6 \%$ to yield an estimate for 2007 . Scale factors for both segments were computed as the ratio of the 2007 estimate under the new FWHA methodology and the extrapolated value. As shown in the table, the scale factors were 1.47 (= $118,133 / 80,344)$ for single-unit trucks and 1.28 for combination trucks. The scale factors were applied to all of the previous vehicle travel estimates for 1970 through 2006.

For fuel consumption or fuel economy, there is unfortunately no outside data source that can be used to adjust the 2006 estimates. Furthermore, there was no stable trend in the fuel economy for single-unit trucks over the previous four years (fluctuating from 7.35 to 8.36 miles per gallon), while for combination trucks, the change in fuel economy was very stable (ranging from 5.21 to 5.06 over those same years). Thus, a reasonable choice for the 2006 estimate under the revised FHWA methodology was to assume the fuel intensity to be equal to its 2007 value. With that assumption, the scale factors were computed in a similar manner to the values for vehiclemiles and were applied to the earlier estimates, 1970 through 2006. Total fuel consumption was estimated by dividing these revised fuel economy estimates into the vehicle-miles travelled estimates.

\section{A.4.3 Data Sources and Methodology Used for Buses}

The transportation segment for buses includes three sub-categories: 1) local transit, 2) intercity, and 3) school. Transit and school buses provide well-defined passenger transportation services. "Intercity buses", as defined in the system of energy intensity indicators, provide a diverse mix of services. These buses are generally commercial in nature, and include scheduled (and fixed route) intercity transportation, charters and tours, and airport and commuter buses. Local transit for the purpose of the energy intensity indicators work includes those entities that report to the American Public Transit Association (APTA) and, thus, there may be some public service that also serve airport and commuters).

In terms of the relative sizes of these segments, measured by the estimates of passenger-miles in 2011, school buses account for the largest share (53\%), followed by intercity (36\%), and transit (11\%). On the whole, however, bus transportation is dwarfed (accounting for about $1.2 \%$ of total passenger-miles in 2011) by transport from private vehicles.

The discussion below is intended to provide an overview of the data sources and methods that have been used to develop the energy intensity indicators for each of these sub-categories. The

\footnotetext{
${ }^{39}$ The output data can be accessed via the BLS Industry Output and Employment webpage: http://www.bls.gov/emp/ep_data industry_out_and_emp.htm, last accessed 1/13/2013
} 
data quality and historical consistency is much better for transit buses than for either of the other two bus categories. As a result, most of the discussion below relates to intercity and school buses, with the aim of showing the key assumptions and imputations that have been made to construct the historical series of transportation activity and energy use.

\section{Transit Bus}

The data for buses used for local transit transportation is exclusively taken from either statistical material on the APTA website or from older editions of ORNL's Transportation Energy Data Book (which, in turn, used data from the APTA). An excerpt from the first page of Appendix A (Historical Data) in APTA's most recent Public Transportation Fact Book provides relevant background information: ${ }^{40}$

"The American Public Transportation Association is a nonprofit international association of over 1,500 public and private member organizations including transit systems; planning, design, construction and finance firms; product and service providers; academic institutions; transit associations; and state departments of transportation. APTA members serve the public interest by providing safe, efficient, and economical transit services and products. Over ninety percent of persons using public transportation in the United States and Canada are served by APTA members.

The Public Transportation Fact Book (formerly the Transit Fact Book) was first published in 1943. This is the 65th edition of the Fact Book published by the American Public Transportation Association and its predecessor organizations.

Data in the Public Transportation Fact Book have been calculated following statistically rigorous procedures since the data were first accumulated. All Fact Book data from the beginning of its collection represent the entire transit industry for those modes for which data were collected and reported for the year of the data."

The availability of data in the APTA Fact Book is aided by the fact that all local transit systems receiving federal aid are required to report to the Federal Transit Administration. Beginning in 1979, the data submittals have been incorporated into the National Transit Database (NTD). The NTD serves as the primary repository on all transit-related data and statistics in the United States. The performance data from the NTD is used annually to allocate FTA funds to agencies as well as report on public transit performance to Congress and other interests. The NTD is legislated under Title 49 U.S.C. 5335(a). In 1984 APTA members began providing APTA with copies of their submissions to the NTD rather than completing special surveys. The implication of this development is that the growth in transit bus passenger-miles from 1983 to 1984 appears to be on the order of $5 \%$ higher than it would have been under the previous reporting system.

The reporting requirements for the NTD changed in 2007. The APTA 2014 Fact Book (Appendix A) describes this change as follows:

\footnotetext{
${ }^{40}$ The 2014 Public Transportation Fact Book can be accessed from the APTA from the following URL: http://www.apta.com/resources/statistics/Pages/default.aspx
} 
"NTD data were first reported for agencies in Urbanized Areas (UZA). UZAs are areas defined during the Decennial Census with at least 50,000 persons including a central city. Prior to 2007, data for systems outside of urbanized areas, rural systems, were not collected or published by the NTD and were estimated by APTA based on other data sources.

Beginning in 2007 the NTD collected and made available data for rural agencies. The Federal Transit Administration Rural Transit Assistance Program also sponsored a survey of rural transit agencies. These surveys allowed APTA to more accurately assess the distribution of bus, demand response service, and transit agency vanpool service in rural areas. In association with this, APTA also conducted a survey of other data sources to identify agencies not included in the main NTD report or the NTD rural data. The increase in data available over the Internet from state agencies which oversee transit entities also allows a more accurate estimate of data for agencies eligible for federal transit assistance which provide non-profit service to elderly persons and persons with disabilities and are, therefore, included in demand response data."

As a result of this change, the reported values in the indicators system for transit buses and demand response service are inconsistent between 2006 and 2007 (van pool service is not considered in the intensity indicators system). Passenger-miles for demand service as a result of this reporting difference increase from 1,078 million in 2006 to 1,502 million in 2007. The comparable numbers for all transit buses are 22,821 million in 2006 and 20,976 million in 2007. Thus, while a portion of the decline for buses can be attributed to the change in reporting system, it is evident that the majority of the decline was caused by other factors. ${ }^{41}$

Neither the 1984 nor the 2007 discontinuity in the transit bus data was deemed sufficiently large to warrant any attempt to calibrate the older data to match more recent new data. Moreover, the changes have no significant impact on the implied fuel economy of transit buses in these transition years.

As discussed in the body of this report, the energy intensities for passenger transportation are defined in terms of energy per passenger-mile. This treatment implies that changes in energy intensity may arise from either 1) changes in fuel economy for equipment (in this case, buses), or 2) from changes in average passenger loads. Because the data for both of these metrics are consistently available (with the small exceptions noted for 1984 and 2007) from the APTA (via the NTD), it is instructive to examine the behavior of both of these indicators over time. Figure A.19 shows on the same graph the calculated values for miles per gallon (MPG) and average load factor (passengers per transit bus) over the period 1970 to 2011. The MPG figures were derived by converting the estimated total energy use by transit buses into gallons of diesel

\footnotetext{
${ }^{41}$ Nor is the small increase in transit vanpool from 712 to 857 million passenger-miles sufficient to account for much of the reduction in the transit bus activity between 2006 and 2007.
} 


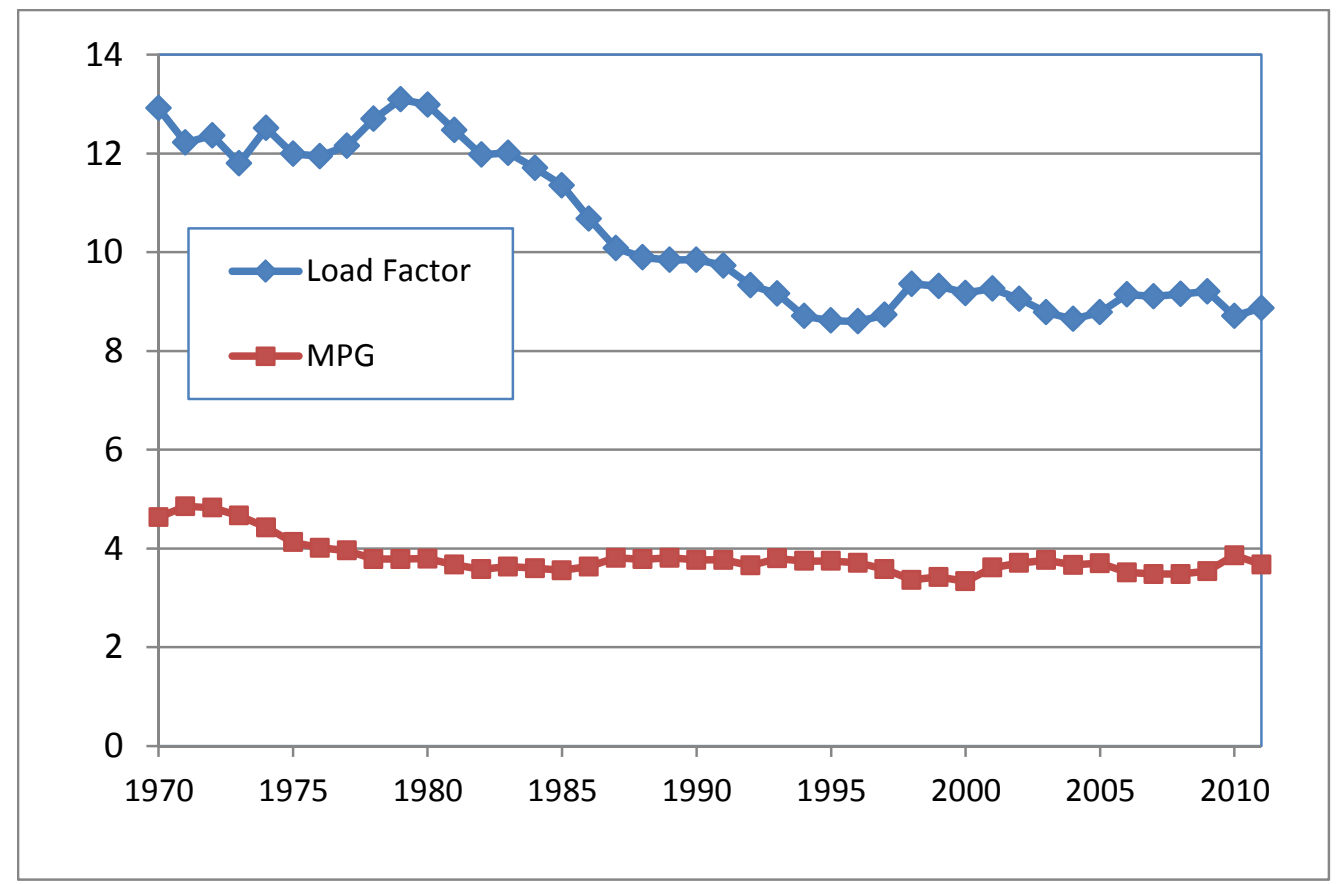

Figure A. 19. Average passenger loads (load factor) and fuel economy (MPG) for transit buses, 1970-2011

equivalent. ${ }^{42}$ The figure demonstrates that nearly all of the change in energy intensity over the entire time period was the result of a decline in average bus occupancy over about a 15 -year period extending from 1980 through 1995. This decline stemmed from both a decline in ridership and an implied extension of transit service, the latter represented by a $30 \%$ increase in estimated vehicle-miles traveled by transit buses.

The bottom line in Figure A.19 shows that average fuel economy of buses has changed very little since the mid-1970s. Throughout the period, fuel economy has generally been between 3.5 and 4.0 miles per gallon. As mentioned below in the discussion of intercity buses, one can speculate that improvements in diesel engine fuel efficiency have largely been absorbed by better emission control technology and perhaps other amenities. The lower fuel economy values for transit buses, as compared to those shown later for intercity and school buses, is consistent with large periods of idle time for loading and unloading passengers, as well as waiting at stop signals in urban environments.

\section{Intercity Bus}

What is termed the intercity bus segment in the system of energy intensity indicators consists of a number of distinct transportation activities. The American Bus Association (ABA) uses the

\footnotetext{
${ }^{42}$ As means of lowering urban air pollution from vehicles, beginning in the mid-1990s the share of transit bus fuel from compressed natural gas $(\mathrm{CNG})$ has grown significantly, reaching about $20 \%$ of all fuel on the basis of total gallons used. CNG has a lower energy content per gallon than diesel; for this calculation a relative energy content of 0.93 was used.
} 
term "motorcoach" to characterize this industry. In their recent statistical survey of the industry for 2010, ABA distinguished seven service categories: charter (46.1\%), scheduled service $(28.8 \%)$, commuter $(10.3 \%)$, tour $(7.9 \%)$, airport $(3.5 \%)$, sightseeing $(1.2 \%)$, and special operations $(1.2 \%)$. (Percentages shown represent estimated percentages of total service mileage).

Unfortunately, there exists no consistent data source to measure activity and fuel consumption for this industry. Through the early 1980s, the ABA published estimates of vehicle-miles, passenger-miles, and fuel consumption. This information was based largely on reports to the Interstate Commerce Commission (ICC) and state regulatory agencies for regulated carriers. Annual reports issued by the ABA in the 1970s rely on this information, "supplemented by estimates to cover unavailable segments" (as cited from America's Number 1 Passenger Transportation Service, the 1978 annual report from the American Bus Association).

After deregulation of this industry in the early 1980s, the ABA discontinued publication of data related to the industry over most of ensuing two decades. The last available data from ABA prior to 2000 relates to 1983 . In the 2000 s, the ABA resumed efforts to quantitatively characterize the industry. Three benchmarking studies were conducted that developed estimates of activity and fuel use for the years 2000, 2004, and 2007. However, these studies are not currently available on the ABA website. Instead, summary data is contained in several derivative reports that examined $\mathrm{CO}_{2}$ emissions from the various transportation modes. ${ }^{43}$

In 2011, the ABA undertook a more serious effort to accurately represent the size and composition of the motorcoach industry. In June 2012, the ABA released 2010 data from what it termed its Motorcoach Census 2011. The ABA subsequently reissued the report, after a more extensive review of the industry. ${ }^{44}$ Under contract to the ABA, the consulting firm John Dunham and Associates contacted "nearly 5,000 companies to see if they fit the industry definition and verify ownership structure." On the basis of this work, the reissued report indicated that the number of carriers in the originally issued report was about $10 \%$ too high. However, the reissued report does not compare estimates of service mileage or fuel consumption between the original and reissued report.

A principal difficulty in measuring the historical changes in this industry is that the composition of activities has changed markedly since the 1970s. The intercity scheduled service segment of the industry saw sharp declines in activity, particularly in the wake of the deregulation. Simply put, national carriers such as Greyhound and Trailways (later purchased by Greyhound) were no

\footnotetext{
${ }^{43}$ These reports are: Comparison of Energy Use \& $\mathrm{CO}_{2}$ Emissions From Different Transportation Modes, May 2007 and Updated Comparison of Energy Use \& $\mathrm{CO}_{2}$ Emissions From Different Transportation Modes, October 2008. Both report can be accessed from the ABA webpage: http://www.buses.org/ABA-Foundation/Research, "Full Report 2007" and "Full Report 2008," respectively.

${ }^{44}$ This ABA report, Motorcoach Census 2011, can be accessed from the ABA webpage: http://www.buses.org/ABA-Foundation/Research, under the heading "Full Report 2011." The subsequent 2012 and 2013 reports are found in the same location.
} 
longer obligated to provide services to smaller rural locations. This downward trend was most pronounced in the decade between 1982 and 1992. Based on data from the Bureau of Labor Statistics, overall employment in "Intercity and rural bus transportation" (Standard Industrial Classification 413) fell from almost 40,000 in 1982 to 23,000 in 1992.

On the other hand, the charter and tour segments of the industry have grown substantially over the past three decades. This growth can be attributed growth in personal income that stimulated overall leisure travel demand and charters to serve new gambling venues such as Atlantic City. For this segment, deregulation boosted activity because many new companies were able to enter this market without the previous restrictions imposed by the regulatory agencies.

While these trends are clearly present in the structure of the data between the 1970s and the present, there is not sufficient annual data to be able to accurately characterize these two distinct segments (scheduled intercity service and charter buses). As such, a major reexamination of the data for this sector that was conducted in the summer of 2014 was not able to provide separate intensity indexes for these segments.

Moreover, at this point, it should be pointed out that the inconsistent reporting of data for this industry appears to lead to overstatement of the overall growth of the industry from the 1970s to the present, based on the most recent statistical surveys conducted by the American Bus Association. In terms of overall vehicle (bus) miles, the 1984 annual report from the ABA (Annual Report 1984: On the Frontier of Change) shows an estimate 1,120 million miles for 1983. This value was extrapolated to 1997 by the Eno Transportation Foundation (ETF); as shown in the $19^{\text {th }}$ Edition of the Oak Ridge Transportation Energy Data Book (TEDB-19) the 1997 value (based on the ETF work) was 1,276 million miles. In the (revised) 2011 Motorcoach Census from the ABA, the estimate for vehicle miles had grown to 1,950 million miles by 2010 . The change between 1997 and 2010, representing an annual growth rate of $3.3 \%$ is likely too high. However, there is insufficient data and information to attempt adjust the earlier figure to represent what the current statistical approach used by ABA might have yielded had it been conducted in the late 1990s. Accordingly, the user of this data should be aware of the limitation caused by inconsistent measurement of the industry. ${ }^{45}$

\footnotetext{
${ }^{45}$ The blending of the various data sources is explicitly shown in the spreadsheet for the transportation sector constructed for the system of energy industry indicators. A separate worksheet was developed for the intercity bus transportation sector and is shown in the publicly available spreadsheet. With regard to the vehicle-miles, the ABA's 2007 report on $\mathrm{CO}_{2}$ emissions shows an estimate of 2,390 million miles for 2004. In the subsequent 2008 report with estimates for 2007, the estimate was 1,798 million miles. The more comprehensive methodology later conducted by John Dunham and Associates (and reported in the Motorcoach Census 2011, referenced above) showed an estimate of 1,948 million miles for 2010. For purposes of the intensity indicators, the very high 2004 estimate was judged to be inconsistent with the earlier and later estimates, and was not used. Estimates of vehiclemiles were interpolated linearly between the 1998 and 2007 estimates, although it is recognized that the resulting series would not represent the effects of the 2002-2003 recession. However, no other suitable data source has been identified that would better represent the variation during this particular time period. While the 2007 and 2010 estimates come from incomparable statistical approaches, an increase between these two years is qualitatively consistent with what the ABA believes has been a trend over this period.
} 
With regard to energy intensity indicators, the more important focus is on what the data show with regard fuel use and implied fuel economy. The last available estimate for overall fuel economy from the ICC-based data was for 1980. In terms of fuel economy, the data indicated an overall average of 5.5 miles per gallon. Moving ahead nearly three decades, the ABA-developed estimate for 2007 was 5.67 miles per gallon, calculated across all segments of the intercity bus industry. ${ }^{46}$ In essence, there appears to have been little change in the reported fuel economy. One may surmise that improvements in diesel engine fuel efficiency were largely "taken up" by reduced vehicle emissions and perhaps improved bus amenities such as air conditioning and air filtration. $^{47}$

Lacking data for individual years between 1980 and 2007, the average miles per gallon values were linearly interpolated between these two years. Total fuel use was subsequently derived from dividing total bus miles by the estimated average miles per gallon.

In the system of energy intensity indicators, energy intensity for highway passenger transportation is defined in terms of energy per passenger-mile, rather than energy per vehiclemile. On this basis, energy intensity has substantially fallen over the past four decades. From the last annual report (1983) issued by the ABA that was based upon ICC data, the average passenger load (occupancy) was just under 24 persons per bus. The recent statistical efforts by the ABA since 2004 show average passenger loads between 32 (in 2010) and 36 (in 2012) persons per bus.

The limited data available for scheduled service show perhaps a comparable increase. The 1978 ABA annual report (America's Number 1 Passenger Transportation Service) showed the average number of passengers per bus for "regular route intercity service" of 19.9. The two ABA reports issued in the 2000s (data for years 2004 and 2007) suggest a significant increase. For 2004, the data for scheduled service indicate an average passenger load of 26. For 2007, a somewhat broader category termed "fixed route" (defined as airport shuttle, commuter, intercity, and special operations) showed an average passenger load of 30.6 .

The passenger load estimates published in the 2007 (for 2004) and 2008 (for 2007) " $\mathrm{CO}_{2}$ emission" reports indicate much higher values for charter service and tour buses. The 2005 estimate for charter buses is 38.0. For 2007, charter and tour buses are combined, and the average passenger load was estimated to be 41.9 .

\footnotetext{
${ }^{46}$ Table 2.2 in ABA Report, Updated Comparison of Energy Use \& $\mathrm{CO}_{2}$ Emissions From Different Transportation Modes, October 2008. From ABA website: http://www.buses.org/ABA-Foundation/Research, under heading "Full Report 2008."

${ }^{47}$ To this point, no source has been identified that might generate an historical series of diesel engine fuel efficiency, holding other factors constant. For the system of intensity indicators, the average miles per gallon (MPG) estimates for the years 1981 through 1997 were interpolated between the reported 1980 and 1997 estimates. The MPG estimate from the ABA report for 2004 was 5.52, but was not used. See previous footnote. For purposes of estimating total fuel use, the interpolated vehicle-mile estimates discussed in the previous footnote were divided by the average MPG estimates.
} 
As a tentative conclusion, the available data suggest that average passenger loads in this segment of bus transportation have increased significantly. The increase can be attributed to two factors: 1) an increase in the average passenger loads for the scheduled service, and 2) a greater share of activity pertaining to charter buses that have higher passenger loads on average. The second factor is clearly a case of structural change in the overall intercity bus segment. However, the data to accurately measure the magnitude of this effect — separate historical series of energy intensities for scheduled service and charter-tour service--are not available. ${ }^{48}$

\section{School Bus}

School buses are estimated to currently represent more than half of the activity, measured by passenger-miles, of the entire bus transportation sector. However, similar to the intercity bus segment, there are no consistent historical sources to measure either activity or energy use.

Data through the late 1990s for school bus vehicle-miles and passenger-miles were largely based on data from the Federal Highway Administration (FHWA) and annual reports entitled Accident Facts issued by the National Safety Council. The values from these sources through 1991 are shown in an historical compendium of the transportation data published by the Bureau of Transportation Statistics (BTS) in September 1993 (Bureau of Transportation Statistics 1993). The BTS data show estimated vehicle-miles from 1970 forward and passenger-miles from 1980 forward.

In Edition 19 of the ORNL Transportation Energy Data Book (TEDB-19), these series are extended through 1997, although estimates for 1992 and 1993 are not shown. The passengermile estimates were shown only from 1990 forward, given the implausible estimates developed in Accident Facts. That source appears to have increased its coverage of state supplied estimates through the first years of the 1980s. For example, the value shown in the 1993 BTS publication for school bus passenger-miles was 41 billion in 1980 and 78 billion in 1984. ORNL appropriately decided to not include these earlier passenger-mile estimates for buses in TEDB19.

\footnotetext{
${ }^{48}$ As cited above, the average passenger load from the 1983 data published by the ABA was 24 (23.7). The subsequent estimates through 1997, shown in Edition 19 of the Transportation Energy Data Book, implied that the average passenger load changed only slightly over this period. This behavior is questionable in light of the changes in the industry that occurred over this period. Nevertheless, these values are used (implied) in the present set of estimates for this segment. The average passenger loads were interpolated linearly between the 1997 estimate of 24.0 and the 2004 estimate of 33.4 in the 2007 ABA report. (Admittedly, there is some inconsistency in the use of the average passenger load from the 2007 report, but not the magnitude of total passenger-miles as discussed earlier. Clearly, it is assumed that the methodology used for that report more accurately measured the average passenger load than aggregate activity in the sector.) Total passenger-miles over this time period were developed by multiplying the estimates of bus miles times the average passenger load. Given the interpolation of average passenger loads between two different sources over a relatively short period of time (1997 to 2004), the resulting decrease in the computed energy intensity over this period should not be taken too literally. The longer-term reduction in energy intensity since the early 1980s (or the 1985 base year used in the system of energy intensity indicators) is hopefully a reasonable representation of this segment.
} 
For the development of activity measures for the indicators system, the approach focused upon developing a credible historical series of vehicle-miles for school buses. To reduce the implausible year-to-year variation of vehicle-miles in the 1975-1994 data, the estimates at fiveyear intervals (with the exception of 1994) were taken as published (in the TEDB-19, Table 8.14). Intervening values were developed by multiplying average annual miles per bus times the number of buses (in TEDB-21, Table 8.13). Annual miles per bus for years not ending in 0 or 5 were interpolated between the values in years ending in 0 or 5 . This procedure was used to develop vehicle-miles through 1994.

Beyond 1994, the estimates of vehicle-miles were developed from data supplied by School Bus Fleet Magazine (SBFM). ${ }^{49}$ SBFM annually publishes a "Fact Book" that shows state-level figures for public and private school pupils transported, total number of buses, and total "route mileage." Total "route mileage" is an estimate of the total miles required to be driven by buses in the state to transport students to and from school. This value is taken to be a reasonable proxy for the actual number of vehicle-miles driven by school buses.

As valuable as the SBFM data is for this transportation segment, it is not without limitations. SBFM relies on voluntary reporting by the appropriate state agencies that are involved with public school transportation. As such, the reporting is not complete for each year. First, four states have never provided estimates of route mileage. Second, some states do not update estimates for each and every year; rather they may report the same data for two or more years.

Finally, in an increasing number of recent instances, some states have not provided any value of route mileage for a given year. ${ }^{50}$

While SBFM provides a total national estimate for route mileage for each year, it makes no attempt to impute missing state data in such estimates. Given the distortion in the year-to-year changes in the national estimates that might be caused by missing values for large states, an attempt to make approximate imputations was undertaken for the intensity indicators effort. In general, the imputation relied upon linear interpolations between known values or use of other data items such as the number of buses, pupils transported, or total public/private school enrollment to inform the interpolation procedure. For the states with no route mileage

\footnotetext{
${ }^{49}$ These data are available to subscribers of SBFM. Historical statistical data from its "Fact Book" are available from the "research" webpage: http://www.schoolbusfleet.com/research/default.aspx

${ }^{50}$ The data for California from the SBFM was particularly perplexing, with a number of years that showed implausible changes in mileage from the previous year. After communication with the California Department of Education, it was learned that the Highway Safety Unit in the Commercial Vehicle Section of the California Highway Patrol (CHP) is responsible for collecting data on school bus vehicle-miles in California. The CHP data from 1995 forward were graciously provided by that organization (personal e-mail communication from Ali Khouie, July 11, 2014). For a few years the SBFM figures matched those from the CHP, but overall the CHP data clearly displayed a more stable, and more realistic, time series.
} 
information, estimates were based upon multiplying the number of buses (reported in SBFM) times an approximate national average of annual miles per bus (for this work, taken to be 9,000).

The incorporation of the state-level imputations results in more credible annual estimates of national route mileage. For example, the significant one-year declines shown in the unadjusted SBFM national estimates for 1999 and 2005 are eliminated. The substantial 18\% decline in overall mileage between 2006 and 2011 is reduced to 13\% after missing values are imputed.

When compared to the 1994 national estimate of school vehicle-miles from TEDB-19 (4.4 billion), the 1995 estimate based upon the adjusted SBFM data (4.37) is acceptably close. To account for growth between 1994 and 1995, the final set of SBFM estimates were uniformly adjusted upward by $5 \%$. This adjustment accounts for what is likely to be conservative estimate of the additional vehicle-miles for school buses that are related to extracurricular activities, not typically accounted for in the reported route mileage data.

The only period in which there appears to be somewhat consistent estimates for both school bus vehicle-miles and passenger-miles is 1985 through 1997 . However, these values rely primarily on data from Accident Facts, and the values show implausible changes from one year to the next, particularly the passenger-mile estimates. The implied passenger (pupil) loads range from 19 to 24, computed dividing passenger-miles by vehicle-miles.

The SBFM data provide national average estimates of miles per bus and pupils per bus. Across all the years, the number of pupils per bus averages just over 52 on a national basis. If one assumes that pupils are picked up in a linear fashion, with equal distance between pupils, then the average number of pupils per bus on any route is 26 . This estimate is reduced about $12 \%$ to account for mileage required prior to the first student, and puts the estimate (23) in the range of the external values from Accident Facts. Lacking more explicit information as to whether average pupil loads have trended over time, a constant value of 23 was assumed for all years. This value is multiplied by total vehicle-miles to generate estimates of total passenger-miles.

The final required data element concerns fuel usage by school buses. While ORNL no longer presents an annual historical series on school bus vehicle- or passenger-miles in the Transportation Energy Data Book, it continues to show historical estimates of school bus energy use (TEDB-32 for 2013). The estimates for fuel use from 1970 through 2000 are based upon the report by the Eno Transportation Foundation, Transportation in America, 2001, Nineteenth Edition. Beyond 2000, the estimates are extrapolated by ORNL on the basis of total bus vehiclemiles from the FWHA Highway Statistics (Table VM-1).

A similar approach is followed for the indicators work in this report. Fuel use is extrapolated from the 1994 estimate shown in TEDB-32 on the basis of the national estimates of school bus 
vehicle-miles described above. ${ }^{51}$ The modification of approach here from that used by ORNL yields an estimate of 2011 fuel use 549.6 million gallons versus 532.6 million gallons in TEDB32. For purposes of converting fuel use in the Btu terms, the approach follows TEDB in allocating $90 \%$ of fuel as diesel, and $10 \%$ as gasoline.

The reader will note that the use of a constant pupil load per bus, combined with an extrapolation of fuel use based on vehicle-miles, yields no change in energy intensity over the much of the most recent two decades. The result is consistent with the very small change in bus fuel economy that was developed for the intercity (and commercial) and bus segment of the industry (as well as the historical series of MPG estimates shown for transit buses in Figure A.19). The difference with regard to energy intensity indicators is that the intensity fell in the intercity segment almost exclusively as a result of increased passenger load factors; no such change can be reliably estimated for school buses.

In the earlier period from 1970 through 1994, the implied miles per gallon can be calculated for school buses. The estimate miles per gallon increase from 7.0 in 1970 to 8.1 in 1994 . These values are somewhat higher than the range of 6 to 6.5 estimated for the intercity segment. One can speculate that fuel efficiency in gasoline-powered school buses made some contribution to this improvement, although it is unlikely to be responsible for the bulk of the change.

\section{School bus fuel economy - a statistical snapshot for Washington State}

A small effort was made to try to develop an estimate of average fuel economy for a single state, with the hope that the results could be extrapolated to a national basis. Over the past several years, the agency in Washington state responsible for public education (Office of Superintendent of Public Instruction, OSPI) has requested that local school districts report diesel and gasoline use along with their estimates of route mileage (that form the basis of state funding of basic pupil transportation). The implied miles per gallon figures were calculated for 282 school districts for most recent school year 2012-2013. Gasoline use, which accounted for a little over 5\% of total fuel consumption, was converted into "diesel equivalent" based on Btu content per gallon $(125,000 / 138,700=0.90)$.

It was apparent that some districts supplied inconsistent data that resulted in either implausibly high or low estimates of average fuel economy. To mitigate this problem, the top and bottom six observations for fuel economy were omitted. From the remaining 270 observations (school districts), the aggregate fuel economy was computed to be 7.2 miles per gallon.

The implied fuel economy values, however, display considerable variation. After the trimming of the dataset, the remaining calculated miles per gallon values ranged between 3.5 and 16.1. An

\footnotetext{
${ }^{51}$ The extrapolation is made from 1994 rather than 2000 because there is uncertainty as to whether the Eno Transportation Foundation had any direct information on fuel use over this period. The source note to the 2001 Eno report reads, "school bus figures based on data from National Safety Council's Accident Facts." Unfortunately, it is not clear where and when any independent estimates of school bus fuel use have been developed.
} 
average of the individual observations was 9.8 miles per gallon with a standard deviation of 1.8 miles per gallon. The difference between the calculated value of 7.2 miles per gallon from the aggregate data (i.e., total miles/total gallons) and the (unweighted) average of the individual observations ( 9.8 miles per gallon) is consistent with the notion that fuel economy is higher in smaller rural school districts, with relatively fewer stops per mile to pick up pupils. However, the data suggest that this relationship does not uniformly apply; some small districts have very low implied MPG values and some larger, more urban, districts have greater than average MPG values. Clearly, other factors such as the age and type of buses, as well as driver operating practices, come into play in influencing overall fuel usage.

The limited statistical study of the Washington state data suggests the difficulty one would have in linking any engineering estimate of (diesel) engine fuel economy to on-road fuel economy for buses. The variation across the school districts in implied fuel economy indicates that there are a number of factors that affect this metric. Moreover, in the case of Washington state, there appear to be issues on the reliability of fuel consumption estimates that have been submitted on a somewhat voluntary basis. (Currently, the OSPI in Washington state does not actively audit the fuel consumption submittals by school districts). However, in spite of these issues, the existence of such data over of long period of time (e.g., a decade or longer) and for a number of states, would potentially yield suitably robust estimates of trends in school bus energy efficiency. A more thorough examination of this approach, however, must be deferred to future updates of the overall energy intensity indicators.

\section{A.4.4 Detailed Sources and Brief Methodology Descriptions}

In the documentation of the data source in the tables in remainder of this section, the objective is to present one or more available sources for each data item. The source or sources actually used in the most recent edition of the energy intensity indicators will be indicated by highlighted cells in the tables. Because the data sources often present information related to transportation activity along with energy consumption data, both activity and energy use will be cited together for each individual transportation segment. In general the discussion below will focus on issue areas and special adjustments. The tables documenting these sources, along with notes alluding to any special data adjustment procedures, are included together at the end of this (transportation) section.

\section{Passenger Transportation}

Passenger transportation is broken out into three major modes: 1) highways, 2) rail, and 3) air. Passenger highway transportation is split into segments for personal vehicles and buses.

Highway Passenger - Personal Vehicles 
Table A.17 presents the data sources for the personal vehicles portion of the passenger highway segment, comprised of three types of vehicles: car, light trucks, and motorcycles. As implied by the discussion above, the primary source for energy use and activity for cars and light trucks is via the latest Edition 32 of the TEDB (2013).

The time series for motorcycle use and fuel consumption was also affected by the FHWA change in methodology in 2007. The resulting increase in vehicle-miles travelled for motorcycles is likely in the range of 60 to $70 \%$, compared to the previous methodology. However, because the share of total highway passenger-miles from motorcycles is still estimated to be on the order of $0.5 \%$, no adjustments have yet been made to eliminate the 2006-2007 discontinuity in this series.

A factor to be recognized in all segments of highway transportation is that the estimated passenger-miles should all be viewed with some degree of caution. The load factors used to convert from vehicle-miles to passenger-miles are based upon periodic surveys, as documented in Table A.17, and thus carry with them the sampling error associated with any survey. The motivation for using passenger-mile estimates in the system of energy intensity indicators is that the highway estimates can be compared to other travel modes. The detailed, publicly available spreadsheets contain data for vehicle-miles for those analyses for which vehicle-miles (and energy intensity per vehicle-mile, i.e., average miles per gallon) is more appropriate.

\section{Highway Passenger - Buses}

A detailed discussion of the data and methods used for buses was presented in the previous Section, A.4.3. Accordingly, Table A.18 only summarizes the major elements from that discussion. To reiterate, buses are divided into three categories: 1) transit, 2) intercity, and 3) school. The historical estimates for fuel use and activity for transit buses are robust, relying on the compilation of data from across the U.S. the Federal Transit Administration and the American Public Transit Association (APTA). As evident in the discussion in the previous section, the data situation with the other two segments of bus transportation is much weaker. For the intercity bus segment, the estimates were generally based upon various reports that have been issued by the American Bus Association, but have employed inconsistent data collection methods. For school buses estimates for activity and fuel use were derived from reports from the National Safety Council (in Accident Facts) and from estimates developed and published by the Eno Transportation Foundation For the most recent years, energy use for school buses has been extrapolated on the basis of national estimates of route miles traveled by school buses.

\section{Passenger - Rail}

Table A.19 shows data source for passenger rail transportation. The American Public Transit Association (APTA) provides detailed data for the rail segment of commuter and transit transportation. As shown in the last column of the table, this data is very accessible from the APTA website, and is published as an appendix in their annual Fact Book. The APTA source is 
particularly good in that it provides a consistent source for both energy use and activity (i.e., estimated passenger-miles) in this segment.

The data for intercity rail (Amtrak) used in the EERE system of energy intensity indicators is taken from the TEDB (Edition 32). The TEDB conveniently shows both historical energy use and activity back to 1971 (the first year of operations for Amtrak).

The National Transportation Statistics data published by the Bureau of Transportation Statistics is alternative source for some of the data elements. However, as shown in Table A.19, the fuel data shown in the BTS-NTS Table 4-15 combines both transit rail and bus components, and thus does not provide the necessary detail required for the energy intensity indicators system.

$$
\text { Passenger - Air }
$$

The sources for the energy use and activity for airlines and "general aviation" are shown in Table A.20. As shown by the highlighted cells, the primary data source is the TEDB. Several issues need to be noted with regard to the construction of energy intensity indicators for airlines. First, the data include both scheduled and unscheduled activity of U.S. air carriers. Second, the system of energy intensity indicators has sought to develop separate intensity indexes for the passenger and freight segments of major carriers. The highlighted cell in the rightmost column of Table A.20 indicates that an allocation of total fuel use is made on the basis of reported and estimated ton-miles. Passenger-miles are converted to ton-miles on the basis of an average 0.2 tons (400 pounds) per passenger-mile. This assumption was based on a comparison of load capacities for the cargo version and the passenger version of a commonly used aircraft in the U.S for both 
freight and passenger transportation. ${ }^{52}$ Given the separate estimates of freight and passenger tonmiles, the fuel data are allocated proportionately between the two categories.

Finally, there is the issue of combining domestic and international operations. In various tables, Edition 31 of the TEDB shows either data associated with domestic use or data combining domestic and international data. ${ }^{53}$ For the current set of energy intensity indicators, the intensities are based upon the combination of domestic and international operations (with subsequent allocation between passenger and freight modes). Future updates may attempt to separately characterize domestic and international categories. It should be noted that no consistent set of historical data for both domestic and international operations appeared to be presently available for the 2011 update of the intensity indicators.

The bottom three rows of Table A.20 relate to general aviation. As shown in the row with the sources for fuel use, data from TEDB-32 were used for the update described in this report. Unfortunately, there is no current source of corresponding information for activity, as measured by passenger-miles. Estimates of passenger-miles up through 2001 were developed by the Eno Transportation Foundation (2002). After that point, the estimates of passenger-miles have been extrapolated by the fuel consumption data provided by TEDB (ultimately, from a survey conducted by the Federal Aviation Administration). This method, of course, results in no change in energy intensity after 2001 for this segment. For 2011, the estimates indicate that general aviation accounted for about $12 \%$ of total passenger air transportation use, but only about $2.5 \%$ of total passenger-miles. At this point, there is no independent corroboration of the relative magnitudes of the average energy intensities across these two categories, although one clearly expects energy intensities in general aviation to be much higher than those associated with the large aircraft used by the major air carriers. Until the FAA requests information in its survey that could be used to estimate travel activity in the general aviation segment, there does not appear to be an easy way to resolve this problem. ${ }^{54}$

\footnotetext{
${ }^{52}$ The largest proportion of jet aircraft currently used by Federal Express is the cargo version of the Boeing 757. The maximum revenue cargo capacity for this plane is 87,700 pounds. A common seating configuration of the passenger version of this plane (757-200PF) is 224 seats. Thus, at full capacity, the load per (revenue) passenger, is about 400 pounds $(\sim 87,700 / 224)$. The value appears to be reasonable given the load associated with each passenger, in terms of the additional weight of the seat, baggage, flight attendants, and other amenities on a passenger aircraft.

${ }^{53}$ For example, Table 9.2 in TEDB-32 shows total energy use for domestic and international operations, while Table 2.12 shows the 2010 energy intensity based solely data for domestic operations. As cited in Table 9.2, fuel use for international operations includes fuel that is purchased outside the U.S.

${ }^{54}$ Two potential solutions to this issue should be noted. The first is to try to reproduce the methodology used by the Eno Transportation Foundation (ETF) in estimating passenger-miles after 2001. Unfortunately, the ETF methodology is itself based upon extrapolating a very old estimate of passenger-miles, published in the 1974 edition of the Interstate Commerce Commission's Transport Economics. The second approach would be to estimate energy intensity from a sample of aircraft used in general aviation and try to find an appropriate surrogate measure from the FAA survey of general aviation to estimate changes over time.
} 


\section{Freight Transportation}

Freight transportation is disaggregated into four major modes: 1) trucks, 2) rail, 3) air, and 4) water.

\section{Highway Freight - Trucks}

Table A.21 presents the data sources and methodology summary for trucks used for freight hauling. Two categories of trucks are presented in the table: medium, single-unit trucks, and heavy combination trucks.

As discussed above, the Federal Highway Administration recently changed the methodology by which it categorized and measured the fuel use and travel volume for all segments of highway travel. This change in methodology resulted in revised estimates for 2007 and later years for all segments of highway transportation. With regard to trucks, the approach to make a historically consistent set of vehicle-mile and fuel consumption estimates was to adjust the pre-2007 data to line up with the more recent data. These adjustments were summarized in Table A.16 above. In Table A.21 the highlighted cells in the rightmost column related to fuel use and vehicle-miles refer to these adjustments.

The conversion of total fuel use in gallons to energy use in trillion Btu (TBtu) depends upon the mix of fuels consumed by trucks. As shown in the table, allocation of fuels among diesel, gasoline, and LPG was based on data shown in the TEDB (that was derived originally from various periodic surveys conducted by the Census Bureau. ${ }^{55}$ )

The last element in the development of intensity indicators for trucking is to convert estimates of vehicle-miles into ton-miles. For single-unit trucks, no data source is available to that support any particular choice of an average load. For purposes of the energy intensity indicators system, the assumption has been to assign a constant average load of 3 tons. It should be noted that this assumption only has relevance for estimating the total share of total freight that can be attributed to single-unit trucks. The specific magnitude of the load (i.e., 2 tons versus 3 tons, or some other value) has no bearing on the overall energy intensity index for freight transportation, because the indexes across the various modes are weighted by shares of energy, not activity.

For combination trucks, there are independent estimates of intercity freight carried by trucks. As Table A.21 shows, these estimates were taken from the Bureau of Transportation Statistics' website containing the on-line version of the National Transportation Statistics (BTS-NTS). The ultimate source of these estimates is the most recent $\left(20^{\text {th }}\right)$ edition of Transportation in America, published in 2007 by the Eno Transportation Foundation (ETF 2007).

\footnotetext{
${ }^{55}$ For brief description of these surveys, see: $\underline{\text { http://www.census.gov/econ/overview/se0501.html }}$
} 
This most recent edition from ETF contains estimates of intercity freight ton-miles (here assigned to combination trucks) from 1990 through 2003. These estimates are somewhat higher than ETF's estimates shown in its previous $\left(19^{\text {th }}\right)$ edition of the report (approximately $16 \%$ higher in 1990). Accordingly, the previous estimates from the $19^{\text {th }}$ edition of Transportation in America were used to extrapolate the 1990 estimate from the most recent edition back to 1970 . For years beyond 2003, the ton-mile estimates were extrapolated on the basis of the (revised) vehicle-mile estimates. (The implied average load for these most recent years, based upon the vehicle-mile and ton-mile estimates, is just over 7 tons.)

\section{Freight - Rail and Air}

Table A.22 shows the data source and methodology summaries for rail and air freight transportation. The data for rail freight is taken from Edition 32 of the TEDB. The primary source for the data is the Association of American Railroads' publication Railroad Facts. This source provides estimates for both total fuel use and ton-miles of freight carried by the nation's railroads. All fuel is assumed to be diesel in the calculation of energy in TBtu.

The first element for air freight is to estimate the amount of fuel used by major carriers for freight. This estimate is based upon an allocation of total fuel between passenger transportation and freight transportation. As explained above, this allocation is based upon the shares of tonmiles between passenger and freight, where the passenger portion has been estimated on the basis of 0.1 tons per passenger-mile. The historical series of ton-miles and passenger miles relies on data from both the TEDB and downloaded data from the Bureau of Transportation website (as cited in the rightmost cell in the table related to ton-mile estimates.) After the allocation of energy use between passenger and freight transportation, the calculation of historical energy intensities for freight based on freight ton-miles is straightforward.

\section{Freight - Waterborne}

The cells in the top three rows of Table A.23 pertain to waterborne freight transportation. Waterborne freight in the system of energy intensity indicators covers the movement of freight within the U.S. by means of inland waterways (lakes, rivers, and canals), as well as along the coasts.

The following description of the situation with respect to waterborne commerce was made in Edition 32 of the TEDB with regard to Table 9.5, "Summary Statistics for Waterborne Commerce":

The U.S. Army Corps of Engineers Navigation Data Center collects a wealth of waterborne commerce data. Energy use data, however, have never been collected as part of this effort. The energy use data collected by the Energy Information Administration (EIA) on vessel bunkering was formerly displayed on this table. The EIA data include different uses of fuel, not just fuel for domestic waterborne commerce; therefore it was misleading to display those data together. 
However, for the first time in any edition of the TEDB, a set of credible estimates of energy intensity for domestic waterborne commerce were published. These estimates were developed by a researcher at the University of Tennessee and cover the years 1997 through 2010. The specific citation of these estimates was provided in the TEDB as follows: ${ }^{56}$

Energy use - Modeled by Chrisman A. Dager, University of Tennessee, Knoxville, using Waterborne Commerce Statistics Center detail records and annual IRS reports on the Inland Waterway Trust Fund tax on diesel fuel used on the inland waterway.

Ton-miles - Based on detailed records from the U.S. Department of the Army, Army Corps of Engineers, Waterborne Commerce Statistics Center. Includes only ton-miles on taxable waterways

To employ these data in the energy intensity indicators, it was assumed that the sample of waterborne freight used by Dager was representative of all domestic waterborne. Thus, the energy intensities in the Dager analysis could be applied more broadly. As cited above, the Corps of Engineers gathers detailed data on the volume of such freight. Accordingly, an estimate of total energy associated with all domestic freight was calculated by multiplying total ton-miles times the Dager-generated energy intensities.

This methodology provides the appropriate estimates for the years 1997 through 2010, but still leaves the question of how to generate estimates for earlier years. As noted by ORNL above, the EIA data on vessel bunkering fuel cannot be directly associated with the Corps of Engineers data on waterborne freight transportation. However, some previous editions of the TEDB presented proxy estimates of waterborne fuel based upon estimating the amount of total bunkering fuel that is consumed for domestic uses. ${ }^{57}$ Domestic use was assumed to consume $77.5 \%$ of distillate bunkering fuel and $9.3 \%$ of residual bunkering fuel. Previous estimates of the energy intensity indicators used these percentages to estimate historical series of energy that was assumed to correspond to the ton-mile magnitudes from the Corps of Engineers.

The implied historical series of energy intensities derived from the adjusted (for domestic) bunkering fuel from EIA indicate that over the period 1970 through 1995, there had been a distinct downward trend in the intensities. However, the year-to-year and cyclical behavior of this series showed implausible changes in intensity that cannot be explained by changes in the energy efficiency of the vessels themselves. Nevertheless, there remains the strong presumption that over this period, some improvement in overall vessel or system energy efficiency warrants a method that in some manner reflects this change.

In this case, the methodology undertaken for the system of intensity indicators was to represent the changes in energy intensity in waterborne freight over the 1970-1997 time period as a constant percentage decline in each year. This average rate of decline is based on a simple

\footnotetext{
${ }^{56}$ ORNL, TEDB-32, Appendix A, p. A-32.

${ }^{57}$ For example: ORNL, Transportation Energy Data Book, Edition 20, ORNL-6959, October 2000, p. A-15
} 
logarithmic trend regression of the implied energy intensities. This trend regression yielded a coefficient of -0.013 . The associated t-statistic of 4.1 indicates the presence of a strong downward trend over this overall time frame, in spite of implausible behavior over short subperiods within.

Clearly, there is considerable uncertainty, as reflected in the ORNL statement in the TEDB-32, that it is problematic to link the EIA fuel consumption data with the freight ton-mile statistics. One can argue however that the vast majority of the bunkering fuel not used for domestic freight was used for international waterborne freight. Moreover, it seems evident that the growth in international trade, and concomitant freight energy use, has been greater than the growth in the domestic economy and waterborne commerce within the U.S. Thus, any historical series that is based upon constant percentages of total bunkering fuel is likely to overstate the growth in fuel use for domestic freight activity, and conversely understate the decline in energy intensities for domestic freight transportation since 1970.

As a final step, the trend rate of reduction in the implied energy intensities was set at $-1.0 \%$ per year, rather than the $-1.3 \%$ estimated in the regression. This further step is taken to help ensure that the energy intensity indicators derived in the manner is likely to represent a conservative estimate of the overall decline over the 1970-1997 time period. Figure A.20 shows the historical series of energy intensities implied by employing the trend rate from 1970 through 1997, followed by the intensities by measured by Dager at the University of Tennessee.

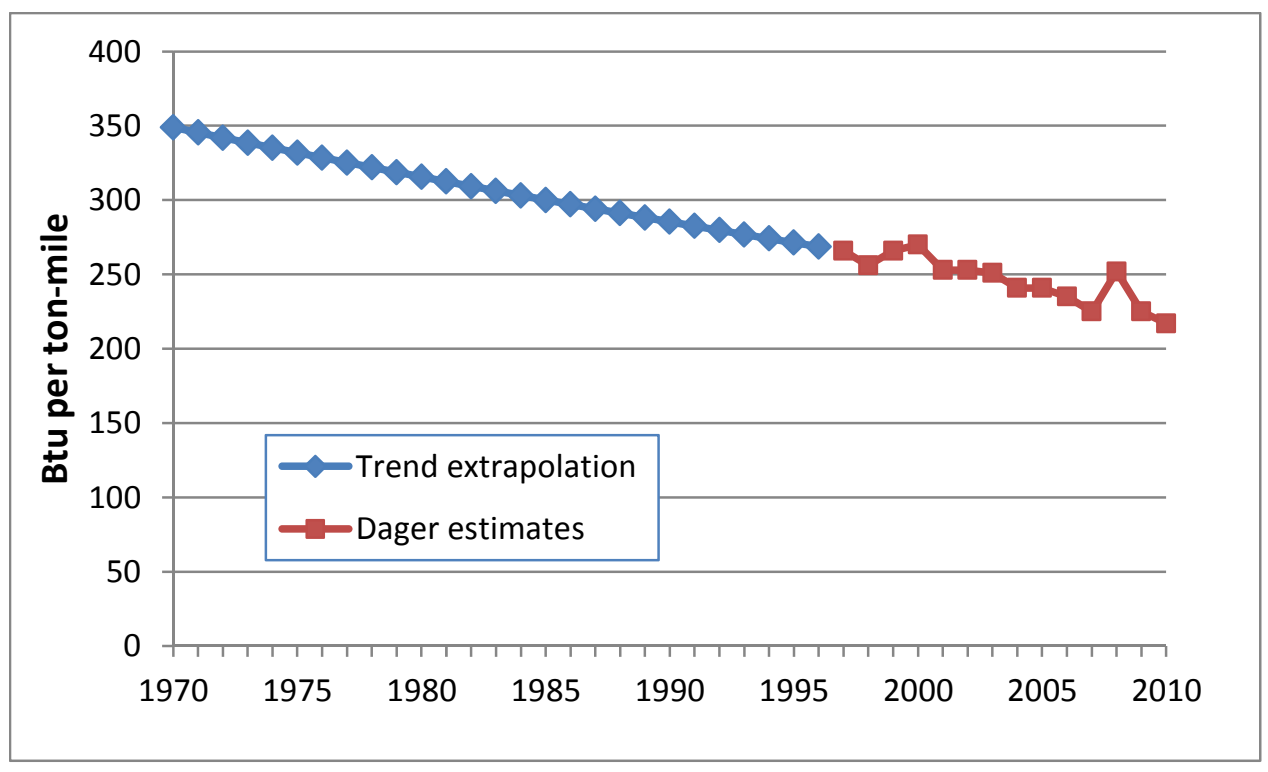

Figure A. 20. Estimated energy intensities for domestic waterborne transportation 
One final observation is warranted with regard to the energy intensities benchmarked to the Dager estimates. For 2010 the energy intensity for waterborne transportation was $217 \mathrm{Btu} /$ tonmile, compared the estimate for rail freight of $289 \mathrm{Btu} / \mathrm{ton}-\mathrm{mile}$. Thus, at least qualitatively, this value reflects the supposition that the energy required to move freight by water is lower than that by land transportation. (Note: the Dager value is roughly one-half the magnitude of the previous estimate of waterborne intensity based on the (adjusted) EIA vessel bunkering fuel data.)

\section{Freight - Pipelines}

The bottom portion of Table A.23 shows the sources and methodology for developing intensity indicators for pipelines. Currently, only natural gas pipelines are included in the system of energy intensity indicators. As shown in the first row devoted to gas pipelines, the method seeks to estimate both the natural gas and electricity used to transport natural gas through the nation's pipelines. The rightmost cell in this row displays the source for the natural gas consumption (EIA's Annual Energy Review, Table 6.5). The electricity consumption is based upon engineering analysis that was conducted by ORNL and is reported in Table A.12 of TEDB-32. As shown in the following row (rightmost cell), electricity consumption is converted to (source) Btu with a constant conversion factor of $10,339 \mathrm{Btu} / \mathrm{kWh}$ (following the convention in TEDB$32)$.

The final row of the table presents the methodology used to calculate ton-miles for pipeline transportation of natural gas. The methodology here again depends upon an engineering analysis. Essentially, the conversion depends upon an estimate of the weight of a given quantity of natural gas (at a defined pressure) and the average distance of transport.

At this point, oil pipelines are excluded from the system of energy intensity indicators, because there are not suitable historical time series of energy consumption and quantities of oil transported. ORNL apparently includes the energy (electricity) used by oil pipelines in their estimates of total pipeline use in Table 9.1 of the TEDB-32, but according to other documentation in the TEDB, the estimate has remained constant over time. ${ }^{58}$ With regard to the quantity of oil transported by pipelines, the most recent data on the BTS-NTS website (Table 161) provides estimates of ton-miles for both crude petroleum and refined petroleum products (provided by the Association of Oil Pipelines).

\footnotetext{
${ }^{58}$ Specifically, page A-18 of Appendix A in the TEDB-32 discusses the methodologies to estimate pipeline energy use.
} 
Table A.17. Data sources for highway passenger transportation - personal vehicles

\begin{tabular}{|c|c|c|c|}
\hline Transportation Segment & $\begin{array}{l}\text { Transportation Energy } \\
\text { Data Book (Ed. 32) }\end{array}$ & $\begin{array}{l}\text { Bureau of Transportation } \\
\text { Statistics (National } \\
\text { Transportation Statistics) }\end{array}$ & $\begin{array}{l}\text { Primary or Other } \\
\text { Source/Methodological } \\
\text { Note }\end{array}$ \\
\hline $\begin{array}{l}\text { Passenger cars - total fuel } \\
\text { (gallons) }\end{array}$ & $\begin{array}{l}\text { TEDB-32, Table } 4.1 \text {. } \\
\text { Adjusted estimates for } \\
2009 \text { and later (see text) }\end{array}$ & & $\begin{array}{l}\text { Federal Highway } \\
\text { Administration, Highway } \\
\text { Statistics, Table VM-1; } \\
\text { estimated from extrapolation } \\
\text { procedure for } 2009 \text { and later. }\end{array}$ \\
\hline $\begin{array}{l}\text { Passenger cars - total energy } \\
\text { (TBtu) }\end{array}$ & $\begin{array}{l}\text { Total fuel allocated } \\
\text { among gasoline, gasohol, } \\
\text { and diesel. Source: } \\
\text { TEDB-32, Table A.1 }\end{array}$ & & \\
\hline $\begin{array}{l}\text { Passenger cars - vehicle- } \\
\text { miles }\end{array}$ & TEDB-32, Table 4.1 & $\begin{array}{l}\text { BTS Table 1-35 (matches } \\
\text { TEDB through 2006) }\end{array}$ & $\begin{array}{l}\text { Increased by } 3.5 \% \text { to } \\
\text { account for FHWA } \\
\text { methodology change, for } \\
\text { years } 2009 \text { and later. See } \\
\text { text. }\end{array}$ \\
\hline $\begin{array}{l}\text { Passenger cars - Passenger- } \\
\text { miles }\end{array}$ & $\begin{array}{l}\text { Combine vehicle-miles } \\
\text { and load factors from } \\
\text { TEDB-32, Table A.18 }\end{array}$ & $\begin{array}{l}\text { BTS Table 1-40 (Data does } \\
\text { not match calculation using } \\
\text { TEDB data prior to } 2007 . \\
\text { After } 2007 \text { data is for short } \\
\text { wheel base vehicles, not } \\
\text { consistent with earlier } \\
\text { data, see text discussion) }\end{array}$ & $\begin{array}{l}\text { Load factors from Nationwide } \\
\text { Personal Transportation } \\
\text { Surveys and National } \\
\text { Household Travel Survey (See } \\
\text { TEDB-32 for sources) }\end{array}$ \\
\hline $\begin{array}{l}\text { Light trucks -total fuel } \\
\text { (gallons) }\end{array}$ & TEDB-32, Table 4.2 & & $\begin{array}{l}\text { Highway Statistics, Table } \\
\text { VM-1; estimated from } \\
\text { extrapolation procedure for } \\
2009 \text { and later }\end{array}$ \\
\hline $\begin{array}{l}\text { Light trucks - total energy } \\
\text { (TBtu) }\end{array}$ & $\begin{array}{l}\text { Total fuel allocated } \\
\text { among gasoline, gasohol, } \\
\text { and diesel. Source: } \\
\text { TEDB-32, Table A.5 }\end{array}$ & & \\
\hline Light trucks - vehicle-miles & TEDB-32, Table 4.2 & $\begin{array}{l}\text { BTS Table 1-35 (matches } \\
\text { TEDB through 2006) }\end{array}$ & $\begin{array}{l}\text { Highway Statistics, Table } \\
\text { VM-1; adjusted by } 3.5 \% \text { to } \\
\text { account FHWA methodology } \\
\text { change for } 2009 \text { and later }\end{array}$ \\
\hline $\begin{array}{l}\text { Light trucks - passenger- } \\
\text { miles }\end{array}$ & $\begin{array}{l}\text { Combine vehicle-miles and } \\
\text { load factors from TEDB-30 } \\
\text { for } 2009 \text { and TEDB-32 for } \\
2010 \text {, Table } 2.12 \text { (load } \\
\text { factors for previous years in } \\
\text { earlier TEDBs) }\end{array}$ & $\begin{array}{l}\text { BTS Table 1-40 (Data does } \\
\text { not match calculation using } \\
\text { TEDB data prior to } 2007 \text {. } \\
\text { After } 2007 \text { data is for short } \\
\text { wheel base vehicles, not } \\
\text { consistent with earlier } \\
\text { data, see text discussion) }\end{array}$ & \\
\hline $\begin{array}{l}\text { Motorcycles - total fuel } \\
\text { (gallons) }\end{array}$ & TEDB-32, Table A.2 & & $\begin{array}{l}\text { Highway Statistics, Table } \\
\text { VM-1 }\end{array}$ \\
\hline $\begin{array}{l}\text { Motorcycles - total energy } \\
\text { (TBtu) }\end{array}$ & $\begin{array}{l}\text { Assume all motorcycle } \\
\text { fuel is gasoline }\end{array}$ & & $\begin{array}{l}\text { Assume all motorcycle fuel } \\
\text { is gasoline }\end{array}$ \\
\hline Motorcycles - vehicle-miles & $\begin{array}{l}\text { Table } 2.12 \text { for most } \\
\text { current year, time series } \\
\text { not available in TEDB-30 } \\
\text { or TEDB-32 }\end{array}$ & $\begin{array}{l}\text { BTS Table 1-35 (with } \\
\text { some interpolation prior to } \\
1990 \text { ) }\end{array}$ & $\begin{array}{l}\text { Highway Statistics, Table } \\
\text { VM-1 }\end{array}$ \\
\hline $\begin{array}{l}\text { Motorcycles - passenger- } \\
\text { miles }\end{array}$ & $\begin{array}{l}\text { Table } 2.12 \text { for most } \\
\text { current year (not used) }\end{array}$ & $\begin{array}{l}\text { BTS Table 1-40 (not used, } \\
\text { implied load factors are not } \\
\text { stable/plausible in } \\
\text { historical series }\end{array}$ & $\begin{array}{l}\text { Assumed load factor of } 1.1 \\
\text { for all years x vehicle- } \\
\text { miles }\end{array}$ \\
\hline
\end{tabular}


Table A.18. Data sources for highway passenger transportation - buses

\begin{tabular}{|c|c|c|c|}
\hline $\begin{array}{l}\text { Transportation } \\
\text { Segment }\end{array}$ & $\begin{array}{l}\text { Transportation } \\
\text { Energy Data Book } \\
\text { (Ed. 32) }\end{array}$ & $\begin{array}{l}\text { Bureau of Transportation } \\
\text { Statistics (National } \\
\text { Transportation Statistics) }\end{array}$ & $\begin{array}{l}\text { Primary or Other } \\
\text { Source/Methodological Note }\end{array}$ \\
\hline $\begin{array}{l}\text { Transit buses - } \\
\text { Fuel use (gallons } \\
\text { by type of fuel) }\end{array}$ & TEDB-32, Table A.3 & $\begin{array}{l}\text { BTS-NTS, Table 4-15 } \\
\text { (Includes fuel and electricity } \\
\text { use for all commuters and } \\
\text { transit, buses + rail), Not } \\
\text { used. }\end{array}$ & $\begin{array}{l}\text { American Public Transit Association } \\
\text { (APTA), Public Transportation Fact } \\
\text { Book. } \\
\text { http://www.apta.com/resources/statistic } \\
\text { s/Documents/FactBook/2012-Fact- } \\
\text { Book-Appendix-A.pdf }\end{array}$ \\
\hline $\begin{array}{l}\text { Transit buses - } \\
\text { Energy use }\end{array}$ & $\begin{array}{l}2011 \text { estimate in } \\
\text { TEDB-32, Table } 2.12\end{array}$ & & $\begin{array}{l}\text { Apply conversion factors (Btu/gallon). } \\
\text { Note: APTA reports CNG in diesel- } \\
\text { equivalent. Biodiesel conversion factor } \\
\text { from AER } 2008 \text {, p. } 373\end{array}$ \\
\hline $\begin{array}{l}\text { Transit buses - } \\
\text { Passenger-miles }\end{array}$ & TEDB-32, Table 5.16 & $\begin{array}{l}\text { BTS-NTS Table } 1-40 \\
\text { (data for most years excludes } \\
\text { ferries, no exact match with } \\
\text { APTA data, not used. }\end{array}$ & $\begin{array}{l}\text { Same source as for fuel use, APTA } \\
\text { website. }\end{array}$ \\
\hline $\begin{array}{l}\text { Intercity buses, } \\
\text { Fuel use (gallons) }\end{array}$ & $\begin{array}{l}\text { TEDB-32, Table } 2.12 \text {. } \\
\text { Data for } 2011 \\
\text { estimated based upon } \\
\text { extrapolation of } 2000 \\
\text { Eno estimate. Not } \\
\text { used. }\end{array}$ & & $\begin{array}{l}\text { Primary source is American Bus } \\
\text { Association (ABA) with earlier data in } \\
\text { TEDB-19, and later data from ABA } \\
\text { reports. Fuel use was estimated on } \\
\text { basis of separate estimates of average } \\
\text { MPG and vehicle-miles. See text. }\end{array}$ \\
\hline $\begin{array}{l}\text { Intercity buses - } \\
\text { Energy use (TBtu) }\end{array}$ & & & $\begin{array}{l}\text { All fuel for intercity buses assumed to } \\
\text { be diesel. }\end{array}$ \\
\hline $\begin{array}{l}\text { Intercity Buses - } \\
\text { Passenger-miles }\end{array}$ & Not estimated & $\begin{array}{l}\text { BTS Annual Report, } \\
\text { published in September } 1993 . \\
\text { Table } 6 \text { for estimates from } \\
1970 \text { through 1991. For } \\
\text { 1991-1997, TEDB-23, Table } \\
5.23 .\end{array}$ & $\begin{array}{l}\text { For 1998-2006, estimates of vehicle- } \\
\text { miles interpolated between } 1997 \text { value } \\
\text { from TEDB-19 and ABA } 2007 \text { value. } \\
\text { Average passenger load factors } \\
\text { interpolated over same period. } \\
\text { Passenger-miles computed as load } \\
\text { factor x vehicle miles. Most recent } \\
\text { estimated from ABA reports. See text. }\end{array}$ \\
\hline $\begin{array}{l}\text { School buses - } \\
\text { Fuel use (gallons) }\end{array}$ & $\begin{array}{l}\text { TEDB-32 Table A.4 } \\
\text { for years 1970-1994, } \\
\text { at typically five-year } \\
\text { intervals. Data after } \\
1994 \text { extrapolated by } \\
\text { vehicle-miles (not } \\
\text { used) }\end{array}$ & $\begin{array}{l}\text { Data (estimates) for school } \\
\text { buses not separately } \\
\text { identified }\end{array}$ & $\begin{array}{l}\text { Estimates of fuel use interpolated for } \\
\text { years other than ending in } 0 \text { or } 5 \text {, based } \\
\text { upon estimates of vehicle-miles and } \\
\text { average fuel economy. The approach } \\
\text { was used over the period 1970-1994. } \\
\text { See text. }\end{array}$ \\
\hline $\begin{array}{l}\text { School buses - } \\
\text { Energy use (TBtu) }\end{array}$ & $\begin{array}{l}\text { TEDB-32, Table A.4. } \\
\text { Fuel assumed to be } \\
90 \% \text { diesel, } 10 \% \\
\text { gasoline }\end{array}$ & & \\
\hline $\begin{array}{l}\text { School buses - } \\
\text { Passenger-miles }\end{array}$ & $\begin{array}{l}\text { 1980-1994: TEDB, } \\
\text { various issues for } \\
\text { vehicle-miles. }\end{array}$ & $\begin{array}{l}\text { Data (estimates) for school } \\
\text { buses not separately } \\
\text { identified }\end{array}$ & $\begin{array}{l}\text { 1995-2011: } 1994 \text { estimate extrapolated } \\
\text { from U.S. route mileage for public } \\
\text { school transportation, used by } \\
\text { permission from School Bus Fleet } \\
\text { magazine, Fact Books. Passenger-miles } \\
\text { calculated from assumed constant pupil } \\
\text { load of 23. See text. }\end{array}$ \\
\hline
\end{tabular}


Table A.19. Data sources for passenger rail transportation

\begin{tabular}{|c|c|c|c|}
\hline $\begin{array}{l}\text { Transportation } \\
\text { Segment }\end{array}$ & $\begin{array}{l}\text { Transportation Energy } \\
\text { Data Book (Ed. 31) }\end{array}$ & $\begin{array}{l}\text { Bureau of } \\
\text { Transportation Statistics } \\
\text { (National Transportation } \\
\text { Statistics) }\end{array}$ & $\begin{array}{l}\text { Primary or Other } \\
\text { Source/Methodological Note }\end{array}$ \\
\hline $\begin{array}{l}\text { Commuter rail-- } \\
\text { Fuel use (kWh, } \\
\text { Gallons) }\end{array}$ & TEDB-32, Table A.14 & $\begin{array}{l}\text { BTS-NTS, Table 4-15 } \\
\text { (Includes fuel and } \\
\text { electricity use for all } \\
\text { commuters and transit, } \\
\text { buses + rail), Not used. }\end{array}$ & $\begin{array}{l}\text { American Public Transit } \\
\text { Association (APTA), Public } \\
\text { Transportation Fact Book. } \\
\text { http://www.apta.com/resources/stat } \\
\text { istics/Documents/FactBook/2012- } \\
\text { Fact-Book-Appendix-A.pdf, } \\
\text { Tables 38, 39: electricity and diesel } \\
\text { fuel consumption }\end{array}$ \\
\hline $\begin{array}{l}\text { Commuter rail- } \\
\text { Energy use - Tbtu }\end{array}$ & $\begin{array}{l}\text { TEDB-32, Table } 9.11 \text { and } \\
\text { 9.12. (Data from APTA) } \\
\text { (matches direct calculation } \\
\text { with APTA data) }\end{array}$ & & $\begin{array}{l}\text { Conversion to TBtu with electricity } \\
\text { and diesel energy conversion } \\
\text { factors (electricity conversion at } \\
10,339 \mathrm{Btu} / \mathrm{kWh} \text { from TEDB }\end{array}$ \\
\hline $\begin{array}{l}\text { Commuter rail - } \\
\text { Passenger-miles }\end{array}$ & $\begin{array}{l}\text { TEDB-32, Table } 9.11 \text { and } \\
\text { 9.12. (Data from APTA) }\end{array}$ & BTS-NTS, Table 1-40 & $\begin{array}{l}\text { APTA source as above for fuel } \\
\text { use. Passenger-miles in Table } 3 \text { of } \\
\text { Appendix A of APTA publication. }\end{array}$ \\
\hline $\begin{array}{l}\text { Transit rail - Fuel } \\
\text { use (kWh, } \\
\text { Gallons) } \\
\text { (combines heavy } \\
\text { and light rail) }\end{array}$ & TEDB-32, Table A.15 & $\begin{array}{l}\text { BTS-NTS, Table 4-15 } \\
\text { (Includes fuel and } \\
\text { electricity use for all } \\
\text { transit, buses + rail), Not } \\
\text { used. }\end{array}$ & $\begin{array}{l}\text { Same source as commuter rail } \\
\text { (APTA, Fact Book), Tables } 38 \text { and } \\
39 \text { in Appendix A. }\end{array}$ \\
\hline $\begin{array}{l}\text { Transit rail - } \\
\text { Energy use - Tbtu }\end{array}$ & $\begin{array}{l}\text { TEDB-32, Table } 9.12 \text { and } \\
\text { 9.12. (Data from APTA) } \\
\text { (matches direct calculation } \\
\text { with APTA data) }\end{array}$ & & $\begin{array}{l}\text { Conversion to TBtu as for } \\
\text { commuter rail }\end{array}$ \\
\hline $\begin{array}{l}\text { Commuter rail - } \\
\text { Passenger-miles }\end{array}$ & $\begin{array}{l}\text { TEDB-32, Table } 9.12 \text { and } \\
\text { 9.12. (Data from APTA) }\end{array}$ & BTS-NTS, Table 1-40 & $\begin{array}{l}\text { APTA source as above for fuel } \\
\text { use. Passenger-miles in Table } 3 \text { of } \\
\text { Appendix }\end{array}$ \\
\hline $\begin{array}{l}\text { Intercity rail } \\
\text { (Amtrak) - } \\
\text { Fuel use } \\
\text { (kWh, Gallons) } \\
\end{array}$ & $\begin{array}{l}\text { 1994-2011: TEDB-32, } \\
\text { Table A.16; prior data } \\
\text { extrapolated from TEDB- } \\
\text { 30, Table } 9.10\end{array}$ & BTS-NTS, Table 4-18 & $\begin{array}{l}\text { Assume } 1993 \text { and } 1994 \text { have same } \\
\text { energy use to account for } \\
\text { discontinuity in } 1994 .\end{array}$ \\
\hline $\begin{array}{l}\text { Intercity rail - } \\
\text { Energy use (TBtu) }\end{array}$ & TEDB-32, Table 9.10 & & $\begin{array}{l}\text { Conversion to TBtu as for } \\
\text { commuter rail }\end{array}$ \\
\hline $\begin{array}{l}\text { Intercity rail- } \\
\text { Passenger-miles }\end{array}$ & TEDB-32, Table 9.10 & BTS-NTS, Table 1-40 & $\begin{array}{l}\text { Revenue passenger-miles (does not } \\
\text { include contract commuter } \\
\text { passengers) }\end{array}$ \\
\hline
\end{tabular}


Table A.20. Data sources and methodology for airline passenger transportation

\begin{tabular}{|c|c|c|c|}
\hline $\begin{array}{l}\text { Transportation } \\
\text { Segment }\end{array}$ & $\begin{array}{l}\text { Transportation } \\
\text { Energy Data Book } \\
\text { (Ed. 31) }\end{array}$ & $\begin{array}{l}\text { Bureau of Transportation } \\
\text { Statistics (National } \\
\text { Transportation Statistics) }\end{array}$ & $\begin{array}{l}\text { Primary or Other } \\
\text { Source/Methodological Note }\end{array}$ \\
\hline $\begin{array}{l}\text { Air carriers - Fuel use } \\
\text { (gallons) }\end{array}$ & TEDB-32, Table A.9 & $\begin{array}{l}\text { BTS-NTS, Table } 4-8 \\
\text { (Another source cited by } \\
\text { TEDB is: } \\
\text { www.transtats.bts.gov/fuel. } \\
\text { asp }\end{array}$ & $\begin{array}{l}\text { 1) All fuel for international flights } \\
\text { for domestic carriers was included } \\
\text { with fuel for domestic operations } \\
\text { in } 2010 \text {. }\end{array}$ \\
\hline $\begin{array}{l}\text { Air carriers - Energy } \\
\text { use }\end{array}$ & $\begin{array}{l}\text { TEDB-32 Table } 9.2 \\
\text { includes all energy } \\
\text { for domestic and } \\
\text { international } \\
\text { operations, } \\
\text { (Table } 2.12 \text { includes } \\
\text { only domestic air } \\
\text { service) }\end{array}$ & & $\begin{array}{l}\text { 1)All fuel is assumed to be jet fuel } \\
\text { 2) Allocation between passenger } \\
\text { and freight transportation based on } \\
\text { ton-miles. } 1 \text { pass-mile }=0.1 \text { ton- } \\
\text { mile, as per BTS. Passenger } \\
\text { percentage } \sim 70 \% \text { in } 2011 \text {. }\end{array}$ \\
\hline $\begin{array}{l}\text { Air carriers - } \\
\text { Passenger-miles }\end{array}$ & $\begin{array}{l}\text { TEDB-32, Table 9.2, } \\
\text { and previous TEDB's } \\
\text { for years before } 1985\end{array}$ & $\begin{array}{l}\text { BTS-NTS Table 1-40. } \\
\text { Table } 1-40 \text { contains only } \\
\text { data for domestic } \\
\text { operations and does not } \\
\text { match other sources. Not } \\
\text { used. }\end{array}$ & \\
\hline $\begin{array}{l}\text { General aviation - } \\
\text { Fuel use (gallons) }\end{array}$ & TEDB-32, Table A.8 & & $\begin{array}{l}\text { Department of Transportation, } \\
\text { Federal Aviation Administration, } \\
\text { General Aviation and Avionics } \\
\text { Survey }\end{array}$ \\
\hline $\begin{array}{l}\text { General aviation - } \\
\text { Energy use (TBtu) }\end{array}$ & TEDB-32, Table 9.3 & & $\begin{array}{l}\text { Conversion to Btu with factors for } \\
\text { aviation fuel and jet fuel }(120,2 \text { and } \\
135.0 \mathrm{kBtu} / \text { gallon, respectively. }\end{array}$ \\
\hline $\begin{array}{l}\text { General aviation - } \\
\text { Passenger-miles }\end{array}$ & Not available & Not available & $\begin{array}{l}\text { 1970-2001: Eno Transportation } \\
\text { Foundation, Transportation in } \\
\text { America 2001, 19th Edition, p.45 } \\
\text { Passenger-miles after 2001 } \\
\text { extrapolated by total energy use. }\end{array}$ \\
\hline
\end{tabular}


Table A.21. Data sources and methodology for highway freight transportation

\begin{tabular}{|c|c|c|c|}
\hline Transportation Segment & $\begin{array}{l}\text { Transportation Energy } \\
\text { Data Book (Ed. 31) }\end{array}$ & $\begin{array}{l}\text { Bureau of } \\
\text { Transportation Statistics } \\
\text { (National } \\
\text { Transportation } \\
\text { Statistics) }\end{array}$ & $\begin{array}{l}\text { Primary or Other } \\
\text { Source/Methodological } \\
\text { Note }\end{array}$ \\
\hline $\begin{array}{l}\text { Single-unit trucks, Class } 3 \\
\text { to } 8 \text { - fuel use (gallons) }\end{array}$ & $\begin{array}{l}\text { TEDB-32, Table 5.1 } \\
\text { Table shows discontinuity } \\
\text { from FWHA methodology } \\
\text { change in } 2007, \text { not used. }\end{array}$ & & $\begin{array}{l}\text { Pre-2007 revised to match } \\
\text { current FHWA } \\
\text { methodology, see text and } \\
\text { Table A.13. }\end{array}$ \\
\hline $\begin{array}{l}\text { Single-unit trucks, } \\
\text { energy use (TBtu) }\end{array}$ & $\begin{array}{l}\text { Total fuel allocated among } \\
\text { gasoline, gasohol, and } \\
\text { diesel. Source: TEDB-32, } \\
\text { Table A.6 }\end{array}$ & & $\begin{array}{l}\text { Implausible estimate from } \\
1982 \text { Truck Inventory and } \\
\text { Use survey (TIUS) } \\
\text { showing diesel at only } \\
60 \% \text { of truck fuel. } \\
\text { Changed to remain above } \\
80 \% \text { in years proximate to } \\
1982 \text {. }\end{array}$ \\
\hline $\begin{array}{l}\text { Single-unit trucks, vehicle- } \\
\text { miles }\end{array}$ & $\begin{array}{l}\text { TEDB-32, Table 5.1 } \\
\text { Table shows discontinuity } \\
\text { from FHWA methodology } \\
\text { change in } 2007, \text { not used. }\end{array}$ & $\begin{array}{l}\text { BTS-NTS Table 1-35 } \\
\text { (Carries discontinuity from } \\
\text { FHWA methodology } \\
\text { change in 2007), not used. }\end{array}$ & $\begin{array}{l}\text { Pre-2007 revised to match } \\
\text { current FHWA } \\
\text { methodology, see text and } \\
\text { Table A.13. }\end{array}$ \\
\hline $\begin{array}{l}\text { Single-unit trucks, ton- } \\
\text { miles }\end{array}$ & $\begin{array}{l}\text { Not estimated by ORNL in } \\
\text { TEDB }\end{array}$ & Not estimated by BTS & $\begin{array}{l}\text { Estimate based upon } \\
\text { assumed average load of } 3 \\
\text { tons per truck (x vehicle- } \\
\text { miles) }\end{array}$ \\
\hline $\begin{array}{l}\text { Combination trucks, Class } \\
7-8 \text {, fuel use (gallons) }\end{array}$ & $\begin{array}{l}\text { TEDB-32, Table } 5.2 \\
\text { Table shows discontinuity } \\
\text { from FWHA methodology } \\
\text { change in } 2007, \text { not used. }\end{array}$ & & $\begin{array}{l}\text { Pre-2007 revised to match } \\
\text { current FHWA } \\
\text { methodology, see text and } \\
\text { Table A.13. }\end{array}$ \\
\hline $\begin{array}{l}\text { Combination trucks, Class } \\
7-8, \text { energy use (TBtu) }\end{array}$ & $\begin{array}{l}\text { Total fuel allocated among } \\
\text { gasoline, gasohol, and } \\
\text { diesel. Source: TEDB-32, } \\
\text { Table A.6 }\end{array}$ & & $\begin{array}{l}\text { See note above for single- } \\
\text { unit trucks }\end{array}$ \\
\hline $\begin{array}{l}\text { Combination trucks, Class } \\
7-8, \text { ton-miles }\end{array}$ & $\begin{array}{l}\text { Not estimated by ORNL in } \\
\text { TEDB }\end{array}$ & $\begin{array}{l}\text { BTS-NTS Table 1-49 } \\
\text { BTS publishes ton-miles } \\
\text { for intercity truck (1990- } \\
\text { 2003) from most recent } \\
\text { edition of Transportation } \\
\text { in America, published by } \\
\text { Eno Transportation } \\
\text { Foundation in 2007. } \\
\text { Column to right shows } \\
\text { data used to extrapolate } \\
\text { before } 1990 \text { and after } 2003\end{array}$ & $\begin{array}{l}\text { 1970-1989: Eno } \\
\text { Transportation } \\
\text { Foundation, } \\
\text { Transportation in America } \\
\text { 2001, 19th Edition, p.42 } \\
\text { Used to extrapolate } 1990 \\
\text { estimate back to } 1970 \text {. } \\
\text { Extrapolate } 2003 \text { ton-miles } \\
\text { with vehicle-miles }\end{array}$ \\
\hline
\end{tabular}


Table A.22. Data sources and methodology for rail and air freight transportation

\begin{tabular}{|c|c|c|c|}
\hline $\begin{array}{l}\text { Transportation } \\
\text { Segment }\end{array}$ & $\begin{array}{l}\text { Transportation } \\
\text { Energy Data Book } \\
\text { (Ed. 31) }\end{array}$ & $\begin{array}{l}\text { Bureau of Transportation } \\
\text { Statistics (National } \\
\text { Transportation Statistics) }\end{array}$ & $\begin{array}{l}\text { Primary or Other } \\
\text { Source/Methodological Note }\end{array}$ \\
\hline $\begin{array}{l}\text { Rail - Fuel use } \\
\text { (gallons) }\end{array}$ & $\begin{array}{l}\text { TEDB-32, Table } \\
\text { A.13 }\end{array}$ & & $\begin{array}{l}\text { Association of American Railroads, } \\
\text { Railroad Facts, } 2011 \text { Edition }\end{array}$ \\
\hline $\begin{array}{l}\text { Rail - Energy use } \\
\text { (TBtu) }\end{array}$ & TEDB-32, Table 9.8 & & $\begin{array}{l}\text { Convert to TBtu with conversion } \\
\text { factors for diesel fuel (matches } \\
\text { TEDB-32 estimates) }\end{array}$ \\
\hline Rail - Ton-miles & TEDB-32, Table 9.8 & BTS-NTS, Table 1-46a & $\begin{array}{l}\text { Association of American Railroads, } \\
\text { Railroad Facts, } 2011 \text { Edition }\end{array}$ \\
\hline $\begin{array}{l}\text { Air carriers - Fuel } \\
\text { use (gallons) }\end{array}$ & $\begin{array}{l}\text { TEDB-32, Table A.9, } \\
\text { Reports fuel use for } \\
\text { both domestic and } \\
\text { international } \\
\text { operations }\end{array}$ & & $\begin{array}{l}\text { See note in cell below - freight fuel } \\
\text { use based on allocation of total fuel } \\
\text { use allocated on basis of ton-miles } \\
\text { for passengers and ton-miles for } \\
\text { freight }\end{array}$ \\
\hline $\begin{array}{l}\text { Air carriers - } \\
\text { Energy use for } \\
\text { freight }\end{array}$ & $\begin{array}{l}\text { TEDB-32 Table } 9.2 \\
\text { includes all energy } \\
\text { for international }+ \\
\text { domestic operations }\end{array}$ & & $\begin{array}{l}\text { 1)All fuel is assumed to be jet fuel } \\
\text { 2) Allocation between passenger and } \\
\text { freight transportation based on ton- } \\
\text { miles. } 1 \text { pass-mile }=0.1 \text { ton-mile, as } \\
\text { per BTS. Passenger percentage } \sim \\
70 \% \text { in } 2011 .\end{array}$ \\
\hline $\begin{array}{l}\text { Air carriers - Ton- } \\
\text { miles }\end{array}$ & $\begin{array}{l}\text { Not reported, no } \\
\text { intensities estimated } \\
\text { for air freight. Table } \\
9.2 \text { contains historical } \\
\text { data on revenue cargo } \\
\text { ton-miles. }\end{array}$ & $\begin{array}{l}\text { BTS-NTS, Table 1-46a. } \\
\text { (Reports only freight from } \\
\text { domestic operations, not } \\
\text { used) }\end{array}$ & $\begin{array}{l}\text { BTS, Airline Data and Statistics: } \\
\text { revenue ton-miles, } \\
\text { http://www.bts.gov/xml/air traffic/sr } \\
\text { c/index.xml\#CustomizeTable Data } \\
\text { for both domestic and international } \\
\text { operations }\end{array}$ \\
\hline
\end{tabular}


Table A.23. Data sources and methodology for water and pipeline freight transportation

\begin{tabular}{|c|c|c|c|}
\hline $\begin{array}{l}\text { Transportation } \\
\text { Segment }\end{array}$ & $\begin{array}{l}\text { Transportation Energy } \\
\text { Data Book (Ed. 31) }\end{array}$ & $\begin{array}{l}\text { Bureau of } \\
\text { Transportation } \\
\text { Statistics (National } \\
\text { Transportation } \\
\text { Statistics) } \\
\end{array}$ & $\begin{array}{l}\text { Primary or Other } \\
\text { Source/Methodological Note }\end{array}$ \\
\hline $\begin{array}{l}\text { Waterborne-Fuel } \\
\text { use (gallons) }\end{array}$ & $\begin{array}{l}\text { TEDB-32, Table A.10 } \\
\text { (Used for pre-1997 } \\
\text { regression, see text) }\end{array}$ & & \\
\hline $\begin{array}{l}\text { Waterborne-- } \\
\text { Energy use (TBtu) }\end{array}$ & $\begin{array}{l}\text { Not available, only } \\
\text { intensities published in } \\
\text { TEDB-32, Table } 2.15\end{array}$ & & $\begin{array}{l}\text { TEDB-32, Table } 2.15 \text { presents } \\
\text { improved estimates of intensity } \\
\text { (Btu/ton-mile). Intensities used with } \\
\text { domestic ton-miles to estimate } \\
\text { historical energy consumption. See } \\
\text { text. }\end{array}$ \\
\hline $\begin{array}{l}\text { Waterborne - } \\
\text { Ton-miles }\end{array}$ & TEDB-32, Table 9.5 & BTS-NTS, Table 1-46a & \\
\hline $\begin{array}{l}\text { Natural gas } \\
\text { pipelines - Fuel } \\
\text { use (cubic feet and } \\
\text { kWh) }\end{array}$ & $\begin{array}{l}\text { TEDB-32, Table A.12, } \\
\text { Reports natural gas and } \\
\text { electricity. Gas from } \\
\text { EIA, electricity is } \\
\text { estimated, see note in } \\
\text { TEDB }\end{array}$ & & $\begin{array}{l}\text { EIA, Annual Energy Review 2011, } \\
\text { Table } 6.5 \text { (Natural gas used as fuel in } \\
\text { delivery to customers) } \\
\text { http://www.eia.gov/totalenergy/data/a } \\
\text { nnual/pdf/sec6_13.pdf }\end{array}$ \\
\hline $\begin{array}{l}\text { Natural gas } \\
\text { pipelines - } \\
\text { Energy (TBtu) }\end{array}$ & $\begin{array}{l}\text { TEDB-32, Table } 2.5 \\
\text { shows energy } \\
\text { consumption for all } \\
\text { pipelines for } 2011 \text {, } \\
\text { however electricity use } \\
\text { for oil pipelines and coal } \\
\text { slurry is an old estimate, } \\
\text { and held constant }\end{array}$ & & $\begin{array}{l}\text { Conversion to energy units with } \\
\text { factor of } 1,031 \mathrm{Btu} / \mathrm{cu} \text {.ft for gas, and } \\
10,339 \mathrm{Btu} / \mathrm{kWh} \text { for electricity }\end{array}$ \\
\hline $\begin{array}{l}\text { Natural gas } \\
\text { pipelines - } \\
\text { ton-miles }\end{array}$ & & Not estimated or reported & $\begin{array}{l}\text { Natural gas converted to tons using } \\
\text { methane density of } 0.0448 \mathrm{lb} / \mathrm{cu} . \mathrm{ft} \text {. } \\
\text { Average length of travel for natural } \\
\text { gas assumed to be } 620 \text { miles. }\end{array}$ \\
\hline Oil pipelines & $\begin{array}{l}\text { TEDB-32, p. A-18 } \\
\text { includes discussion of } \\
\text { energy use for oil } \\
\text { pipelines }\end{array}$ & $\begin{array}{l}\text { BTS-NTS, Table 1-61 } \\
\text { contains statistics on ton- } \\
\text { miles for both crude } \\
\text { petroleum and refined oil } \\
\text { products }\end{array}$ & $\begin{array}{l}\text { No energy intensity indicator, as } \\
\text { there are no historical series for both } \\
\text { energy use and ton-miles of oil } \\
\text { transported through pipelines }\end{array}$ \\
\hline
\end{tabular}




\section{A.5 Electricity Generation}

In addition to the major end-use sectors, the system of energy intensity indicators has developed an extensive set of indicators that pertain to the generation of electricity. As discussed in the main body of this report, improved energy efficiency in the electric utility sector has had a significant impact on reducing the nation's total energy consumption over the past decade.

\section{A.5.1 Background and General Data Sources}

The available data sources for historical energy consumption for electricity generation rely extensively on EIA sources, as published in Chapter 8 of the Annual Energy Review. EIA collects information on electricity generation and fuel consumption for plants that produce only electricity (electricity-only) and plants that produce both electricity and heat (combined heat and power or CHP). The more formal term for heat used by EIA for heat is "useful thermal output. $"$ "59

In the spring of 2013, EIA announced the suspension of publication of the Annual Energy Review. Normally, this publication (i.e., Annual Energy Review 2012) would have been released in the late summer of 2013 and would have contained final electricity-related data for 2011 and preliminary data for 2012. While some elements of these data used in the energy intensity indicators are published in the Monthly Energy Review, that publication does not display the detailed sector-level and fuel/technology detail that was previously shown in the Annual Energy Review. For this report, the most recent data were obtained by special request from EIA. ${ }^{60}$ In November of 2013, EIA updated its internal database with final 2012 data that would have been included in the Annual Energy Review (in 2014). These data have been incorporated into the set of indicators shown in this report, specifically in terms of intensity series shown graphically in Figures 3.18 and 3.19.

EIA distinguishes three sectors that generate electricity (and thermal output). The dominant sector is termed the Electric Power Sector, which comprises electricity-only and CHP plants within the NAICS 22 classification whose primary business is to sell electricity, or electricity and heat, to the public. Electricity and heat generation is also performed in facilities classified as either industrial or commercial. EIA classifies the industrial sector to include those establishments classified as agriculture (NAICS 11), mining (NAICS 21), or manufacturing (NAICS 31-33). All other establishments with generation facilities are classified as commercial.

EIA first included separate estimates for electricity-only and CHP plants in the Annual Energy Review 2001. These estimates stemmed from a comprehensive review undertaken by EIA to

\footnotetext{
${ }^{59}$ Both "heat" and "useful thermal output" will be used interchangeably in the discussion below.

${ }^{60}$ Personal communication with Channele Wirman, EIA on November 14-15, 2013. Wirman sent a spreadsheet that included all data (previously) shown in the Annual Energy Review on November 15, 2013 (AER Tables 2005 to 2012.xlsx).
} 
"improve the quality and consistency of its electric power data throughout all data and analysis products." From the review, EIA completely revamped its reporting detail associated with the electric power sector as well as providing information on electricity and heat production in industrial and commercial sectors. These changes are documented in Appendix H, "Estimating and Presenting Power Sector Fuel Use in EIA Publications and Analysis.” (EIA 2002).

Based upon existing data from prior surveys, in 1989 EIA was able to construct its revised data structure for the electricity generation. Thus, many of the data series shown in the tables in Chapter 8 of subsequent editions of the Annual Energy Review start in that year. For that reason, all of energy intensity indexes for the electricity generation sectors are rebased to 1990 rather than 1985.

\section{Thermal conversion factors - heat rates for electricity generation}

For purposes of measuring the energy input for sources other than fossil fuels or biofuels (wood and waste), EIA has adopted thermal conversion factors based upon the annual average heat rate factor for fossil-fueled power plants in the U.S. As discussed in (the last page of) Appendix A in the Annual Energy Review, EIA states that "By using that factor, it is possible to evaluate fossil fuel requirements for replacing those sources during periods of interruption such as droughts." (EIA 2012a). These factors are used to measure the inputs for power plants that generate electricity from hydro, geothermal, wind, photovoltaic, or solar thermal energy sources. ${ }^{61}$

As explained in the same appendix to the Annual Energy Review, the thermal conversion factors for nuclear plants "are calculated annually by dividing the total heat content consumed in nuclear generating units by the total (net) electricity generated by nuclear generating units." This treatment results in a very small decline in the heat rate for nuclear plants since 1985, falling from $10,622 \mathrm{Btu} / \mathrm{kWh}$ in 1985 to 10,452 in 2010.

Table A.24 shows, for selected years, the fossil fuel heat rates for electricity that are used to make imputations for hydroelectric and renewables, as well as the heat rates for nuclear and geothermal generation.

\footnotetext{
${ }^{61}$ For geothermal plants (accounting for about $0.4 \%$ of U.S. electricity generation), the imputation method was changed to match other renewables sources in the Annual Energy Review 2011. In previous editions of the AER, the method was technology-based, with the characterization from EIA that the overall geothermal rate was calculated by "weighting the annual average heat rates of operating geothermal units by the installed nameplate capacities, as reported on Form FPC-12, 'Power System Statement' ."
} 
Table A.24. Heat rate values used by EIA to measure energy inputs for electricity generation from hydro/renewables

\begin{tabular}{|c|c|c|}
\hline Year & $\begin{array}{c}\text { Total fossil fuels - } \\
\text { values imputed for } \\
\text { noncombustible } \\
\text { renewable energy }\end{array}$ & Nuclear \\
\hline 1970 & 10,494 & 10,977 \\
\hline 1975 & 10,406 & 11,013 \\
\hline 1980 & 10,388 & 10,908 \\
\hline 1985 & 10,447 & 10,622 \\
\hline 1990 & 10,402 & 10,582 \\
\hline 1995 & 10,312 & 10,507 \\
\hline 2000 & 10,201 & 10,450 \\
\hline 2005 & 9,999 & 10,436 \\
\hline 2010 & 9,756 & 10,452 \\
\hline
\end{tabular}

Source: Table A6, Annual Energy Review 2011 (EIA 2012a)

\section{A.5.2 Methodology for intensity indicators for electricity generation}

The EERE system of energy intensity indicators develops separate indexes for the three sectors distinguished by EIA: 1) electric power sector, 2) industrial, and 3) commercial. However, only the electric power sector is considered in one aggregation of sector-level intensity indexes for an intensity index for the economy as a whole. The fuel used by the industrial and commercial for electricity and useful thermal output is already included in the total fuel consumption by these sectors. Thus, to include the intensity indexes for electricity (and heat) for the industrial and commercial sectors would essentially distort the overall importance of this particular use of energy in an economy-wide energy intensity index. Thus, the representation of improvements in the efficiency of electricity generation is restricted to the development of intensity indexes for the electric power sector

The tables from Chapter 8 in the Annual Energy Review used to develop the intensity are shown in Table A.25. The last column of Table A.25 describes briefly how each table from the AER table is used. Further explanation of the tables is presented below.

For the tables presented by EIA for CHP plants, there are separate estimates for the amount of fuel allocated to electricity versus the amount of fuel used for useful output. For the period up through 2004, EIA explained that it estimated the fuel used for thermal output in the following manner (EIA 2002):

First a steam boiler efficiency rate of $80 \%$ was assumed. Then the reported or estimated value for useful thermal output (in Btu) was divided by 0.8 to estimate the fuel used to generate this amount of thermal output. Next, this value was subtracted from total fuel consumption and remainder was assumed to be the amount used for electric generation. 
Table A.25. Key electricity-related tables from the Annual Energy Review

\begin{tabular}{|l|l|l|}
\hline Table Number & Table Name (excludes year ranges) & Main purpose \\
\hline Table 2.1f & Electric Power Sector Energy Consumption & $\begin{array}{l}\text { Used to infer TBtu content of } \\
\text { fuels used to produce useful } \\
\text { thermal output, along with } \\
\text { Table 8.4b }\end{array}$ \\
\hline Table 8.2b & $\begin{array}{l}\text { Electricity Net Generation: Electric Power } \\
\text { Sector }\end{array}$ & $\begin{array}{l}\text { Used for generation estimates } \\
\text { prior to 1989 }\end{array}$ \\
\hline Table 8.2c & $\begin{array}{l}\text { Electricity Net Generation: } \\
\text { Electric Power Sector by Plant Type }\end{array}$ & $\begin{array}{l}\text { Used for generation estimates } \\
\text { for electricity-only and CHP } \\
\text { plants }\end{array}$ \\
\hline Table 8.2d & $\begin{array}{l}\text { Electricity Net Generation: } \\
\text { Commercial and Industrial Sectors }\end{array}$ & $\begin{array}{l}\text { Uses for generation estimates } \\
\text { for commercial and industrial } \\
\text { sectors, 1989 and later }\end{array}$ \\
\hline Table 8.4b & $\begin{array}{l}\text { Consumption for Electricity Generation by } \\
\text { Energy Source: Electric Power Sector }\end{array}$ & $\begin{array}{l}\text { Provides estimates in TBtu for } \\
\text { all fuel and renewable energy } \\
\text { inputs for total electric power } \\
\text { sector }\end{array}$ \\
\hline Table 8.4c & $\begin{array}{l}\text { Consumption for Electricity Generation by } \\
\text { Energy Source: Commercial and Industrial } \\
\text { Sectors }\end{array}$ & $\begin{array}{l}\text { Used for consumption } \\
\text { estimates for commercial and } \\
\text { industrial sectors }\end{array}$ \\
\hline Table 8.5c & $\begin{array}{l}\text { Consumption of Combustible Fuels for } \\
\text { Electricity Generation: Electric Power } \\
\text { Sector by Plant Type }\end{array}$ & $\begin{array}{l}\text { Quantity data by fuels used to } \\
\text { allocate TBtu estimates from } \\
\text { Table 8.4b between electricity- } \\
\text { only and CHP plants }\end{array}$ \\
\hline
\end{tabular}

The use of this assumption essentially holds constant the energy intensity of the thermal output. For purposes of deriving the energy intensity indicators in the electric power sector, only the electricity generation aspect of CHP plants is measured.

EIA later changed to its method of allocating fuel consumption between thermal output and electricity consumption, beginning with the data for 2004. EIA describes this methodology as follows:

A new method of allocating consumption between electric power generation and useful thermal output (UTO) was implemented for 2004-2008 [and later years]. This new methodology proportionately distributes combined heat and power (CHP) losses between the two output products (electric power and UTO). In the historical data [prior to 2004], UTO was consistently assumed to be $80 \%$ efficient and all other losses at the plant were allocated to electric power. This change resulted in the fuel for electric power to be lower, while the fuel for UTO to be higher than the prior set of data as both are given the same efficiency. This results in the 
appearance of an increase in the efficiency of production of electric power between 2003 and $2004 .^{62}$

As discussed in the main body of the report, the approach for this document has been to accept this change without adjustment. Because the energy consumption from CHP plants represents such a small percentage of the electric power sector, no effort was made to adjust the later data for the discontinuity first observed in 2004.

The available data from EIA are used to develop separate energy intensity indexes for electricityonly and CHP plants within the electric power sector. The data provided by EIA are used to estimate energy intensity for electricity-only plants from 1949 forward. For 1989 and later years, a separate set of intensity indexes is estimated for the electricity generated by CHP plants.

The rows in Table A.26 show the data sources for the four separate energy intensity indexes that are developed for the electric power sector. ${ }^{63}$ Separate indexes are developed for fossil fuels

Table A.26. Key AER tables used to construct the detailed energy intensity indexes for the electric power sector

\begin{tabular}{|c|c|c|c|}
\hline Electricity Segment & $\begin{array}{l}\text { Generation } \\
(\mathrm{kWh})\end{array}$ & $\begin{array}{l}\text { Fuel Consumption } \\
\text { (TBtu) }\end{array}$ & Notes \\
\hline $\begin{array}{l}\text { Electricity only, } \\
\text { Fossil fuel plants: }\end{array}$ & $\begin{array}{l}\text { For } 1949-1988, \text { Table } \\
8.2 \text { b. } \\
\text { For } 1989 \text { and later, Table } \\
8.2 \text { c }\end{array}$ & $\begin{array}{l}\text { Pre-1989, Table } 8.4 \mathrm{~b} \text {. } \\
\text { For } 1989 \text { and later: } \\
\text { Allocation to electricity- } \\
\text { only plants made from } \\
\text { conversion of quantity } \\
\text { consumption to Btu across } \\
\text { electricity-only and CHP } \\
\text { plants. See text. }\end{array}$ & $\begin{array}{l}\text { EIA does not break out } \\
\text { electricity-only plants } \\
\text { from CHP plants prior to } \\
1989 .\end{array}$ \\
\hline $\begin{array}{l}\text { Electricity only, } \\
\text { Renewable facilities, } \\
1989 \text { and later }\end{array}$ & $\begin{array}{l}\text { Data available for only } \\
1989 \text { and later, Table 8.2c, }\end{array}$ & $\begin{array}{l}\text { Data available for only } \\
1989 \text { and later: } \\
\text { For wood and waste, upper } \\
\text { portion of Table } 8.5 \mathrm{c} \\
\text { For geothermal, solar, and } \\
\text { wind; Table } 8.4 \mathrm{~b}\end{array}$ & $\begin{array}{l}\text { Data for wood and waste } \\
\text { input for years prior to } \\
1989 \text { in Table } 8.5 \mathrm{~b} \text {, but not } \\
\text { comparable with } 1989 \text { data } \\
\text { and later, not used }\end{array}$ \\
\hline $\begin{array}{l}\text { Electric Power Sector: } \\
\text { CHP Plants, Fossil Fuels, } \\
1989 \text { and later }\end{array}$ & $\begin{array}{l}\text { Data available for only } \\
1989 \text { and later, Table 8.2c }\end{array}$ & $\begin{array}{l}\text { Allocation to electricity- } \\
\text { only plants made from } \\
\text { conversion of quantity } \\
\text { consumption to Btu across } \\
\text { electricity-only and CHP } \\
\text { plants. See text }\end{array}$ & \\
\hline $\begin{array}{l}\text { Electric Power Sector: } \\
\text { CHP Plants, Renewables } \\
\text { (Biomass), } 1989 \text { and later }\end{array}$ & $\begin{array}{l}\text { Data available for only } \\
1989 \text { and later, Table } 8.2 \mathrm{c} . \\
\text { For CHP, only biomass } \\
\text { (wood and waste) is } \\
\text { included. }\end{array}$ & $\begin{array}{l}\text { Data available for only } \\
1989 \text { and later: } \\
\text { For wood and waste, lower } \\
\text { portion of Table } 8.5 \mathrm{c}\end{array}$ & \\
\hline
\end{tabular}

62 Source: http://www.eia.gov/electricity/data/eia923/ Bracketed insertions are from author.

${ }^{63}$ See discussion above about the most recent data (primarily 2011 and 2012) supplied by EIA via a special request. 
and renewable sources for both electricity-only plants and CHP plants. The cells in Table A.26 provide brief descriptions of the source for generation (activity) and energy input.

For both electricity-only and CHP plants, the two separate indexes for fossil fuels and renewables are aggregated into a single index for each type of plant. Together with nuclear and hydro plants, the two separate intensity series (for electricity-only and CHP plants) are blended into a single intensity index for the entire electric power sector.

One issue that must be addressed is that the time series for CHP plants can be developed only for years 1989 and later. A small shortcoming of the multiplicative version of the log-mean Divisia index is that it cannot aggregate sub-sectors where the energy consumption (weight) is zero in any period (i.e., those years prior to 1989 for CHP). However, this problem can be overcome by setting the consumption in such years to a negligibly small value (e.g., $0.000001 \mathrm{TBtu}$ ). Thus, by setting the fuel consumption for CHP plants to such a small value for years 1949-1988, an aggregation of both electricity-only and CHP plants can be computed for 1989 and subsequent years. Between 1988 and 1989, a (hypothetical) intensity index for CHP plants is assumed to be unchanged. In 1989, the shares of energy use are used to calculate the aggregate index. ${ }^{64}$ Because the initial CHP share of total energy input is very low $(\sim 1.5 \%)$, the effect on the aggregate intensity index for 1989 is very small, affecting the index only in the sixth significant digit. $^{65}$ The bottom line is that the Divisia method is able to incorporate the impact of intensity changes for CHP plants starting in 1989 without any major distortion in the intensity index for the aggregate electric power sector.

For purposes of including the electric power sector in the economy-wide energy intensity indexes, the choice of an alternative base year (1990 versus 1985) for this sector is not an issue. The important point is that for each major (end-use + electric power) sector, energy intensity index and associated estimate of energy use are available to be used in the Divisia index procedure. The methodology described above indicates that both energy consumption and an intensity index can be developed for the electric power sector for the complete historical period of the system of intensity indicators (1970-2011), even when data for one of the component subindexes (i.,e., CHP plants) are not available for all years.

To repeat, Table A.24 shows the relevant tables from Chapter 8 of the Annual Energy Review that are used as sources for electricity generation and fuel or renewable energy input. For the energy input for renewable generation, the data sources from the AER are straightforward: Table 8.4b ("Consumption for Electricity Generation") and Table 8.5c (Consumption of Combustible Fuels"). In both of these tables, the energy input for renewables and biomass is

\footnotetext{
${ }^{64}$ See the treatment of the Divisia index in Appendix B which indicates the energy shares used to calculate the intensity change from one year to the next are really a (log mean) weighted average of the shares in the current and previous year.

${ }^{65}$ The estimates for the percentage of total fossil fuel use for CHP indicates a maximum share of $4.5 \%$ in 2003 , falling to just under $3.5 \%$ in 2010 .
} 
converted to TBtu input. (The conventions used by EIA for these conversions is presented below.)

Unfortunately, for fossil fuel consumption, EIA does not provide separate estimates in TBtu for electricity-only and CHP plants. Rather, the fuel inputs are given only in physical units, e.g., tons of coal, barrels of fuel oil, etc. (Table 8.5c). However, there is a combined estimate in terms of TBtu for both types of plants provided in Table $8.4 \mathrm{~b}$.

For coal and natural gas, the allocation of total TBtu from Table $8.4 \mathrm{~b}$ is made on the basis of the relative shares (to electricity-only and $\mathrm{CHP}$ ) of fuel quantities shown in Table $8.5 \mathrm{c}$. The situation for petroleum is slightly more complicated. Using the conversion factors for each type of product (distillate fuel oil, other liquids, and petroleum coke), preliminary estimates of the total Btu content were made for consumption for both electricity-only and CHP plants. The allocation of the published TBtu consumption in Table $8.4 \mathrm{~b}$ was then made on the basis of these preliminary estimates.

Table A.27 refers to the tables in the AER that are used to construct energy intensity indexes for electricity generation for the commercial and industrial sectors. All of the indicators can be derived from Table 8.2d (for generation) and Table 8.4c (for energy input). Renewable energy includes only wood and waste that are used to generate electricity, either in electricity-only or CHP facilities. ${ }^{66}$ Building-installed renewable electricity, i.e. solar photovoltaic, is currently only estimated by EIA for the residential sector and is included as part of residential consumption by EIA and not as a separate category of electricity consumption.

Table A.27. Key AER tables used to construct detailed energy intensity indexes for electricity generation in the commercial and industrial sectors

\begin{tabular}{|l|l|l|}
\hline Electricity Segment & $\begin{array}{l}\text { Generation } \\
(\mathrm{kWh})\end{array}$ & $\begin{array}{l}\text { Fuel Consumption } \\
(\mathrm{TBtu})\end{array}$ \\
\hline $\begin{array}{l}\text { Commercial, } \\
\text { Fossil fuel plants }\end{array}$ & Table 8.2d. & Table 8.4c \\
\hline $\begin{array}{l}\text { Commercial, } \\
\text { Renewable facilities }\end{array}$ & Table 8.2d & $\begin{array}{l}\text { Table 8.4c (includes only } \\
\text { wood and waste) }\end{array}$ \\
\hline $\begin{array}{l}\text { Industrial, } \\
\text { Fossil fuel plants }\end{array}$ & Table 8.2d & Table 8.4c \\
\hline $\begin{array}{l}\text { Industrial, } \\
\text { Renewable facilities }\end{array}$ & Table 8.2d & $\begin{array}{l}\text { Table } 8.4 \mathrm{c} \text { (includes only } \\
\text { wood and waste) }\end{array}$ \\
\hline
\end{tabular}

\footnotetext{
${ }^{66}$ As Table 10.2a in the Annual Energy Review makes clear for the commercial sector, the Btu content of the wood and waste used to generate electricity is also included with other wood and waste (biomass) used for other purposes. As such, this energy consumption is included in the total energy consumed by the commercial sector (aggregated to biomass in Table 2.1c of the Annual Energy Review) (EIA 2012a). The comparable situation occurs within the industrial sector. As explained above, this double-counting is the reason the energy intensity indexes for commercial and industrial sector electricity generation are not included as part of the energy intensity indexes for the overall economy.
} 



\section{APPENDIX B}

Relationship between Economy-wide Energy Intensity Indexes Based on Source Energy and Delivered Energy 



\section{APPENDIX B - Relationship between Economy-wide Energy Intensity Indexes Based on Source Energy and Delivered Energy}

As discussed in Section 2.3 of the report, fuels and electricity consumption were combined in two ways to generate total delivered energy and total source energy. Alternative energy intensities are constructed based upon both of these concepts of energy consumption by end users. Section 2.6 expands this treatment to discuss adjustments to source energy that effectively remove the influence of improved electricity generation (and transmission) efficiency in the electric power sector.

For the economy as a whole, total energy can be considered to be sums of two alternative sets of sectors:

Total energy $=$ Sum of source energy for all major end-use sectors,

Total energy $=$ Sum of delivered energy for all major end-use sectors, plus the generation and transmission losses in the electric power sector

Energy intensity indexes have been computed using both definitions of energy for the end-use sectors, and a separate intensity index has been computed for electricity generation (Section 3.5). Thus, economy-wide intensity indexes can be calculations from either classification of sectors. A natural question is whether they yield similar results, and if not, is there a simple way of converting between one intensity index and the other?

To use the variable designations, as in Section 2.5 and 2.6, let SSR be the source-to-site ratio for the electricity generation for a given year. To be clear,

$S S R=$ total fuel consumption by the electric power sector/total delivered (sales) of electricity (both measured in Btu)

For convenience, let us consider the case with only one end-use sector, which consumes both fuels $(F)$ and (delivered) electricity $\left(E^{d}\right)$. Energy intensity is constructed as total energy divided by a measure of activity, expressed generically here as $B$. With these definitions, the source energy intensity $\left(I^{s}\right)$ is defined in a conventional manner:

$$
I^{s}=\left(F+S S R * E^{d}\right) / A
$$

The construction of the delivered energy intensity involves combining both the end-use sector intensity and the intensity for electricity generation. For electricity generation, it is clear that the activity measure is the amount of electricity generated, expressed in either $\mathrm{kWh}$ or Btu. However, there is a choice of what to use as the numerator in the calculation of intensity-- either 1) total (fuels and renewable) energy, or 2) only the energy content of the generation and 
transmission losses. For purposes of this analysis, it turns out that the second choice is preferred. In some sense, it is really the energy that is used up, so to speak, that is relevant to the calculation of intensity. This concept would be equivalent to concept of energy "used up" in the production of goods in the industrial sector, for example. Thus, given this decision, the delivered energy intensity $\left(I^{d}\right)$ for this hypothetical one end-user economy is given by

$$
I^{d}=\left(F+E^{d}\right) / A+\left((S S R-1) * E^{d}\right) / E^{d}
$$

One cannot think of Equation (B.2) in strictly literal terms, because the units in the denominators in both terms are not the same. Rather, the approach follows all of the other index construction in that only changes over time are relevant. Using the Divisia (LMDI) approach described in Section 2.5, one applies the LDMI weights--roughly equivalent to energy shares--separately to the logarithms of the year-to-year changes in both terms. The energy shares would be delivered energy use (applied to the first term) and electricity generation and transmission losses (applied to the second terms). Of course, the sum of these energy components is equal to total energy consumption in this simple economy.

If we go back to the simple expression for the source intensity in (B.1), it can be rewritten as:

$$
I^{S}=\left(F+S S R * E^{d}\right) / A=\left(F+E^{d}\right) / A+\left((S S R-1) * E^{d}\right) / A
$$

With the reformulation of source energy in (B.3), one can see what factor defines the difference between source energy index and the delivered energy intensity index. The first two terms of Eq. (B.2) and (B.3) are the same. If one multiplies the second term in (B.3) by the factor $E^{d} / A$, we achieve an equivalence, when translated into LDMI indexes between the two metrics. Explicitly,

$$
\left.\left(F+E^{d}\right) / A+\left((S S R-1) * E^{d}\right) / E^{d} *\left(E^{d} / A\right)=\left(F+E^{d}\right) / A+\left((S S R-1) * E^{d}\right) / A\right)=I^{s}
$$

Again, Equation (B.4) has to be considered in terms of LDMI indexes. Thus, if the index of energy intensity for the electricity power sector (the second term in B.2) is multiplied by an index of electricity intensity $\left(E^{d} / A\right)$, then the resulting Divisia intensity index is identical to the source intensity index.

The implication of this analysis is that when the electricity intensity increases over time, the economy-wide index of delivered energy intensity, based upon a combination of intensities for end-use sector and the electric power sector, is going to result in a greater decrease (or smaller absolute increase) as compared to the source energy intensity.

This overall result holds for the situation with more than a single end-use sector. In this more general case, the factor that determines the difference between the economy-wide intensity indexes in B.1 and B.2 is the behavior of the economy-wide index of electricity intensity. If the overall electricity intensity increases, and there is a decline in the delivered intensity index computed on the basis of the five-sector formulation (four end-use sectors plus the electric power 
sector) over the same period, then the calculated economy-wide source energy index will fall less than the index based on delivered energy.

This latter situation is what is observed in the historical data for U.S. Figure B.1 compares the source intensity index for the economy as a whole (B.1) with a delivered intensity index computed for the economy as a whole using Equation (B.2). The large difference in the 19701985 period stems from a $20 \%$ increase in the economy-wide index of electricity intensity over the same period. By contrast, the overall electricity index increased only by about $7 \%$ between 1985 and 2011, and, as a result the divergence between the source and delivered indexes was not as great. In 2011, the delivered intensity index (normalized to 1985) was about $1.7 \%$ lower than the source intensity index ( 0.845 versus 0.860$)$.

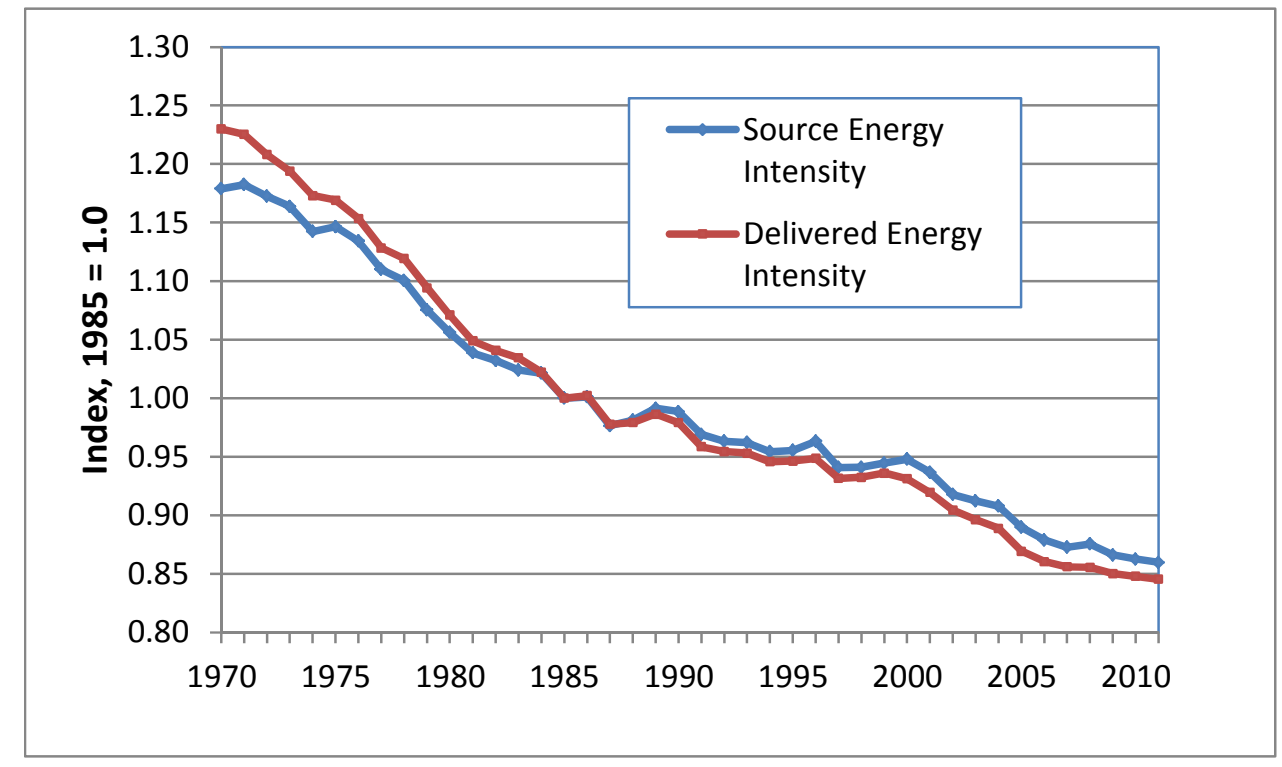

Figure B.1. Comparison of economy-wide source and delivered energy intensity indexes

From this discussion, it should be emphasized that the appropriate intensity index for the entire economy is the source energy intensity index. All direct and indirect (generation and transmission losses) energy is assigned to the end-use sectors. However, for analysis of individual end-use sectors, any of the three individual total energy intensity indexes (delivered, source, or "adjusted" source) may be appropriate, depending on the nature of the analysis.

Also note that the discussion in this appendix does not have direct bearing on measuring the influence of changes in electricity generation efficiency upon the source intensity. This topic was addressed in Section 2.6 of the report, and the results presented in Figure 4.2. The analysis shows that about one-sixth of the decline of the economy-wide source intensity index by 2011 (relative to 1985) can be associated with improved electricity generation efficiency. This result 
is independent of the difference between economy-wide indexes based on either (published) source energy and delivered energy, the focus of this appendix. ${ }^{1}$

\footnotetext{
${ }^{1}$ For some years after the initial development of energy intensity indicators system, the very small difference between the economy-wide delivered and source intensity indexes was considered to be idiosyncratic, thus depending any number of factors related to the weighting of the of the component indexes. The derivation in Equation (B.4) clearly shows that the difference depends on the behavior of the electricity intensity index. This result has been captured as an option in the spreadsheet used to calculate the economy-wide intensity indexes. When the option (switch) is turned on, the log changes of the electricity index are added to the log changes in the electric power sector intensity in the computation of the Divisia index for the economy-wide delivered intensity (as per Equation B.4). The resulting series of intensities then closely matches that for the source intensity. (Very small differences persist because the negligible amount of electricity in transportation is ignored in the intensity indicators system). Exercising this option is useful as another device to check internal consistency among the various intensity indicators.
} 


\section{APPENDIX C}

Energy Consumption Shares Used in the Development of Intensity Indexes 



\section{APPENDIX C - Energy Consumption Shares Used in the Development of Intensity Indexes}

This appendix presents the shares of energy consumption by sector and subsector (or activity) that underlie the development of energy intensity indexes at various levels of aggregation. This information is useful to understanding how changes in a specific energy intensity index would influence an index at a higher level in the indicators hierarchy.

\section{C.1 Energy Consumption Shares and LDMI Weights}

As discussed in Section 2.5 of the report, the development of energy intensity indexes relies on the use of the log mean Divisia index method (LMDI). In using this method, the weights to combine two or more specific energy intensity indexes are not the energy consumption shares themselves, but rather a transformation that typically yields a value very close to those shares. Because all variants of the Divisia method result in a chained type of index, the energy consumption shares associated with successive time periods (years) are employed in the calculation.

To repeat from the discussion in Section 2.5, the logarithmic mean of any two variables in is defined as

$$
L(\mathrm{x}, \mathrm{y})=(\mathrm{y}-\mathrm{x}) / \ln (\mathrm{y} / \mathrm{x})
$$

As applied to the energy consumption shares ( $w_{i}$ for component $\left.i\right)$ in successive time periods, the logarithmic mean function is defined

$$
L\left(w_{i, 0}, w_{i, T}\right)=\left(w_{i, T}-w_{i, 0}\right) / \ln \left(w_{i, T} / w_{i 0}\right)
$$

The final weights $w_{i}^{*}$ are based upon a normalization that ensures that they exactly sum to one:

$$
w_{i}^{*}=L\left(w_{i, 0}, w_{i, T}\right) / \sum_{i} L\left(w_{i, 0}, w_{i, T}\right)
$$

A simple numerical example will help to clarify the relationship between the LMDI weights and the energy shares. Table C.1 shows a case for two activities (or sectors). The shares of energy consumption for the first activity increase from 0.19 to 0.21 between periods (i.e., years in the present context) 1 and 3. By construction, the shares for activity 2 fall from 0.81 to 0.79 over the same time interval.

The weights used in the LMDI methodology are applied to the changes in the respective intensity indexes, expressed in log terms. The changes in the intensity indexes are independent of the weights, and no (arbitrary) hypothetical values of the individual intensity indexes

themselves are shown in the table. The important point is that the log changes are weighted by 
the log mean of their respective consumption shares in the terminal period of the change, in the current system in the second year of each two-year time period. Thus, the weights in the example can only be defined beginning in year 2 of the table. For activity 1, the log mean is calculated as $(0.20-0.19) /[\ln (0.20 / 0.19)]=0.194957$. The same calculation for activity yields 0.804990. As shown in Equation C. 3 above, the log mean values must be normalized to sum to exactly 1.0 in order for the overall method to yield exact decomposition between changes in the mix of activities and changes in energy intensity (as described in Section 2.5 and the Ang and Choi article in the Energy Journal). The same procedure is applied to the energy consumption shares for periods 2 and 3 to yield the LMDI weights for period 3.

While the final weights depend upon the specific values selected for the example in Table C.1, it is clear that the weights are approximately the same as the energy shares themselves. This is generally observed in the overall construction of the LMDI weights across all of the various energy intensity indexes considered in this report.

Table C. 1. Energy shares and LMDI weights - a numerical example

\begin{tabular}{|c|c|c|c|c|c|c|c|}
\hline & & & & & & \\
Period & $\begin{array}{c}\text { Energy } \\
\text { Share - 1 }\end{array}$ & Log Mean & $\begin{array}{c}\text { Normalized } \\
\text { Weight }\end{array}$ & $\begin{array}{c}\text { Energy } \\
\text { Share - 2 }\end{array}$ & Log Mean & $\begin{array}{c}\text { Normalized } \\
\text { Weight }\end{array}$ \\
\hline 1 & 0.190 & & & 0.810 & & \\
\hline 2 & 0.200 & 0.194957 & 0.194968 & 0.800 & 0.804990 & 0.805032 \\
\hline 3 & 0.210 & 0.204959 & 0.204970 & 0.790 & 0.794990 & 0.795030 \\
\hline
\end{tabular}

Another way of considering the correspondence between the energy consumption shares and the LMDI weights is illustrated in Table C.1. If one averages the final weights for periods 2 and 3 , the values are very near the energy consumption shares for period 2 . For activity 1 , the average weight is 0.199969 and for activity, the average weight is 0.800031 . Thus, in this view, the energy consumption share for a given year $t$, can be considered the average of the two LMDI weights that employ that given year, the first weight based on year $t$ and $t-1$, and the second weight based on year $t$ and $t+1$. Of course, the correspondence of this average and the actual share for year $t$ depends on whether there is a reasonably constant trend in the energy shares around the year in question, a trend that would show the changes in the energy consumption share to be similar over the successive two-year periods.

In the tables to follow in this appendix, the numerical values presented all relate to shares of energy consumption. While the foregoing discussion indicates that the shares are not exactly the actual weights in the LMDI approach, the discussion does help to show that the shares are generally close approximations to the actual weights. Thus, the shares, in fact, adequately represent the importance of the changes in any particular intensity index on any higher-level 
intensity index that includes the particular index. Another consideration to show the energy consumption shares is their transparency, a feature that allows readers to gauge the relative importance of energy intensity changes of specific sectors or activities, regardless of the type of formal index methodology used.

\section{C.2 Tables with Energy Consumption Shares}

The remainder of this appendix presents energy consumption shares by major end-use sector, in terms of both source and delivered energy. Table C.2 is a high-level summary of shares by the major sectors by decade. These shares are used to develop the economy-wide indexes shown in Section 4 of the report. ${ }^{1}$ Using source energy, only the four major end-use sectors are usedimprovements in electric generation efficiency are implicitly included in each sector's intensity (see Figure 4.2 where electricity generation improvements are decomposed from other changes in energy intensity). The most striking observation in Table C.2 is the dramatic increase in that sector's share of total U.S. energy consumption over the 40-year period, although the rate of increase of the share was much slower after 1990. The increase of the share of source energy came primarily at the expense of a reduction in the share of energy attributed to the industrial sector.

An economy-wide index using delivered energy includes the electric power sector, whose share of total energy consumption is shown in the lower panel of Table C.2. The energy consumption for the electric power sector includes fossil fuels, as well as hydroelectric, nuclear, and renewables. For the latter three types of energy, EIA imputes a value for input energy, as discussed in Section A.6. In these terms, the share of delivered energy consumption for the electric power sector has increased significantly over the past 40 years, but much of that increase was prior to 1990 . Overall, there is considerably more variation in the energy shares across sectors in terms of delivered energy as compared to source energy.

\footnotetext{
${ }^{1}$ The important point is that the shares shown in Table C.2 are those used in developing the economy-wide indexes in the overall set of EERE energy intensity indicators. The shares differ from those calculated on the basis of energy use by sector published by EIA (from supply-side sources, as in Section 2 of the Annual Energy Review). As presented in Appendix A, the data sources for energy used in the industrial and transportation sectors are not based upon the reporting by energy suppliers. In addition, industrial energy consumption used for petrochemical feedstocks is not considered in the development of energy intensity indexes. For the commercial sector, an adjustment to reported electricity consumption has been made to account for reclassifications over time between customers classified as commercial versus industrial (see Section A.2.1). Total energy for the residential and electric power sectors do correspond to the EIA (supply-side) reporting, but their associated shares of national energy consumption will differ as a result from the different magnitudes of energy consumption in the other major sectors that go into the sum for total national consumption.
} 
Table C. 2. Energy Consumption Shares for Major Sectors

\begin{tabular}{lrrrrr} 
& 1970 & 1980 & 1990 & 2000 & 2010 \\
\cline { 2 - 6 } Source Energy & & & & & \\
Residential & 0.2238 & 0.2250 & 0.2234 & 0.2432 & 0.2207 \\
Commercial & 0.1357 & 0.1515 & 0.1739 & 0.1837 & 0.1962 \\
Industrial & 0.3945 & 0.3588 & 0.3271 & 0.3054 & 0.2592 \\
Transportation & 0.2460 & 0.2646 & 0.2783 & 0.2875 & 0.3014 \\
& & & & & \\
Delivered Energy & & & & & \\
Residential & 0.1612 & 0.1412 & 0.1265 & 0.1283 & 0.1228 \\
Commercial & 0.0884 & 0.0860 & 0.0881 & 0.0888 & 0.0937 \\
Industrial & 0.3150 & 0.2695 & 0.2376 & 0.2212 & 0.1853 \\
Transportation & 0.2460 & 0.2646 & 0.2783 & 0.2875 & 0.3014 \\
Electric Utilities & 0.1894 & 0.2387 & 0.2694 & 0.2798 & 0.2914
\end{tabular}

Tables C.3 through C.7 display the energy consumption shares for the individual end-use sectors, for the years 1990 and 2010, and for source (where applicable) and delivered energy. ${ }^{2}$ Table C.3 presents the energy consumption shares for the residential and commercial sectors. The current set of intensity indicators for these sectors contains subsector detail only with respect to census regions for the residential sector. The most notable aspect of this structure is the increasing share of energy consumption in the South, primarily at the expense of falling shares in the Northeast and Midwest. Because there is no available historical time series for regional floor space, the commercial sector is represented by only a single intensity index for the U.S. as a whole.

The next two tables, C. 4 and C.5, provide the energy shares by subsector for the industrial sector. The values in Table C. 4 are in terms of shares based upon source energy. Table C. 5 shows the shares with respect to delivered energy. As described in the report and Appendix A, the industrial sector is broadly divided into manufacturing and nonmanufacturing subsectors. In manufacturing, the tables show the further disaggregation into eighteen industries based upon the North American Industrial Classification System (NAICS) at the 3-digit level. For nonmanufacturing, the disaggregation includes three subsectors, based upon 2-digit NAICS sectors (Agriculture, Forestry, and Fishing; Mining; and Construction). The energy consumption shares within each of these two broad sectors sum to one, and are distinguished by different shading in the table.

\footnotetext{
${ }^{2}$ These tables are shown together at the end of this appendix.
} 
Table C. 3. Energy Shares for Residential and Commercial Sectors

\begin{tabular}{|c|c|c|c|c|c|}
\hline & \multicolumn{2}{|c|}{ Source Energy } & \multicolumn{3}{|c|}{ Delivered Energy } \\
\hline & 1990 & 2010 & & 1990 & 2010 \\
\hline \multicolumn{6}{|l|}{ Residential Sector } \\
\hline In Economy-wide Index & 0.2234 & 0.2207 & & 0.1265 & 0.1228 \\
\hline Total U.S. & & & 1.0000 & & \\
\hline Northeast & 0.1968 & 0.1680 & & 0.2348 & 0.2037 \\
\hline Midwest & 0.2682 & 0.2421 & & 0.3037 & 0.2713 \\
\hline South & 0.3608 & 0.4163 & & 0.2897 & 0.3441 \\
\hline West & 0.1742 & 0.1737 & & 0.1718 & 0.1809 \\
\hline & & & & & \\
\hline & & & & & \\
\hline \multicolumn{6}{|l|}{ Commercial Sector } \\
\hline In Economy-wide Index & 0.1739 & 0.1962 & & 0.0881 & 0.0937 \\
\hline & & & & & \\
\hline Total U.S. & 1.0000 & 1.0000 & & 1.0000 & 1.0000 \\
\hline
\end{tabular}

From the values in these tables, one can readily assess the impact of a change in the intensity index of a particular, detailed subsector upon the intensity indexes at higher levels of aggregation. To illustrate, consider how a $1 \%$ reduction in the current energy intensity in the Primary Metals industry would affect the overall economy-wide index of energy intensity. One begins with the share of (source) energy for Primary Metals with respect to total manufacturing. In 2010, this share was 0.1247 . The impact on the index for the industrial sector is based upon the share of Primary Metals energy consumption for the industrial sector. This share is readily calculated as the product of the Primary Metals share in manufacturing, 0.1247 , times the share of manufacturing energy consumption in the industrial sector, 0.8617 . This result is 0.1075 .

To estimate in the impact on the economy-wide index, one must consider the energy consumption share of the industrial sector with regard to the total economy. As shown at the top of Table C.4, this value in 2010 was 0.2592 . Thus, the energy consumption share of Primary Metals across the entire economy is calculated as $0.1075 * 0.2592$, yielding a value of 0.0279 . Thus, a $1 \%$ reduction in the energy intensity index for Primary Metals, by itself, would cause the economy-wide energy intensity index to fall by $0.0279 \%$ or approximately $0.03 \%$. 
Table C. 4. Energy Shares for Industrial Sector, Source Energy

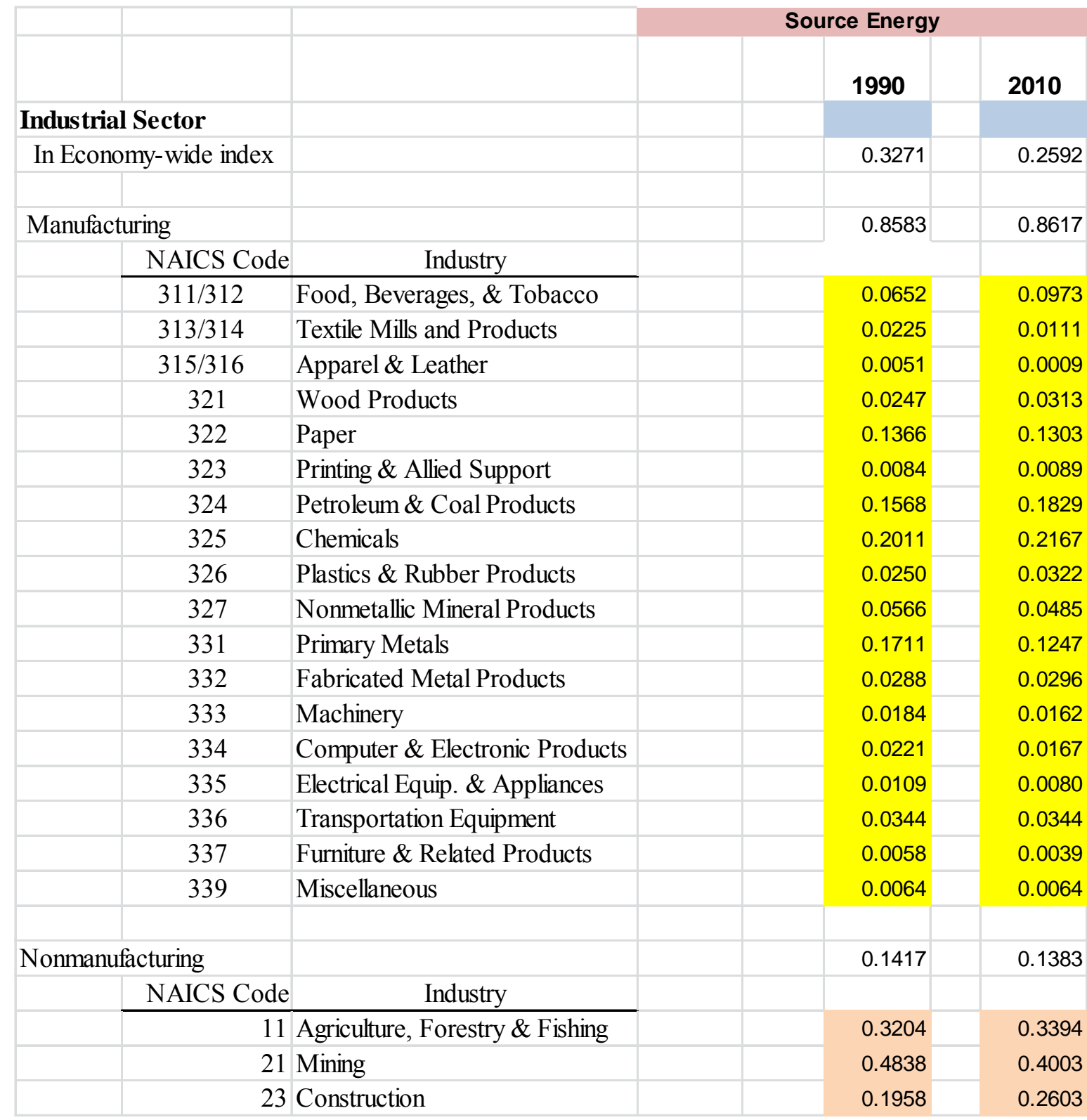


Table C. 5. Energy Shares for Industrial Sector, Delivered Energy

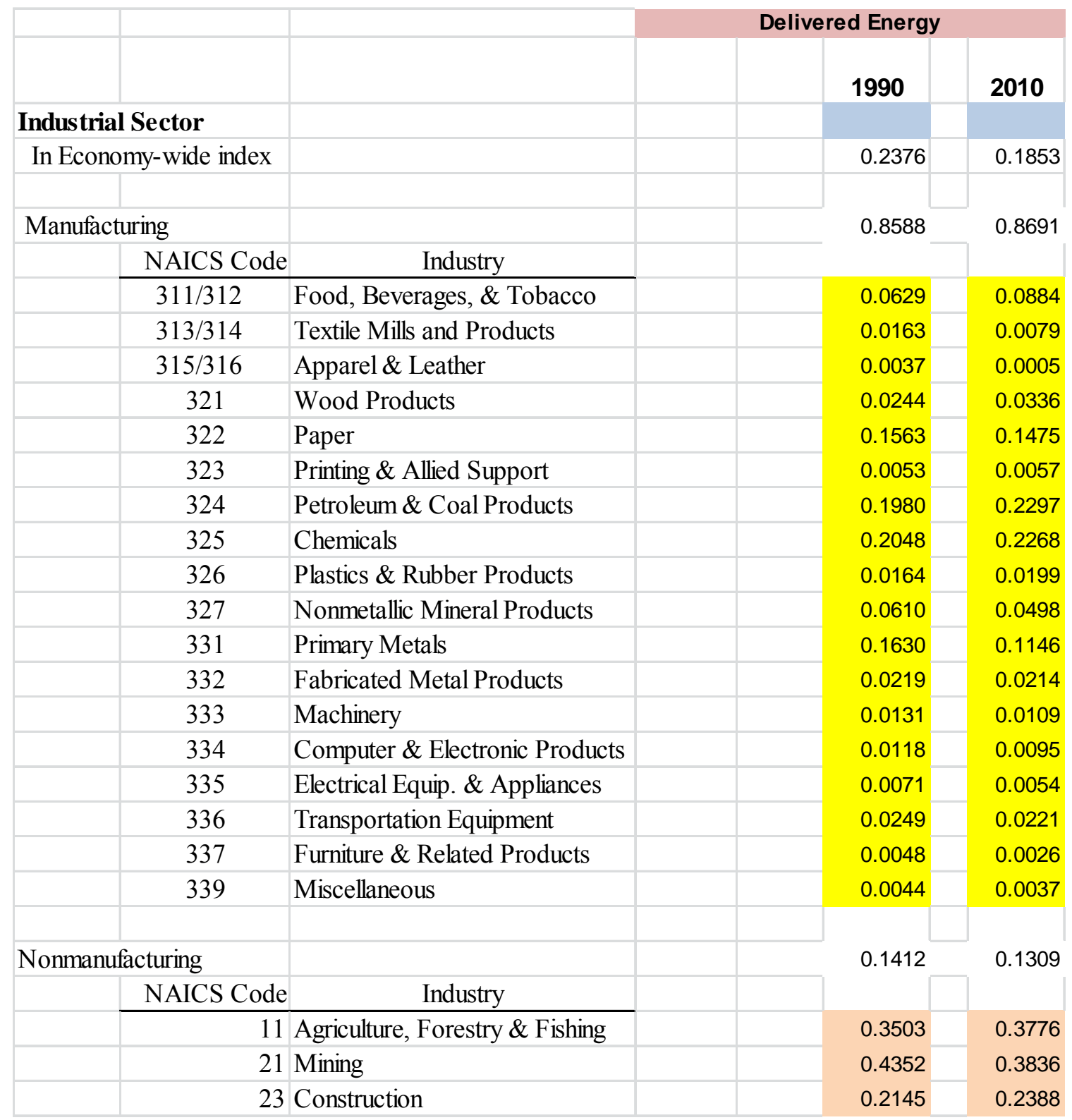

Table C.6 shows the shares for the various passenger and freight transportation modes. The label at the top of the table indicates that the shares can be considered either source or delivered energy. In 2010, approximately $99.6 \%$ of transportation energy was from fossil fuels. The small amount of electricity used in the urban and intercity rail segments was converted to Btu. ${ }^{3}$

\footnotetext{
${ }^{3}$ The conversion factor used followed the convention in the ORNL Transportation Energy Data Book, Edition 32, in which a factor 10,339 Btu/kWh was used (see Table A.16 in that source).
}

\section{C.7}


Table C. 6. Energy Shares for Transportation Sector

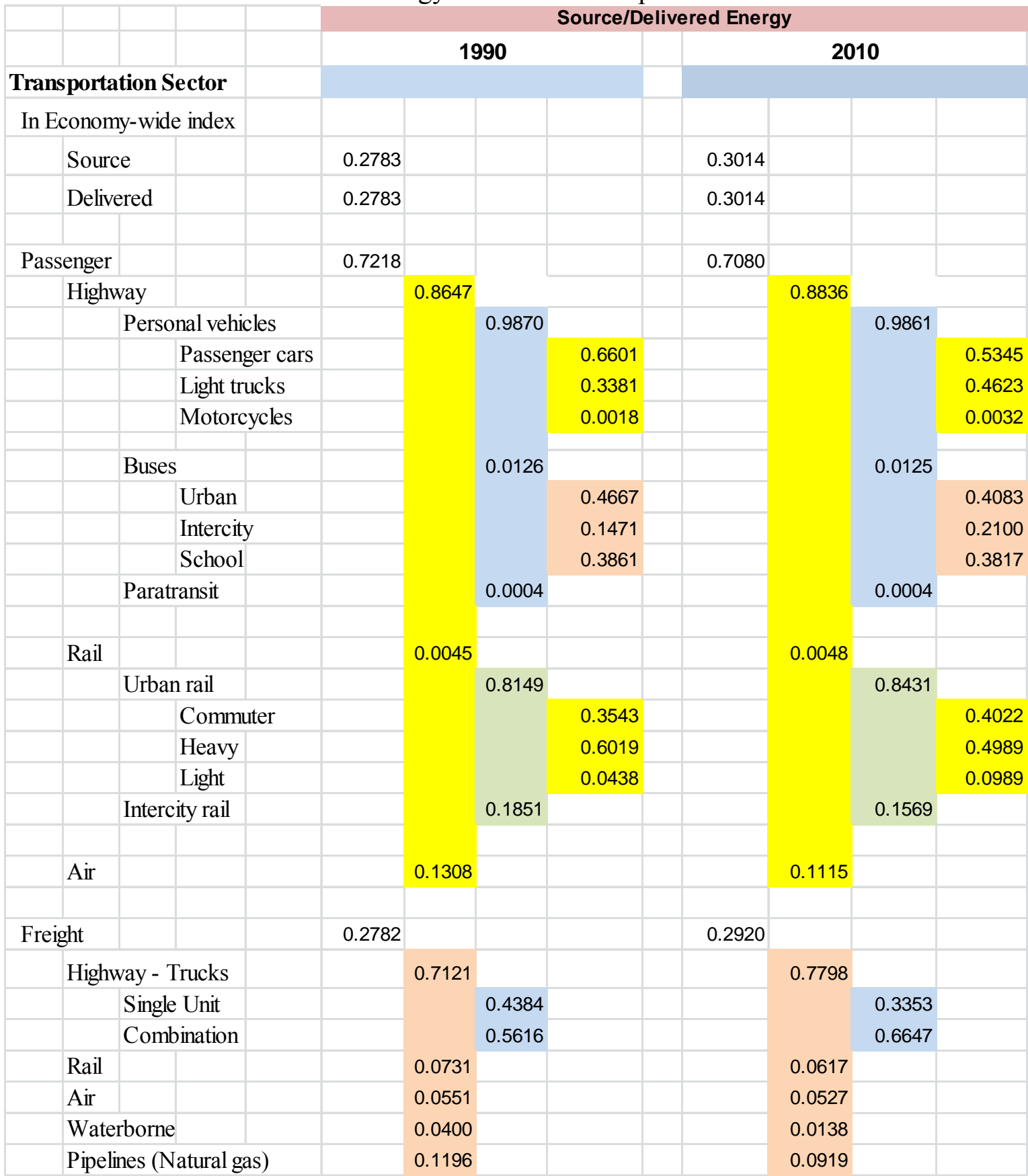


Table C. 7. Energy Shares for Electric Power Sector

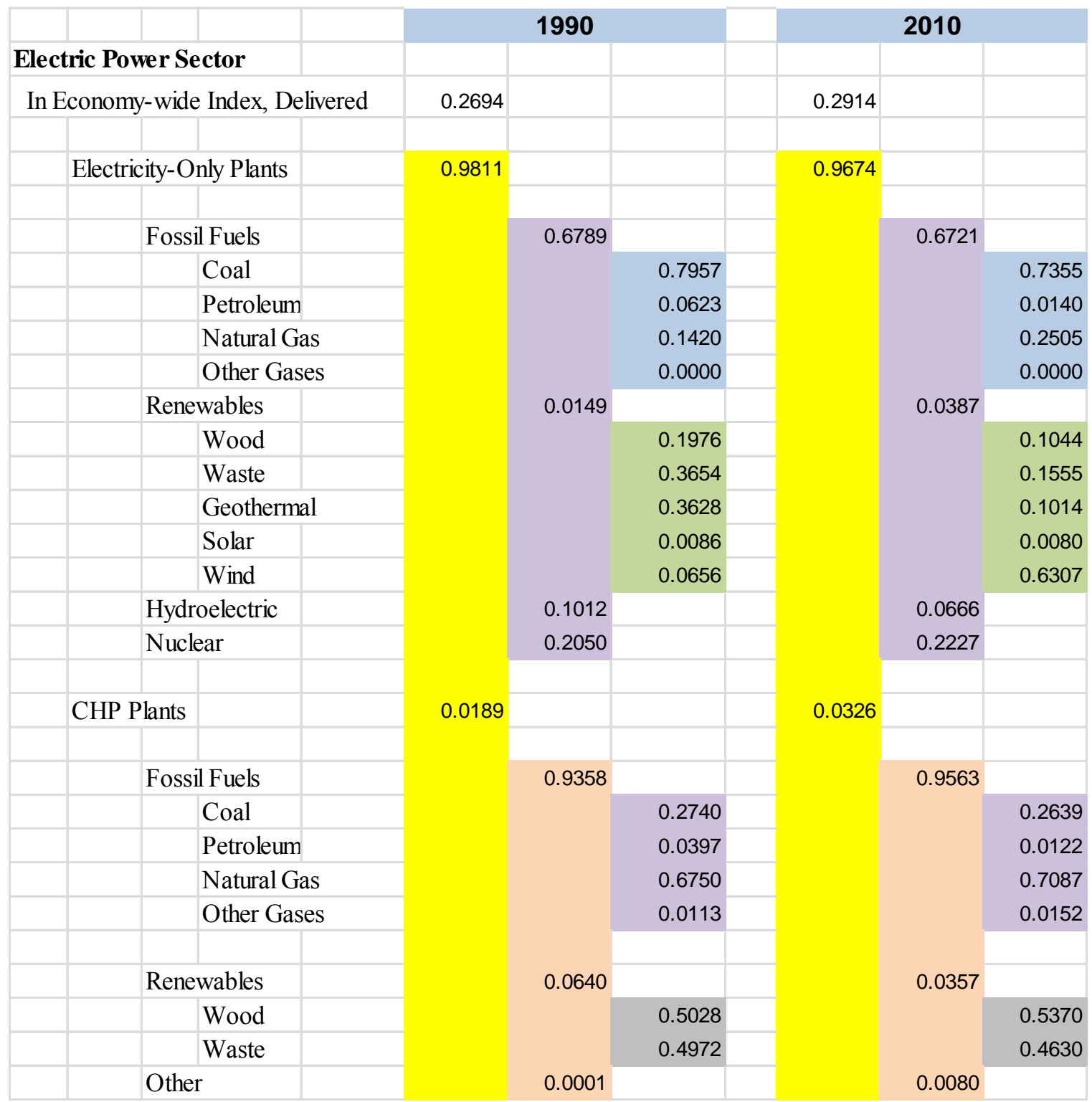


Because the amount of electricity used in transportation sector has historically been very small, there has been no effort to develop separate tables for source and delivered energy. ${ }^{4}$

Following the convention used in the previous tables, the shares are all based upon the lowest tier of the indicators hierarchy. This should be clear from fact that each separately colored set of shares in the table add up to 1.0 .

Again, the process to determine the impact of an intensity change in a particular transportation mode consists in calculating the energy consumption share with respect to a selected higher level of aggregation. Consider as an example, an impact of a 10\% change in the fuel economy of light trucks ( $\sim$ a bit over $2 \mathrm{mpg}$ ) on the overall transportation and economy-wide energy intensity indexes. With regard to all transportation energy use (using the values for 2010), the share attributed to light trucks can be calculated as the product of $0.4623 * 0.9861 * 0.8836 * 0.7080=$ 0.2852 . These shares correspond to the shares relative to personal vehicles $(0.4623)$, highway transportation (0.9861), passenger transportation (0.8836), and total transportation $(0.7080)$, values seen by moving upward and to the left in Table C.6 for higher levels of aggregation. Thus, as an approximation a 10\% increase in light truck fuel economy (approximately equivalent to a $10 \%$ reduction in the intensity index) results in about a 3\% decline in the overall transportation intensity index.

With respect to the entire economy, the one additional required step is to calculate the share of light truck energy consumption with regard to all U.S. energy use. On a source energy basis, this calculation involves multiplying the value of 0.2852 by the overall transportation share of 0.3014 (found at the top of Table C.6). This calculation yields a value of 0.086 . Thus, to conclude the analysis of the simple example, a 10\% improvement (reduction) in light-truck fuel energy intensity would yield about a $0.9 \%$ reduction in the economy-wide energy intensity index.

Table C.7 shows the energy consumption shares for the electric power sector. As discussed above, if these shares are used to estimate the impact at the total economy level, the relevant intensity index is defined in terms of delivered energy.

The most dramatic changes in the shares between 1990 and 2010 for electricity-only plants relate to the composition of renewable sources. The share of renewable energy consumption attributable to wind energy increased nearly ten-fold between 1990 and 2010.

For electricity generation plants burning fossil fuels, the natural gas share increased by nearly $80 \%$, at the expense of both coal and petroleum. The nuclear share of total energy consumption remained about $20 \%$, while the share attributable to hydroelectric plants fell by nearly $30 \%$. (Note from the discussion above and in Section A.6, the energy consumption estimates for these types of plants, as well as many of the renewables, are based upon imputations made by EIA).

\footnotetext{
${ }^{4}$ Strictly speaking, the shares in Table C.7 relate to source energy, because a source conversion factor was applied to the electricity consumption used in the rail segment. See previous footnote.
} 
The bottom portion of Table C.7 shows the shares within individual segments of combined heat and power (CHP) plants. The CHP share of total energy consumption within the electric power sector nearly doubled between 1990 and 2010, but currently is still less than $4 \%$ of all electricity generated in the sector. The dominant fuel in these plants remains natural gas, comprising approximately two-thirds of energy consumption in such plants. 